Portland State University

PDXScholar

$1-1-1980$

\title{
Community impacts on organizational interaction
}

Frederick Dalton Keast

Portland State University

Follow this and additional works at: https://pdxscholar.library.pdx.edu/open_access_etds Let us know how access to this document benefits you.

\section{Recommended Citation}

Keast, Frederick Dalton, "Community impacts on organizational interaction" (1980). Dissertations and Theses. Paper 879.

https://doi.org/10.15760/etd. 879

This Dissertation is brought to you for free and open access. It has been accepted for inclusion in Dissertations and Theses by an authorized administrator of PDXScholar. Please contact us if we can make this document more accessible: pdxscholar@pdx.edu. 
FREDERICK DALTON KEAST

A dissertation submitted in partial fulfillment of the requirements for the degree of

DOCTOR OF PHILOSOPHY

in

URBAN STUDIES

Portland State University

1980

(c) 1980 Frederick Dalton Keast 
TO THE OFFICE OF GRADUATE STUDIES AND RESEARCH:

The members of the committee approve the dissertation of

Frederick Dalton Keast presented July 11, 1980.
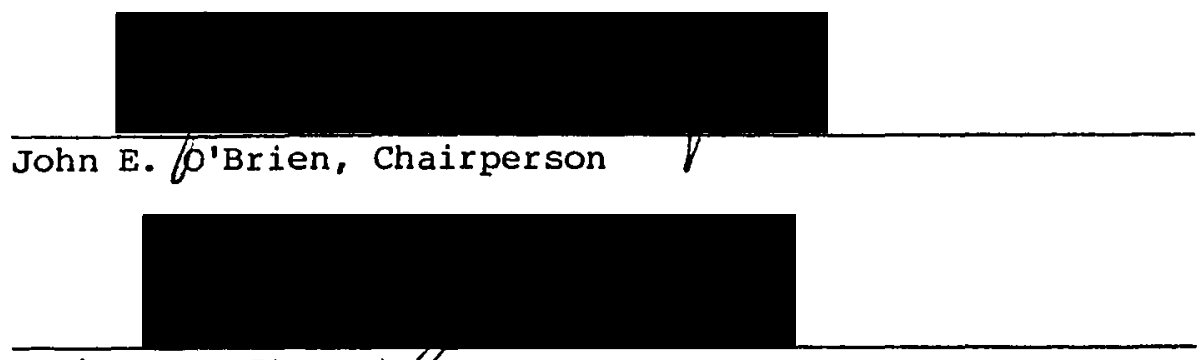

Barbara J. Stewart

Jan Hajdá
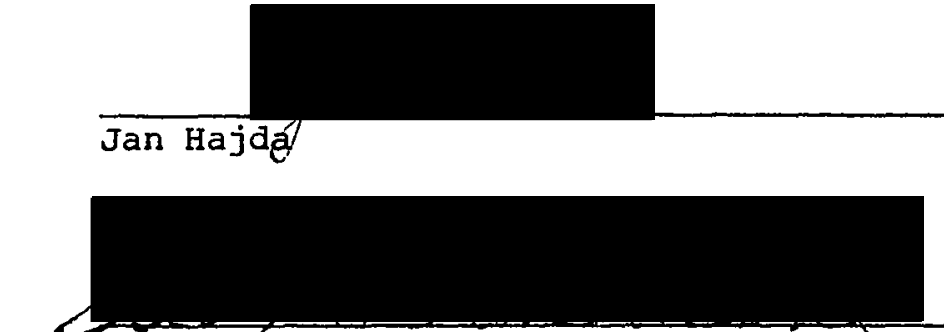

Jerry W. Lansdowne

APPROVED :

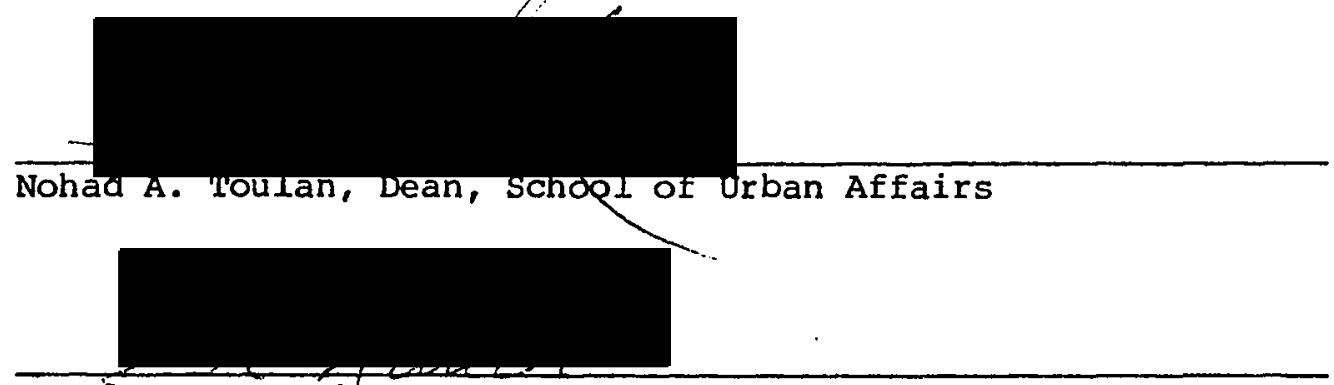

Stanley E. Rauch, Dean, Graduate Studies and Research 
AN ABSTRACT OF THE DISSERTATION OF Frederick Dalton Keast for the Doctor of Philosophy in Urban Studies presented July 11, 1980.

Title: Community Impacts on Organizational Interaction.

APPROVED BY MEMBERS OF THE DISSERTATION COMMITTEE:
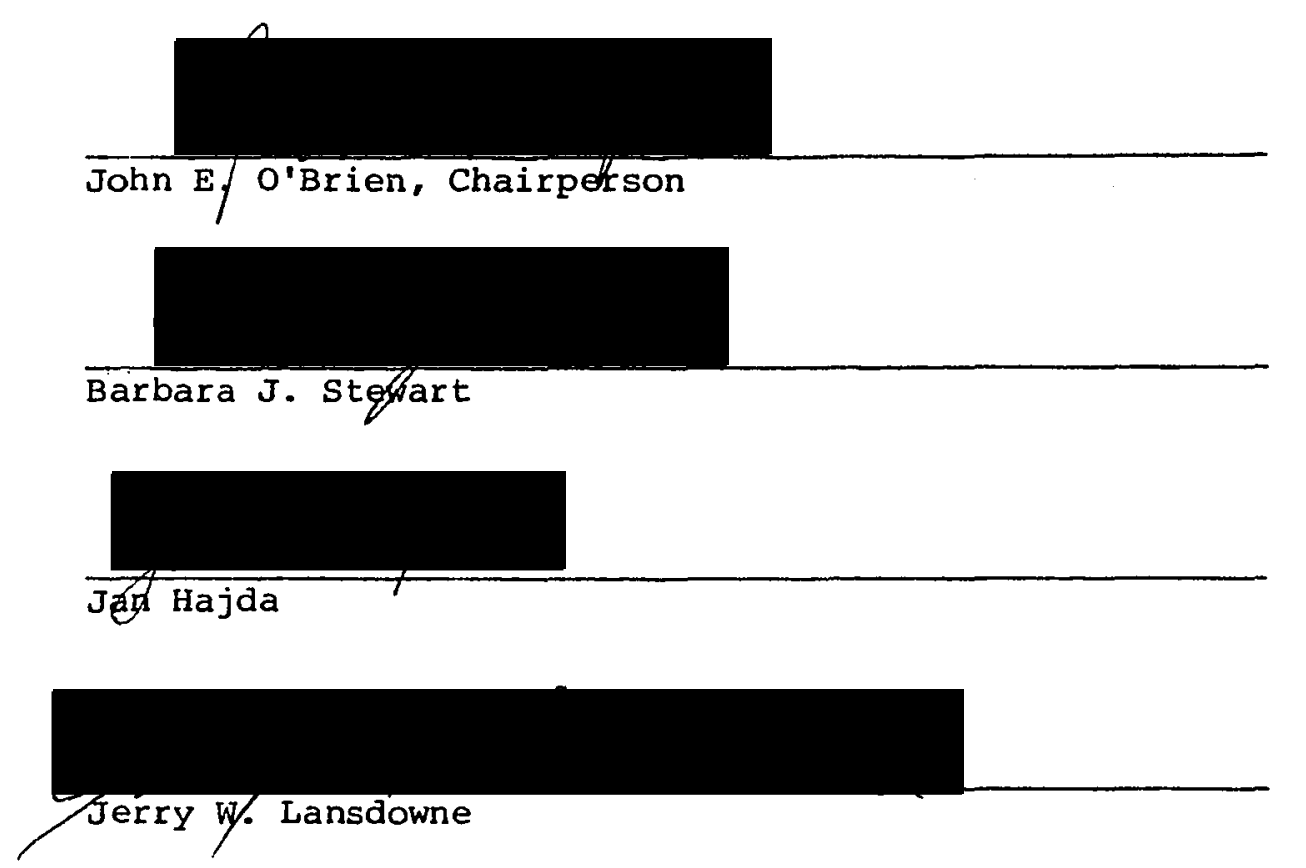

This dissertation addresses the following research question.

Do the criteria by which organizations assess the benefits of entering into interagency agreements vary by city?

Employing data obtained from 183 human service agencies in six western cities, organizational emphases on two classes of goals as they relate to the decision to interact with other agencies are assessed as functions of six organizational variables and city. The organizational variables include organizational goal, reliance on 
federal sources for funding, and a range of environmental uncertainty measures. The two classes of organizational goals studied are: first, those which directly accrue to the agency itself, and second, those which accrue directly to entities outside the organization. Findings suggest that while emphases on intraorganizational goals are invariant between cities, those pertaining to extraorganizational entities may well vary between locales. These findings bear theoretical implications for the future study of organizations, and practical implications for entities seeking to develop programs or regulations for application across broadly defined jurisdictions. 


\section{ACKNOWLEDGMENTS}

Few have earned their doctorates without incurring substantial debts to those around them. While I could never thank all of those who have helped me in this undertaking, I am pleased and proud to acknowledge several individuals for their contributions during the completion of this document.

My friends and colleagues, Drs. Douglas G. Montgomery and Lois F. Copperman. Their support and understanding throughout the generation of this dissertation far exceed reasonable expectation.

Dr. Nohad A. Toulan, Dean, School of Urban Affairs. His persistent prodding and encouragement throughout my association with his School were often necessary and always appreciated.

Dr. John Hanson, who initiated the process and who provided valuable advice at several important junctures in the project's design.

Drs. John O'Brien, Barbara Stewart, Jan Hajda, and Jerry Lansdowne, the members of my dissertation advisory committee. Their advice, confidence, and professional demeanor have earned my respect and affection many times over.

Pat Scott, a respected friend and an excellent typist.

Fred and Vera Keast, my parents. Their enthusiasm, interest, and confidence in me have been more important than they would ever suspect. 
Finally, and most importantly, Vicki, whose love, encouragement, and uncommonly good sense have made it all possible. For these and countless other reasons, no one could ask for more in a spouse.

To these individuals and many more, I offer my sincerely heartfelt gratitude. 
TABLE OF CONTENTS

PAGE

ACKNOWLEDGMENTS .................... . . . 1 . . . . . .

LIST OF TABLES. . . . . . . . . . . . . . . . . viii

LIST OF FIGURES . . . . . . . . . . . . . . . . . xii

CHAPTER

I INTRODUCTION. . . . . . . . . ...... 1

II REVIEW OF THE LITERATURE. . . . . . . . . . . 8

The Microeconomic Model of the Firm . . . . . . 9

Consumers: Utility Maximization ....... 11

Firms: Profit Maximization......... 13

Challenges to the Microeconomic Model of the Firm . . 16

Applications to the Microeconomic Model of the Firm . 26

Organizational Theory ............ . . 29

Organizations. . . . . . . . . . . 32

Environments . . . . . . . . . . . . . 34

Organizational Goals . . . . . . . . 37

Goal Setting: The Environment

Goal setting: The Organization

Social Exchange Theory . . . . . . . . . 41

III LOCAL MARKETS AND THE PRIMITIVE ECONOMY MODEL . . . . 50

Community: The Market Context. . . . . . . . 51

The Primitive Economy Model . . . . . . . . . 59 
The Primitive Economy Model: Specification. . . . . 66

The Primitive Economy Model: Analytical

Applications . . . . . . . . . . . . 69

IV METHODOLOGY . . . . . . . . . . . . . . 73

Research Question and Hypotheses. . . . . . . 75

Design. . . . . . . . . . . . . . 77

Sample. . . . . . . . . . . . . . 77

Cities................. 79

Organizations.............. 82

Respondent Selection . . . . . . . . 85

Interview Type

Organization Position

Missing Information

Interview schedule. . . . . . . . . . . 89

Variables ................. . 89

Dependent Variables. . . . . . . . . 90

Intraorganizational Criteria

Extraorganizational Criteria

Independent Variables. . . . . . . . .

Community

Organizational Variables

Summary of Independent Variables

Analysis. . . . . . . . . . . . . . 122

V RESULTS . . . . . . . . . . . . . . . 125

Introduction. . . . . . . . . . . . 125

Analytical Results: Summary. . . . . . . . . 126

Analytical Results: Textual Presentation . . . . 127 
Intraorganizational Criteria. . . . . . .

Analysis of Variance

Analysis of Covariance

Multiple Regression Analysis

A Word About Community

Extraorganizational Criteria. . . . . . .

152

Analysis of Variance

Analysis of Covariance

Multiple Regression Analysis

A Word About Community

Intraorganizational and Extraorganizational

Decision Making Criteria: Summary . . .

Intraorganizational Criteria: Hypothesis 1 Extraorganizational Criteria: Hypothesis 2 Intraorganizational and Extraorganizational Criteria: Hypothesis 3

VI.

CONCLUSIONS AND RELEVANCE. . . . . . . . . . . .

Introduction . . . . . . . . . . . . 195

Review ................... 196

Discussion ................... 199

Conclusions. . . . . . . . . . . . . 212

Implications . . . . . . . . . . . . 215

Theoretical Implications. . . . . . . . 215

Policy Implications . . . . . . . . . . 218

SELECTED BIBLIOGRAPHY. . . . . . . . . . . . . . . . . .

\section{APPENDICES}

I TESTS OF MUTUAL INDEPENDENCE OF INSTRUMENTS 1 AND 2. 


\section{LIST OF TABLES}

TABLE

PAGE

I Cities: Selected Facts. . . . . . . . 80

II Organizational Distribution Between Cities . . . . 85

III Final Sample By City . . . . . . . . . . 88

IV Descriptive statistics of Items from Instrument 1 , Interagency Agreements . . . . . . . . . . 9 94

V Intraorganizational Criteria: Rotated Factor Loadings BY Item . . . . . . . . . . . 9 96

VI Summary Measures of Intraorganizational Dependent variables. ............... 101

VII Intercorrelations Between Intraorganizational Dependent Variables. ............. 101

VII Descriptive statistics of Items from Instrument 2, Interagency Agreements and the Community . . . . 102

IX Extraorganizational Criteria: Rotated Factor Loadings By Item . . . . . . . . . . . 104

$x$ Summary Measures of Extraorganizational Dependent variables. . . . . . . . . . . . . 108

XI Intercorrelations between Extraorganizational Dependent Variables. . . . . . . . . . . . . . .

XII Summary of Independent Variables (Based Upon Sample Employed in Intraorganizational Analyses). . . . . .

XII Intercorrelations of Independent Variables . . . . . 112

XIV Factor Analysis: Rotated Factor Loadings in Development of Uncertainty Measures. . . . . . . . .

XV Summary of Independent Variables (Based Upon Sample Deleted from Intraorganizational Analyses) . . . . .

XVI Analysis of Variance: Grand Mean and Community Deviations from Grand Mean by Intraorganizational

Dependent Variable . . . . . . . . . . . . . . . 
XVII Analyses of Covariance: Covariate Contributions to Intraorganizational Decision Making Criteria, p<.10... . . . . . . . . . . . . . . .

XVIII Agency Enhancement: Grand Mean and Community Deviations by Covariate . . . . . . . . . . . .

XIX Autonomy: Grand Mean and Community Deviations by Covariate. . . . . . . . . . . . . . . . .

XX Internal Orientation: Grand Mean and Community Deviations by Covariate . . . . . . . . . . . . .

XXI Summary of Multiple Regression Analysis, Agency Enhancement as Dependent Variable . . . . . . . .

XXII Multiple Regression Analysis, Beta Values Relating Communities to San Bernardino: Agency Enhancement. .

XXIII Summary of Multiple Regression Analysis, Autonomy as Dependent Variable . . . . . . . . . . . . . .

XXIV Multiple Regression Analysis, Beta Values Relating Communities to San Bernardino: Autonomy. . . . . . .

XXV Summary of Multiple Regression Analysis, Internal Orientation as Dependent Variable . . . . . . . . . .

XXVI Multiple Regression Analysis, Beta Values Relating Communities to San Bernardino: Internal Orientation . . . . . . . . . . . . . . . .

XXVII Analysis of Variance: Grand Mean and Community Deviations from Grand Mean by Extraorganizational Dependent Variable. . . . . . . . . . . . . .

XXVIII Analysis of Covariance: Covariate Contributions to Extraorganizational Decision Making Criteria,

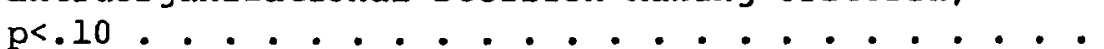

XXIX Instrumental Coordination: Grand Mean and Community Deviation by Covariate. . . . . . . . . . . . .

Xxx Expressive Coordination: Grand Mean and Community Deviation by Covariate. . . . . . . . . . . . . . .

XXXI Exclusion: Grand Mean and Community Deviation by Covariate. . . . . . . . . . . . . . . . . . 
XXXII Outside Input: Grand Mean and Community Deviation by Covariate. . . . . . . . . . . . . 160

XXXIII External Orientation: Grand Mean and Community Deviation by Covariate. . . . . . . . . . . . .

XXXIV Summary of Multiple Regression Analysis, Instrumental Coordination as Dependent Variable. . . . . . . . .

XXXV Multiple Regression Analysis, Beta Values Relating Communities to San Bernardino: Instrumental

Coordination. . . . . . . . . . . . . . . .

XXXVI Summary of Multiple Regression Analysis, Expressive Coordination as Dependent Variable. . . . . . . . .

XXXVII Multiple Regression Analysis, Beta Values Relating Communities to San Bernardino: Expressive Coordination. . . . . . . . . . . . . . . .

XXXVIII Summary of Multiple Regression Analysis, Outside Input as Dependent Variable . . . . . . . . . . .

XXXIX Multiple Regression Analysis, Beta Values Relating Community to San Bernardino: Exclusion . . . . . .

XL Summary of Multiple Regression Analysis, Outside Input as Dependent Variable . . . . . . . . . . . .

XLI Multiple Regression Analysis, Beta Values Relating Communities to San Bernardino: Outside Input . . .

XLII Summary of Multiple Regression Analysis, External Orientation as Dependent Variable . . . . . . . . .

XLIII Multiple Regression Analysis, Beta Values Relating Communities to San Bernardino: External

Orientation . . . . . . . . . . . . . . . . .

XLIV Selected Descriptors of Correlations Between Paired Items from Instruments 1 and 2. . . . . . . . . 236

XIV Factor Analysis of Instruments 1 and 2...$\cdot$. . . . 238

XLVI Intercorrelations between Dependent Variables . . . . 239

XLVII Analyses of Variance, Intraorganizational Criteria by Community. . . . . . . . . . . . . . . . 
XLVIII Analyses of Covariance, Agency Enhancement as Dependent Variable. . . . . . . . . . . . . . . . .

XLIX Analyses of Covariance, Autonomy as Dependent

Variable. . . . . . . . . . . . . . . . . .

L Analyses of Covariance, Internal Orientation as Dependent Variable. . . . . . . . . . . . . . . .

LI Multiple Regression Analysis: Agency Enhancement as Dependent Variable . . . . . . . . . . . . . .

LII Multiple Regression Analysis: Autonomy as Dependent Variable. . . . . . . . . . . . . . . .

LII Multiple Regression Analysis: Internal Orientation as Dependent Variable . . . . . . . . . . . . .

LIV Analyses of Variance, Extraorganizational Criteria by Community. . . . . . . . . . . . . . . . .

IV Analyses of Covariance, Instrumental coordination as Dependent Variable . . . . . . . . . . . . . .

LVI Analyses of Covariance, Expressive Coordination as Dependent Variable . . . . . . . . . . . . . .

IVII Analyses of Covariance, Exclusion as Dependent Variable. . . . . . . . . . . . . . . . .

LVIII Analyses of Covariance, Outside Input as Dependent Variable: . . . . . . . . . . . . . . . .

LIX Analyses of Covariance, External orientation as Dependent Variable. . . . . . . . . . . . . . .

IX Multiple Regression Analysis: Instrumental Coordination as Dependent Variable. . . . . . . .

LXI Multiple Regression Analysis: Expressive Coordination as Dependent Variable. . . . . . . . .

LxII Multiple Regression Analysis: Exclusion as Dependent Variable. . . . . . . . . . . . . . . . .

LXIII Multiple Regression Analysis: Outside Input as Dependent Variable. . . . . . . . . . . . . . .

LXIV Multiple Regression Analysis: External Orientation as Dependent Variable . . . . . . . . . . . . 


\section{LIST OF FIGURES}

1. Diagram of the Organizational Interaction Model. . . .

2. Applicability of Microeconomic, Social Exchange, and Primitive Economy Models to Intra- and Extraorganizational Factors in Organizational Utility Function . . . . . .

3. Research Design. . . . . . . . . . . . . 78

4. Multiple Regression Analyses: Traces of Cities' Beta Weights by Dependent Variable . . . . . . . . .

5. Multiple Regression Analyses: Standard Deviation of Cities' Beta Weights by Dependent Variable . . . . . .

6. Comparison of Associations, Community with Decision Making Criteria. . . . . . . . . . . . . . . 


\section{CHAPTER I}

\section{INTRODUCTION}

Daniel Bell (1973) and numerous others have noted that in many important ways, the United states is entering into an age of organizations. The escalation of governments' roles in citizens' lives, the expansion of large firms' roles in the economy, the steady expansion of influence among politically-oriented organizations, and a host of other developments all support Bell's position.

Perhaps nowhere is this point more poignantly apparent than in the human service industry. By anyone's standards, the role of this industry has expanded considerably during recent years. Federal expenditures on aging services, for example, increased by over 9308 in the 13 years culminating in 1978 (Estes, 1979, p. 50). Organizations-non-profit organizations, primarily--have constituted the primary means by which these resources have been transformed into programs at the local level.

The nature of the human services industry is in many ways unique in the American economy. A number of characteristics contribute to this singularity.

Perhaps most readily apparent is the limited geographic scope within which most human services agencies operate. While funding sources tend to be concentrated at the federal and state echelons of government, the actual delivery of services is typically undertaken by 
organizations serving a single locale. Frequently, though not always, limited by charter to given jurisdictions, service delivery is most often limited in practice by the distance which can reasonably be traveled by clients or service delivery personnel. The ultimate result of this limitation of geographic scope in service provision is the independent existence of similar service delivery systems in different locales. In short, virtually all cities and towns exceeding certain critical population thresholds have service delivery systems which are quite similar in many respects to those of other cities and towns of similar size.

A second key characteristic of the human services industry is the non-profit nature of many of its organizations. While profitoriented organizations are not unknown (particularly in health-related fields), the modal organization in the delivery of social services cannot, by charter, orient toward the accumulation of profit in its operations.

A third characteristic of agencies in the human services industry lies in the independent origination of organizations. While notable exceptions to the more general case exist, most service agencies are founded by local individuals or groups reacting to local problems. Once formed, outside funding is generally attained to allow actual service delivery, but the creation of the organizations is typically local.

A fourth and more recent development in the human services industry is the creation by federal agencies of local coordinating organizations with the mandated function of integrating local services 
into service networks designed to meet the needs of a targeted class of clients (0'Brien et al., 1975). In this horizontal integration of service agencies, the emphasis rests on the ordering of agencies and of their services. This allows identification of potential duplication and also of "gaps" in service, with potentially beneficial impacts on system-wide costs and effectiveness.

Horizontal integration also allows for another, more clientoriented benefit. For the most part, service agencies are founded on a problem orientation. As examples, Legal Aid provides legal assistance, health agencies treat their clients' medical maladies, and family counseling addresses problems of a familial type. While exceptions exist to the general condition, in the end result lie two potential problems. First, multi-problem clients may encounter difficulties in having all their various maladies treated. Second, and not entirely unrelated to the first, specific classes within an overall client population may not find their particular needs met at all.

One way to remedy these problems lies in the coordination of problem-orienteä service agencies so as to create an identifiable pattern of services capable of meeting the needs characteristic of an identifiable client group. This can be accomplished through the addition to the local service industry of organizations oriented to the focal classes of client, and which have as their mandate the creation of such service networks.

In essence this strategy promotes the development of a human service "supermarket" with a "complete stock" of services. The range 
of services is geared to the focal client group, and clients use those elements of the system which are consistent with their needs. Each service is available to other classes of clients as well as that under consideration, so that eack, agency may participate in as many networks as there are defined client groups. While not performing services in the normal sense of the word, the coordinating agency can serve a viable function on a relatively small budget in three ways: (1) by coordinating a system out of a less organized group of service providers; (2) by making known the needs and interests of its particular class of clients; and (3) by advocating with other, more functionoriented Community Decision Organizations (Warren, 1967).

Area Agencies on Aging represent this type of organization (O'Brien and Wetle, 1975). Operating under the provisions of the 1973 amendments to the 1965 older Americans' Act, Area Agencies on Aging (AAAs) operate in jurisdictions serving virtually the entirety of America's population. While predominantly operational at the city or county level, a number of states have also implemented these offices at the state echelon. Their job, in short, lies in the development and coordination of services available to the elderly: stated differently, AAAs' function lies in systematizing local service provision and thereby in improving system-wide service delivery to the locale's aged clientele.

The efficient application of integrating strategies among previously existing organizations demands that coordinating agencies be able to identify coordinative strategies which "fit" the organizations to be integrated. Stated alternatively, the strategies employed 
by AAAs must alter the behavior of needed service agencies in such a way as to induce their cooperation in serving aging clients in concert with the activities of other agencies. To do so demands an understanding of organizational behavior.

To date, however, much of the foundation upon which organizational theory is based simply does not apply well to the field of human services provision.

The standard microeconomic model of rational behavior by firms has been under attack for a considerable period of time. In a succession of considerable duration, critics have joined one another in pointing out that various weaknesses in the model itself and in the assumptions which accompany the model make it unsuitable for analyzing the activities and decisions of individual organizations. While the rationales for critiquing the microeconomic approach vary, the conclusion reached by most authors is a decision making model in which profit is a factor, but not the sole factor in determining organizational behavior. Firms under these models act to maximize utility to the greatest extent possible, and they accomplish this end by pursuing multiple, often competing goals.

Most microeconomic analyses are confined to organizations within the private sector. In this context, where profit is ultimately a prerequisite to continued operation, the utility function employed by firms invariably contains a profit-related goal, although it is often couched in terms which at best serve to proxy the actual measure. Few attempts have been made to incorporate these utility functions with the findings of a burgeoning literature on organizational 
theory, which has its roots in psychology and sociology. While based in the parallel orientation of social exchange theory, the specification of commodities of exchange and of organizational goals presented by this approach have the potential not only for enriching the narrower products of economic inquiry, but additionally offer the promise of extending the basic concepts of utility theory to areas where profits per se are inappropriate--non-profit organizations. It further provides explicit mechanisms through which to relate organizational behavior to characteristics of the organization's environment. In the context of human service organizations, the role of the environment in the determination of organizational behavior is likely to be great. As noted earlier, organizations in this industry are typically linked directly to their environments through a range of operational processes and historical associations. In conjunction with the limited geographic scale of most such organizations' operational territories, these linkages can combine to promote high degrees of responsiveness to local inputs among organizations in this industry. subject to differences borne of scale and other differentiating characteristics, this responsiveness can reasonably be expected to influence organizations in other industries as well.

This dissertation has as its goal the assessment of inter-local differences in the operational goals of human service organizations. Analysis will be heavily based on the Primitive Economy Model of organizational operation (O'Brien, 1976b), which relates organizational activity both to intraorganizational goals and to goals identified primarily with beneficiaries outside the organization. Operationalized 
through a modified utility function, this model permits the comparison of goal orientations between agencies in different cities.

The dissertation's analyses are based on a sample of 183 human service agencies located in six western cities. Assessments of intercity differences in goal orientation are based on analysis of variance and analysis of co-variance models. 
This chapter is devoted to illustrating the theoretical foundations upon which the Primitive Economy Model is based. Accordingly, the theoretical bases for the PEM will be explored and interrelated in order to create a conceptual backdrop against which the PEM's contributions may be presented.

The model's development will begin with a brief explication of the microeconomic theory of the firm. This description will concentrate on the behavioral characteristics ascribed to the firm by microeconomists, and will pursue these observations to the point of developing a simple model of organizational decision making behavior. Next, the chapter will catalog a number of the objections to the "Classical Theory of the Firm"l (Simon, 1959) which have been registered by organizational analysts. Suggestions for alternative models of organizational behavior will be developed into a general formulation based upon that which was cited in the microeconomic context. The chapter's third section will explore the contributions of

$1_{\text {Following the lead of Dr. Simon (1959), the term "Classical }}$ Theory of the Firm" will be employed in this dissertation to denote the microeconomic model of the firm, and not to provide specific reference to a "classical" period or body of thought within economics. Based on the work of Smith (1909) and Marshall (1948), the classical theory of the firm posits organizational behavior in sole pursuit of profit, perfect competition, atomistic competitors, and market transactions. Throughout this dissertation, classical theory of the firm and "the microeconomic model" will be employed interchangeably, and will be synonymous. 
exchange theorists to the field of organizational analysis, again ultimately including these observations in a general formulation of organizational behavior based upon that which was developed earlier. The Primitive Economy Model of organizational behavior will be introduced in Chapter III. Its ties to the work of earlier theorists will be illustrated, and its further contributions discussed. As with the other approaches addressed earlier, the PEM will be re-stated in a general formulation based upon the earlier sections of the chapter. This model will constitute the foundation upon which the dissertation's analytical endeavors will be based.

THE MICROECONOMIC MODEL OF THE FIRM

The 1776 publication of Adam Smith's The Wealth of Nations (Smith, 1909) constituted not only an initial description of competitive commerce, but also a prescription for England's commercial policies. Still in process of turning its back on the unsuccessful mercantile policies which had dominated the country's commerce for many years, England's legal fabric produced an intricate network of barriers to free trade and, inextricably, personal freedom. Smith's book provided an economic rationale to accompany the political and social forces which stood in opposition to continued mercantilism.

At the heart of Smith's system was the much-cited "invisible hand." The general statement addressed by this metaphor was the inclination of rational men to apply themselves singularly to the pursuit of singular goals when unfettered by restraints; if acting only to achieve profits, the rational person was posited to engage in 
affairs in such a way as to maximize profits. While probably not aware of the inter-relations which exist between the myriad of decisions and activities undertaken, rationality would dictate that the individual maintain certain patterns of resource acquisition which would tend to reflect in the activities of the firm. Because all commercial concerns react to these influences through the common motivation of all owners/managers, basic relationships between different types of resources and outputs were posited to remain relatively constant between businesses which themselves might be quite different.

Smith's model was elaborated most advantageously in the late 19th century by Alfred Marshall (1948) in his Principles of Economics. A lengthy volume comprised primarily of verbal exposition, this work systematically expanded on the ideas first enunciated by Smith, and additionally specified a number of basic functions and relationships in the Mathematical Appendix which borrowed heavily from Marshall's contemporaries.

The contributions of both authors have been widely discussed and extended by a host of later authors. Nonetheless, the discipline of microeconomics exists now much as a product of these two germinal, early works. Accordingly, the Classical Theory of the Firm, alternatively termed the microeconomic theory of the firm, can be traced directly back to their works.

It is important to recognize that both authors saw their models as "ideal typical" (Weber, 1947). While the absolute incarnation of their work would rarely if ever be found in reality, the associations 
they described would nonetheless portray general inclinations and directions of association as encountered in reality. Marshall makes this point in the Preface to the First Edition as follows: "Economic laws and reasonings in fact are merely part of the material which Conscience and Common-sense have to turn to account in solving practical problems, and in laying down rules which may be a guide in life" (Marshall, 1948, p. iv).

Microeconomics, generally, is a discipline oriented to studying how resources are employed in the conduct of individual and organizational affairs. At the heart of the discipline are certain assumptions about what compels the various entities to behave as they do. It is assumed in this regard that economic beings will engage in activities so as to maximize their well-being; given two courses of action, the economic entity will engage in that alternative which provides the greatest return to the costs incurred in support of activity undertaken in its pursuit.

Exactly how the entity perceives its interest best served rests on how the entity itself is defined. Two alternatives are recognized; the consumer and the firm.

Consumers: Utility Maximization

Consumers are envisioned as multifaceted individuals who in the process of pursuing their affairs seek to enhance their personal welfare to the greatest extent possible, subject to budgetary constraints. Among decisions faced by individuals in this pursuit are those which relate to work and countless others which relate to their consumption of goods and services, each of which provides unique 
satisfactions.

The very variety of the returns by which consumers derive satisfaction creates a situation within which the modeling of decision making behavior must be very general. Thus, when referring to the benefits accruing from consumer activity, economists employ a generic term for satisfaction, "utility." People seek to achieve the highest level of welfare available to them, a goal orientation referred to as utility-maximizing behavior. Koplin summarizes the concept as follows.

Utility or satisfaction is the capacity of a good to satisfy

a human want. The rational individual will choose among the alternatives open to him those that maximize his utility. Economic theory assumes that each individual attempts to maximize his utility (Koplin, 1971, p. 29).

The general relation between the individual's well-being and the commodities actually consumed can be stated in terms of the "utility function." Utility functions describe the contributions of each good or service consumed to the overall satisfaction of the consumer. A typical representation of a utility function is presented in (1), below (Jevons, as cited in Samuelson, 1976; Marshall, 1948).

$$
\mathrm{u}=\mathrm{v}_{1}\left(\mathrm{x}_{1}\right)+\mathrm{v}_{2}\left(\mathrm{x}_{2}\right)+\cdots \cdot+\mathrm{v}_{\mathrm{i}}\left(\mathrm{x}_{\mathrm{i}}\right)+\cdots \cdot \mathrm{v}_{\mathrm{n}}\left(\mathrm{x}_{\mathrm{n}}\right)
$$

Here, $U$ denotes utility, while $v_{i}$ represents the satisfaction associated by the consumer with the $i^{\text {th }}$ good or service, $x_{i}{ }^{2}$. Total utility in this formulation is equal to the sum of the utilities derived separately from each of the consumed goods and services.

The rational consumer, then, tailors consumption of the various

2 In this context, the value of $\mathrm{V}$ is related to the quantity of the commodity consumed, such that $v_{i}\left(x_{i}\right)^{\prime}>0$, and $v_{i}\left(x_{i}\right) \cdots<0$. 
commodities so that overall utility is maximized. Since the individual's budget is fixed, the enhancement of total utility can be achieved only through tailoring the consumption of all items so that balance is achieved between the benefit received from each and its price ${ }^{3}$. In this context, the consumer faces a problem of optimization. Because greater consumption of one good necessarily entails the reduction of other goods' consumptions (owing to the fixed budget), and since each good contributes independently to total utility, the rational consumer tailors expenditures on each so that overall utility is the highest possible.

\section{Firms: Profit Maximization}

The firm constitutes an economic entity which is definitionally

distinct from the consumer. Koplin addresses the firm as follows.

The business firm is an organizational device, an economic and legal institution. It incurs costs in acquiring inputs, which are factors of production such as labor, land, and capital, or intermediate goods purchased from other firms. The inputs are converted into output through a production process. The firm receives revenues by selling its outputs to individuals, other firms, or government and nonprofit agencies (Koplin, 1971, p. 81).

Principal among the differences between firms and consumers are the goals they pursue. As an instrumentality formed by individuals, the firm's role lies in the unique contribution it makes to the utility function of its owner or operator--income in the form of profit.

${ }^{3}$ This balance is achieved when the ratios relating the marginal utilities of each good or service are equal to the ratios of their prices. The interested reader is referred to any microeconomic text, of which Samuelson (1964) and Koplin (1971) are representative. 
The firm as such is not human. It has no utility function and no preference maps. The firm is a tool designed to further the interests of individuals. It is difficult but essential to distinguish between the interests and objectives of individuals, who are assumed to be utility maximizers, and the objectives of the firm .... The standard assumption of microeconomic theory is that a firm attempts to maximize its profits (Koplin, 1971, p. 81).4

In the classical microeconomic theory of the firm, then, the goal of the firm is singular--profit maximization. As such, the problem facing the firm differs fundamentally from that of the individual: where the consumer optimizes, the firm maximizes.

Profit constitutes the difference between the costs of engaging in business, and the revenues derived, as below (Samuelson, 1976).

$$
P=R-C
$$

where $P$ denotes profit, $R$ represents revenue, and $C$ signifies costs. The firm maximizing profits, then, faces the following problem.

$$
\operatorname{Max} P=R-C .^{5}
$$

4 It should be noted that the firm may also contribute to the owner's well-being in other, non-monetary ways. For example, the personal preference for being "one's own boss" may compel a firm's owner to accept a lower income than would be realized in a salaried role for another employer. Where this is the case, this personal freedom represents a form of return to the owner which can be valued monetarily, and equated conceptually with profit. The interested reader is referred to koplin (1971, pp. 82-83).

5 Samuelson's formulation (1976), like others, goes on to note that the firm will realize the point of profit maximization when the profit realized from the production of the last unit of output is zero, or $P=R-C=0$. This point is achieved through the alteration of output quantities, which directly affects revenues (which are constant or decreasing with increases in output) and costs (which are increasing with increases in output) associated with the last unit of output. The interested reader is referred to any microeconomic text, including Samuelson (1964) or Koplin (1971). Samuelson (1976) provides a more sophisticated presentation. 
Profit, in the context in which it is employed here, constitutes a univariate counterpart to the multivariate concept of consumer utility. It is within the definitions of both concepts to envision a firm's profit as a synonymous term for its utility, as follows.

(4) $\quad P=U$

Envisioned in this light, the firm's welfare is maximized when the firm maximizes its total net revenue, as signified by the reformulation of (5), as follows.

(5) $\operatorname{Max} U=R-C$

In sum, the principal distinction separating firm and consumer in microeconomic theory lies not in different behavioral orientations, for each is oriented to the maximization of its own position. Rather, firm and consumer are distinguished in terms of the criteria by which their success is measured. Consumers relate to a multi-dimensional concept of welfare, reflecting the benefits associated with a range of goods, services, and activities. Firms, being instrumentalities created to serve owners through the generation of net revenues, are oriented to a uni-dimensional goal--profit--and therefore behave so as to maximize.

There are those, however, who would suggest that the distinctions between consumers and corporate welfare are less distinct than those proposed by microeconomic theory. As explained in the pages which follow, these authors challenge the classical Theory of the Firm as excessiveiy over-simplified and, accordingly, offer modifications to the Classical Theory which posit organizational utility functions similar to those described above as pertaining to consumers alone. 
CHALLENGES TO THE MICROECONOMIC MODEL OF THE FIRM

Dissatisfaction with the prosaic neoclassical profit maximization rationale has led many economists to search for a more viable alternative (Kania and McKean, 1979).

The profit maximization assumption has long been under attack, chiefly on the grounds that it lacks realism (Koplin, 1963).

For a long time, there has been dissatisfaction with the traditional theory of the firm and its basic axiom that firms maximize profits (Monsen and Downs, 1965).

Since dissatisfaction with the classical theory began vigorously being registered in the 1920's and 1930's, theories of the firm have been increased abundantly (Schramm and Sherman, 1974).

The theory of the firm as it exists in present economic literature is a deductive system based on assumptions of human motivation that appear doubtful in light of present day psychology, and on assumptions of organizational behavior that are implausible (C. Bernard, 1950).

These introductions to relatively recent works in the analysis of organizational behavior constitute a representative sampling of introductions employed in a new branch of the economic literature. Having noted that the microeconomic model fails to satisfactorily account for organizational behavior as empirically observed, authors typically challenge the profit maximization assumptions which underlie the classical model of the firm. In its stead, authors suggest alternative goals which, in conjunction with or instead of profit attainment, could better explain the observed behavior of commercial enterprises.

If profit maximization is the sole motivation in the operation of firms, behaviors which are oriented to the achievement of other, incompatible goals are by definition irrational. Yet it is empirically 
apparent that considerable reason is frequently applied to the applicaton of organizational resources to other ends, and this general departure from the assumptions of microeconomic theory is cited as undermining the model's credibility.

Chester Bernard (1950) launched what was perhaps the most influential, modern attack on the Classical Theory of the Firm. In his discussion of executive functions within the organization, he noted two ubiquitous processes which accompany processes of organizational development: (1) a tendency to growth, and (2) an orientation to survival. Neither is consistent in and of itself with the maximization of profit, and so Bernard's remarks suggest an element to organizational behavior which reflects ends and processes other than profit. Cyert and March (1955) take Bernard's work a step further by suggesting a consciousness in the multiplicity of goals established by organizations: this, too, is inconsistent with the microeconomic model of organizational behavior. As will be further substantiated later, the list of authors contributing to these and other sources of challenge has become legion.

Herbert A. Simon (1959) has addressed the apparent failure of the Classical Theory of the Firm. His remarks draw attention to the different ends to which such a model can be applied, and to the different requirements which must be met in each of the applications if a behavioral model is to vindicate itself.

Simon points out that microeconomists have typically been interested in the impacts of policy and other exogenous variables on the economy as a whole. At this level of aggregation, a decision 
making model based solely on profit maximization has allowed findings of sufficient accuracy to vindicate the analytical framework employed in their derivation; individual differences in the decision making criteria of firms tend to be lost at this level of generality. Where the unit of analysis is the individual firm, however, variations from the profit maximizing principle are likely to be both dramatic and important: at this level of specificity, a model of greater precision may well be necessary for a number of analytical purposes. In support of this observation, he presents the following metaphor.

Supposing we were pouring some viscous liquid--molasses-into a bowl of very irregular shape. What would we need in order to make a theory of the form the molasses would take in the bowl? How much would we have to know about the properties of molasses to predict its behavior under the circumstances? If the bowl were held motionless, and if we wanted only to predict behavior in equilibrium, we would have to know little, indeed, about molasses. The single essential assumption would be that the molasses, under the force of gravity, would minimize the height of its center of gravity. With this assumption, which would apply as well to any other liquid, and a complete knowledge of the environment--in this case the shape of the bowl--the equilibrium is completely determined. Just so, the equilibrium behavior of a perfectly adapting organism depends only on its goal and its environment; it is otherwise completely independent of the internal properties of the organism (Simon, 1959, p. 255).

In this, simon points out the value of the microeconomic theory of the firm. By predicting differences in equilibrium states prompted by a broad range of disturbances, the model provides a sound basis for the prediction of general patterns of response.

\section{Simon continues his metaphor as follows.}

If the bowl into which we were pouring the molasses were jiggled rapidly, or if we wanted to know about the behavior before equilibrium was reached, prediction would require much more information. It would require, in particular, more information about the properties of molasses: its viscosity, the rapidity with which it 'adapted' itself to the containing 
vessel and moved towards its 'goal' of lowering its center of gravity. Likewise, to predict the short-run behavior of an adaptive organism, or its behavior in a complex and rapidly changing environment, it is not enough to know its goals. We must know also a great deal about its internal structure and particularly its mechanisms of adaptation (p. 255).

In short, the microeconomic theory of the firm simply is not suited to analyzing the more specific behaviors of firms in activities neither oriented nor related to the attainment of equilibrium states. To the extent that analysis is oriented to such foci, the strength of the microeconomic model's generality is diluted by its weakness of imprecision.

In another article, Simon summarized the challenges to the Classical Theory in terms of five general classes. Two (the distinctions which separate long-term from short-term profits, and the role of psychic, non-monetary income in the calculation of profit) are largely semantic and not germane to this context. Three other classes of objection, however, are central to the further development of the microeconomic model. These are as follow.

1. Satisficing behavior. Borrowing from the literature in psychology, simon identifies profit-satisficing behavior as that which is willing to settle for profit levels less than the maximum possible so long as minimal thresholds are surpassed. Satisficing behavior is clearly inconsistent with the maximizing behavior upon which the classicial theory of the firm is based, and plays an important role in the modifications to the classical theory of the firm which arise out of the field of economics.

2. Owner/Manager separation. The Classical Theory of the Firm defines organizations as instrumentalities serving the purposes of its 
owners. Since the interests of owners are served solely through profit attainment, profit maximization is the only rational motivation for the firm. Implicit in this reasoning is a direct and unbroken association between the owners and the operations of the organization. An important source of challenge to the basic model lies in the observation that in modern corporations--which dominate the economy-owners typically do not manage their firms; rather, they typically own a relatively small proportion of the company and, with other owners, hire managers to oversee the company's operations. To the extent that managers orient to goals other than those of the owners, the classical theory of the firm will not accurately predict the organization's operations. This point--that managers may pursue their own ends through company operations--is a very important source of challenge to the classical theory.

3. Imperfect Competition. Baumol (1967), Niskanen (1968), and most other authors challenging the microeconomic theory of organizational behavior phrase their remarks in the context of the large organization which exists in a market context other than the perfectly competitive. This is an important distinction. In microeconomic theory, profit maximization as an organizational pursuit is of paramount importance if organizations are to survive the competitive pressures of the market place. In monopolistic and oligopolistic industries, however, the relation between marginal costs and marginal revenues at equilibrium levels of demand and supply allow the firm to price its output higher than would be possible under perfectly competitive conditions. In short, the continued viability of the firm 
need not hinge solely on its profit maximization; rather, the firm enjoys by virtue of the structure of its market an excess of revenues over and above those necessary to pay for the cost of doing business. The disposition of this organizational slack is the central focus of most economists' challenges to the microeconomic theory of the firm. Profit satisficing behavior is perhaps the most important of the three points cited above, and is consequently widely cited by authors addressing this general subject area (Cyert and March, 1956; Monsen and Downs, 1965; Cohen and Cyert, 1965; Simon, 1959; Baumol, 1967; Niskanen, 1968; Hannan and Freeman, 1977). While explicit distinctions are rare, authors tend to identify two general classes of excess resources which ultimately derive from satisficing behavior. "Organizational slack," a term introduced by Cohen and Cyert (1965), is a body of unallocated resources which develop through the interaction of conservative orientations by managers with respect to revenueproducing endeavors and with respect to costs: the first leads to higher revenues than planned, while the latter produces costs which are less than foreseen. While posited by many (such as Cyert and March, 1956; Hannan and Freeman, 1977) as providing stability to organizational operations, the existence of these resources by definition detracts from profit maximization. A second group of authors suggest that managerial attentions tend to orient to goals other than profitmaximization, and so create conditions under which excess resources may be generated.

In either case, two derivative issues arise out of profitsatisficing behavior. First, in being willing to settle for less than 
maximal profit levels, owners are likely to exert less influence than might otherwise be the case in their control over the firm's operation and, second, in settling for less than maximal profits, owners permit the pursuit of other standards of success which, in their attainment, free organizational resources which otherwise would be reflected in profit. Each of these derivative points carried great significance in the suggestions tendered in the literature for modification of the classical theory.

The least radical suggestions for changing the classical theory simply suggest that goals other than profit maximization seem to guide organizational behavior. A broad range of possible goals has been suggested, including revenue per se (Baumol, 1967), dividend payout (Kania and McKean, 1979), security (Schramm and Sherman, 1974), and growth (Niskanen, 1968). That these goals coexist with profit in firms' programs of operations is the more noteworthy inasmuch as it has been shown that only in rare cases will the maximization of any of these performance standards occur concurrently with profit maximization; in most cases they are incompatible and cannot be simultaneously served (Herendeen, 1974; Baumol, 1967; J. Williamson, 1966). The recognition of any of these alternative goals, then, connotes the prior existence of profit-satisficing behavior by owners.

The separation of ownership and management in the modern corporation is a second important source of suggestions for modification to the Classical Theory of the Firm, and one which has generated considerable attention. It is not, however, a new topic of discussion. Speaking to the removal of private firms from freely competitive 
markets, Adam Smith wrote of a tendency toward "negligence, profusion, and malversion of [the company's] own servants, whose aisorderly conduct seldom allows the company to exceed the ordinary rate of profit in trades which are altogether free" (1909, p. 481). Alfred Marshall (1948) similarly, though less colorfully, noted that among large corporations managers tend to be insulated from owners' control and safe fròm criticism.

A number of authors have carried these observations into the more recent context by noting the continued insulation of corporate management from the control of owners. While Smith and Marshall recognized problems associated with this pattern of management, it was generally thought that competitive forces would mitigate the potential effects of such a separation on organizational performance. A number of more recent authors, however, note that no such control is apparent in the context of modern, large business firms (Monsen and Downs, 1965; Gordon, 1962; Koplin, 1963). Rather, it is posited that managerial freedom from control has led to a high degree of latitude in the fulfillment of managerial responsibilities, and that this latitude can be manifested in any number of ways.

Some maintain that this latitude is important to organizational efficiency in the absence of the competitive forces which framed Smith and Marshall's analyses (Cyert and March, 1956; Crew et al., 1971; Leibenstein, 1960, 1966). Where this is the case, the organization's response to market forces would parallel those predicted by the microeconomic model, but would do so for different reasons. Where competitive market forces influence organizational responses in the 
microeconomic model, in the context of the large corporation, organizational response is occasioned by astute management operating in lieu of market influences.

Other authors maintain that the owner/manager split invariably impacts the relation between organizational operations and owners' goals. The exact nature of the impacts, however, is subject to a number of interpretations.

Most conservatively, it is posited that management in this context will pursue more conservative policies than would ownermanagers in similar operational situations. This conservatism is likely to take a number of forms. First, in order to avoid establishing performance standards which may not be achievable in subsequent time frames, managers will endeavor to minimize variations in organizational earnings from year to year (Monsen and Downs, 1965; Kania and McKean, 1979; Galbraith, 1967). Second, managers will seek to avoid risk (Monsen and Downs, 1965; Schramm and Sherman, 1974; Kania and Mckean, 1979), with derivative implications of reduced profit, reduced growth, and reduced likelihood of bankruptcy.

A second class of more direct impacts have been posited, including including a heightened tendency to orient toward revenue maximization (Baumol, 1967; Galbraith, 1967), hastened organizational growth (Galbraith, 1967; J. Williamson, 1966; Penrose, 1959; Marris, 1964; C. Bernard, 1950), and higher rates of return on corporate assets (Herendeen, 1974). Common among these writings, however, is a general tendency to associate managerial orientations in controlling firms' 
operations with the interests of owners, which become more broadly defined as a result of the split.

A third class of effects have been associated with the divergence of ownership and management. Here it is suggested that managers can and do exercise the latitude availed them by pursuing their own ends through the operation of the firm. So long as owners' interests are served through the realization of minimum profit and any other goals explicitly or implicitly recognized, managers are free to pursue their own ends with the company. Herendeen (1974) succinctly states the point that "the relevant question is not whether profits are maximized, but whose profits are maximized" (p. 60).

In this context, it is appropriate to assess organizational performance not only with respect to the interests of owners, but also those of managers. Cited as important considerations with respect to the latter are a number of motivators, among which are: security (Marris, 1964), lifetime income (Monsen and Downs, 1965; Niskanen, 1968), organizational growth for its direct effects on income (Marris, 1964 : O. Williamson, 1964), luxurious emoluments (0. Williamson, 1964; Niskanen, 1968), and such non-monetary rewards as leisure, and power (Monsen and Downs, 1965; Niskanen, 1968; Azariadis et al., 1972). In summary, a large group of authors have sought to expand the Classical Theory of the Firm to include goal orientations other than strict profit maximization. Suggested modifications include goals which are identified with owners as well as a number which pertain to managers. 
APPLICATION TO THE MICROECONOMIC MODEL OF THE FIRM

It will be recalled that the principal differentiation between consumers and firms as posited by microeconomic theory centers on the differences between their respective motivations.

Consumers, as noted by Samuelson (1964) and Koplin (1971), are oriented toward the maximization of their personal welfare--their utility--through optimization of their consumption mix. They tailor their purchases so as to maximize the total utility realized from their overall purchases, as follows.

$$
\mathrm{U}=\mathrm{v}_{1}\left(\mathrm{x}_{\mathrm{I}}\right)+\mathrm{v}_{2}\left(\mathrm{x}_{2}\right)+\ldots \cdot \mathrm{v}_{\mathrm{i}}\left(\mathrm{x}_{\mathrm{i}}\right)+\ldots \cdot+\mathrm{v}_{\mathrm{n}}\left(\mathrm{x}_{\mathrm{n}}\right)
$$

Firms, however, are singular in purpose and so orient toward maximizing behavior. Since their orientation involves profit, profitmaximizing behavior follows. Samuelson, it will be recalled, formulated this relation as follows.

(3) $\operatorname{Max} P=R-C$

The authors cited in the preceding pages have suggested that the microeconomic approach oversimplifies the actual case. It is more appropriate, they note, to envision firms as orienting to a range of simultaneous goals, which include profit as well as other motivations. In this situation, firms do not maximize, they optimize. One such case is presented as follows (Kania and McKean, 1979, p. 29).

(6) $\quad U=f\left(s_{1}, s_{2}, s_{3}\right)$

where utility $(U)--$ the generalized term used earlier to refer to consumer satisfaction, but now applied to organizational well-being-accruing to a firm is a product of its profits $\left(S_{1}\right)$, its capital 
growth $\left(s_{2}\right)$, and its dividend payout $\left(s_{3}\right)$.

Two characteristics of this formulation merit comment for their relevance to preceding discussions: the first deals with satisficing behavior applied directly to profit, and the second addresses which motivating factors are represented in firms' behavior.

Satisficing behavior, as mentioned earlier, may be represented in this conceptualization in one of two ways. First, firms' owners may orient toward a multitude of goals and so seek to optimize the firms' overall utility as represented by utility function. If so, owners do not satisfice in the classic sense of the term; rather, they settle for less than maximal profit in order to devote resources to other ends. This allows them to maximize utility by optimizing the attainment of profit and other ends included in the organization's utility function. Second, owners may in fact satisfice with respect to the utility function as a whole, and therefore allow the discretionary use of organizational slack by managers. This would make possible the use of organizational resources by managers in pursuit of their own ends.

In both cases, the firm responds to a utility function and so pursues an optimal welfare position. In the first case, the following formulation, which essentially re-states the Kania and McKean model, applies.

$$
U=f\left(v_{f 1} x_{f l}+v_{f 2} x_{f 2}+. \cdot \cdot v_{f i} x_{f i}+\cdot \cdot \cdot v_{f n} x_{f n}\right)
$$

where $U$ again represents the firm's utility, $V_{f i}$ constitutes the value to the firm of the firm's $i^{\text {th }}$ measure of success, $x_{f i}$. This formulation represents the utility-maximizing case where owners of the firm 
orient to a number of goals. The absence of organizational slack prohibits the incorporation of managers' goals into the utility function of the firm.

The second case, where owners pursue multiple goals but where they satisfice with respect to utility, may be summarized as follows.

(8) $U=f\left(\Sigma v_{f i} x_{f i}+v_{m l} x_{m l}+v_{m 2} x_{m 2}+\ldots v_{m i} x_{m i}+\ldots+v_{m n} x_{m n}\right)$ Here, $\sum V_{f i} X_{f i}$ represents the influence on the firm's welfare position attributable to the identified interests of the firm's owners; in terms of formula (3), this term constitutes the aggregated value of the individual terms. $v_{m i}$ is the value attached to the $i^{\text {th }}$ managerial goal, which is represented by the term $x_{m i}$. The sum of the utility values attributable to the various managerial goals constitutes the difference between available organizational resources and those resources identified by owners as minimally acceptable returns on their investment; in short, the sum of the $v_{m i} x_{m i}$ terms represents the organizational slack introduced by Cyert and March (1963).

It is, then, possible to summarize the recent contributions of economists to the Classical Theory of the Firm through the summary formulation which follows.

(9) $U=f\left(\Sigma V_{f i} x_{f i}+\sum V_{m i} x_{m i}\right)$

This formulation is nothing more than a concise specification that organizational utility and, therefore, behavior, is explainable in terms of the rewards accruing first to the firm's owners and second to its managers.

In general, this fundamental specification of organizational goals is not entirely inconsistent with those of the early 
microeconomists. The orientation to utility maximization, as suggested earlier, in reality constitutes a more general case of the maximization model specified for profit. The addition of managers' interests to those of owners constitutes a fundamental variation from the classical model, but so long as managers maximize the utility derived from their employment of organizational resources, the utility maximization premise remains intact. The firm (and its management) in this context remains a rational, economic entity, and still orients its operations to the achievement of a finite range of ends. Koplin (1963) summarizes the relation as follows: "The dominance of utility maximization more simply but more fundamentally suggests that the proper definition of profit maximization is consistent with utility maximization" (p. 131).

\section{ORGANIZATIONAL THEORY}

To borrow once again from Simon's metaphor, the revisions to the Classical Theory of the Firm described to this point allow for the further "fleshing out" of the microeconomic model. In so doing, the model's applicability is extended from the comparative analysis of equilibrium states to the less easily addressed realities of day-today operation. The basic mode of analysis is, however, unchanged.

1. The unit of analysis remains the profit-oriented firm.

2. The firm retains its identity as an economic entity, seeking to enhance its position, however defined, to the greatest possible extent.

3. The firm's relationship to the remainder of the world remains 
limited to that series of associations which are mediated through any of a variety of market contexts.

4. Organizational well-being remains an absolute value: welfare is not measured with specific reference to other firms, nor is it compared with any other extra-organizational entities. Change over time in the firm's welfare position constitutes the only relevant point of reference.

As such, the model as developed to now bears a number of important limitations.

First, it cannot be readily applied to organizations which do not operate for profit, or for which output is unrelated in a direct, causal sense to revenue.

Second, it cannot be readily applied to organizations which operate as distinctly identifiable sub-units of larger organizations which themselves bear an integral identity.

Third, the model does not accomodate organizational associations with extra-organizational entities which exist for reasons other than purely transactional interactions in market contexts.

Of these, the necessity of a price/revenue component in the profit-based model, even as revised, is perhaps the greatest impediment to its applicability in areas where profit per se is not an applicable reality. Price performs two critical functions in the classical model of the firm.

First, price is the principal allocative device on the demand side of a market economy. Economic theory deals with the treatment of scarce resources. To the extent that a commodity or service is 
unpriced, it is in the strictest sense not a scarce good. This is an important limitation. It is true that price alone is an incomplete index of the cost of a good or service, for it only very indirectly reflects non-market impediments to the good's attainment: time, accessability, and numerous other variables may enter on the demand side of the transaction to limit clients' quests for the product. Nonethe-.. less, the market price mechanism does largely determine a good or service's ultimate cost to the consumer, and it does interact with the prices of other goods and services to establish cost ratios between different goods and services which may well share relatively equal nonprice-related cost figures. That unpriced accessability may well be a desirable element of a program is a non-economic consideration, and as such it seriously violates the basic postulates of the economic model of the firm.

In a similar vein, the absence of a price mechanism as it pertains to organizational output precludes the use of revenue as a component in the analysis of organizational activity. Organizations seeking to maximize profits (or, conversely, to minimize losses) will consciously or unconsciously tailor their production to match incremental per-unit costs with per-unit revenues (see note 4 , Chapter II). The absence of a revenue component renders this relationship insoluble and undermines standard microeconomic approaches to the assessment of organizational activity.

In the absence of a price component, an alternative conceptualization is necessary to the analysis of organizational behavior. Such a perspective has been developed under the general classification of 
"organizational theory," based largely in the disciplines of psychology, sociology, public and business administration. The general field of organizational theory addresses a broad range of interest areas including intraorganizational issues, interorganizational topics, and organizational-environmental interactions, of which the last two are of most direct relevance to this dissertation's development. The model developed will constitute one which is amenable to integration with the Classical Theory of the Firm, as originally formulated and as modified by subsequent writers, and indeed will in its greater generality be one of which the profit-maximizing case might be termed a specific application.

The discussion of organizational theory will begin with a discussion of organizational definitions, a brief treatment of organizational environments, a discussion of organizational goal setting and, finally, a description of social exchange theory as it has been applied to organizational analysis. The section will conclude with the incorporation of these observations in a reformulation of the organizational utility function.

\section{Organizations}

The defining criterion of a formal organization--or an organization, for short--is the existence of procedures for mobilizing and coordinating the efforts of various, usually specialized, subgroups in the pursuit of joint objectives (Blau, 1968, p. 304).

Stated alternatively, organizations are social entities designed to accomplish stated goals through group action (Katz and Kahn, 1972; Parsons, 1956; Lyden, 1975). 
Formal organizations are deliberately established by the whole or part of a social aggregate to serve a goal identified as important and untreated.

Organizations must serve a purpose of importance to entities outside the organization. Because scarce resources are necessary to organizational development, maintenance, and operation, the creation of a product which is of importance to some extraorganizational entity is essential if requisite resources are to continue in availability and, indirectly, if the organization is to survive. This observation connotes an open-system conceptualization within which organizations constitute a sub-unit of successively larger systems, each incorporating smaller systems as sub-components.

In this sense, organizations as entities are quite consistent with those defined earlier in the Classical Theory of the Firm. In the microeconomic context, organizations perform a service (such as selling hardware or repairing shoes) in the pursuit of a higher, more prevalent motivation--the attainment of profit.

The processes cited earlier by Koplin (input acquisition, the processing of resources, and ultimate dissemination of output) have been applied in organizational theory as well. Parsons (1956) noted that primary among the functions of organizations is goal attainment, the fulfillment of the functional necessity for which the organization was created. Perrow (1961) similarly but in more discrete fashion noted that organizations must secure inputs, marshal a technology, and coordinate members' activities in fulfilling the organizational function. Katz and Kahn (1972) suggest a seven-step description of 
the means by which organizations serve their prescribed function.

Less distinctly identified in organizational theory are the ultimate motivations which compel organizations to engage in prevalent behavioral modes, the equivalent to profit in the microeconomic model. Of considerable importance in this assessment is the relation of the organization to other components of the larger system in which it operates. Together, these extraorganizational entities are collectively referred to as the "environment," and they constitute the focus of the ensuing section.

\section{Environments}

Organizational analysts in the $1950^{\prime}$ s and 1960's increasingly recognized that while organizations bear a number of system-like characteristics themselves, seldom do they exist, or operate, in a vacuum. Rather, while organizations exist as systems in their own right, they are also components in larger systems representing their communities, their organizational networks, and others. These larger entities, and important components within each, are referred to as environments (Levine and White, 1972). Hawley (1968) notes that: "Environment includes all that is external to and potentially or actually influential upon an object of investigation" (p. 1).

Organizational environments have been more narrowly defined as well. Dill (1962) defined the term as only those features of the organization's field which are capable of affecting, or being affected by, the organization. Dill, in noting that different roles within the organization involve interaction with different elements of the environment, coined the term "task environment" in order to denote the 
multiplicity of environmental components which can bear upon organizational operations. Waldman (1972) noted that the organization may be most profitably modeled in terms of two general environmental components. The first, the "input component," is that group of people and organizations from which the organization receives resources and support, while the second, the "output component," is that environmental component which relies on the organization for needed resources. From the perspective of the organization, the environment serves two general functions: it provides key resources, and it employs the organization's output. These two functions are closely related (Thompson and McEwen, 1972). The organization, it will be recalled, serves a function perceived by the environment as necessary; to the extent that it does in fact serve this function, the environment will avail requisite resources (Gawthrop, 1969) in the form of either revenue (in the commercial context) or other types of support. of importance is the set of causal relations which link the organization and its environment.

A sizable group of authors have noted that the environment is capable of generating change within organizations. Gawthrop (1969) notes that the organizations must continually react to changing environmental conditions if it is to survive, a general orientation shared by Gross (1969). The ability of constantly changing environmental components to constantly alter the demands placed on the organization, and to enforce those demands through control of resources, supports the contention that organizational change is generally a product of environmental forces (Terreberry, 1968; 
Khandwalla, 1972). In parallel observations, other authors point out that organizational survival in the long run is largely determined by the organization's ability to adapt to altered operational demands and conditions (Gross, 1969; Rickson and Simpkins, 1972; Schein, 1970; Thompson and McEwen, 1972; Gawthrop, 1969; Hannan and Freeman, 1977).

Others note that through such strategies as competition and cooperation (Thompson and MCEwen, 1972), power (Rickson and Simpkins, 1972), cooptation (Katz and Kahn, 1972), manipulation and environmental selection (Child, 1972) organizations are frequently in positions to influence their environments.

The general picture developed by these authors is one of mutual influence whereby organizations and the environment are each subject to change induced by the other.

At the risk of belaboring a point inferred above, it is pertinent to note that the environment associated with any given organization will in many respects be unique to that organization. As noted earlier, the entities comprising a relevant environment are in large measure determined by the functions which the organizational unit serves (Dill, 1962). Not only will these functions determine the nature of the organization's output component, but they will dictate the types and sources of necessary input resources as well (Katz and Kahn, 1972). As a result, organizations operating in proximal physical locations, in similar functional pursuits, or in otherwise like conditions are nonetheless likely to experience environmental contexts which are quite different.

overall, it is clear that the organization and the environment 
exist in a state of continual interaction, and that changes in each are likely to be reflected through changes in the other. It is further appropriate to note that the organization's mandated goals constitute a pivotal focus in this interaction. The section which follows investigates the derivation of mandated organizational goals.

\section{Organizational Goals}

Etzioni (1975) describes organizational goals as desired states of affairs which the organization attempts to realize. Left unaddressed in this definition, however, are whose goals constitute the driving force behind organizational activity. It was noted in the preceding discussion that environmental forces play a large role in determining the mandated goals of organizations. Implicit, however, in the concepts of organizational flexibility and reactions to changing environmental expectations is a recognition that organizations harbor goals which exist separately and distinctly from those functions mandated for them. This section will explore the literature pertaining to mandated goal setting and to organization-specific goals, and will culminate with the incorporation of each type of goal into a general utility function based on that developed earlier.

\section{Goal Setting: The Environment}

Organizations are founded when five conditions exist simultaneously (Stinchcombe, 1972).

1. A group finds better ways to achieve ends which are not easily served within existing social arrangements.

2. The future reflects a reasonable probability that the 
organization will pay for the trouble of founding it.

3. Either the founders or some other desired group will realize the benefits returned by the organization.

4. The founding group can obtain the necessary key resources to develop the organization.

5. The founding group can avoid defeat by opponents.

Central to the first condition is the concept of goal derivation. Organizations are founded with an eye to achieving a desired state, and through their achievement of those states to attain both the necessary resources and the legitimization necessary to continued operation (Thompson and McEwen, 1972; Gross, 1969).

To the extent that the environment is of critical importance in the evaluation of the stated goal's worth, in assessing the organization's performance in pursuing it, and in maintaining the flow of key resources, the environment plays a key role in organizational survival (Thompson and McEwen, 1972). To the extent that the environment is a dynamic entity in its own right, however, its concepts of what constitutes an appropriate goal can be somewhat fluid. As a result, a number of authors have noted that organizations must constantly reappraise their goals in light of the changing expectations of important environmental entities (Thompson and McEwen, 1972; Maniha and Perrow, 1965; Magid, 1969).

The linkage between the organization and its environment with respect to mandated goals is well documented. As noted earlier, however, there is reason to suspect that organizations respond to goals other than those for which they were expressly founded. 


\section{Goal Setting: The Organization}

Acknowledgement of the fact that organizations retain goal flexibility necessarily entails the parallel acknowledgement that organizations orient to goals other than those for which they were founded. If, per Gross (1969), organizational survival is contingent upon the organization's ability to maintain flexibility in its formal goals, then some motivational factor other than pursuit of its formal goals must compel the organization to embrace flexibility. It is additionally reasonable to anticipate that organizations which are protected from challenge might well orient to goals other than those for which they were founded.

In both cases a process of "goal displacement" has been noted. Goal displacement is a phenomenon in which organizations replace the environmentally-derived goals for which they were founded with others which more directly serve the organization itself. As reflected in the two cases cited above, goal displacement has been addressed from two perspectives.

In large, protected organizations, it has been noted that stated goals tend over time to be re-defined in terms of the finite steps required for their achievement. Catrice-Lorey (1973), in her study of the French social security administration, noted that organizational members had, over time, ceased to respond to client service as their primary responsibility. Instead, they oriented primarily to the regulations and processes which their individual jobs served. In this context, goal displacement refers to the replacement of organization-wide goals with the procedural requirements originally 
developed to support the mandated goal. Catrice-Lorey identified this process as a pathological phenomenon associated with bureaucratization. Goal displacement has also been noted in a second context.

J. Kenneth Benson (1975) has suggested that once an organization is established, organizational and managerial attentions turn to key resource (authority and money) acquisition and protection, at the expense of originally chartered organizational functions. During the displacement process, the latter come to be defined in terms of the new emphasis on resource acquisition. Benson notes that this process tends to diminish the functional distinctions which might otherwise differentiate organizations. This observation derives from the fact that stated goals, which are more or less unique to each organization, are displaced by goals which are derivative of the means initially employed in their achievement. Because the emergent set of goals arises out of activities--acquisition and protection of key resources-which prevail among organizations of all types, the emergent goals themselves would tend to be relatively constant across organizations in spite of their various stated purposes.

In each of these cases, the goals established by the environment tend to diminish in their influence over organizational activity as organization-specific goals emerge.

This general class of observation is consistent with the economic models discussed earlier; indeed, the commercial enterprises addressed earlier provide a familiar case which can be employed to illustrate the goal displacement case acknowledged by Benson. Grocery stores, for example, are founded in order to respond to two sets of goals. 
On the one hand, their purpose lies in dispensing food products to consumers. Additionally, however, they orient to the pursuit of profit, which is itself attained through the previously mentioned sales activities. In these terms, the observations above would recognize grocery sales as the stated purpose of the organization, displaced over time by the pursuit of profit. In the economic model, the two sets of goals are not only compatible but mutually necessary; in the context of organizational theory, however, which is largely based in public administration and non-profit operation, the two are not compatible and may be mutually exclusive.

It is appropriate to note that both parties to the goal-setting process--the organization and the environment--interact in order to further their own interests. Relevant environmental elements seek through the organization to improve their own positions, while the organization is serving the environment promotes its own well-being. The two are associated in a mutually supportive association of benefit to each party. This association parallels that posited by economists in conjunction with parties to market transactions, although it bypasses explicit reference to immediate reciprocity as employed by economists. Viewed in these terms, both profit-oriented and non-profit organizations may be examined through a common behavioral model. Social exchange theory is one such model.

\section{Social Exchange Theory}

Social exchange theory applied to organizations, particularly to those in the non-profit sector, posits that organizations engage in 
exchange transactions in order to enhance survival and authority. In this context, the organization relates to key environmental elements in hierarchic associations based on the ability of each party to the interaction to provide needed resources to the other.

The organizational environment is important in exchange theory to the extent that it can influence resource supplies to organizations, and to the extent that it can influence interorganizational relations by delegating authority for resource distribution (Benson, 1975). The most important element of the environment is typically the organizational network, as defined by interaction patterns which directly or indirectly bear on the focal agency. Mindlin and Aldrich (1975) amplify this point by noting that "...organizations must be studied in the context of the population of organizations with which they are competing and sharing scarce resources" (p. 382).

In this context, organizations are seen as entering into exchanges so as to improve their own position, either with respect to goods and services or with respect to less tangible ends which specify the nature of interorganizational hierarchic relations.

The former of these ends are easily envisioned. Organizations possessing sufficient stocks of one resource--say, supplies or staff-may exchange those resources either for other goods and services for which they have a need--perhaps funding or cooperation--or for reciprocal consideration at a later date which may or may not involve previously specified commodities.

O'Brien and Wetle (1975) developed a model of interorganizational exchange entitled the Organizational Interaction Model which provides a 
concise elaboration of interorganizational exchange principles. The Organizational Exchange Model is comprised of three elements: Commodities, Valuing Criteria, and Arenas (see Figure 1).

Commodities are the media of exchange and are of importance to organizations for their contributions to organizational operation and survival. Included as a representative but not exhaustive listing of exchange commodities are clients, funds, staff, technology, access to influentials, and access to information.

Valuing Criteria are the standards by which the costs and benefits associated with exchanges are appraised. Thus, an organization entering into a transaction with another agency would exchange commodities, as described above, with an eye to maintaining or improving its position in terms of one or more of the valuing Criteria. Included among Valuing Criteria are autonomy, integration, domain, power, status, and ideology (world view). The valuing criteria in this model are paralleled by profit in the microeconomic model and more generally reflect goals by which organizational well-being is assessed.

Arenas of Exchange are the transactional situations within which exchanges take place; they are the activities within which interorganizational exchanges occur. Those enumerated in Figure 1 are: planning, hearings and meetings, contracts and letters of agreement, evaluation and monitoring, and client transfers.

Overall, transactions are seen as encompassing exchanges of commodities, each of which is appraised in accordance with each agency's valuing criteria, in the operational setting of 


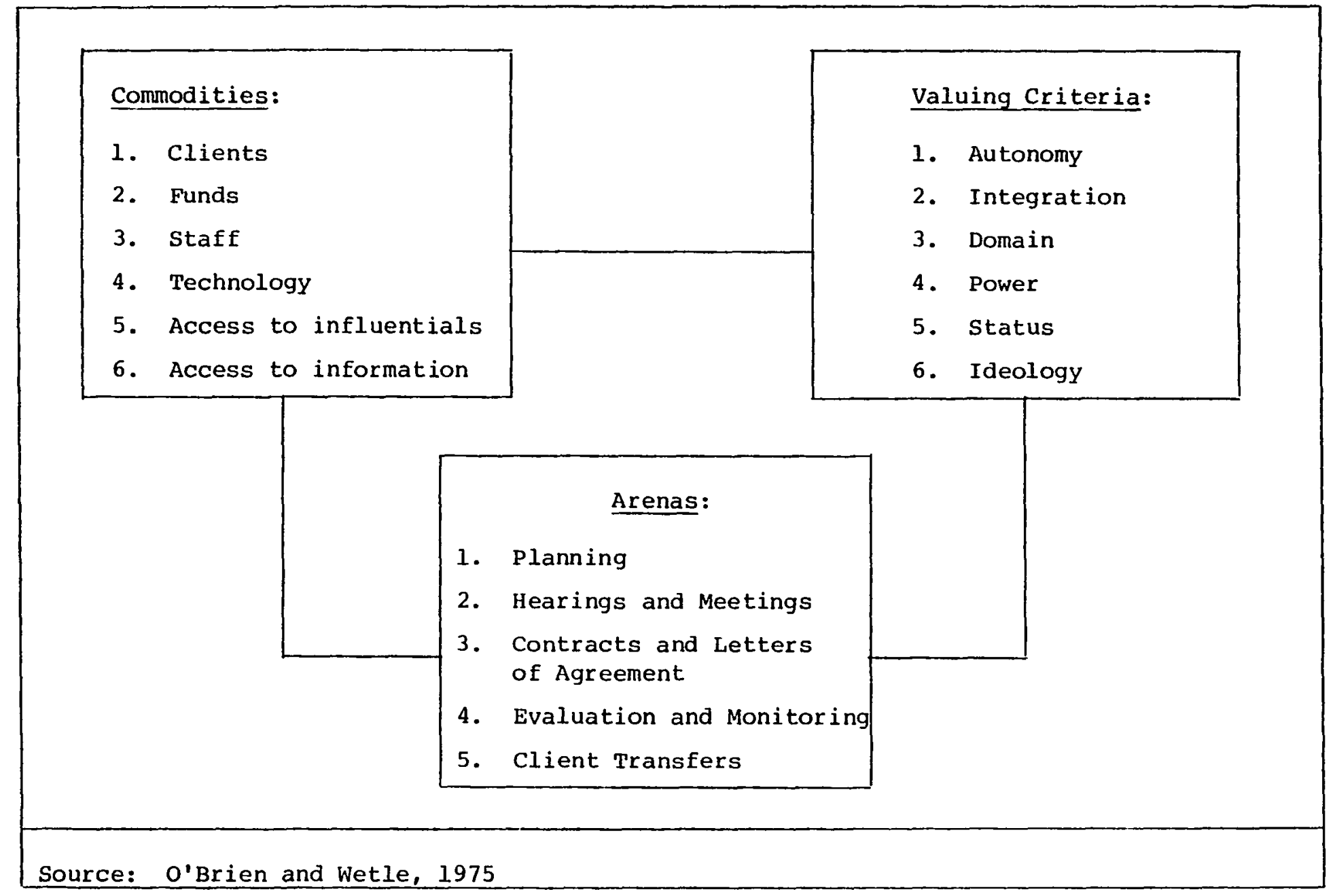

Figure 1. Diagram of the Organizational Interaction Model 
an arena of exchange. In this context, a number of qualities can influence the determination of what constitutes "reciprocity" in exchange.

The valuing criteria together constitute one source of interorganizational valuation, which reflects the valuing hierarchies of each party to the transaction. The relative values evident in transactions reflect the valuing hierarchies of each party to the transaction. The valuing criteria correspond to goals pursued through the organization's operations, and so correspond to the $x_{i}$ terms employed in the various formulations developed earlier. The relative values associated with goals may additionally reflect such other variables as the organizations' positions in the interorganizational hierarchy, and in characteristics of the commodities and their distribution processes: in the minds of many authors, these two sources of variation are closely related (Blau and Homans, as cited in Waldman, 1972; Benson, 1975; Emerson, 1962).

Differential power positions among parties to a transaction allow the more powerful of the parties to influence the terms of exchange. Power in this sense is best described as the ability of one party to unilaterally affect another party's actions, with degrees of power envisioned as the degree of resistance which can be overcome in affecting such changes (Emerson, 1962). Benson (1975) notes that power can be achieved through two general strategies: organizations may achieve power through control of centralized functions in the network, or they may gain power through linkages to environmental elements. 
The control of critical network functions is generally seen as entailing control over focal commodities, such as funding, information, or clients. By granting or withholding to other agencies supplies of critical commodities, organizations can influence those agencies' chances of survival and thereby achieve power.

The development of linkages to the environment is an alternative strategy for amassing power. By being able to mobilize environmental support, the agency can gain leverage against other, competing organizations (Benson, 1975).

The degree of leverage attainable through environmental linkages has been tied to the size of the group providing support, to the degree of mobilization possible, and to the social rank of the elements comprising the supportive body.

In general, social exchange theory as applied to organizations by the organizational interaction model can be related closely to the Classicial and modified Classical Theories of the Firm. To the extent that the valuing criteria constitute a set of appraisal indexes which operate concurrently, organizations may be said to be utility maximizing, as was the case in the modified Classical model. Exchanges, designed to enhance participating organizations' positions with respect to these referents, correspond closely to the transactions of microeconomics.

Differentiating social exchange theory from the microeconomic model are two points, summarized by Blau (1974).

1. Social exchange may involve unspecified obligations, differentiating it from the precise, contractual exchanges 
of economic transactions.

2. Social exchange may engender relationships which extend beyond the actual transaction through "feelings of personal obligation, gratitude, and trust."

These points of distinction, however, do not impede the reformulations presented earlier, the exchange model described above may be presented as follows.

$$
\mathrm{U}=\mathrm{f}\left(\mathrm{v}_{\mathrm{el}} \mathrm{x}_{\mathrm{el}}+\mathrm{v}_{\mathrm{e} 2} \mathrm{x}_{\mathrm{e} 2}+. .+\mathrm{v}_{\mathrm{ei}} \mathrm{x}_{\mathrm{ei}}+. .+\mathrm{v}_{\mathrm{en}} \mathrm{x}_{\mathrm{en}}\right)
$$

In this formulation $U$ connotes utility, as it has in past formulas. Vei connotes the value ascribed to the $i$ th $g o a l, x_{e i}$, labeled Valuing Criteria in the Organizational Interaction Model.

To now, three general classes of goals have been identified as contributing to organizational well-being.

1. Organization-specific goals of an absolute variety. Profit, return on investment, and dividend payout are examples (these were identified in (7) as $x_{f i}$ ).

2. Managerial goals. Lifetime income, power, and emoluments are examples (these were identified in (8) as $x_{m i}$ ).

3. Organization-specific goals of a relative variety. Power, autonomy, and domain are examples (there were identified in (10) as $x_{e i}$.

These may be simultaneously stated in a grand organizational utility function as follows.

(II) $U=f\left(\Sigma v_{f i} x_{f i}+\sum v_{m i} x_{m i}+\sum v_{e i} x_{e i}\right)$

This formulation, based on terms identified earlier, can be employed as a general statement of organizational goals and, indirectly, of 
organizational behavior. Simply stated, it stipulates that organizational well-being is based upon the organization's position with respect to commercial indicators, its position as identified through managerial aspirations, and its position with respect to other elements in its environment. Different organizations' overall positions can be expected to reflect different weightings with respect to each of the various criteria and, indeed, it is probable that certain organizations may evidence no success measures of one or more of the classes. By incorporating pertinent measures within each of the broad classes of goals, however, the decision making processes and the behavior influenced by those processes may be stated.

Three points must be made by way of summary. First, organizations select from a multitude of goals in their specification of organizational strategies. Contingent upon the type of organization under study, upon the environmental setting within which the organization operates, and upon the internal structure of the organization, organizations can pursue a range of goals.

Second, it is not realistic to assume that all desired states identified by the organization are of equal importance to it; it is more realistic to acknowledge an organization's pursuits as being of varying importance as reflected in an ordered hierarchy. That an organization pursues profit does not preclude the simultaneous pursuit of autonomy or market share. Moreover, that it pursues all three goals simultaneously does not connote that the three are of equal importance in the identification of appropriate strategies, or in the assessment of organizational well-being. 
Finally, all of these goals are directly associated with the organization itself: none relate directly to entities outside the organization. In part, outside entities' welfare may be reflected indirectly through organization-specific measures, such as profit. Numerous organizational contexts exist, however, where profit is not an applicable referent, and where organizational functions and attention relate primarily to entities outside the organization: the human services industry constitutes such a context. This model does not address that class of goal.

The following chapter is devoted to creating a conceptual setting within which this model may be applied to human service organizations. In this, the chapter will review the literature on community theory in order to identify potential influences on organizational behavior which might be unique to locality. Employing both the organizational and community discussions as foundations, the Primitive Economy Model (O'Brien, 1976b) will be presented as a method for analyzing organizational behavior. 
CHAPTER III

LOCAL MARKETS AND THE PRIMITIVE ECONOMY MODEL

It was noted early in this dissertation that locale in many ways constitutes the major operational setting for organizations in the human services industry. In the terms set forth in the preceding chapter, locale defines the scope of many environmental elements of importance to the organization, and in most cases defines the geographic scope in which it operates. To borrow from economic jargon, locale defines the market within which service agencies operate. For these reasons it is reasonable to anticipate that organizational operations in this industry may well be influenced by forces which are indigenous, and unique, to the local area.

This chapter addresses local influences on organizational operation. It is comprised of three general sections. The first briefly synopsizes the literature treating community, with emphasis placed on community uniqueness. The second section introduces the Primitive Economy Model (O'Brien, 1976b), which relates organizational activity to the environments within which the organization operates. Finally, the third section specifies the model of organizational goals, based on the utility function developed in the first chapter, which will provide the foundation for the dissertation's analyses. 
COMMUNITY: THE MARKET CONTEXT

As noted elsewhere in this dissertation, a primary characteristic of the human service industry is its operational concentration in relatively small geographic areas. As such, the spatial extent of relevant markets in this industry are largely defined by geographic area and by the social aggregate--the community--which lends significance to its geographic area. In order to address organizational linkages to their markets--their environments--in this context, it is necessary to gain some understanding of community.

Community is a phenomenon which has been widely addressed, and an extensive literature exists treating the topic. The wide attention leant to community has, however, led to little standardization of the definitions used in the field. Perhaps nowhere is this lack of unanimity more apparent than in the definition of "community." In one summary of the literature (Hillery, 1968), 94 definitions of the term were reviewed, with no two found to be identical in content. The greatest degree of consensus was found to encompass three elements of the definition: territoriality, social interaction, and a degree of identity which is unique to the community. These elements were found to be present in the writings of 69 of the 94 authors, of which the following are representative.

Robert MacIver (1970) addressed the topic as follows.

By community I mean any area of common life, village or town, or district or county, or even wider area. To serve the name community, the area must be somehow distinguised from further areas, the common life may have some characteristic of its own such that the frontiers of the area have some meaning. All the laws of the cosmos, physical, biological, and psychological, conspire to bring it about that beings who live together 
shall resemble one another.... These are the signs and consequences of an effective common life" (p. 30).

A second conceptualization of the phenomenon, developed with specific respect to the American reality, is generally consistent with that included above.

A human community is a functionally related aggregate of people who live in a particular geographic community at a particular time, share a common culture, are arranged in a social structure, and exhibit an awareness of their uniqueness and separate identity as a group (Mercer, 1956, p. 65).

Territoriality, as noted earlier, is of direct relevance to the focus of this dissertation. Unfortunately, while the value of territoriality is widely acknowledged, the parallel issue of territorial boundaries has proven difficult to address.

The importance of spatial propinquity to community is acknowledged primarily for its facilitation of personal interaction between residents (J. Bernard, 1962; Warren, 1963; Stacey, 1969; Suttles, 1972; Polsby, 1968; Coleman, 1957). One author writes,

[i]t is the inescapable fact that people's clustering together in space has important influences on their daily activities which gives us perhaps our best clue to a definition of the community as a social entity (Warren, 1963, p. 9).

Per Coleman (1957), interaction between inhabitants gains its importance not only from the common identities it breeds, but also for the similarities in attitude and value that it promotes and for the enhancement of unanimity in perception (MacIver, 1970: Dewey, 1954).

Boundaries, however, are generally conceded to be problematic (J. Bernard, 1962; Warren, 1963; Polsby, 1968; Suttles, 1972; Grimes et al., 1976). Polsby (1968) provides a representative discussion of 
community boundaries as follows.

The problem of setting boundaries on the community is, perhaps, ultimately insoluble except by arbitrary means, because it is freely conceded that externally made decisions may have a significant impact on the allocation of values and on important private and public decisions within the community, however defined (p. 158).

Virtually all authors ultimately dismiss the concept of boundaries as being inappropriate to the concept of community, although suttles (1972) discusses a number of conditions which can promote the clarification of boundaries under certain circumstances. Jessie Bernard (1962) suggests that the concept of boundaries might well be replaced by that of margins. Noting that one element of community rests in the common interests of residents, she suggests that given communities might be identified as extending only to those points where common interests are defined differently. Because these interests are more likely to be gradually supplanted in a population than to be abruptly altered, the idea of marginal community areas where this process of supplanting can be identified gains some credibility.

A more common approach to dealing with the problem of community boundaries lies in the concept of scale. Rather than addressing community as a discrete phenomenon, these authors address community identity as a variable subject to continuous gradations of strength. In this context, strength of community identity is related inversely to geographic scale (MacIver, 1970; Suttles, 1972). This approach is additionally recommended by its capacity for encompassing multiple community identities which may simultaneously exist for residents. Suttles (1972), for example, cites the face-block, the defended 
neighborhood, the community of limited liability (a term borrowed from Janowitz, 1952), and the expanded community of limited liability as successively larger territorial entities each of which may be a source of identification for the individual. The same logic may be applied to cities, regions, states, or even nations.

The subject of territoriality, then, while of critical importance to the study of communities, is a topic which has not been fully resolved. The predominant orientation to community parallels the "open system" concept, where individual community entities exist as components of larger systems. Each provides a source of identity to inhabitants, and each is capable to some degree of influencing activities and orientations in the others. Strength of community identity in this schema is inversely related to geographic scale. Uniqueness is a second widely-cited element of community, and one which has generated interest among a wide range of disciplines. Indeed, the typing of communities may constitute the most widely pursued aspect of community study.

While communities tend to be identified by external entities in terms of such society-wide referents as racial composition, economic measures, and income (Suttles, 1972; Timms, 1971), there are additionally a number of identificational sources which are unique to the community itself. Among these are the community's relation to its inanimate environment (Rickson and Simkins, 1972), its history (Aiken and Mott, 1970; Thernstrom, 1970), its traditions (Thernstrom, 1970; Lowry, 1968), its economic structures (Logan, 1976; Miernyk, 1965), its political structures (Coleman, 1957), and its policies toward 
growth and development (Logan, 1976).

of critical importance in the community's evolution is the fact that once established, these characteristics tend to influence subsequent development; community identification, in short, gains stability in part through the influences it exerts over the local development which leads to future conditions.

In large measure, this influence is felt through selective demographic shifts. While conscious policies may be undertaken by localities to influence demographic turnover (Logan, 1976; Hunter, 1975), a considerable body of Iiterature suggests that migrants self-select into locales within which they have social contacts (Craven and Wellman, 1973) or which they perceive as being most consistent with their needs and desires.

The following citation is highly representative of those addressing self-selection in residential migration.

The residential movement of individuals and groups is highly systematic. As a result of the existing structure of the residential system and of the positive feed-back induced by the patterns of information flow, residential mobility is channeled in particular directions. The principal spatial effect of the complex of individual aspirations, mental maps, capabilities and decisions, information flows, the structure of the market and the activities of a wide range of housing, financial and planning institutions, is to sift and sort the population into distinct residential clusters, organized in terms of the basic social differential considered important at the time and place concerned (Timms, 1971, p. 122).

While other authors tend to address more narrowly these processes of selective residential movements, the dynamics cited by Timms have been broadly reported (Srole, 1972; Suttles, 1972; Fischer, 1975; Rees, 1971; Logan, 1976; Bish and Ostram, 1973; Ostram, Tiebout and Warren, 1961). 
The observations of these authors have been verified through the limited number of empirical analyses of community consistency. Logan (1976) found that population characteristics in a number of American cities remained quite constant between 1940 and 1960 in spite of intervening population turnover and growth. This finding is paralleled by those of Schnore and Alford (1963) comparing 1940 and 1960 populations, and Farley (1964) comparing SES characteristics of 1920 and 1960 populations in selected cities. Suttles (1972) returned to the Chicago neighborhoods studied by Park and Burgess, finding that many had retained their identities even after having lost their ethnic populations. In another, similar analysis, J. Bernard (1962) found considerable stability in the identity of a community, in spite of population turnover. She summarizes her study as follows.

The people ebbed and flowed; but the community of Springdale itself remained as an entity in its own right. In a similar way people come and go in New York, Chicago, San Francisco, but the communities themselves, whether loved or hated, continue with identities of their own (p. 10).

Consistency in community identity bears implications for the values shared by community members, and for the mechanisms through which those values are applied to common pursuits undertaken by community members acting in concert.

Values have been defined as desired states of affairs (Williams, 1967; George and wilding, 1972). Values bear not only on the identification of goals but also on the means undertaken in their realization (Williams, 1967), it is reasonable to anticipate that communities would be to some extent identifiable through their value systems. Indeed, a number of authors have suggested that this is the case 
(Angel1, 1974; Laumann et al., 1977; Stacey, 1969; J. Bernard, 1968). Writing with respect to communities, J. Bernard (1968) writes:

(a) normative structure is either inherited from the past or self-consciously instituted in each subsystem, and conformity to its demands is usually sufficient to guarantee that the [necessary] functions will be performed (p. 163).

Addressing the same topic, Angel (1974) writes that "moral integration involves a mutually consistent set of norms derived from common values, norms which members of the group, community, or society have internalized as guides to their behavior" (p. 610).

While many of the values operant in local settings are derived from larger societal units (Angell, 1974; Warren, 1963), a number of studies have demonstrated that differing local values concerning various focal topics can have demonstrable effects on local activity as well. Addressing anti-black sentiment at the regional level, Middleton (1976) found significant differences between the south and non-south. Flinn (1970) found that differences between localities in residents' adoptions of innovative truck farming practices were mirrored in local orientations toward innovation in general; this finding has been found in other settings and on other scales by Marsh and Coleman (1954), Young and Coleman (1961), and Rogers and Burge (1962).

In the context of this dissertation, community-specific values derive their primary importance through their influences on the operations of organizations serving the resident population. Kroll (1962) makes perhaps the most direct linkage between values and collective action through his suggestion that values represent patterns of belief which set social priorities in the relations which link 
government and society. Other authors address this linkage with a greater eye to the processes through which the linkage is made. Dewey (1954) posits that people join together to form a Public when they find themselves commonly and indirectly affected by activities over which they have no control. With organization, Publics can create governments in order to serve their interests, staffed by officials serving as "factors doing the business of others in securing and obviating consequences that concern them" (p. 19). Dahl (1961), addressing the relations between established governments and their constituencies, sees in electoral activities a similar communication of value orientations between constituents and elected officials. Not so widely documented is the degree to which local organizational endeavors are influenced by values and conditions which are unique to their locales. Schimpeler and Greco (1972) explicitly relate the goals of the community to the process of transportation planning, while Kaplan (1973) suggests that value orientations among a resident population must be considered as focal determinants in the process of social planning. Saltzstein (1977) is one of few to test such associations empirically, finding that local applications for federal grants reflect primarily the values and orientations of local officials, and bear no significant associations with various measures of need.

While empirical support for linkages between local conditions and organizational endeavor are yet scarce, there does exist considerable theoretical justification for such an expectation. 
First, at least among human service organizations, the relevant market is locally defined. When organizational well-being, however defined, is contingent upon organizational appeasement of demand as manifested in the context of a relevant market, there exists a direct tie between organizational success and those forces which underlie demand. Where those forces are determined primarily through local processes, it is reasonable to anticipate a direct relation between locale and organizational behavior. In one, well-documented sense, this association is likely to be ramified in the types of organizations serving locales (Winsborough, 1962; Logan, 1976), which tend to differ with the economic bases supporting local comerce.

In a less strictly economical sense, the degree to which locale constitutes the organization's relevant environment can be expected to reflect itself in the operations of locally-located organizations (Warren, 1963). For agencies which are operationally related exclusively to a single locale, the impacts of local values and conditions are likely to be great.

The Primitive Economy Model (O'Brien, 1976b) provides a model capable of assessing linkages between locale and organization, and constitutes the subject of the remainder of this chapter.

THE PRIMITIVE ECONOMY MODEL

The theoretical approaches discussed in Chapter II constitute widely endorsed foundations employed in the analysis of organizational behavior. As is summarized in that chapter's concluding pages, the many similarities apparent between the Classical Theory of the 
Firm and the various other analytical approaches allow for their combination in a general statement of organizational behavior. The final utility function of the chapter, (11), shows how such a function might be phrased in its most general form. As noted, the utility function is comprised of three general classes of goals: profit and other absolute indexes, managerial goals, and non-commercial organizational goals of a more relative nature. The values attached to each component in the model, the $V$ terms, serve the general purpose of indicating the relative valuations assigned to each of the various goals. This model serves as the conceptual point of departure for the Primitive Economy Model (PEM) (O'Brien, 1976b) which specifies that organizational behavior is best understood in terms of both intraand extraorganizational goals.

The PEM adds to the basic exchange-based conceptualization an extraorganizational class of goals derived largely from the field of economic anthropology. Through this, the model ties transactions not only to the concept of specific reciprocity entailed in the market context, but also to the values and societal orientations which exist in the larger social context within which the transactions take place. Transactions conforming to the former case are those serving intraorganizational goals of the type discussed in the preceding chapter, while those consistent with the latter type are oriented to impacts and beneficiaries outside the organization.

Distinguishing the two transactional contexts are the spheres of intended consequences associated with the transactions, and a number of characteristics by which the transactions may be distinguished. 
Because the former class of transactions--those serving various intraorganizational goals--were covered in the preceding chapter, these will not be discussed further here. What does call for elaboration, however, is the derivation of extraorganizational goals and beneficiaries as a class of motivations for organizations.

The Primitive Economy Model relates organizational behavior in part to the societal context in which the organization operates. Organizations in this model are envisioned as instruments of the environment. They are consciously originated by a cognizant social body to complement the facilities already available to it. As such, the defining characteristics of organizations are reflective of the qualitative features of the society in which they were inspired. In essence, the traditional, historical, and integrative qualities characteristic of the society, as well as its goals, become critical characteristics of the organizations developed by that society.

At the most fundamental level, this orientation suggests that the exchange-based models of behavior discussed in the preceding chapter constitute only one segment of a wider range of exchangerelated transactions typically taking place in modern societal bodies. While most individuals and organizations can, and must, pursue desired ends in the market context, other ends exist which the social body as a whole (or in significant part) can most appropriately pursue through the development of organizational intermediaries. Human service organizations constitute one such type of organizational intermediary which, in their founding and operations, embody the initial goals and the underlying motivations which compelled the founding society to 
take action.

There is support for this conceptualization in a number of literatures, perhaps the most fertile of which is economic anthropology. Karl Polanyi, for example, noted in The Great Transformation that economic transactions in underdeveloped and archaic cultures are reflective of and, indeed, components of larger social institutions (Dalton, 1968). The transactions themselves are not the appropriate units of analysis in these societal contexts, but rather serve to illustrate operational mechanisms derived from more fundamental social relationships which establish norms governing the economic functions of resource extraction, production, and distribution. Polanyi noted that only with the advent of capitalism did the concept of an autonomous market emerge to replace the social function of resource distribution with the economic function of resource allocation. In later efforts to collectively control certain market functions, Polanyi saw a re-imposition of social values over the valueless market mechanism (Polanyi, 1944). In short, the values which lead to the manifestation of local concern in the development of human service agencies are potentially of critical importance in the operations of those agencies as they respond to the collective demands of a mobilized constituency. John Dewey (1954) provides a conceptual framework within which societal orientations and motivations could be integrated into the organizations founded by a collective to serve its interests and purposes. As noted earlier, Dewey suggests that when members of a group are similarly affected by an event or process beyond their control, they can organize into a recognizable organization in order to 
gain a measure of influence over their problem. Under supportive conditions, this class of organization can be elevated to a governmental role in response to the identified needs, orientations, and mandates of $i t s$ constituency. In short, the government, and other organizations similarly founded, are closely tied to their founding constituencies. This process is consistent with the Polanyi thesis described above.

In this context, organizations--particularly public organizations-could well be expected to mirror the expectations of constituents in their operations as well as those specific to the organizations themselves. 6

Thus, organizations are, in effect, the instrumentalities through which a public undertakes to advance ends perceived to be in the public's benefit, but which are for a range of reasons not as attainable through other mechanisms. This interpretacion is fully consistent with those described in the preceding chapter in conjunction with

${ }^{6}$ An important distinction separates the common interest goals identified in the PEM from the external costs and benefits (more generically termed "externalities") of microeconomic theory. Externalities have been defined as "unpriced effects produced jointly with other priced goods and services" (Koplin, 1971, p. 249). While recognizing that impacts derivative of the focal transaction or process accrue to parties outside the organization as well as within it, the concept of externalities is differentiated from the PEM's common-interest criteria by intent. In the case of externalities, costs and benefits accruing to extraorganizational entities are not considered in the organizational decision leading to the initiation or continuation of the externalityproducing activity. In the PEM, however, those extraorganizational benefits and costs associated with an organizational activity are incorporated or, alternatively stated, internalized, into the decision making process. The purposeful identification, valuation, and internalization of extraorganizational benefits and costs into the decision making process distinguishes the PEM's common-interest criteria from the externalities of microeconomics. 
organizational initiation in a more general context (for example, Stinchcombe, 1972).

While the characteristics of transactions undertaken in each of the two modes reflect differentiating distinctions, ${ }^{7}$ the two classes of goals themselves are of greatest importance to this dissertation and will constitute the focus of the remaining pages in this chapter. The basic differences in intended consequences distinguishing the Primitive Economy Model from those of microeconomics and social exchange theories are summarized in Figure 2, on the following page.

Organizational behavior in the human service industry constitutes one focus of analysis where the Primitive Economy Model promises particular rewards. Three qualities of the industry contribute to this applicability. First, the preponderance of non-profit

7 'Brien (1976b) suggests six distinctions which differentiate transactions envisioned in the Primitive Economy Model from those addressed in microeconomic and social exchange theories. These distinctions are summarized in the following manner.

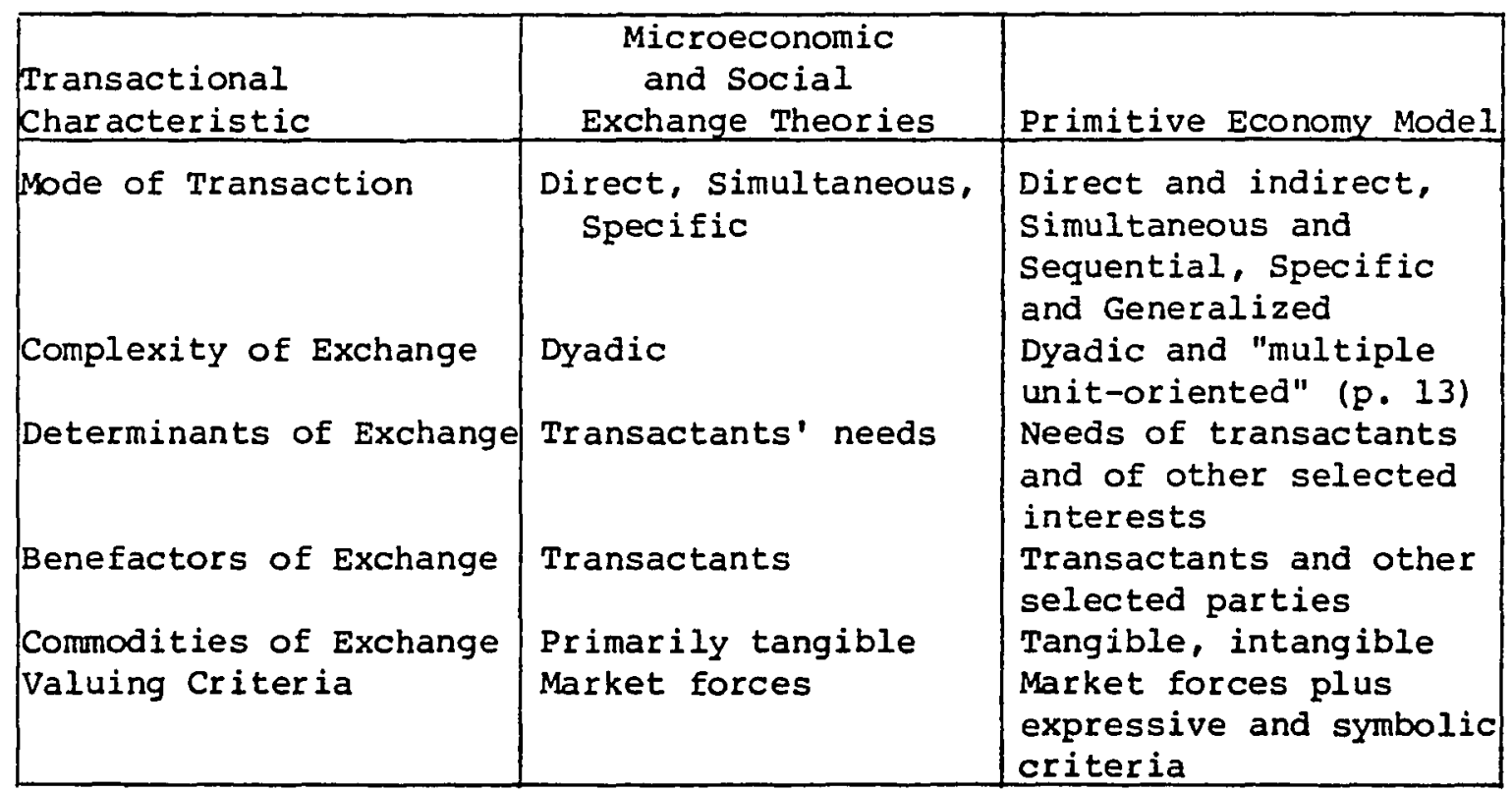




\begin{tabular}{|c|c|c|c|}
\hline & $\begin{array}{c}\text { Organizational } \\
\text { Effects on } \\
\text { Intraorganizational } \\
\text { Goals }\end{array}$ & $\begin{array}{c}\text { Environmental } \\
\text { Effects on } \\
\text { Intraorganizational } \\
\text { Goals }\end{array}$ & $\begin{array}{c}\text { Organizational } \\
\text { Effects on } \\
\text { Extraorganizational } \\
\text { Goals }\end{array}$ \\
\hline Microeconomic Model & Yes & No & No \\
\hline Social Exchange Model & Yes & Yes & No \\
\hline Primitive Economy Model & Yes & Yes & Yes \\
\hline
\end{tabular}

Figure 2. Applicability of microeconomic, social exchange, and primitive economy models to intra- and extraorganizational factors in organizational utility function 
organizations in this industry neutralizes the concentration on profit per se. Second, the extraorganizational orientation of agencies in this industry promotes the inclusion of non-organizational impacts in decision making. Finally, the local scale of the markets within which agencies in different locales operate suggests that the operational realities facing agencies will be differentiated in terms of conditions and characteristics which distinguish the communities themselves.

THE PRIMITIVE ECONOMY MODEL: SPECIFICATION

As described above, the Primitive Economy Model constitutes a modification of the behavioral models employed in social exchange theory and in microeconomic theory. Like these, it stipulates that organizations maintain goals, the pursuit of which influence organizational operations, policies, and decision making. The contribution of the Primitive Economy Model lies in its addition of extraorganizational goals to the intraorganizational orientations specified in the other two perspectives. The following pages will be devoted to the PEM's explication and derivation.

The first chapter was oriented to a description and general specification of a decision making model reflecting in the most general of terms the simultaneous influence of three general classes of motivators. From the Classical Theory of the Firm was borrowed the concept of profit, a critical measure of success in the private sector. From economic modifications to the Classical theory came two classes of motivators: the first represented alternative motivators for firms' owners and included such indexes as return on investment and growth, 
while the second specified goals which arose out of managerial aspirations, including such as lifetime income maximization and emoluments. From organizational exchange theory came a third class of motivators reflecting organizational relations to extraorganizational entities, including power, autonomy, and domain. As a group, these three classes of motivators were specified in a grand model of organizational behavior through formula (11), as follows.

(11) $U=f\left(\Sigma v_{f i} x_{f i}+\Sigma v_{m i} x_{m i}+\Sigma v_{e i} x_{e i}\right)$

While subject to meaningful distinctions which in many contexts warrant or demand their separate identification, it is possible to simplify the formula (11) in order to simply note that utility is influenced by the simultaneous interaction of a range of goals which are derived from sources within the organization. Restated in this manner, organizational behavior's linkage to intraorganizational goals can be specified through the following formula.

$$
\text { (I2) } U=f\left(\Sigma V_{I i} X_{I i}\right)
$$

where $U$, as always, denotes utility, $V_{I i}$ denotes the absolute value ascribed to the $i^{\text {th }}$ intraorganizational, $x_{I i}$. While this specification neutralizes any advantages which might accrue from the more precise function which discretely recognizes each of the three classes of intraorganizational goals, it promises rewards through its brevity in applications where greater precision is unwarranted.

As noted above, the Primitive Economy Model adds an extraorganizational component to the organization's utility function. In this, the PEM internalizes into the decision making process an extraorganizational element which in most other models is left untreated or 
else dismissed. Such a model can be operationalized as in (13), below.

(13) $U=f\left(\left(\Sigma V_{I i} X_{I i}\right)+\left(\Sigma V_{E j} X_{E j}\right)\right)$

To the terms introduced earlier, this formulation adds $V_{E j}$, representing the value associated with the $j^{\text {th }}$ extraorganizational goal which itself is represented by $x_{E j}$ •

The first element of $(13),\left(V_{I i} x_{I i}\right)$ is oriented to the inclusion of intraorganizational criteria as reflected in (12), above; this class of criteria can be referred to as self-interest criteria, for they reflect the organization's own interests. The second half of the formulation, $\left(V_{E j} X_{E j}\right)$, is a parallel component addressing desired states which exist primarily outside of the focal organization; this class of criteria can be termed common-interest criteria, for they refer to the interests of entities outside the organization. In this formulation, organizational decision making and behavior is a determinant both of direct benefits to the organization and of benefits which are perceived by the organization as accruing to other selected entities. Three qualities recommend this conceptualization to the study of organizational behavior.

First, the model retains the internal relationships which constitute the foci of microeconomic and social exchange theories. This is important: no organization operates to the exclusion of its own needs, nor long can it. Those who seek to study organizations and fail to address the survival orientation are likely to fall short of complete success.

Second, the model addresses the external class of goals. In the introduction to this chapter, human service agencies were described as 
the creations of a cognizant public acting in order to facilitate its achievement of some desired state. At least in its inception, then, the organization is solely oriented to external (to it) benefits. Goal displacement notwithstanding, an agency's survival in this light is contingent at least in part on the degree to which it satisfies its sponsors' expectations, and it is these that are reflected in the organization's extraorganizational goals.

The third element of the model which extends its usefulness lies in the weighting coefficients, shown earlier as $v_{i}$ and $v_{j}$. Exclusive of these coefficients, the model would lend equal weight to the various internal and external goals. Since this is likely to seldom be the case, the weighting coefficients allow for adjustment of the criteria's relative importance to the organization in the specification of its utility function.

THE PRIMITIVE ECONOMY MODEL: ANALYTICAL APPLICATION

The general specification of the PEM as reflected in (13) indicates that organizational well-being constitutes the sum of its position with respect to various indicators of intraorganizational and extraorganizational success, weighted to reflect differential valuation by the organization, as follows.

$$
\text { (13) } U=f\left(\left(\Sigma V_{I i} X_{I i}\right)+\left(\Sigma V_{E j} X_{E j}\right)\right)
$$

The actual operationalization of this conceptualization, however, is hindered by all of the various impediments which have been recognized in the cost-benefit analysis literature as hindering the valuation of non-economic conditions (Clawson and Knetsch, 1966). The full 
utilization of this formulation will ultimately hinge upon the treatment of the problems identified in that literature.

However, it is possible to provide initial testing of the formulation through assessment of variance in the basic components of the model, and this constitutes the focus of this dissertation's research question. By learning from respondents how they perceive the potential benefits associated with given courses of action in response to a hypothetical phenomenon, prevailing patterns of organizational goals and their respective valuations may be identified. The instruments from which the dependent variables for this dissertation were taken constitute such an attempt (see Chapter IV).

Necessarily missing from this approach to testing is any measure of cost, except as implicitly recognized by respondents. This general absenting of the cost component of organizational activity leads to a simplification of the decision making process, but not necessarily one which neutralizes the value of the exercise. To the extent that informants are asked to identify the benefits associated with given responses to a specified event, the influences of differential costs are negated: cost considerations are held constant through the specification of a single mode of response.

A further simplification has been made in this particular application. Because little is known of the extraorganizational component of the utility function, and because profit as a motivator is not directly applicable to non-profit organizations, the goals potentially identified by respondents as being important to their firms were limited by the items included in the interview instrument. Rather than 
being free to specify which goals prevail in their decision making processes, respondents were free only to specify the degree of importance attached to each of 24 criteria as specified by the research team. Thus, the formulation actually tested in this particular application of the Primitive Economy Model is as follows.

(14) $\quad U=f\left(\left(\Sigma V_{I i} \bar{x}\right)+\left(\Sigma V_{E j} \bar{x}_{E j}\right)\right)$

Here, $\bar{x}$ connotes the fact that the benefit terms were exogenously fixed, so that respondents were free only to indicate degrees of importance attached to each.

In all, then, the valuation terms, $v_{I i}$ and $v_{E j}$, are the only components of the formulation which can reflect variance, and it is through these that the Primitive Economy Model will be initially tested in this dissertation. The operational premise through which testing will take place is a derivative of the Primitive Economy Model, termed the Differential Mix Hypothesis.

The Differential Mix Hypothesis posits that organizations of a given type will tend to reflect in their operations patterns of goals which are different from those pursued by organizations of another type. Drawing both on intraorganizational and extraorganizational goals, this premise simply notes that the operational orientations of firms constitutes one means of classifying firms and, inversely, represents a means of verifying classification systems derived through other approaches. Thus, one might anticipate finding systematic differences in patterns of goal valuation among profit-oriented organizations than would be found among non-profit agencies, for example. similarly, one could expect different goals to be represented in the utility functions of 
organizations in the extractive industries than would pertain to firms manufacturing consumer goods. Educational institutions would likely pursue different goals than would health-care institutions. Finally, and of primary interest in this dissertation, human service agencies in one locale might be expected to pursue a mix of goals which are different from those pursued in a different community. For the purposes of this dissertation, the differential mix hypothesis will be implemented by classifying organizations according to the cities within which they operate.

The analytical application of the differential mix hypothesis involves the assessment of variance associated with the valuing terms $\left(V_{I i}\right.$ and $V_{E j}$ in (15)). By identifying organizations in terms of whatever classificational device is selected (as here, by community), analysis of variance and covariance techniques can be employed to assess the value of the classifying scheme in explaining variance. To the extent that these analyses reveal meaningful contributions to variance, the value of the classificational scheme as an appropriate means of identifying organizations is substantiated. Alternatively, where analysis reveals no meaningful contributions to variance, the value of the classifying scheme in that particular application can be called into question. The differential mix hypothesis will be applied in this dissertation to test for the contributions of locale in explaining variance encountered in the valuation terms. By identifying organizations in terms of the cities within which they operate, differences in valuation between cities may be identified. This approach will be described more fully in the ensuing chapter. 
CHAPTER IV

METHODOLOGY

The dissertation research presented in the following two chapters addresses the application of the Primitive Economy Model to organizational decision making among agencies in the aging services industries of six western cities. The analysis is guided by a single research question: Do the criteria by which organizations assess the benefits of entering into interagency agreements vary by city? If they do, the general underpinnings of the Primitive Economy Model--that organizations pursue goals other than those directly impacting the organization itself--are supported. If organizations are found to systematically respond to different patterns of extra-organizational "goals" from city to city, then a pattern of goal development will have been identified through microeconomic and organizational theories. The presence of different operational orientations is testable through the analysis of organizations' confrontations with identical situations in different locales, and this strategy constitutes the heart of the dissertation research being reported.

The dissertation is based on data obtained from personal interviews with human service agency personnel in six western cities. Interviews were completed during June and July, 1977, as part of a research project, entitled Testing a Community Intervention Model (O'Brien and Wetle, 1978), funded through Grant Number 90-A-1020/01 by the Administration on Aging, DHEW. 
The six cities selected for study were chosen in conjunction with a set of criteria including population, relation to neighboring cities, and the existence of Area Agencies on Aging. They are located in six states and range throughout the western region of the country.

Within each of the cities, approximately 30 organizations were contacted for interviews, as determined through a two-staged sampling technique termed "snowball sampling" (Griffith et al., 1973; Roistacher, 1974). In each city the directors of human service coordinating agencies provided a list of agencies with which their own organizations maintained most frequent contact. The agencies named by these informants became the sample from which data for the study was obtained. Each city's sample included five or six "broker agencies," agencies which arrange for other agencies to provide services, and approximately 25 "direct service agencies," those agencies which actually provide the service to the client.

The interview schedule was created employing insights gained both through extensive literature review, and through analysis of organizational data obtained in a prior study by O'Brien and wetle (1975). The instrument was pre-tested in the Portland, Oregon area and modified as necessary prior to its use in actual data collection. Designed for use with informants in administrative roles, the instrument was administered through personal interviews with 183 informants, holding the positions of local agency director, assistant director, or department head.

The author of this dissertation served as a Research Assistant in the study described above, and was involved in the project from its 
inception through its completion. Job responsibilities included participation in the conduct of background research, questionnaire development, data analysis, and report writing.

RESEARCH QUESTION AND HYPOTHESES

As noted earlier, the research reported in this dissertation addresses the following research question.

Do the criteria by which organizations assess the benefits of entering into interagency agreements vary by city?

This question will be addressed through the Differential Mix Hypothesis, a corollary of the Primitive Economy Model. As described in the previous chapter, the Differential Mix Hypothesis is a nondirectional statement which suggests that different classes of organizations will pursue different mixes of goals in their utility functions, as determined by systematic distinctions in their mandated functions, their relevant environments, and other factors. Since an important element of the social service industry is the local scope of its relevant environment, it is realistic to anticipate systematic differences in the goals pursued by service agencies as one moves between different local markets. These differences are reflected in formula (14) through the valuing coefficients, $v_{1 i}$ and $v_{E j} \cdot$ Since two classes of criteria are under study, the differential mix hypothesis is pursued in two predictive statements.

1. It is hypothesized that differences exist between cities in the intraorganizational criteria by which human service organizations assess the benefits of entering into interagency agreements. 
2. It is hypothesized that differences exist between cities in the extraorganizational criteria by which human service organizations assess the benefits of entering into interagency agreements.

There is reason to suspect, however, that the effects of interlocal differences will not be uniformly reflected in both classes of decision making criteria. It is realistic to anticipate that organizational orientation to the self-interest criteria will reflect a degree of continuity as one moves from city to city, regardless of the values and orientations of the Iocal community. Further contributing to a potentially diminished reflection of local variation in the selfinterest criteria are the federal guidelines and requirements which accompany the funding of many of these organizations, the professional orientations of many of the practitioners, and the influences of widelyaccepted business procedures. The Common Interest criteria, however, are expected to be quite reflective of local conditions. Because these organizations are posited as being fundamentally oriented to the social ecology within which they are operated, and because they are expected to reflect a continued dynamic interaction with the communities through which their markets are defined, it is realistic to anticipate considerable differences between organizational orientations to these criteria as one moves between locales. Accordingly, local variation in the operational procedures and orientations attached to the intraorganizational criteria is predicted to be less than among the extraorganizational criteria, which are seen as arising to a greater extent out of local conditions. This observation leads to a third hypothesis.

3. It is hypothesized that the differences found to exist between 
cities with respect to the extraorganizational criteria will exceed those associated with the intraorganizational criteria.

The effects of locational differences in the values attached to the decision making criteria will be examined both before and after parceling out the effects of selected organizational variables.

\section{DESIGN}

Figure 3 provides a graphic representation of the dissertation's design. The dependent variable, "Interaction Decision Criteria," is depicted as reflecting a set of organizational variables as well as characteristics of the community context within which the organization operates. In practice, the associations of the organizational variables with the dependent variable are parceled out prior to the introduction of the community "contextual" variable in an analytical technique termed "contextual analysis" (Farkas, 1974; Meyer, 1970; Wright, 1977). It is hypothesized that this series of analyses will disclose associations between organizational goal orientations and the communities within which the organizations operate. To the extent that this finding is realized, its application to local service strategies will contribute to more effective service provision.

\section{SAMPLE}

The sampling strategy employed in the selection of organizations to be included in the study was comprised of a two-step process: the first stage involved the selection of cities to be addressed, and the second involved identifying organizations within those cities. Each 


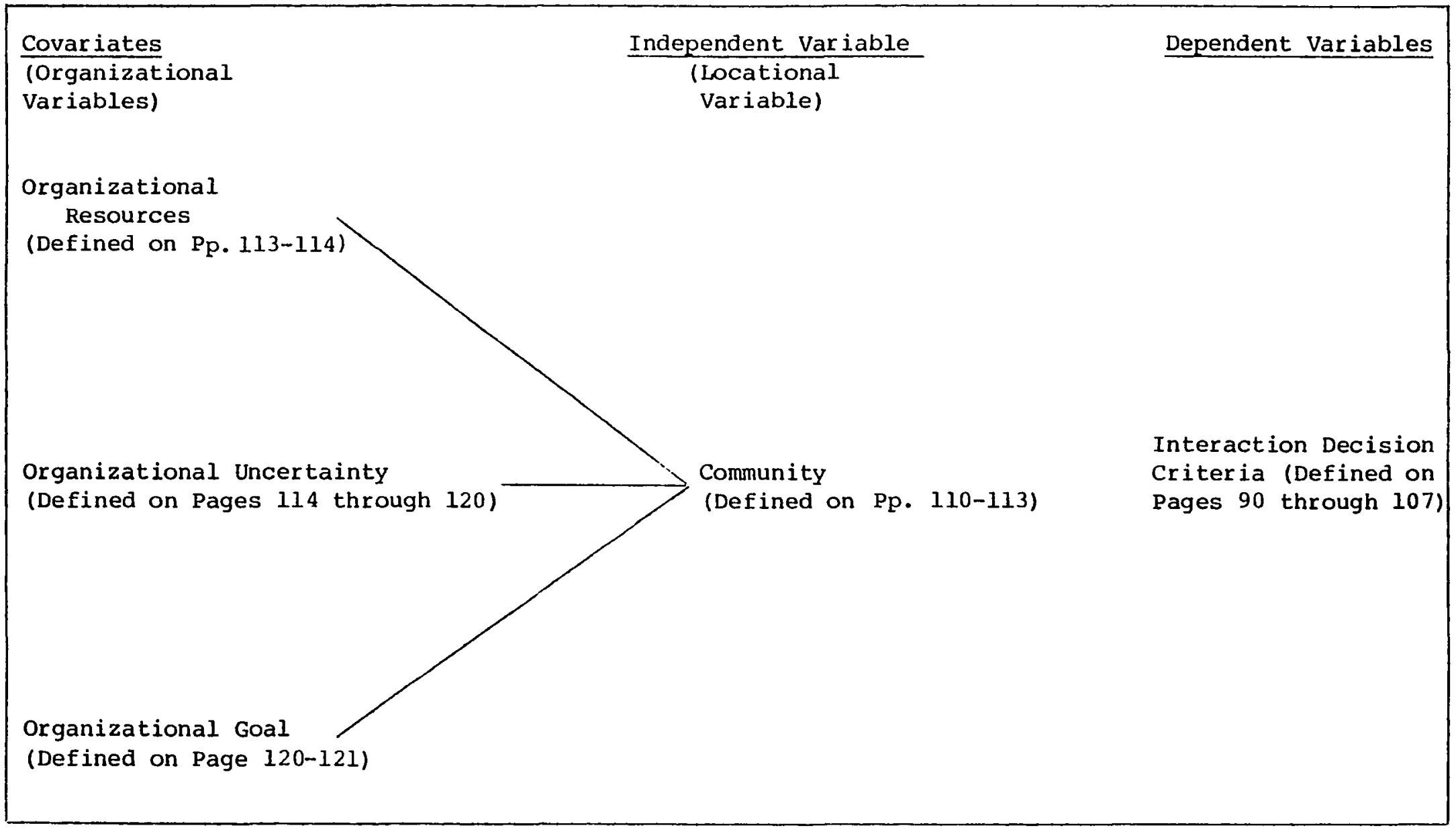

Figure 3. Research design 
step will be addressed individually.

\section{Cities}

Six cities were studied during the course of the project.

1. San Bernardino, California

2. Tacoma, Washington

3. Las Vegas, Nevada

4. Tucson, Arizona

5. Boulder, Colorado

6. Salt Lake City, Utah

The cities were purposively selected according to a number of criteria which are Iisted below in approximately their order of importance. It should be noted that no widely accepted guide exists for the selection of cities for use in surveys of this type. While locale-related theoretical bases exist in a wide range of disciplines, the concise application of this broad body of thought to the actual selection processes appropriate to survey research does not exist. The selection criteria described below constitute the factors identified by the research team as being most important to the theoretical underpinnings of the research being undertaken, and additionally reflect considerations born of cost and manageability. Key characteristics of the cities are summarized in Table $I$.

1. Independence. It was hoped that the cities included in the study would be independent of other, larger cities with respect to the delivery and direction of human services. It will be noted from Table I that two cities included in the study are quite close to the nearest city of equal or greater size, these being Boulder and Tacoma. In each 
TABLE I

CITIES: SELECTED FACTS

\begin{tabular}{|c|c|c|c|c|c|c|}
\hline city & Population & $\begin{array}{l}\text { Distance From } \\
\text { Nearest City } \\
\text { of Equal or } \\
\text { Greater Size }\end{array}$ & $\begin{array}{l}\text { Percentage } \\
\text { of Population } \\
\text { Non-White }\end{array}$ & $A A A$ & in City? & $\begin{array}{l}\text { Number of } \\
\text { Organizations }\end{array}$ \\
\hline $\begin{array}{c}\text { San Bernardino } \\
\text { California }\end{array}$ & 104,394 & 48 & 37.9 & & Yes & 28 \\
\hline $\begin{array}{l}\text { Tacoma, } \\
\text { Washington }\end{array}$ & 154,555 & 12 & 10.7 & & Yes & 32 \\
\hline $\begin{array}{c}\text { Las Vegas, } \\
\text { Nevada }\end{array}$ & 125,641 & 178 & 17.1 & & No * & 31 \\
\hline $\begin{array}{l}\text { Tucson, } \\
\text { Arizona }\end{array}$ & 262,933 & 96 & 29.1 & & Yes & 31 \\
\hline $\begin{array}{l}\text { Boulder, } \\
\text { Colorado }\end{array}$ & 66,870 & 20 & 7.0 & & Yes & 30 \\
\hline $\begin{array}{l}\text { Salt Lake City } \\
\text { Utah }\end{array}$ & , 175,813 & 340 & 9.7 & & Yes & 31 \\
\hline Source: 1972 & City and County & Y Data Book $(1970$ & Census), Inte & natio & onal City & Management Assn., 1977. \\
\hline
\end{tabular}


case, informants in those cities were contacted prior to the implementation of the study in order to ascertain the degree of independence evidenced in the focal city's human services networks. In each case, assurances were given that these functions were, in fact, independent.

2. General Location. The study was Iimited by two factors to the western states. First, by limiting the study to a general region of the country, potential cultural differences attributable to wide regional separations could be to some extent avoided. Budgetary parameters limited the total number of cities which could be included in the study, and therefore limited the extent to which macro-regional distinctions of various types could be controlled. The second rationale in limiting the study to the west was more directly budgetary in nature. The western location of the research agency conducting the study meant that travel costs to western destinations would be more economical than would travel to more distant points.

3. Size. The study sought to study organizational relationships as encountered in different local contexts, and for this reason mid-size cities were selected as study sites. Large cities were avoided since the multiplicity of their district identities could introduce local heterogeneity to AAA service areas. Small cities were avoided for fear that their service sectors would not be independent of outside influeneces. The cities ultimately selected ranged in size from just over 66,000 to approximately 262,000 .

4. State. It was decided that in order to achieve the goal of the study it was necessary to select cities so that no two were located in the same state. This precaution insured both widespread regional 
representation, and greater differentiation between locales.

4. Area Agency on Aging. It was desired that each city have an Area Agency on Aging, and this goal was realized in every city but one. Las Vegas is located in a state where the Area Agency on Aging was implemented at the state level, and was purposively included in the sample to provide a contrasting case.

5. Ethnicity. Ethnic composition of the cities was a desired source of variance. Two sources of non-white ethnic composition were predominant, these being Black and Spanish-surnamed. While distributions between cities do not approach continuity to as great a degree as might be hoped, a considerable range was included with respect to each minority group.

6. Cooperation. A final consideration which resulted in the elimination of one city from the sample was the degree of cooperation encountered in the early stages of the selection process. Because considerable distances were involved, it was important that some measure of receptivity be offered.

\section{Organizations}

Within the cities, organizations were selected through a "snowball sampling" technique (Griffith et al., 1973; Roistacher, 1974). Generally, this approach involves contacting a party displaying desired characteristics and requesting a listing of other parties with whom contacts are maintained. Named individuals are then used as the actual sources of data. This technique allows for the study of linkages without the prior imposition of structure by the researcher. With specific reference to the data gathering techniques 
employed in this study, initial contacts were established with the directors of six coordinating agencies in each city. In the sense employed here, coordinating agencies are organizations which fulfill service mandates by enlisting and coordinating the service offerings of other, direct service organizations. In each locale, the directors of the Area Agency on Aging, the local public health department, the local United way, the adult services agency serving the local jurisdiction, the local Title $\mathrm{xx}$ agency, and the local mental health coordinating organization were requested to provide the names of agencies to which the highest level of funding was provided. The named agencies constitute the sample from which data was obtained. In each city approximately 30 organizations were selected for the sample: of the 30, it was desired that five or six be broker agencies, and approximately 25 be service organizations.

It is clear that this sampling strategy does not conform to the random sampling mode. While there is merit in this observation and in the reservations which follow, other considerations contribute to the desirability of this strategy for this particular study.

As was mentioned earlier, the cities employed in the study were purposively selected to conform to a set of criteria. It was explicitly recognized that city size very likely confounds the relationships under study. By limiting the sample to the range represented it is recognized chat findings and implications will be tenuous when extended to cities of other scales.

Within the cities, organizations were also selected by other than random means, and the non-random method of sampling may well be seen as 
impacting on the generalizability of the study's findings to a universe of other organizations. While the strategy for selecting agencies for study was designed to conform as closely as possible to the snowball technique described earlier, the responses of contacted respondents undoubtedly reflect an operational component: to the extent that this is the case, network embeddedness may well have been supplanted by characteristics more reflective of the agency's service or administrative style. To the extent, however, that sampling strategies within each of the six cities are identical, there is no reason to believe that intercity comparisons will be affected. In essence, the portion of each service community included in the sample was obtained through identical methods and therefore should be considered comparable. Moreover, there is every reason to believe that similar techniques in other cities would produce similar agency samples, so that generalization across cities of this scale is reasonable.

Finally, this method of sampling guarantees that contacted organizations will have had prior interorganizational experience of the type being studied, so that information gained through interview and questionnaire is more likely to accurately portray organizational concerns than might be the case were random sampling methods employed. In all, the sampling strategy employed here allows for the identification and contacting of agencies of the desired type at least possible cost while not adversely affecting generalizability within the scope envisioned by the researcher. 
Respondent Selection

The sample developed for the earlier study drew from a total of 183 organizations. Table 2 shows how these organizations were distributed among the six cities.

TABLE II

ORGANIZATIONAL DISTRIBUTION BETWEEN CITIES

\begin{tabular}{|cccccc|}
\hline $\begin{array}{c}\text { San } \\
\text { Bernardino }\end{array}$ & Tacoma & $\begin{array}{c}\text { Las } \\
\text { Vegas }\end{array}$ & Tucson & Boulder & $\begin{array}{c}\text { Salt Lake } \\
\text { City }\end{array}$ \\
\hline 28 & 32 & 31 & 31 & 30 & 31 \\
\hline
\end{tabular}

The sample employed in the dissertation analysis is based upon the original study's sample, but differs from it by virtue of three additional selection criteria which will be explained below. These include Interview Type, Respondent Position, and Missing Information.

\section{Interview Type}

of the 183 personal interviews, 20 were eliminated from the sample for one of two reasons relating to circumstances surrounding the interview. Thirteen of these interviews were undertaken during the early phases of the study and were designed primarily to identify other agencies in the various communities which might be employed in the actual gathering of data. While these agencies provided sufficient information of various types to be included in the data set for the original study, their contribution of information needed for this dissertation was insufficient to justify their inclusion. Additionally, seven agencies were eliminated from the sample in accordance with the recommendation of interviewers. Among these were agencies where the 
contacted person appeared to be ill-informed in operational topics of importance to the study, and other organizations where there was reason to suspect either the veracity of the informant or the operational status of the agency.

\section{Organizational Position}

Administrators included in the dissertation's sample are of three job types.

1. Agency Directors

2. Assistant Directors

3. Department Heads

This limitation is an extension of the principles recognized in the sample selection processes of the original study. Because respondents in each organization were to be tapped for information on the organization and not as units of observation in their own right, it was acknowledged that they should be in a position to report authoritatively on the actions of their agency and on the processes by which decisions were undertaken; those in managerial and administrative roles were identified as best suiting this criterion. The limitation of data sources to these three positions carries the original logic one step further by eliminating regional directors (who must respond to other than local influences) and other, less authoritative informants from the sample.

The limitation of data sources to these three positions additionally serves the end of improving comparability between organizations, eliminating potential variance arising out of differences in pexspective arising out of differences in responsibilities. 
Deleted from the sample were 19 respondents with job responsibilities extending beyond the local service area, or with nonadministrative positions such as direct service workers and support staff. These included 13 Regional Directors, three city or county employees in other than administrative positions, two direct service workers, and one volunteer. Represented are four broker agencies, 12 direct service agencies, and three advocate organizations.

\section{Missing Information}

Not all of those contacted provided responses to all of the items. Missing information here, as in social research generally, constitutes a dilemma to the researcher. While the absence of pertinent data makes difficult the assessment of interrelationships between bodies of data, the elimination of all data given by a respondent because of non-response to one or a limited number of items constitutes a potentially large loss of valuable information.

In an effort to address both of these considerations, the following strategy was developed for dealing with missing information among the items used in developing the study's dependent variables. Informants were retained in the sample if in their responses to items on the dependent variable instruments they left no more than three items unanswered per instrument, of the 12 included on each. This mechanism is designed to optimize the extent to which respondents could be operationalized in terms of the dependent variables employed in the analysis. Missing information as encountered with respect to the independent variables was not addressed, except through standard deletion techniques. 
The inclusion of respondents in spite of their non-response to various items was accomplished as follows. If a respondent answered nine or more of the 12 items, a value was attached to missing items equal to the local mean value for that item.

This solution addresses both considerations cited above. First, it means that in addressing individual respondents, no less than 758 of the data describing each will in fact be attributable to information provided by each. Second, respondents may be retained in the investigation who otherwise would have been lost.

Final sample size, then, constitutes the number of informants who hold the position of agency director, assistant director, or department head, and who provided sufficient information to allow reasonable treatment of the dependent variables. In all, 78.38 of all organizations contacted during the study are reflected in data employed in this dissertation. Table III summarizes the sample by city, including the number and proportion of each city's informants employed in the development of each class of dependent variables.

TABLE III

FINAL SAMPLE BY CITY

\begin{tabular}{|c|c|c|c|c|c|c|c|}
\hline & & Number & $\angle$ Perc & ent of & otal Int & rviews & \\
\hline $\begin{array}{c}\text { Intraorganizational } \\
\text { Criteria }\end{array}$ & $\begin{array}{l}\text { S.B. } \\
\frac{28}{100.0}\end{array}$ & $\begin{array}{l}\text { Tacoma } \\
\frac{28}{84.4}\end{array}$ & $\begin{array}{l}\text { L.V. } \\
\frac{21}{64.5}\end{array}$ & $\begin{array}{c}\text { Tucson } \\
\frac{23}{71.0}\end{array}$ & $\begin{array}{l}\text { Boulder } \\
\frac{21}{66.7}\end{array}$ & $\begin{array}{l}\text { SLC } \\
\frac{24}{74.2}\end{array}$ & $\begin{array}{l}\text { Total } \\
\frac{145}{76.5}\end{array}$ \\
\hline $\begin{array}{c}\text { Extraorganizational } \\
\text { Criteria }\end{array}$ & $\frac{28}{100.0}$ & $\frac{28}{87.5}$ & $\frac{23}{74.2}$ & $\frac{23}{74.2}$ & $\frac{21}{70.0}$ & $\frac{24}{77.4}$ & $\frac{147}{80.3}$ \\
\hline Total Interviews & 28 & 32 & 31 & 31 & 30 & 31 & 183 \\
\hline
\end{tabular}




\section{INTERVIEW SCHEDULE}

The interview schedule employed in the larger study on which this dissertation is based was 24 pages in length and required from 45 to 90 minutes to administer. All interviews were completed by trained personnel.

Two data-gathering techniques were employed in the interview schedule. The first involved structured questions presented orally by the interviewer, while the second format employed multi-measure instruments (henceforth referred to as checklists) which the informants completed independently in the presence of the interviewer. The entire instrument was extensively pre-tested in the Portland, Oregon area prior to its use in data collection..

The items which formed the interview instrument were selected in order to plumb both the commodities around which organizations interact, and those organizational and environmental characteristics which might influence interorganizational interactions.

The data for this dissertation were derived from selected structured questions and from a number of the checklists, as described in the ensuing pages.

\section{VARIABLES}

Variables employed in this dissertation are of three general types. The first addresses the objectives of organizations in their entry into interagency agreements: these are treated in the analytical model as dependent variables. The second type of variable is descriptive of organizations and of their interactions with various 
environmental elements: these are treated generally as intervening variables. The third class of variable is the community identity of responding organizations; this variable is employed as the dissertation's independent variable.

\section{Dependent Variables}

The comparative study of community behaviors demands the identification and employment of a stimulus which is capable of generating reactions which themselves become the objects of study. Two problems surface in this context. First, events which impact similarly and sufficiently on numerous locales to produce comparable reactions in each tend to be sporadic and unpredictable. Second, the nature of the event producing such reactions will frequently not be of a type which is supportive of reactions consistent with the desired object of study.

Researchers tend to fall into three patterns in their reactions to this situation. One group, including the political power analysts (as exemplified by Dahl, 1961; Coleman, 1972; Mcclelland and Form, $1964)$ tend to operate without precipitating events per se, rather seeking to describe relationships as evidenced in reactions to recurrent events. A second group, including the "disaster researchers" (including B. Bell, 1978, and Kilijanek and Drabek, 1979), maintain readiness to enter the field until such time as a satisfactory event occurs. A third approach to studying community behavior involves the creation of hypothetical events and seeks to identify and measure how respondents would react were such an event to actually occur. 
Where a precipitating event of some type is necessary, one of the last two approaches is necessary. There are predictable costs and benefits attached to each, generally based upon the trade-off which exists between gaining actual versus reported indications of behaviors and upon manageability in the field segments of the research project.

The data analyzed in this dissertation were generated through the "hypothetical event" approach.

Each respondent was asked to read a card describing a hypothetical event which would present a context within which responses to two instruments would be sought. The hypothetical event was described as follows.

Assume that legislation is passed enacting Human Services Revenue Sharing. The program will be implemented by the designation of a local government agency to broker and monitor the pass through and use of the services funds. The actual service monies will be awarded through contracts with various local service agencies such as the one you work for.

Assume that your agency is approached to participate in the program. To do so will result in certain modifications in your program and in your funding picture. In order to participate, your agency must negotiate a contract setting down the terms of this interagency agreement.

We are specifically interested in what factors you would consider in attempting both to decide whether or not to seek to participate in the program, and later, assuming you were interested, in how you would set your priorities relative to the specifics involved in the contract.

Upon having read the hypothetical problem statement, each respondent was handed two checklists, the first entitled "Interagency Agreements," and the second entitled "Interagency Agreements and the Community." These instruments provide the basis for the study's dependent variables. Each instrument was comprised of 12 items, with responses invited on a five-point scale ranging from "very important" 
with a value of one, to "not at all important," with a value of five. Each of these checklists was designed to provide information on one of the two distinct classes of organizational motivators posited by the primitive economy model, intra- and extraorganizational goals. The first, entitled "Interagency Agreements" was designed to tap the intraorganizational class of goals, while the second, "Interagency Agreements and the Community," was designed to address extraorganizational motivators. On both instruments, four measures each were oriented to assessing market factors, community factors, and organizational factors.

In sum, the two checklists represent instruments designed to tap separate and conceptually independent dimensions in the organizational decision making process. The independence of the two checklists was tested statistically, with analysis indicating that the two are independent in statistical fact as well as in theory. 8

\section{Intraorganizational Criteria}

Addressed by Instrument 1, "Interagency Agreements," intraorganizational criteria are measures of those goals by which an organization identifies its success in terms of its own needs and desires. These criteria pertain primarily to rewards to the agency itself, and only secondarily if at all to entities outside the

8 An important preliminary investigation involved the testing of $i$ tems and aggregate measures from each of the two instruments for degree of correlation between instruments, since relative independence is critical to work to be reported later in the dissertation. Reported more fully in Appendix I, entitled "Tests of Mutual Independence of Instruments I and II," items on each of the instruments, and composite variables operationalized through aggregation of those items, were found to be relatively uncorrelated across instruments. 
organization.

Instrument 1 contains 12 items designed to measure various intraorganizational criteria, as follow. Measures descriptive of the items are presented in Table IV, while the instrument itself is included in Appendix III.

In considering such agreements, it is important...

1) to use such opportunities to increase the range of services your organization offers.

2) to avoid entanglements that diminish your agency's independence and self direction.

3) to negotiate terms on a here-and-now basis since future obligations may be hard to count on.

4) to avoid making the terms of such arrangements a public matter.

5) to advance the professional interests of your staff in any new programs.

6) to avoid new activities that do not match your agency goals.

7) to concentrate on the bread and butter issues like maximizing your share of the contract money.

8) to use such opportunities to increase the size of your agency staff and departments.

9) to stress clear agreements which avoid long run entanglements with other organizations.

10) to protect your agency by driving a hard bargain.

11) to further the wishes of your board.

12) to maximize the return from the agreement to your agency.

The intraorganizational criteria were operationalized through

three composite measures based on these 12 items.

Two were obtained through factor analysis. Using the SPSS 
TABLE IV

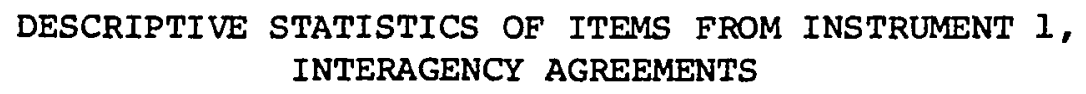

\begin{tabular}{|c|c|c|c|}
\hline Item & $\mathrm{n}$ & $\bar{x}$ & $\mathrm{~s}$ \\
\hline \multicolumn{4}{|l|}{ Instrument 1: Interagency Agreements } \\
\hline $\begin{array}{l}\text { 1. Increase range of services your } \\
\text { agency offers }\end{array}$ & 145 & 1.779 & 1.123 \\
\hline $\begin{array}{l}\text { 2. Avoid entanglements that diminish } \\
\text { independency and self-direction }\end{array}$ & 145 & 1.821 & 1.093 \\
\hline $\begin{array}{l}\text { 3. Negotiate terms on here-and-now } \\
\text { basis }\end{array}$ & 145 & 2.531 & 1.260 \\
\hline $\begin{array}{l}\text { 4. Avoid making terms of arrangements } \\
\text { a public matter }\end{array}$ & 144 & 4.194 & 1.049 \\
\hline $\begin{array}{l}\text { 5. Advance professional interests } \\
\text { of staff }\end{array}$ & 145 & 2.379 & 1.192 \\
\hline $\begin{array}{l}\text { 6. Avoid new activities that do not } \\
\text { match agency goals }\end{array}$ & 144 & 2.083 & 1.305 \\
\hline $\begin{array}{l}\text { 7. Concentrate on bread-and-butter } \\
\text { issues }\end{array}$ & 141 & 2.660 & 1.077 \\
\hline $\begin{array}{l}\text { 8. Increase size of staff and } \\
\text { departments }\end{array}$ & 146 & 3.452 & 1.261 \\
\hline $\begin{array}{l}\text { 9. Stress clear agreements, avoiding } \\
\text { long run entanglements }\end{array}$ & 145 & 1.959 & 1.144 \\
\hline $\begin{array}{l}\text { 10. Protect agency by driving a } \\
\text { hard bargain }\end{array}$ & 141 & 2.979 & 1.176 \\
\hline 11. Further the wishes of your board & 141 & 2.454 & 1.206 \\
\hline $\begin{array}{l}\text { 12. Maximize the return from the } \\
\text { agreement }\end{array}$ & 140 & 2.107 & 1.080 \\
\hline
\end{tabular}


(Nie et al., 1975) package of statistical computer programs, the 12 items enumerated above were factor analyzed employing a principal components procedure followed by a varimax rotation. A pairwise deletion option was used to generate the initial correlation matrix to be factored. Four factors were extracted, accounting for 55.98 of total variance.

The four factors, including the individual items' loadings, are shown in Table $\mathrm{V}$.

The first two factors, representing $37.5 \%$ of total variance and 73.8\% of explained variance were selected for use in the analysis. Throughout the study, variables were assigned to factors according to the following criteria.

1. Variables with factor loadings exceeding .30 were included with that factor.

2. Variables with loadings on two factors exceeding .30 were assigned to the factor upon which they loaded most highly. As no variable loaded on both intraorganizational criteria factors, this proved to be no problem here.

Factor 1 is comprised of the following six items.

1) to avoid making the terms of such arrangements a public matter.

2) to advance the professional interests of your staff in any new programs.

3) to concentrate on the bread and butter issues like maximizing your share of the contract money.

4) to use such opportunities to increase the size of your agency staff and departments.

5) to protect your agency by driving a hard bargain. 
TABLE V

INTRAORGANIZATIONAL CRITERIA: ROTATED

FACTOR LOADINGS BY ITEM

\begin{tabular}{|c|c|c|c|c|c|}
\hline Item & $\begin{array}{r}\text { Factor: } \\
\text { Conceptual Label: }\end{array}$ & $\begin{array}{c}\text { I } \\
\text { Agency } \\
\text { Enhancement } \\
\end{array}$ & $\begin{array}{c}\text { II } \\
\text { Autonomy }\end{array}$ & $\begin{array}{l}\text { III } \\
\text { Not } \\
\text { Used }\end{array}$ & $\begin{array}{l}\text { IV } \\
\text { Not } \\
\text { Used }\end{array}$ \\
\hline 1. & $\begin{array}{l}\text { to use such opportunities to } \\
\text { increase the range of services } \\
\text { your organization offers. }\end{array}$ & .262 & -.062 & .123 & -.050 \\
\hline 2. & $\begin{array}{l}\text { to avoid entanglements that } \\
\text { diminish your agency's inde- } \\
\text { pendence and self direction. }\end{array}$ & .057 & $(.378)$ & .009 & .437 \\
\hline 3. & $\begin{array}{l}\text { to negotiate terms on a here- } \\
\text { and-now basis since future } \\
\text { obligations may be hard to } \\
\text { count on. }\end{array}$ & .179 & $(.410)$ & .152 & .186 \\
\hline 4. & $\begin{array}{l}\text { to avoid making the terms of } \\
\text { such arrangements a public } \\
\text { matter. }\end{array}$ & $(.456)$ & .102 & .016 & .077 \\
\hline 5. & $\begin{array}{l}\text { to advance the professional } \\
\text { interests of your staff in } \\
\text { any new programs. }\end{array}$ & $(.434)$ & .031 & .242 & .193 \\
\hline 6. & $\begin{array}{l}\text { to avoid new activities that } \\
\text { do not match your agency } \\
\text { goals. }\end{array}$ & .048 & .046 & .001 & .643 \\
\hline 7. & $\begin{array}{l}\text { to concentrate on the bread } \\
\text { and butter issues like } \\
\text { maximizing your share of } \\
\text { the contract money. }\end{array}$ & $(.656)$ & .221 & -.094 & .040 \\
\hline 8. & $\begin{array}{l}\text { to use such opportunities to } \\
\text { increase the size of your } \\
\text { agency staff and departments. }\end{array}$ & $(.472)$ & -.021 & .088 & -.036 \\
\hline 9. & $\begin{array}{l}\text { to stress clear agreements } \\
\text { which avoid long run entangle- } \\
\text { ments with other organizations. }\end{array}$ & .061 & $(.873)$ & .089 & .039 \\
\hline 10. & $\begin{array}{l}\text { to protect your agency by } \\
\text { driving a hard bargain }\end{array}$ & $(.441)$ & .241 & .370 & .064 \\
\hline 11. & $\begin{array}{l}\text { to further the wishes of your } \\
\text { board. }\end{array}$ & .100 & .114 & .768 & .017 \\
\hline 12. & $\begin{array}{l}\text { to maximize the return from } \\
\text { the agreement to your agency. }\end{array}$ & $(.434)$ & .238 & .327 & -.111 \\
\hline
\end{tabular}


6) to maximize the return from the agreement to your agency.

Generally, Factor I appears to represent a profit motivation in organizational behavior, though its inclusion of staff advancement and publicity avoidance broadens its scope somewhat. These items notwithstanding, the presence of three items pointedly emphasizing various aspects of net benefit maximization and a fourth citing "driving a hard bargain" clearly point to an orientation encompassing the concepts of profit maximization as described in the first chapter. Accordingly, this factor is entitled "Agency Enhancement."

Agency Enhancement evidences a reliability coefficient of .688. 9

Factor II includes three items, as follows.

1) to avoid entanglements that diminish your agency's independence and self direction.

2) to negotiate terms on a here-and-now basis since future obligations may be hard to count on.

3) to stress clear agreements which avoid long run entanglements with other organizations.

Two related dimensions are apparent in this factor. The first addressed the ability of organizations to regulate their own internal affairs as potentially affected by interorganizational agreements. Organizational avoidance of "entanglements that diminish your agency's independence and self direction," and of "long-run entanglements with formula.

${ }^{9}$ Reliability coefficients were computed through the following

$$
\begin{aligned}
r_{k k}=\frac{k\left(\bar{r}_{i j}\right.}{1+(k-1) \bar{r}_{i j}} \quad & \text { where, } \\
& r_{k k}=\text { reliability coefficient } \\
& \frac{k}{\bar{r}_{i j}}=\text { number of items in scale }
\end{aligned}
$$


other organizations" clearly reflect concerns over the preservation of self-determination in organizational activity. The second dimension involves time, through orientation toward negotiations on a "here and now basis," and avoidance of "long run entanglements." Together, these two dimensions clearly reflect the concept of autonomy, the ability of the organization to pursue its own interests and responsibilities in the absence of extraorganizational direction. The reliability coefficient of Autonomy is .588 . The two factors are operationalized through the aggregation of scores associated with each of the component items. A number of methods exist for the creation of composite variables from individual measures (Susmilch and Johnson, 1975; Alwin, 1973; Nie et al., 1975). This study employs a method described by susmilch and Weldon (1975) involving the unweighted addition of scores to component items to create a composite index, a process referred to as "linear combination" (Nunnally, 1967). While this procedure has been shown to be less effective in meeting each of four important criteria (validity, univocity, reliability, and correlatedness) than other methods, its overall performance has been shown to be equivalent or better than other methods tested (Susmilch and Johnson, 1975; Alwin, 1973). It is pertinent to multi-point scales, is widespread in its applicability, is well adapted to the emphasis of complex measures over the simpler variance associated with single-item measures (Nunnally, 1967), and is economical in its operation.

The aggregation of items from this instrument and, subsequently, from Instrument 2 yields an index which inversely measures the 
importance ascribed to each of the composite measures. This quality arises out of the scaling of responses through a " 1 " for "very important" through "5" for "not at all important." Summary statistics for these measures, as presented in the tables, reflect this inverse scaling. In the reporting of the multiple regression analyses in the next chapter, however, the signs representing the direction of the association between independent and dependent variables will be reversed, allowing direct interpretation of the relation between reported importance of the criteria and the various dependent variables.

A third measure of intraorganizational criteria was created through the simple addition of all items on the instrument. This aggregation is designed to provide a summary measure of organizational interest in organization-specific goals of all the various types. Because of its generality in addressing internal assessment criteria, the measure is entitled "Internal orientation." 10

Internal Orientation generates a reliability coefficient of .696 . Tables VI and VII summarize the three intraorganizational dependent variables.

\section{Extraorganizational Criteria}

Extraorganizational criteria are measures of those goals by which an organization identifies success in terms of its perceptions of the

${ }^{10}$ Item-total correlations 1 inking each of the individual measures and the overall index, Internal orientation, range from a low of .3195 to a high of .6176. All correlacions were generated from a sample of 145 respondents, and all reflect probability levels of $p<.001$. The magnitude of these correlations and the fact that all are positive are seen as supporting the inclusion of all individual items in the aggregate index, Internal orientation. 
needs and desires of entities outside the organization. Also to be employed as dependent variables, these criteria pertain primarily to entities outside the organization and only secondarily, if at all, to the agency itself.

Addressed by Instrument 2, "Interagency Agreements and the Community," the extraorganizational criteria are addressed through 12 items, as follow. Statistics descriptive of the items are presented in Table VIII. A copy of the Instrument is included in Appendix III.

In considering such agreements, it is important...

1) to use the opportunity to link many community agencies for close coordination.

2) to avoid allowing the program to become a competitive struggle among many organizations.

3) to exclude agencies which have been uncooperative with past community efforts.

4) to promote a sense of cooperation among agencies in the community.

5) to minimize the share of the resources which go for agency building and administration.

6) to avoid participation if the distribution process is likely to be dominated by a few self-serving agencies.

7) to set an example of fair play in conducting the negotiations.

8) to seek consultation with community leaders before settling on specific terms.

9) to increase the positive regard of agencies for one another.

10) to discourage the award of funds to agencies with a reputation of not following through with their agreements.

11) to use the funds for strengthening the capacity for human services delivery in the community.

12) to assure open input from client representatives. 
TABLE VI

SUMMARY MEASURES OF INTRAORGANIZATIONAL DEPENDENT VARIABLES

\begin{tabular}{|lccccc|}
\hline VARIABLE & $\mathrm{n}^{\text {II }}$ & $\overline{\mathrm{x}}$ & $\mathrm{s}$ & $\begin{array}{c}\text { Actual } \\
\text { Range }\end{array}$ & $\begin{array}{c}\text { Possible } \\
\text { Range }\end{array}$ \\
\hline $\begin{array}{c}\text { Agency Enhancement } \\
\quad \text { (Factor 1) }\end{array}$ & 145 & 17.781 & 4.250 & $6-27$ & $6-30$ \\
$\begin{array}{c}\text { Autonomy } \\
\text { (Factor 2) }\end{array}$ & 145 & 6.280 & 2.564 & $3-15$ & $3-15$ \\
$\begin{array}{c}\text { Internal Orientation } \\
\text { (Overall Aggregate } \\
\text { Measure) }\end{array}$ & 145 & 30.354 & 6.602 & $12-44$ & $5-60$ \\
\hline
\end{tabular}

TABLE VII

INTERCORRELATIONS BETWEEN

INTRAORGANI ZATIONAL

DEPENDENT VARIABLES

\begin{tabular}{|c|c|c|c|c|}
\hline & & $\mathrm{A}$ & B & $C$ \\
\hline $\begin{array}{l}\text { Agency } \\
\text { Enhancement } \\
\text { (A) }\end{array}$ & $\begin{array}{l}r= \\
p= \\
n=\end{array}$ & & & \\
\hline $\begin{array}{c}\text { Au tonomy } \\
\text { (B) }\end{array}$ & $\begin{array}{l}r= \\
p= \\
n=\end{array}$ & $\begin{array}{r}.2734 \\
.001 \\
145\end{array}$ & & \\
\hline $\begin{array}{l}\text { Internal } \\
\text { orientation } \\
\text { (C) } 12\end{array}$ & $\begin{array}{l}r= \\
p= \\
n=\end{array}$ & $\begin{array}{r}.8569 \\
.001 \\
145\end{array}$ & $\begin{array}{r}.6347 \\
.001 \\
145\end{array}$ & \\
\hline
\end{tabular}

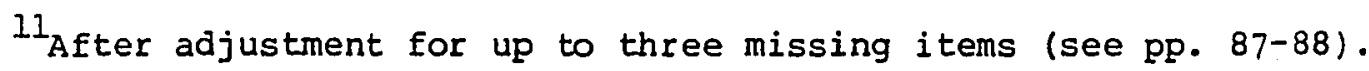

12 Internal Orientation shares items with Agency Enhancement and Autonomy, and so is not considered to be independent. 
TABLE VIII

DESCRIPTIVE STATISTICS OF ITEMS FROM INSTRUMENT 2, INTERAGENCY AGREEMENTS AND THE COMMUNITY

\begin{tabular}{|c|c|c|c|}
\hline Item & $\mathrm{n}$ & $\vec{x}$ & $\mathbf{s}$ \\
\hline $\begin{array}{l}\text { 1. Iink many agencies for close } \\
\text { coordination }\end{array}$ & 147 & 1.354 & .717 \\
\hline $\begin{array}{l}\text { 2. avoid allowing program to become } \\
\text { a competitive struggle }\end{array}$ & 147 & 1.517 & .972 \\
\hline $\begin{array}{l}\text { 3. exclude agencies which have been } \\
\text { uncooperative }\end{array}$ & 145 & 3.455 & 1.220 \\
\hline $\begin{array}{l}\text { 4. promote a sense of cooperation } \\
\text { among agencies }\end{array}$ & 147 & 1.245 & .579 \\
\hline $\begin{array}{l}\text { 5. minimize share of resources for } \\
\text { agency building, administration }\end{array}$ & 147 & 2.000 & 1.240 \\
\hline $\begin{array}{l}\text { 6. avoid participation if dominated } \\
\text { by self-serving agencies }\end{array}$ & 145 & 2.241 & 1.272 \\
\hline $\begin{array}{l}\text { 7. set an example of fair play in } \\
\text { negotiation }\end{array}$ & 147 & 1.537 & .851 \\
\hline $\begin{array}{l}\text { 8. seek consultation with community } \\
\text { leaders }\end{array}$ & 147 & 1.918 & 1.046 \\
\hline $\begin{array}{l}\text { 9. increase positive regard of } \\
\text { agencies for one another }\end{array}$ & 147 & 1.510 & .882 \\
\hline $\begin{array}{l}\text { 10. discourage funds to agencies who } \\
\text { do not follow through }\end{array}$ & 145 & 1.903 & 1.026 \\
\hline $\begin{array}{l}\text { 11. use funds for strengthening human } \\
\text { services capacity }\end{array}$ & 147 & 1.156 & .463 \\
\hline $\begin{array}{l}\text { 12. assure open input from client } \\
\text { representatives }\end{array}$ & 146 & 1.377 & .795 \\
\hline
\end{tabular}


Five measures of extraorganizational criteria were employed in the analysis. Four paralleled those measures derived for the intraorganizational criteria, while one was developed through nonmethodological approaches.

Using the techniques described earlier, three measures were derived through factor analysis of the 12 items in Instrument 2, Interagency Agreements and the Community. This analysis produced three factors, whose rotated loadings are presented in Table IX. All three factors were selected for use in subsequent analysis. Together, they account for 50.68 of total and $100 \%$ of explained variance.

The first factor is comprised of five items, as follow.

1) to promote a sense of cooperation among agencies in the community.

2) to set an example of fair play in conducting the negotiations.

3) to increase the positive regard of agencies for one another.

4) to use the funds for strengthening the capacity for human services delivery in the community.

5) to assure open input from client representatives.

This factor contains items which are oriented to the more figurative aspects of strengthening interorganizational linkages. Four of the five items reflect this theme, including the promotion of "a sense of cooperation," establishing "an example of fair play," improving the mutual "positive regard of agencies," and the general strengthening of services' "capacity for human services delivery." Not so readily related is the fifth item, relating to "open input from client representatives." Possibly explaining the tie which links this 
TABLE IX

EXTRAORGANIZATIONAL CRITERIA: ROTATED FACTOR LOADINGS BY ITEM

\begin{tabular}{|c|c|c|c|c|}
\hline Item & $\begin{array}{r}\text { Factor: } \\
\text { Conceptual Label: } \\
\end{array}$ & $\begin{array}{l}\text { I } \\
\text { pressive } \\
\text { raination }\end{array}$ & $\begin{array}{c}\text { II } \\
\text { Coordination }\end{array}$ & $\begin{array}{c}\text { III } \\
\text { Exclusion } \\
\end{array}$ \\
\hline 1. & $\begin{array}{l}\text { to use the opportunity to link } \\
\text { many community agencies for } \\
\text { close coordination. }\end{array}$ & .272 & $(.508)$ & -.197 \\
\hline 2. & $\begin{array}{l}\text { to avoid allowing the program } \\
\text { to become a competitive strug- } \\
\text { gle among many organizations. }\end{array}$ & .097 & $(.566)$ & .214 \\
\hline 3. & $\begin{array}{l}\text { to exclude agencies which have } \\
\text { been uncooperative with past } \\
\text { commity efforts. }\end{array}$ & -.013 & .013 & .409 \\
\hline 4. & $\begin{array}{l}\text { to promote a sense of coopera- } \\
\text { tion among agencies in the } \\
\text { community. }\end{array}$ & $(.601)$ & .538 & -.074 \\
\hline 5. & $\begin{array}{l}\text { to minimize the share of the } \\
\text { resources which go for agency } \\
\text { building and administration. }\end{array}$ & .110 & $(.403)$ & .238 \\
\hline 6. & $\begin{array}{l}\text { to avoid participation if the } \\
\text { distribution process is likely } \\
\text { to be dominated by a few self- } \\
\text { serving agencies. }\end{array}$ & .126 & .130 & .480 \\
\hline 7. & $\begin{array}{l}\text { to set an example of fair play } \\
\text { in conducting the negotiations. }\end{array}$ & $(.579)$ & .293 & .130 \\
\hline 8. & $\begin{array}{l}\text { to seek consultation with } \\
\text { community leaders before } \\
\text { settling on specific terms. }\end{array}$ & .216 & $(.312)$ & .077 \\
\hline 9. & $\begin{array}{l}\text { to increase the positive regard } \\
\text { of agencies for one another. }\end{array}$ & $(.539)$ & .359 & .087 \\
\hline 10. & $\begin{array}{l}\text { to discourage the award of } \\
\text { funds to agencies with a reputa- } \\
\text { tion of not following through } \\
\text { with their agreements. }\end{array}$ & .132 & .076 & .704 \\
\hline 11. & $\begin{array}{l}\text { to use the funds for strength- } \\
\text { ening the capacity for human } \\
\text { services delivery in the commu } \\
\text { community. }\end{array}$ & $(.511)$ & .045 & .094 \\
\hline 12. & $\begin{array}{l}\text { to assure open input from } \\
\text { client representatives. }\end{array}$ & $(.527)$ & .127 & .062 \\
\hline
\end{tabular}


item to the other four is the recognition of clients--at least in the figurative terms which prevail in this factor--as a contributing component in the service industry. Because of the degree of abstraction evidenced in these items, and because of their general orientation to improving system-wide relations and processes, the factor is entitled "Expressive Coordination."

Expressive Coordination evidences a reliability coefficient of .731.

The second factor is represented by four items.

1) to use the opportunity to link many agencies for close coordination.

2) to avoid allowing the program to become a competitive struggle among many organizations.

3) to minimize the share of the resources which go for agency building and administration.

4) to seek consultation with community leaders before settling on specific terms.

This factor describes more active components in the strengthening of interorganizational ties. Where the factor described above was comprised of the symbolic elements of improving intra-industry ties, this factor is oriented more to the choreographing of active organizational efforts to improve the system's operation, and possibly its linkages to the broader locale. The linking of "agencies for close coordination," the avoidance of "competitive struggle[s]," and the minimization of "agency building" all relate to interagency goals of improving service delivery through improved performance. The fourth item, involving "consultation with community leaders," would also fit this general pattern, perhaps extending it to the larger context of the 
overall community. Reflecting the "action orientation" of the four items of which it is composed, and in keeping with the coordinative focus of the items, this factor is entitled "Instrumental coordination." Instrumental coordination generates a reliability coefficient of .526 .

The third factor is comprised of three items.

1) to exclude agencies which have been uncooperative with past community efforts.

2) to avoid participation if the distribution process is likely to be dominated by a few self-serving agencies.

3) to discourage the award of funds to agencies with a reputation of not following through with their agreements.

The contents of this factor had been identified prior to the factor analysis as a composite measure to be used in data analysis, designed to assess a specific component of organizational orientation. Its surfacing as a viable factor was thus not a complete surprise as such, but was rather a confirmation of prior work. The measure was originally constructed to index the degree to which organizations mobilize to exclude other agencies from interorganizational endeavors, and was entitled "Exclusion."

The reliability coefficient of Exclusion is .568 . An additional composite measure was developed as an index of functional contact with community elements outside the service industry. While not surfacing as a factor in the factor analys is described above, the theoretical ties linking interorganizational networks with their community environments in the Primitive Economy Model suggest that community distinctions will likely evidence 
themselves with respect to this variable. Labeled "Outside Input," this index was operationalized through the addition of responses to the following two items.

Outside Input generates a reliability coefficient of but .208, reflecting both the small number of items employed in the variable's derivation, and their low $(r=.114)$ intercorrelation:

1) to seek consultation with community leaders before settling on specific terms.

2) to assure open input from client representatives.

As with the intraorganizational criteria, an overall composite score was also developed in order to gain a general measure of organizational attention to extraorganizational measures of success. Entitled "External Orientation," this measure constitutes the sum of responses to all items on the instrument. ${ }^{13}$

External Orientation reflects a reliability coefficient of $\mathbf{7 4 4}$. The extraorganizational dependent variables are summarized in Tables $\mathrm{X}$ and $\mathrm{XI}$.

\section{Independent Variables}

The study will employ two general types of independent variables. The first type is community-specific, of which there is one. The second type involves organizational characteristics, selected

${ }^{13}$ Item-total correlations linking each of the individual measures and the overall index, External orientation, range from a low of .3574 to a high of .6167. All correlations were generated from a sample of 147 respondents, and all generate probability levels of $p<.001$. The magnitude of these correlations, and the fact that all are positive are seen as supporting the inclusion of all individual items in the aggregate index, External orientation. 
TABLE $X$

SUMMARY MEASURES OF EXTRAORGANIZATIONAL

DEPENDENT VARIABLES

\begin{tabular}{|c|c|c|c|c|c|}
\hline Variable & $\mathrm{n}^{14}$ & $\bar{x}$ & $\mathbf{s}$ & $\begin{array}{l}\text { Actual } \\
\text { Range }\end{array}$ & $\begin{array}{c}\text { Possible } \\
\text { Range }\end{array}$ \\
\hline $\begin{array}{l}\text { Instrumental coordination } \\
\quad \text { (Factor 1) }\end{array}$ & 147 & 6.929 & 2.549 & $5-18$ & $5-25$ \\
\hline $\begin{array}{l}\text { Expressive Coordination } \\
\quad \text { (Factor 2) }\end{array}$ & 147 & 8.401 & 3.069 & $4-17$ & $4-20$ \\
\hline $\begin{array}{l}\text { Exclusion } \\
\text { (Factor 3) }\end{array}$ & 147 & 7.601 & 2.568 & $3-15$ & $3-15$ \\
\hline Qutside Input & 147 & 3.296 & 1.388 & $2-8$ & $2-10$ \\
\hline $\begin{array}{l}\text { External Orientation } \\
\text { (Overall Aggregate } \\
\text { Measure) }\end{array}$ & 147 & 21.319 & 5.581 & $12-46$ & $5-60$ \\
\hline
\end{tabular}

14 After adjustment for up to three missing items (see pp. 87-88). 
TABLE XI

INTERCORRELATIONS BETWEEN EXTRAORGANIZATIONAL DEPENDENT VARIABLES

\begin{tabular}{|c|c|c|c|c|c|c|}
\hline & & A & $\mathrm{B}$ & $\mathrm{C}$ & $\mathrm{D}$ & $\mathrm{E}$ \\
\hline Expressive & $r=$ & & & & & \\
\hline Coordination & $\mathrm{p}=$ & & & & & \\
\hline (A) & $\mathrm{n}=$ & & & & & \\
\hline Instrumental & $r=$ & .4815 & & & & \\
\hline Coordination & $\mathrm{p}=$ & .001 & & & & \\
\hline (B) & $\mathrm{n}=$ & 147 & & & & \\
\hline \multirow{3}{*}{$\begin{array}{r}\text { Exclusion } \\
\text { (C) } 15\end{array}$} & $r=$ & .1901 & .1909 & & & \\
\hline & $\mathrm{p}=$ & .011 & .010 & & & \\
\hline & $\mathrm{n}=$ & 147 & 147 & & & \\
\hline Outside & $r=$ & .6212 & .5776 & .1382 & & \\
\hline Input & $p=$ & .001 & .001 & .048 & & \\
\hline (D) 15 & $\mathrm{n}=$ & 147 & 147 & 147 & & \\
\hline External & $\mathbf{r}=$ & .7673 & .7711 & .6353 & .6149 & \\
\hline Orientation & $\mathrm{p}=$ & .001 & .001 & .001 & .001 & \\
\hline$(E)^{15}$ & $\mathrm{n}=$ & 147 & 147 & 147 & 147 & \\
\hline
\end{tabular}

${ }^{15}$ Exclusion and outside Input share items with Expressive Coordination and Instrumental Coordination. External orientation shares items with all other measures. 
for their potential in impacting organization-environment interactions, and for their ease in being identified by policy-makers and implementers. Six variables are of the latter type, including organizational reliance on federal funding, four measures of environmental turbulence, and organizational goal. The organizational goals are employed in the analyses as covariates.

The independent variables are discussed in the following pages, and are summarized in Tables XII and XIII.

\section{Community}

Community constitutes the study's independent variable and represents the local service market. As noted earlier, the literature is not specific as to what exactly constitutes a community, except that the social reality may well not conform to jurisdictional boundaries (Suttles, 1972; Stacey, 1969; Janowitz, 1952). This notwithstanding, the question of geographic scale is addressed with authors generally concluding that larger scale correlates with lesser community homogeneity (MacIver, 1970; Suttles, 1972). Based upon the latter conceptualization and mindful of the former, this dissertation analysis will operationalize the construct of community by employing service areas. These approximate urban jurisdictional boundaries and are dictated by the nature of the sample in use. Thus when speaking of, say, Tacoma, the service area centering upon Tacoma is the actual area being studied, as defined by the spatial distribution of organizations named by Tacoman service personnel as being components of the area's service network. The actual "community" under study is functional, 
TABLE XII

SUMMARY OF INDEPENDENT VARIABLES (BASED UPON SAMPLE EMPLOYED IN INTRAORGANIZATIONAL ANALYSES) 16

\begin{tabular}{|c|c|c|c|c|c|}
\hline & $\mathrm{n}$ & $\bar{x}$ & $s$ & $\begin{array}{r}\text { Actual } \\
\text { Range }\end{array}$ & $\begin{array}{c}\text { Possible } \\
\text { Range }\end{array}$ \\
\hline \multicolumn{6}{|l|}{ Organizational Variables } \\
\hline Organizational Resources & 140 & 35.514 & 35.684 & $0-100$ & $0-100$ \\
\hline Local Public Uncertainty & 126 & 18.405 & 6.761 & $0-28$ & $0-28$ \\
\hline State and Federal Uncertainty & 131 & 13.580 & 4.596 & $2-20$ & $0-20$ \\
\hline Clients Uncertainty & 141 & 13.489 & 2.127 & $6-16$ & $0-16$ \\
\hline $\begin{array}{l}\text { Interorganizational } \\
\text { Uncertainty }\end{array}$ & 129 & 4.736 & 1.757 & $0-8$ & $0-8$ \\
\hline \multicolumn{6}{|l|}{ Organizational Goal } \\
\hline Broker & 21 & - & - & - & - \\
\hline Direct Service & 103 & - & - & - & - \\
\hline Advocate & 21 & - & - & - & - \\
\hline \multicolumn{6}{|l|}{ Community } \\
\hline San Bernardino & 28 & & & & \\
\hline Tacoma & 28 & & & & \\
\hline Las Vegas & 21 & & & & \\
\hline Tucson & 23 & & & & \\
\hline Boulder & 21 & & & & \\
\hline Salt Lake City & 24 & & & & \\
\hline
\end{tabular}

${ }^{16} 145$ organizations were found suited for the intraorganizational analyses by virtue of information on the dependent variables. Deviations between 145 and the numbers presented in this Table represent missing information. 
TABLE XIII

INTERCORRELATIONS OF INDEPENDENT VARIABLES

\begin{tabular}{|c|c|c|c|c|c|c|}
\hline . & & $\begin{array}{l}\text { Organiza- } \\
\text { tional } \\
\text { Resources }\end{array}$ & $\begin{array}{c}\text { Local } \\
\text { Public } \\
\text { Uncertainty }\end{array}$ & $\begin{array}{c}\text { State \& } \\
\text { Federal } \\
\text { Uncertainty }\end{array}$ & $\begin{array}{c}\text { Client } \\
\text { Uncertainty }\end{array}$ & $\begin{array}{l}\text { Interorgani- } \\
\text { zational } \\
\text { Uncertainty }\end{array}$ \\
\hline $\begin{array}{l}\text { 1. Organizational } \\
\text { Resources }\end{array}$ & $\begin{array}{l}\mathrm{r}= \\
\mathrm{p}= \\
\mathrm{n}=\end{array}$ & & & & & \\
\hline $\begin{array}{l}\text { 2. Local Public } \\
\text { Uncertainty }\end{array}$ & $\begin{array}{l}r= \\
p= \\
n=\end{array}$ & $\begin{array}{r}-.0941 \\
.142 \\
132\end{array}$ & & & & \\
\hline $\begin{array}{c}\text { 3. State \& Federal } \\
\text { Uncertainty }\end{array}$ & $\begin{array}{l}r= \\
\mathrm{p}= \\
\mathrm{n}=\end{array}$ & $\begin{array}{r}.3009 \\
.001 \\
132\end{array}$ & $\begin{array}{r}3148 \\
.001 \\
123\end{array}$ & & & \\
\hline $\begin{array}{l}\text { 4. Client } \\
\text { Uncertainty }\end{array}$ & $\begin{array}{l}r= \\
p= \\
n=\end{array}$ & $\begin{array}{r}.1555 \\
.030 \\
146\end{array}$ & $\begin{array}{r}.1618 \\
.033 \\
130\end{array}$ & $\begin{array}{r}.1271 \\
.072 \\
134\end{array}$ & & \\
\hline $\begin{array}{l}\text { 5. Inter- } \\
\text { Organizational } \\
\text { Uncertainty }\end{array}$ & $\begin{array}{l}\mathbf{r}= \\
\mathbf{p}= \\
\mathbf{n}=\end{array}$ & $\begin{array}{r}.0508 \\
.285 \\
127\end{array}$ & $\begin{array}{r}.0555 \\
.278 \\
115\end{array}$ & $\begin{array}{r}.0620 \\
.248 \\
123\end{array}$ & $\begin{array}{r}.0941 \\
.144 \\
130\end{array}$ & \\
\hline
\end{tabular}


although it correlates closely with spatial boundaries. In the course of the study, "Community" will be employed as a classificatory device of nominal order, with each of the cities being a class within the larger variable. While somewhat unusual in approach, this is in keeping with commonly accepted techniques (Kerlinger, 1973; Blalock, 1972; Nunnally, 1967; Hays, 1973). Table XII summarizes each city's representation in the sample.

\section{Organizational Variables}

The organizational variables will be employed as control variables allowing for the more accurate assessment of communityrelated differences. As mentioned above, three types of organizational variables will be employed.

1. Organizational Resources. Organizational Resources will represent organizational reliance upon federal sources for funding. As such, it reflects organizational dependence on entities outside the service market, and constitutes an inverse proxy for local autonomy in organizational decision making. Roland L. Warren (1967) notes that one characteristic determining the degree to which communities maintain autonomy and identity is the extent to which organizations within the community have autonomy over their operations; organizational autonomy, he notes, varies inversely with the degree to which the organization depends upon entities outside the local area for support. The funding patterns of many social service agencies is such that a proxy for extracommunity funding and, potentially, control is available through a measure of organizational reliance on federal funding. This variable will be operationalized through the use of 
self-reported data obtained during the interview process which reported the percent of budget obtained from federal sources. Reported in percentages and therefore of ratio order, the information was ascertained through a question presented in the earlier stages of the interviews. The question is presented in Appendix III, and statistics descriptive of the responses are presented in Table XII.

2. Organizational Uncertainty. As was discussed earlier, environmental turbulence is a descriptor not so much of the organization or the environment alone, but rather of the relationship which links the organization with its environment. For this reason, it is reasonable to assume that organizations operating within a locale will encounter different degrees of turbulence simply as a result of their interactions with different environmental components. While the four turbulence measures are conceded to have a major environmental component to their composition, they will be termed "organizational variables" throughout the dissertation. The measures employed here to represent organizational uncertainty are based on those of the report, as developed by another analyst.

The four measures were developed through the factor analysis of three instruments included in the interview instrument, as reflected in Table XIV. The factor analytical work has done employing a principal components procedure and varimax rotation. These scales were developed using all 335 respondents to the original study, and not just the 183 who constitute the sample for this dissertation. Each of the three instruments was designed to tap a distinct aspect of organizational-environmental interaction. Based largely on 
TABLE XIV

\section{FACTOR ANALYSIS: ROTATED FACTOR LOADINGS IN DEVELOPMENT OF UNCERTAINTY MEASURES}

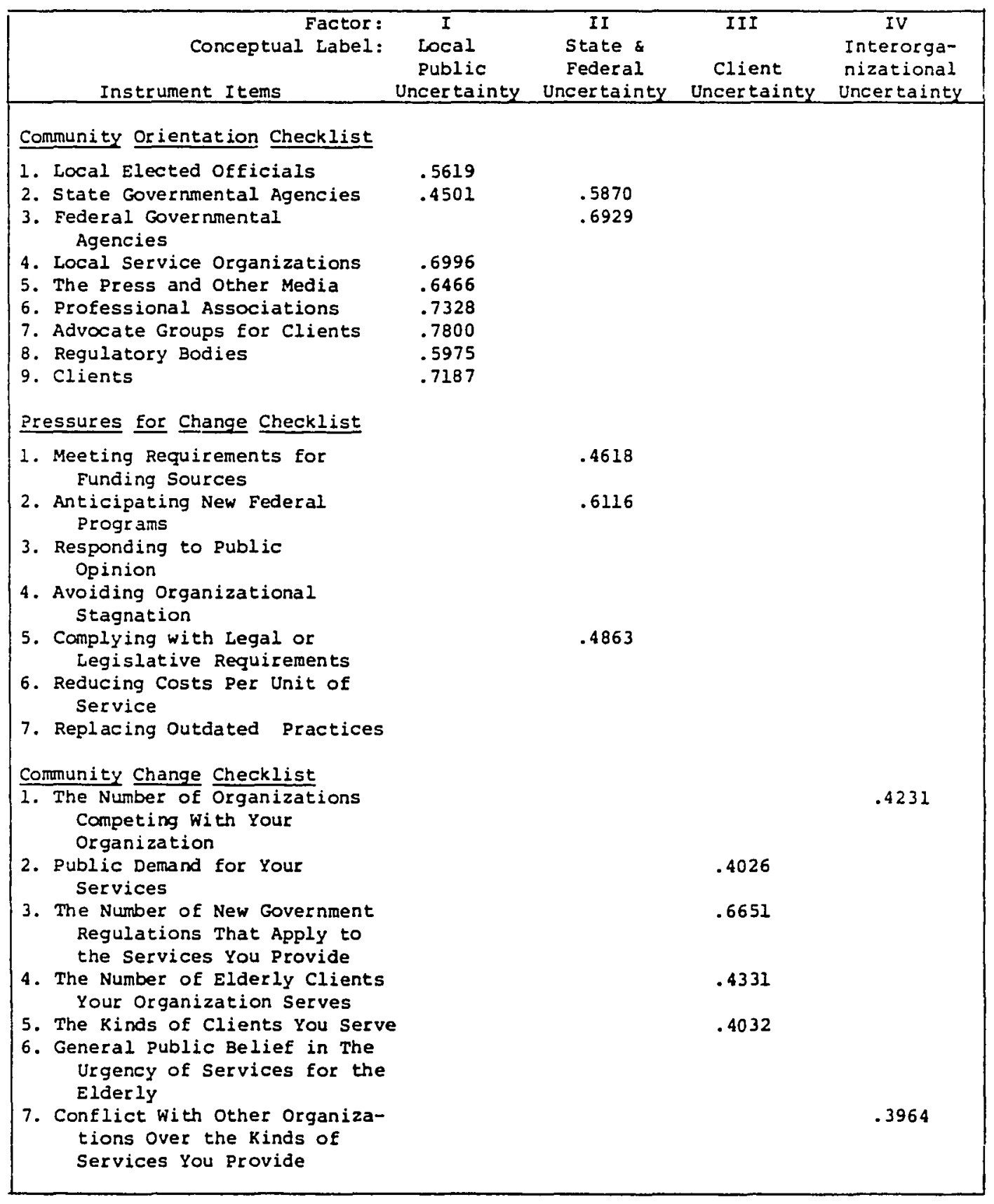


findings developed in a prior study (O'Brien and Wetle, 1975), these were oriented to identifying the environmental entities which directly or indirectiy influence organizational activity. Together, the three tap the degree to which the expectations and demands of various environmental groups reflect in the agency's onging decision making processes, the extent to which they have been influential in the past, and the degree to which organizations perceive their relevant environment as undergoing change. In each case, input and output components of the environment are identified, though the lack of specificity in the theoretical bases offered by the literature made difficult the further identification of specific environmental entities. Accordingly, the project's senior investigators based their selection of several of the specific environmental components employed in the instruments on conceptual grounds and on their own prior research. The instruments are included in Appendix III.

The first of the instruments addressing uncertainty, entitled "Community Orientation," is comprised of nine items, each representing an environmental entity potentially capable of influencing agency operations, as follows.

For each sector listed below, please indicate the extent to which their evaluation of your agency function is a major cause of concern for your organization.
1) Local Elected Officials
2) State Governmental Agencies
3) Federal Governmental Agencies
4) Local Direct Service Organizations
5) The Press and Other Media 
6) Professional Associations

7) Advocate Groups for Clients

8) Regulatory Bodies (i.e., boards and commissions not included in categories above)

9) Clients

Respondents were asked to register the degree of concern they register with respect to each. A five-point scale was developed for this purpose, where one pole registered "very much of concern," and the other represented "of no concern whatsoever."

The second Instrument used in this analysis, entitled "Pressures for Change," sought respondents' perceptions of seven influences potentially capable of impacting organizational activities and direction. The questions presented in the instrument are as follow.

Thinking about changes you have made in the past, please indicate the importance of each in influencing your organization's change decisions.

1) Meeting requirements of funding sources

2) Anticipating new federal programs

3) Responding to public opinion

4) Avoiding organizational stagnation

5) Complying with legal or lesislative requirements

6) Reducing costs per unit of service

7) Replacing outdated programs.

As before, responses were taken on a five-point scale with "very important" at one pole, and "not at all important" at the other.

The third instrument is entitled "Community Change" and is designed to document respondents' perceptions of how their respective 
communities had changed over the past five years. In a real sense, this instrument documents market change. Seven items comprised the instrument, as follow.

Using the past five years as a frame of reference, please indicate whether each of these factors has increased or decreased in your organization.

1) The number of organizations competing with your organization.

2) Public demand for your services.

3) The number of new government regulations that apply to the services you provide.

4) The number of elderly clients your organization serves.

5) The kinds of clients you serve.

6) General public belief in the urgency of services for the elderly.

7) Conflicts with other organizations over the kinds of services you provide.

Again, a five-point scale was used to document responses, with "increased" at one pole, "remained the same" at the mid-point, "decreased" at the other pole.

The factor analysis of the three checklists yielded the loadings reflected in Table XIV. It will be noted that, for the most part, the integrity of the instruments was reaffirmed in the factor analysis. This was anticipated. Factor composition, however, does not perfectly match the checklists.

Local Public Uncertainty represents the degree of concern felt by members of the organization about various local groups, or "publics," in the community. Examples of these groups would include elements of the media and various professional groups. 
The variable was operationalized through the procedures outlined earlier, using the scores obtained from the following items.

a) Local Elected Officials (as a source of concern to the agency).

b) Local Direct Service Organizations (as a source of concern to the agency).

c) The Press and Other Media (as a source of concern to the agency).

d) Advocate Groups for Clients (as a source of concern to the agency).

e) Regulatory Bodies (as a source of concern to the agency).

f) Clients (as a source of concern to the agency).

State and Federal Uncertainty is defined as the degree of concern

felt by the organization over pressures exerted by state and federal

agencies. Examples would include requirements exerted by funding

agencies, and legislative and legal restraints.

This variable was derived using the following items:

a) State Governmental Agencies (as a source of concern to the agency).

b) Federal Governmental Agencies (as a source of concern to the agency).

c) Meeting Requirements of Funding Sources (as an influence in the organization's change decisions).

d) Anticipating New Federal Programs (as an influence in the organization's change decisions).

e) Complying with Legal or Legislative Requirements (as an influence in the organization's change decisions).

Clients Uncertainty is the extent to which the diversity of clients and their demand for the organization's services had increased or decreased. 
The following items were used to develop a value for this

variable.

a) Public Demand for Your Services (has increased or decreased for your organization).

b) The Number of New Government Regulations that Apply to the Services You Provide (has increased or decreased for your organization).

c) The Number of Elderly clients Your Organization Serves (has increased or decreased for your organization).

d) The Kinds of Clients You Serve (has increased or decreased for your organization).

Interorganizational Uncertainty constitutes the extent to which there has been an increase or decrease in the number of organizations competing with the focal organization, as well as conflict with other organizations over types of service provision.

The variable was operationalized through the use of the following items.

a) The Number of Organizations Competing with Your Organization (has increased or decreased for your organization).

b) Conflict with Other Organizations over the Kinds of Services You Provide (has increased or decreased for your organization).

3. Organizational Goal. This variable describes the role of the organization in the overall service system. The limitation of the dissertation's scope to human service agencies recommends a three-fold classificatory variable describing organizational function which is specifically designed for this industry (Burki, 1978), as follows. Agencies were classified according to their own self-descriptions, as confirmed by the judgements of the original research team. 
Service organizations are the agencies which actually supply the service to a clientele. These agencies' access to funding is based on their provision of service. The sample employed in this dissertation includes 115 service agencies.

Broker organizations have as their primary function the development of service strategies, and the completion of arrangements leading to service delivery by service organizations. Rarely do broker organizations provide services themselves. This sample includes 27 broker organizations.

Advocate organizations have as their primary responsibility the representation of a class of client in agitating for needed service options, and the mobilization of members of the client group to act in their own behalf. Advocate organizations generally do not in themselves provide human services to clients; rather, they represent the client in the larger service industry. Twenty-one advocate organizations were included in the sample.

\section{Summary of Independent Variables}

Statistics descriptive of each of the independent variables are presented in Table XII, for those firms included in the intraorganizational analyses.

Table XIII presents Pearson's product moment correlations between the interval order independent variables. With a highest correlation of . 3149, these variables were deemed generally consistent with assumptions of independence accompanying the analytical methods employed in the dissertation. It should be additionally noted that 
with only one exception, the correlations of the four turbulence measures generally reflect independence. As such, the assumption that they reflect different forms of organizational uncertainty is generally supported.

Table XV provides descriptive statistics of those firms deleted from the intraorganizational analyses in terms of the dissertation's independent variables. In no case are measures based on deleted firms significantly different from those related to firms employed in the analyses.

\section{ANALYSIS}

As will be developed more fully in the next chapter, three methodological techniques are employed in the dissertation's analysis: analysis of variance, analysis of covariance, and multiple regression analysis. Each will be undertaken through the SPSS package of computer programs (Nie et al., 1975). These techniques are consistent with the properties of the variables described above.

It will be recalled that two general classes of dependent variables were described: intraorganizational criteria and extraorganizational criteria. Each measure employed within these general classes is a product of summative scaling techniques, and therefore generally consistent with the characteristics of interval scales. The independent variables generally conform with the properties of two scales of measurement. Organizational Resources is a proportional measure and therefore of ratio scale. The four Organizational Uncertainty indexes, like the criterion measures above, are summative 
TABLE XV

SUMMARY OF INDEPENDENT VARIABLES (BASED UPON SAMPLE

DELETED FROM INTRAORGANIZATIONAL ANALYSES) 17

\begin{tabular}{|c|c|c|c|c|c|}
\hline & $\mathrm{n}$ & $\bar{x}$ & $\mathbf{s}$ & $\begin{array}{l}\text { Actual } \\
\text { Range }\end{array}$ & $\begin{array}{l}\text { Possible } \\
\text { Range }\end{array}$ \\
\hline \multicolumn{6}{|l|}{ Organizational Variables } \\
\hline Prganizational Resources & 13 & 39.846 & 45.911 & $0-100$ & $0-100$ \\
\hline Local Public Uncertainty & 11 & 18.091 & 6.123 & $6-28$ & $0-28$ \\
\hline State and Federal Uncertainty & 7 & 12.143 & 5.786 & $4-17$ & $0-20$ \\
\hline Clients Uncertainty & 12 & 13.000 & 2.374 & $9-16$ & $0-16$ \\
\hline $\begin{array}{l}\text { Interorganizational } \\
\text { Uncertainty }\end{array}$ & 5 & 4.200 & 1.304 & $3-6$ & $0-8$ \\
\hline \multicolumn{6}{|l|}{ Organizational Goal } \\
\hline Broker & 6 & & & & \\
\hline Direct Service & 11 & & & & \\
\hline Advocate & 1 & & & & \\
\hline \multicolumn{6}{|l|}{ Community } \\
\hline San Bernardino & 0 & & & & \\
\hline Tacoma & 0 & & & & \\
\hline Las Vegas & 5 & & & & \\
\hline Tucson & 2 & & & & \\
\hline Boulder & 7 & & & & \\
\hline Salt Lake City & 4 & & & & \\
\hline
\end{tabular}

${ }^{17} 18$ organizations were deleted from the intraorganizational analysis for reasons of missing information on the dependent variables. Deviations between 18 and the numbers presented in the Table represent missing information. 
indexes and therefore generally consistent with the properties of interval scales.

Community and Organizational Goal are nominal measures. The application of these variables to regression analysis will be undertaken through the development of dummy variables, a technique which has been widely employed and found to be appropriate for regression analysis (Miller and Erickson, 1974; Nie et al, 1975). 


\section{CHAPTER V}

RESULTS

INTRODUCTION

This chapter reports the findings of the research, as developed in pursuit of the research question and hypotheses presented in the preceding chapter.

The reporting of analytical results will be undertaken in three parts.

First, results will be very generally summarized in the section which immediately follows. The full reporting of results is a lengthy undertaking, and in focusing on the details of analytical findings, it can be difficult to maintain the context within which analyses were planned and executed. By summarizing the results prior to their more complete reporting it is hoped that a context can be established which will assist the reader in addressing the more detailed reporting to follow.

The full textual discussion of results will immediately follow the summary described above. Textual discussion will address all analytical results involving Community, and all involving organizational variables with probability levels of $p<.10$. As will be further discussed in the dissertation's last chapter, this relatively generous probability level reflects the exploratory nature of this research, and a willingness to risk Type I error in exchange for reduced possibilities 
of committing Type II error. The discussion of results will begin with those analyses addressing the intraorganizational criteria as dependent variables, and will conclude with those involving the extraorganizational decision making criteria.

Finally, the tabular presentation of all analytical results is provided in Appendix II.

ANALYTICAL RESULTS: SUMMARY

The data yield no support for the first hypothesis, calling for intercity differences in the orientations of organizations toward intraorganizational measures of success. Analyses employing three measures of intraorganizational decision making criteria--Agency Enhancement, Autonomy, and Internal orientation--as dependent variables demonstrated that no significant differences exist between organizations in the six cities in their respective valuations of this class of goals.

The second hypothesis, suggesting intercity differences in organizational orientation to extraorganizational impacts, received greater support from the data than did the first. Five measures of extraorganizational criteria were developed: Expressive Coordination, Instrumental Coordination, Exclusion, Outside Input, and External Orientation. Here, intercommunity differences were found to exist with probabilities of $p<.076$ (External Orientation), $p<.081$ (Expressive Coordination), $p<.127$ (Instrumental Coordination), $p<.131$ (Outside Input), p<.229 (Exclusion). While none of these measures reflect commonly accepted standards of statistical probability $(p<.05)$, four 
of the five are generally consistent with other standards as they relate to exploratory research (Hays, 1973).

The third hypothesis, calling for greater intercity differences among the extraorganizational criteria than among the intraorganizational criteria was deemed fully supported by the analyses. All measures of intercity differences among the extraorganizational criteria were found to exceed all intercity difference measures among the intraorganizational criteria.

ANALYTICAL RESULTS: TEXTUAL PRESENTATION

The pages which follow are devoted to discussion of the dissertation's analytical results. Analysis is comprised of three steps. First, each of the eight dependent variables is analyzed for intercommunity differences, without employing any of the organizational variables as controls. One-way analysis of variance is employed for this purpose with Community as the single independent variable. This independent variable is comprised of six levels, each representing one of the six cities.

Second, each dependent variable is analyzed through analysis of covariance in order to assess intercommunity differences, employing each of the organizational variables individually as controls.

Third, each dependent variable is analyzed through multiple regression analysis. Here, all organizational variables are employed as controls, with community-related contributions to variance assessed only after parceling out that associated with organizational characteristics. This is comparable to analysis of covariance with multiple 
covariates, the regression technique employed primarily to surmount limitations on covariates encountered in the SPSS package (Nie et al., 1975).

The second and third analytical phases conform to a methodological technique termed "contextual analysis." In contextual analysis, the contributions to variance attributable to a locational or environmental (contextual) variable are analyzed only after having controlled for the contributions of variables which are explicitly related to observational units within the various contexts.

The theoretical and conceptual significance of the analytical results will be discussed following the presentation of findings from each of the two sets of regression analysis.

\section{Intraorganizational Criteria}

\section{Analysis of Variance}

Analysis of variance relating community to the Intraorganizational Criteria produced no statistically significant results. As reflected in the small deviations from the grand mean and the probability levels provided in Table XVI, in none of these analyses was Community found to be a significant factor in explaining organizational emphasis on an intraorganizational decision making criterion. As a result, the hypothesis predicting intercommunity differences in reported patterns of intraorganizational criteria was found to be unsupported in this series of analyses. 
TABLE XVI

ANALYSIS OF VARIANCE: GRAND MEAN AND COMMUNITY DEVIATIONS FROM GRAND MEAN BY INTRAORGANIZATIONAL DEPENDENT VARIABLE

\begin{tabular}{|c|c|c|c|}
\hline & $\begin{array}{c}\text { Agency } \\
\text { Enhancement }\end{array}$ & Autonomy & $\begin{array}{c}\text { Internal } \\
\text { Orientation } \\
\end{array}$ \\
\hline Grand Mean & 17.78 & 6.28 & 30.35 \\
\hline San Bernardino & -.03 & -.28 & -.60 \\
\hline Tacoma & .50 & -.35 & .07 \\
\hline Las Vegas & -1.43 & .51 & -1.03 \\
\hline Tucson & 1.00 & .59 & 1.18 \\
\hline Boulder & .66 & -.38 & 1.23 \\
\hline Salt Lake City & -.84 & .05 & -.69 \\
\hline $\mathrm{p}<$ & .365 & .650 & .787 \\
\hline$F=$ & 1.096 & .666 & .485 \\
\hline$d f=$ & 5,139 & 5,139 & 5,139 \\
\hline
\end{tabular}




\section{Analysis of Covariance}

The analysis of covariance employed in this stage of analysis involves the testing of inter community differences with respect to each of the three measures of intraorganizational decision criteria, individually employing each of the six selected organizational variables as covariates. In all, 18 analyses of covariance are represented in this pursuit. Results of analyses are summarized in Tables XVIII, XIX, and XX.

As reflected in deviations from the grand means and in the probability levels summarized in the three tables, in no case was Community found to be an effective variable for explaining variance among the three independent variables. In the analysis where Community proved strongest in its association with a decision criterion, the statistical significance of its relation was well short of accepted probability levels (with Agency Enhancement as the dependent variable and Organizational Goal as the covariate). The analyses of covariance, then, lend no support to the first hypothesis.

Two other observations are noteworthy with respect to these analyses.

First, as reflected in Tables XVIII through $\mathrm{XX}$, in no case is the inclusion of an organizational variable as covariate in the analysis of a dependent variable accompanied by an improvement in Community's performance as a predictor to a probability level of p<.10. In the most favorable case, with Agency Enhancement and Organizational Goal as dependent variable and covariate respectively, Community's contribution to variance reflects a probability level 
of $p<.143$.

Second, the results of a number of the analyses evidence that the covariates themselves are to varying extents effective in explaining variance in the dependent variables. Summarized in Table XX, each organizational variable will be briefly mentioned though as elsewhere attention will be restricted to those covariates with $F$ values reflecting probability levels of $p<.10$.

Organizational Resources is not an effective predictor with respect to any of the three dependent variables.

Organizational Goal, as is evidenced in Table XVII, is an effective predictor of all three internal decision making criteria (with Agency Enhancement, $F=5.645, d f=2,137, p<.004$; with Autonomy, $F=4.322, d f=2,137, p<.015 ;$ with Internal orientation, $F=4.273$, $d=1,137, p<.016)$. This pattern of distinctions is based primarily on the differences in orientation which are evident between Advocate Agencies and Broker Agencies. These distinctions are evident in the figures relating to Broker Agencies (with Agency Enhancement, F=8.426, $\mathrm{df}=1,137, \mathrm{p}<.004$; with Autonomy, $F=3.829, \mathrm{df}=1,137, \mathrm{p}<.052$; with Internal Orientation, $F=5.237, d f=1,137, p<.024)$. The differences evidenced between Advocate Agencies and Direct Service Agencies are not statistically significant, indicating that these two types of agencies are similar in their orientations to the intraorganizational criteria.

Local Public Uncertainty does not reflect statistically significant associations with any of the three intraorganizational criterion measures. Its strongest relation involves Internal Orientation 
TABLE XVII

ANALYSES OF COVARIANCE: COVARIATE CONTRIBUTIONS TO INTRAORGANIZATIONAL DECISION MAKING CRITERIA, $\mathrm{p}<.10$

\begin{tabular}{|c|c|c|c|}
\hline & \multicolumn{3}{|c|}{ Decision Making Criteria } \\
\hline & $\begin{array}{c}\text { Agency } \\
\text { Enhancement }\end{array}$ & Autonomy & $\begin{array}{c}\text { Internal } \\
\text { Orientation }\end{array}$ \\
\hline \multicolumn{4}{|l|}{$\begin{array}{l}\text { Organizational } \\
\text { Resources }\end{array}$} \\
\hline $\begin{array}{l}\text { Organizational } \\
\text { Goal }\end{array}$ & $\begin{array}{c}F=5.645, d f=2,137 \\
p<.004\end{array}$ & $\begin{array}{c}\mathrm{F}=4.322, \mathrm{df}=2,137 \\
\mathrm{p}<\mathrm{0} 015\end{array}$ & $\begin{array}{c}\mathrm{F}=4.273, \mathrm{df}=2,137 \\
\mathrm{p}<.016\end{array}$ \\
\hline Broker & $\begin{array}{c}F=8.426, d f=1,137 \\
p<.004\end{array}$ & $\begin{array}{c}F=3.829, d f=1,137 \\
p<.052\end{array}$ & $\begin{array}{c}\mathrm{F}=5.237, d \mathrm{df}=1,137 \\
\mathrm{p}<.024\end{array}$ \\
\hline $\begin{array}{r}\text { Direct } \\
\text { Service }\end{array}$ & $\begin{array}{c}F=.333, d f=1,137 \\
p<.565\end{array}$ & $\begin{array}{c}F=.174, \quad d f=1,137 \\
p<.677\end{array}$ & $\begin{array}{c}F=.886, \quad d f=1,137 \\
p<.492\end{array}$ \\
\hline $\begin{array}{l}\text { Local Public } \\
\text { Uncertainty }\end{array}$ & & & $\begin{array}{c}F=3.626, d f=1,119 \\
p<.059\end{array}$ \\
\hline $\begin{array}{l}\text { State and } \\
\text { Federal } \\
\text { Uncertainty }\end{array}$ & $\begin{array}{c}F=7.081, d f=1,124 \\
p<.009\end{array}$ & & $\begin{array}{c}F=3.606, \quad d f=1.124 \\
p<.060\end{array}$ \\
\hline \multicolumn{4}{|l|}{$\begin{array}{l}\text { Clients } \\
\text { Uncertainty }\end{array}$} \\
\hline $\begin{array}{l}\text { Interorgani- } \\
\text { zational } \\
\text { Uncertainty }\end{array}$ & $\begin{array}{c}F=3.391, \quad d f=1,122 \\
p<.068\end{array}$ & & $\begin{array}{c}F=4.848, d f=1.122 \\
p<.030\end{array}$ \\
\hline
\end{tabular}


TABLE XVIII

AGENCY ENHANCEMENT: GRAND MEAN AND COMMUNITY DEVIATIONS BY COVARIATE

\begin{tabular}{|c|c|c|c|c|c|c|c|}
\hline & $\begin{array}{c}\text { With } \\
\text { No } \\
\text { Covariates }\end{array}$ & $\begin{array}{l}\text { With } \\
\text { Organiza- } \\
\text { tional } \\
\text { Resources }\end{array}$ & $\begin{array}{l}\text { With } \\
\text { Organiza- } \\
\text { tional } \\
\text { Goal } \\
\end{array}$ & $\begin{array}{l}\text { With } \\
\text { Local } \\
\text { Public } \\
\text { Uncer- } \\
\text { tainty }\end{array}$ & $\begin{array}{l}\text { With } \\
\text { State \& } \\
\text { Federal } \\
\text { Uncer- } \\
\text { tainty }\end{array}$ & $\begin{array}{l}\text { With } \\
\text { client } \\
\text { Uncer- } \\
\text { tainty }\end{array}$ & $\begin{array}{c}\text { with } \\
\text { Interorgani- } \\
\text { zational } \\
\text { Uncer- } \\
\text { tainty }\end{array}$ \\
\hline GRAND MEAN & 17.78 & 17.78 & 17.78 & 17.60 & 17.79 & 17.80 & 17.79 \\
\hline \multicolumn{8}{|l|}{$\begin{array}{l}\text { DEVIATIONS FROM } \\
\text { GRAND MEAN }\end{array}$} \\
\hline San Bernardino & -.03 & -.03 & -.03 & -.04 & -.01 & .08 & .06 \\
\hline Tacoma & .50 & .50 & .50 & .11 & .67 & .50 & .80 \\
\hline Las Vegas & -1.43 & -1.31 & -1.43 & -1.47 & -1.66 & -1.45 & -1.12 \\
\hline Tucson & 1.00 & 1.00 & 1.00 & 1.30 & 1.45 & .97 & 1.17 \\
\hline Boulder & .66 & .67 & .66 & .35 & -.25 & .64 & -.20 \\
\hline Salt Lake City & -.84 & -.97 & -.84 & -.30 & -.48 & -.86 & -.96 \\
\hline $\mathrm{p}<$ & .365 & .358 & .143 & .542 & .350 & .381 & .429 \\
\hline$F=$ & 1.096 & 1.111 & 1.681 & .814 & 1.126 & 1.069 & .987 \\
\hline $\mathrm{df}=$ & 5,139 & 5,133 & 5,137 & 5,119 & 5,124 & 5,134 & 5,122 \\
\hline
\end{tabular}




\section{TABLE XIX}

AUTONOMY: GRAND MEAN AND COMMUNITY DEVIATIONS BY COVARIATE

\begin{tabular}{|c|c|c|c|c|c|c|c|}
\hline & $\begin{array}{c}\text { With } \\
\text { No } \\
\text { Covariates } \\
\end{array}$ & $\begin{array}{l}\text { With } \\
\text { Organiza- } \\
\text { tional } \\
\text { Resources }\end{array}$ & $\begin{array}{l}\text { With } \\
\text { Organiza- } \\
\text { tional } \\
\text { Goal } \\
\end{array}$ & $\begin{array}{l}\text { With } \\
\text { Local } \\
\text { Public } \\
\text { Uncer- } \\
\text { tainty }\end{array}$ & $\begin{array}{l}\text { With } \\
\text { State \& } \\
\text { Federal } \\
\text { Uncer- } \\
\text { tainty }\end{array}$ & $\begin{array}{l}\text { With } \\
\text { client } \\
\text { Uncer- } \\
\text { tainty }\end{array}$ & $\begin{array}{c}\text { With } \\
\text { Interorgani- } \\
\text { zational } \\
\text { Uncer- } \\
\text { tainty }\end{array}$ \\
\hline GRAND MEAN & 6.28 & 6.28 & 6.28 & 6.19 & 6.32 & 6.33 & 6.41 \\
\hline \multicolumn{8}{|l|}{$\begin{array}{l}\text { DEVIATIONS FROM } \\
\text { GRAND MEAN }\end{array}$} \\
\hline San Bernardino & -.28 & -.28 & -.28 & -.15 & -.21 & -.25 & -.30 \\
\hline Tacoma & -.35 & -.32 & -.35 & -.19 & -.32 & -.25 & -.21 \\
\hline Las Vegas & .51 & .66 & .51 & .53 & .66 & .46 & .47 \\
\hline Tucson & .59 & .59 & .59 & .71 & .30 & .54 & .59 \\
\hline Boulder & -.38 & -.37 & -.38 & -.58 & -.25 & -.43 & -.35 \\
\hline salt Lake city & .05 & -.15 & .05 & -.29 & -.09 & .00 & -.11 \\
\hline $\mathrm{p}<$ & .650 & .743 & .690 & .669 & .814 & .795 & .696 \\
\hline $\mathbf{F}=$ & .666 & .544 & .613 & .641 & .448 & .475 & .605 \\
\hline $\mathrm{df}=$ & 5,139 & 5,133 & 5,137 & 5,119 & 5,124 & 5,134 & 5,122 \\
\hline
\end{tabular}


TABLE XX

INTERNAL ORIENTATION: GRAND MEAN AND COMMUNITY DEVIATIONS BY COVARIATE

\begin{tabular}{|c|c|c|c|c|c|c|c|}
\hline & $\begin{array}{c}\text { With } \\
\text { No } \\
\text { Covariates } \\
\end{array}$ & $\begin{array}{c}\text { With } \\
\text { Organiza- } \\
\text { tional } \\
\text { Resources } \\
\end{array}$ & $\begin{array}{l}\text { With } \\
\text { Organiza- } \\
\text { tional } \\
\text { Goal } \\
\end{array}$ & $\begin{array}{l}\text { With } \\
\text { Local } \\
\text { Public } \\
\text { Uncer- } \\
\text { tainty }\end{array}$ & $\begin{array}{l}\text { With } \\
\text { State \& } \\
\text { Federal } \\
\text { Uncer- } \\
\text { tainty }\end{array}$ & $\begin{array}{l}\text { With } \\
\text { Client } \\
\text { Uncer- } \\
\text { tainty }\end{array}$ & $\begin{array}{l}\text { With } \\
\text { Interorgani- } \\
\text { zational } \\
\text { Uncer- } \\
\text { tainty }\end{array}$ \\
\hline GRAND MEAN & 30.35 & 30.33 & 30.35 & 30.33 & 30.45 & 30.43 & 30.44 \\
\hline \multicolumn{8}{|l|}{$\begin{array}{l}\text { DEVIATIONS FROM } \\
\text { GRAND MEAN }\end{array}$} \\
\hline San Bernardino & -.60 & -.58 & -.60 & -.59 & -.52 & -.43 & -.55 \\
\hline Tacoma & .07 & -.01 & .07 & -.07 & .47 & .11 & .72 \\
\hline Las Vegas & -1.03 & -.74 & -1.03 & -.82 & -1.16 & -1.10 & -.62 \\
\hline Tucson & 1.18 & 1.20 & 1.18 & 1.48 & 1.46 & 1.10 & 1.44 \\
\hline Boulder & 1.23 & 1.26 & 1.23 & .70 & .42 & 1.16 & .26 \\
\hline Salt Lake City & -.69 & -.98 & -.69 & -.51 & -.54 & -.76 & -1.19 \\
\hline $\mathrm{p}<$ & .787 & .726 & .492 & .883 & .929 & .840 & .761 \\
\hline$F=$ & .485 & .566 & .886 & .347 & .270 & .411 & .519 \\
\hline $\mathrm{df}=$ & 5,139 & 5,133 & 5,137 & 5,119 & 5,124 & 5,134 & 5,122 \\
\hline
\end{tabular}


$(F=3.625, d f=1,119, p<.059)$.

State and Federal Uncertainty reflects one statistically significant relation, with Agency Enhancement ( $F=7.081, d f=1,124, p<.009)$. This uncertainty measure also shares a statistically non-significant relation with Internal Orientation ( $F=3.606, d f=1,124, p<.060)$. Interorganizational Uncertainty is involved in a single statistically significant association, with Internal orientation $(F-4.848 ; d f=1,122 ; p<.030)$. It additionally evidences a nonsignificant rleation with Agency Enhancement $(F=3.391 ; d f=1,122$; $p<.068)$

In sum, Community is not indicated through these analyses of covariance to be associated systematically with any of the Intraorganizational Decision Making Criteria, though certain of the selected organizational variables do evidence associations. Organizational Goal shares statistically significant associations with all of the intraorganizational criterion measures, state and Federal Uncertainty is related to Agency Enhancement, and Interorganizational Uncertainty is associated with Internal orientation.

\section{Multiple Regression Analysis}

The multiple regression analyses to be reported were implemented using the step-wise option provided in the sPSS package (Nie et al., 1972). For the purposes of this series of analyses, all variables were left in their original state (see Chapter 4) except for Organizational Goal and Community. These were "dummied" through standard techniques (Miller and Erickson, 1974; Blalock, 1972; 
Nie et al., 1975).

As mentioned above, the stepwise multiple regression feature of the SPSS package was employed in the analysis. Variables were entered into these analyses in two discrete steps. First, all organizational variables (Organizational Resources, Organizational Goal, and the four Organizational Uncertainty measures) were entered as a bloc of covariate measures. Within the group, the SPSS program entered variables in the order of their contributions to variance. When all organizational variables (covariates) had been entered or deleted through the program's default option, the cities were entered simultaneously as a group.

The SPSS program does not offer a statistic to measure the aggregated contribution to variance of grouped, separate variables. This is an important deletion for the purposes of this study, for primary interest is focused on the performance of the cities as a group, and not each individually. In order to address this shortcoming, an $F$ value was computed for the contribution of Community to each formulation, as follows.

$$
F=\frac{\left(S S_{R_{i 2}}-s S_{R_{i 1}}\right) /\left(d f_{i 2}-d f_{i 1}\right)}{\left(s S_{\text {res }_{i 2}} / d f_{i 2}\right)}
$$

where

$$
\begin{aligned}
& F= F \text { value } \\
& \mathrm{SS}_{\mathrm{R}_{\mathrm{i}}}= \begin{array}{l}
\text { regression sum of squares immediately } \\
\text { after entering the Community variable. }
\end{array} \\
& \mathrm{SS}_{\mathrm{R}_{i 1}=} \begin{array}{l}
\text { regression sum of squares immediately } \\
\text { prior to entering the community variable. }
\end{array} \\
& \mathrm{df}_{\mathrm{i} 2=} \begin{array}{l}
\text { degrees of freedom immediately after } \\
\text { entering the Community variable. }
\end{array}
\end{aligned}
$$




$$
\begin{aligned}
\quad \mathrm{df}_{i 1}= & \begin{array}{l}
\text { degrees of freedom immediately prior } \\
\text { to entering the Community variable. }
\end{array} \\
\text { SS }_{\text {resi2 }}= & \begin{array}{l}
\text { residual sum of squares immediately } \\
\text { after entering the Community variable. }
\end{array}
\end{aligned}
$$

This statistic allows the treatment of all cities as a group, and is further recommended through its compatability with easily accessible and understood $F$ tables.

Employing these procedures, each of the Intraorganizational Criterion measures was employed as dependent variable in one of a series of three multiple regression analyses. Results of these analyses are reported in the following pages and in Appendix II in terms of the dependent variables employed in each analysis.

1. Agency Enhancement. Tables XXI and XXII summarize the results of the multiple regression analysis employing Agency Enhancement as a dependent variable.

Only two covariates evidence statistically significant associations. The Broker Agency component of Organizational Goal reflects the strongest association with Agency Enhancement, reflecting a weaker orientation toward Agency Enhancement than is evidenced among Advocate Agencies.

The second covariate found to be significantly related to Agency Enhancement is State and Federal Uncertainty. The relation is direct, indicating that increased turbulence at those echelons is accompanied by increased orientation among service agencies toward organizational welfare maximization.

As reflected in Tables XXI and XXII, variation between communities contributes little to the explanation of variance in Agency 
TABLE XXI

SUMMARY OF MULTIPLE REGRESSION ANALYSIS, AGENCY ENHANCEMENT AS DEPENDENT VARIABLE 18

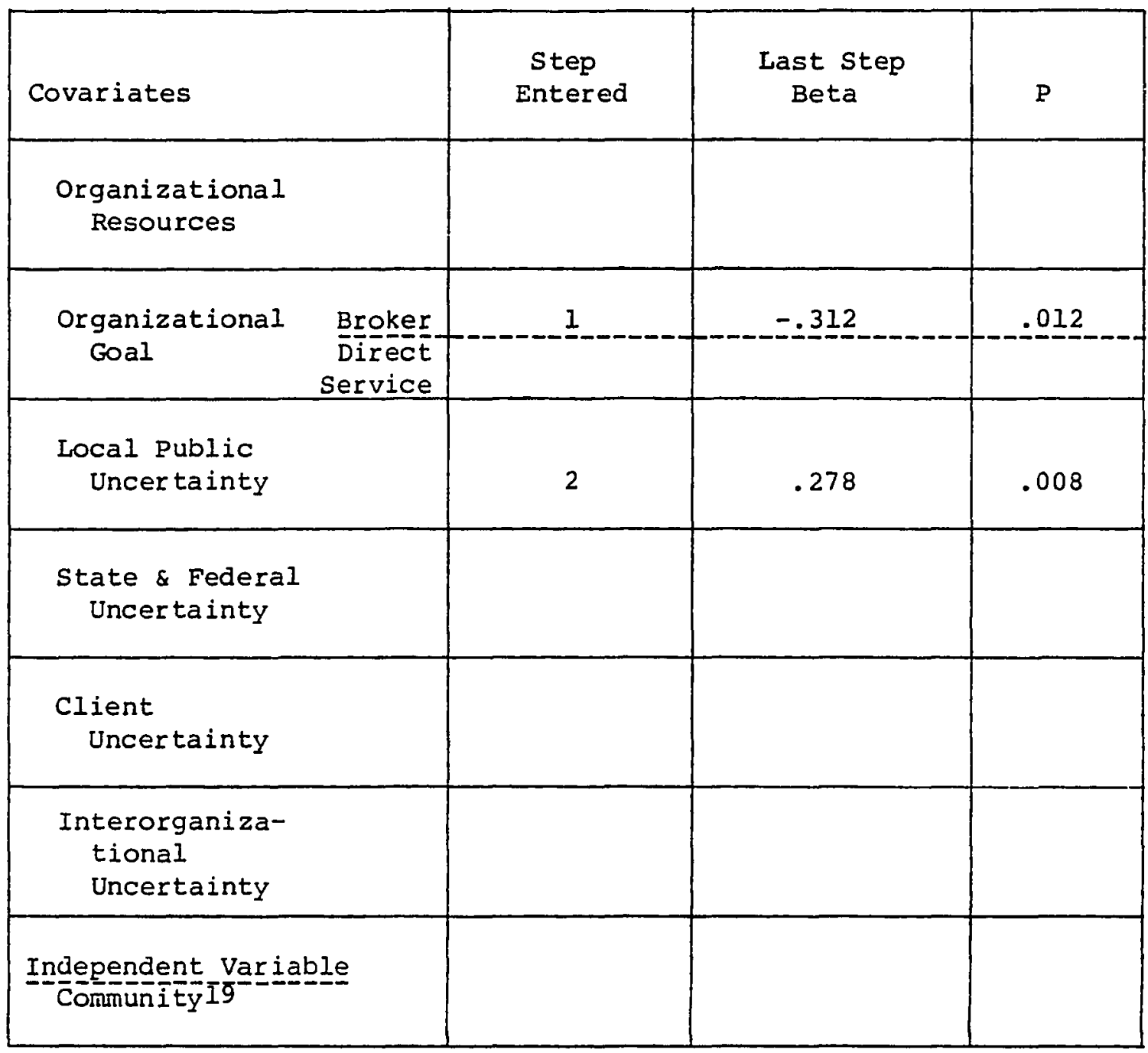

${ }^{18}$ Only independent variables with last step $\mathrm{p}<.10$ are included.

${ }^{19}$ Community was programmed to be the last variable entered into the analysis. 
TABLE XXII
MULTIPLE REGRESSION ANALYSIS BETA VALUES RELATING COMMUNITIES TO SAN BERNARDINO 20
AGENCY ENHANCEMENT

\begin{tabular}{|cc|}
\hline Community & Beta \\
\hline Tacoma & -.03 \\
Las Vegas & -.12 \\
Tucson & .03 \\
Boulder & .05 \\
Salt Lake City & -.08 \\
p $~ .684$ & \\
E $=.621$ & \\
df $=12,102$ & \\
\hline
\end{tabular}

${ }^{20}$ Through dummy techniques, betas for each community signify its deviation from associations identified in San Bernardino. 
Enhancement.

As noted above, Agency Enhancement was found in the multiple regression analyses to share associations with Organizational Goal and with State and Federal Uncertainty.

Organizational Goal was found in the analyses of covariance to be significantly associated with all measures of the intraorganizational decision making criteria, although the multiple regression analyses reflect associations only with Agency Enhancement and, as will be reported later, Intraorganizational orientation. This pattern of association undoubtedly reflects the pervasive effects on organizational orientations and operations which separate the different organizational classes represented by classes of this variable. Perhaps nowhere are these differences more apparent than with the types of issues subsumed within Agency Enhancement. When viewed in terms of Waldman's (1972) input and output components, Broker Agencies must be viewed as among the input components of advocacy and direct service agencies: Broker Agencies disperse funds to the others. In the context of the service industry, then, it is realistic to expect Broker Agencies to exhibit a different orientation to funding and related issues than would the other organizational types. The latter, in turn, might well be expected to share relatively similar orientations toward this class of commodity. Both expectations are supported in the data. Broker Agencies reflect an orientation toward Agency Enhancement of significantly lesser strength than is evidenced among the other two classes of agencies. Advocate and Direct Service Agencies, on the other hand, reflect very similar 
views with respect to this class of criterion. While not of direct relevance in this dissertation, Benson's (1975) explication of social exchange theory would lead one to anticipate that intra-systemic power associations would similarly reflect the patters of differentiation encountered in these analyses.

State and Federal Uncertainty is demonstrated to be directly associated with organizational emphasis on Agency Enhancement. As was noted in the early phases of this dissertation, human service agencies typically derive a considerable proportion of their resources from agencies at the state and federal levels. The mean proportion of total agency funding derived from federal sources alone by agencies in this sample, for example, is over 36\%. As such, this finding ties concern over funding and related issues to the inability to predict events among funding sources. This finding is consistent with the work of authors who note strong propensities among organizations to achieve stability, and the work of Benson (1975), Mindlin and Aldrich (1975), and O'Brien and Wetle (1975), who note the importance of funding and related commodities to organizational well-being. In another sense, the finding is consistent with Dill's (1962) concept of task environments. The ties between aging service organizations and state and federal agencies are largely indirect. While the funding derived from these sources is, as noted above, of considerable importance, much of the federal money going to individual agencies is actually dispensed by intermediary, broker agencies. As such, direct contact between service and governmental organizations is likely to be infrequent. That their indirect influence is 
sufficiently strong to be manifested in these analyses and not, as will be noted, in those addressing Autonomy suggests a relatively narrow sphere of influence.

2. Autonomy. As reflected in Tables XXIII and XXIV, neither organizational variables nor Community were found to share statistically significant associations with Autonomy. One organizational variable, Local Public Uncertainty, however, was found to evidence a positive association with Autonomy reflecting a statistical significance of $\mathrm{p}<.09$.

As noted above, only Local public Uncertainty evidences a reportable association with Autonomy, reflecting a direct relation. This result is noteworthy in several respects.

First, the associations between Autonomy and the organizational variables are quite different from those involving Agency Enhancement. This distinction suggests that at least to an extent the two are functionally independent when assessed in terms of environmental influences on the organization. Where the organization's emphasis on Agency Enhancement was found to be influenced by the agency's function and by uncertainty at the state and federal levels, orientation to Autonomy is associated with turbulence of a local nature. This bifurcation of influences is not entirely consistent with Benson's (1975) description of power relationships, which suggests that patterns of funding distribution will be reflected in power relationships between organizations and, conversely, potential loss of Autonomy. Rather, this set of results suggests an operational independence between the two commodities, as is posited 
TABLE XXIII

SUMMARY OF MULTIPLE REGRESSION ANALYSIS, AUTONOMY AS DEPENDENT VARIABLE21

\begin{tabular}{|l|l|l|l|}
\hline Covariates & $\begin{array}{c}\text { Step } \\
\text { Entered }\end{array}$ & $\begin{array}{c}\text { Last Step } \\
\text { Beta }\end{array}$ & $\mathrm{P}$ \\
\hline $\begin{array}{c}\text { Organizational } \\
\text { Resources }\end{array}$ & & \\
\hline $\begin{array}{c}\text { Organizational Broker } \\
\text { Goal } \\
\text { Direct }\end{array}$ & & & \\
\hline $\begin{array}{c}\text { Local Public } \\
\text { Uncertainty }\end{array}$ & 2 & .090 \\
\hline $\begin{array}{c}\text { State \& Federal } \\
\text { Uncertainty }\end{array}$ & & \\
\hline $\begin{array}{c}\text { Client } \\
\text { Uncertainty }\end{array}$ & & \\
\hline $\begin{array}{c}\text { Interorganiza- } \\
\text { tional } \\
\text { Uncertainty }\end{array}$ & & \\
\hline $\begin{array}{c}\text { Independent Variable } \\
\text { Community22- }\end{array}$ & & \\
\hline
\end{tabular}

${ }^{21}$ Only independent variables with last step $p<.10$ are included.

${ }^{22}$ Community was programmed to be the last variable entered into the analysis. 
TABLE XXIV

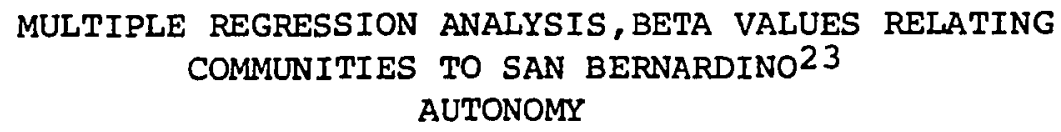

\begin{tabular}{|lc|}
\hline Community & Beta \\
\hline Tacoma & .00 \\
Las Vegas & .14 \\
Tucson & .12 \\
Boulder & .04 \\
Salt Lake City & .04 \\
p $<.789$ & \\
$F=.482$ & \\
df $=12,102$ & \\
\hline
\end{tabular}

${ }^{23}$ Through dummy techniques, betas for each community signify its deviation from associations identified in San Bernardino. 
by O'Brien and wetle (1975). This, in turn, suggests that the operational realities facing human service agencies involve not only the balancing of expenditures and acquisitions, as suggested by the notion of utility functions, but that the "markets" within which the transactions take place are distinct. This is generally consistent with the writings of Dill (1962) and Gawthrop (1969) through the linkage of certain of the commodities with specific task environments. A second source of significance in this finding lies in the nature of the local entity with which autonomy is related. Local Public Uncertainty is associated generally with the local output component, to borrow Waldman's term (1972). That the local output component, Client Uncertainty, is not represented in this body of findings is supportive of Waldman's dichotomy of organizational environments. In this context, the association suggests that local input into the operational endeavors of local service agencies can exist in lieu of total control over monetary resources through, presumably, threats to or enhancement of agency autonomy. Again, the independence of Autonomy is a valued resource in itself is supported.

3. Internal orientation. As shown in Tables XXV and XXVI, the overall aggregate of the intraorganizational measures, Internal Orientation, was found to share statistically significant associations with none of the independent variables, though it does evidence nonsignificant associations with three organizational variables.

The Broker Agency component of Organizational Goal was the first variable entered into the equation, though it proved ultimately not to be the strongest in its association, with a last-step beta significant 
TABLE XXV

SUMMARY OF MULTIPLE REGRESSION ANALYSIS, INTERNAL ORIENTATION AS DEPENDENT VARIABLE 24

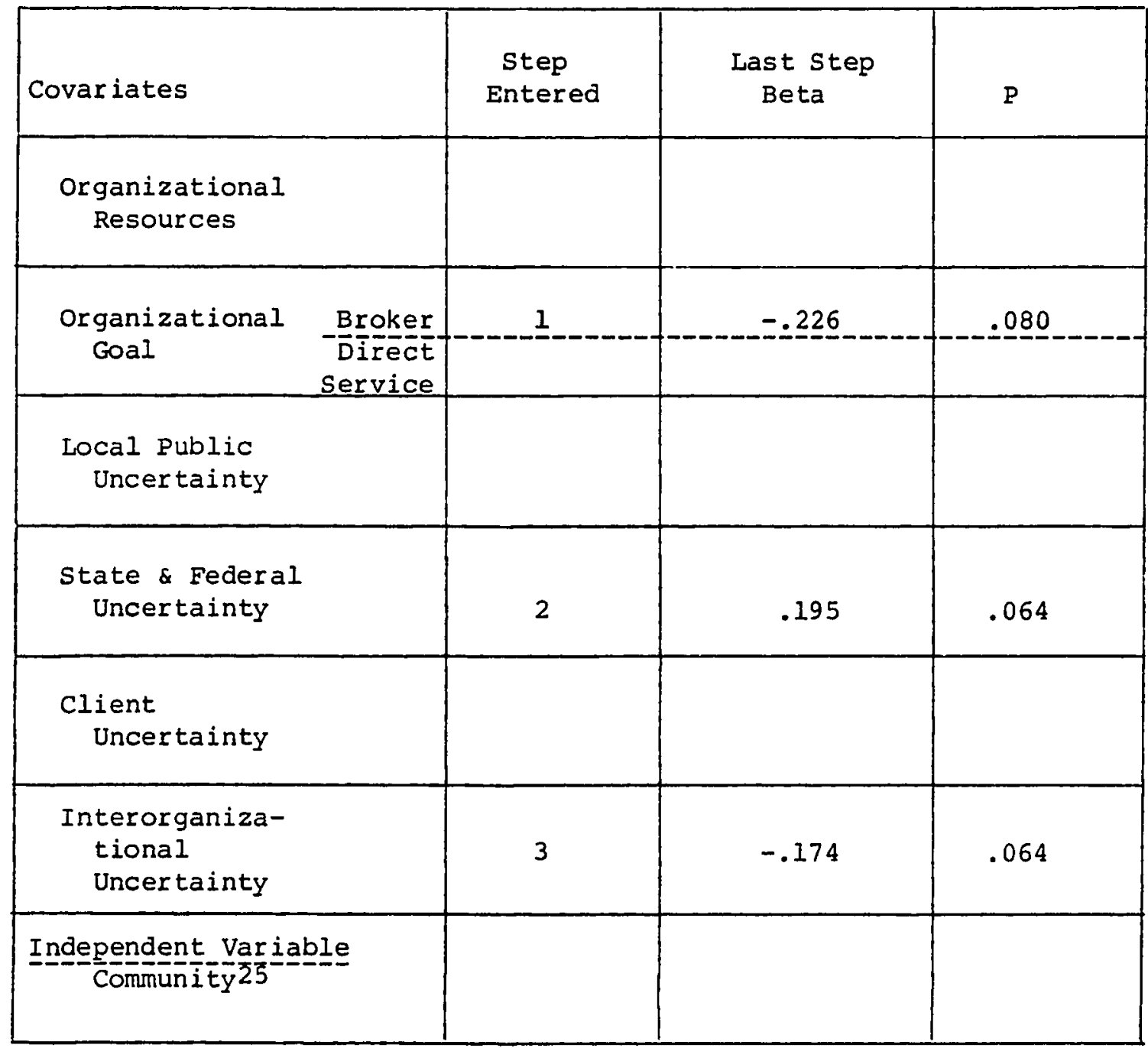

24 Only independent variables with last step $p<.10$ are included. ${ }^{25}$ Community was programmed to be the last variable entered into the analysis. 
TABLE XXVI

MULTIPLE REGRESSION ANALYSIS, BETA VALUES RELATING COMMUNITIES TO SAN BERNARDINO 26

INTERNAL ORIENTATION

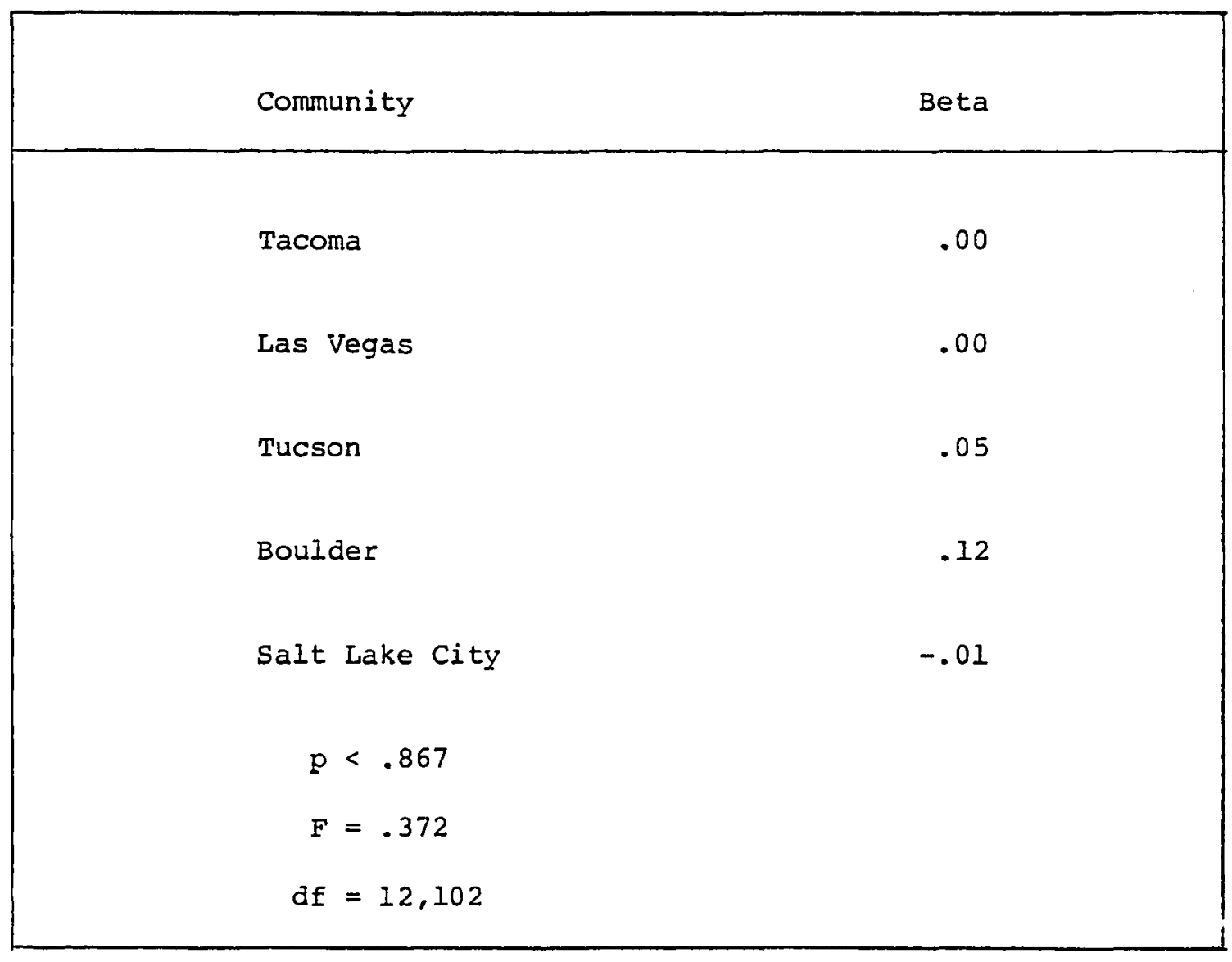

26 Through dummy techniques, betas for each community signify its deviation from associations identified in san Bernardino. 
at $p<.080$.

State and Federal Uncertainty is indicated to be directly associated with Internal Orientation, with an alpha of .064 .

Interorganizational Uncertainty also reflects a non-significant $(p<.064)$ association with Internal orientation. Indicated to be a negative association, this relation would indicate that as stability in the local service inudstry increases, agencies' proclivities toward maximizing their own welfare decrease.

Patterns evidenced in the analytical results reported above suggest that the first two of the three associations reflect in large degree the construction of Internal orientation. As noted in Chapter IV, Internal orientation is a summative scale comprised of all items contained in Instrument 1. As such, it includes the other two intraorganizational criterion measures which are selectively comprised of certain of the items from Instrument 1. Accordingly, Internal Orientation can be expected to evidence to a lesser extent those associations primarily involving variance in the items comprising the other two, more selectively constructed intraorgaizational measures. This possibility appears to be the case with associations involving Organizational Goal and Autonomy. Both independent variables were found more strongly associated with other intraorganizational criteria than with Internal orientation.

The association relating Internal orientation and Interorganizational Uncertainty, however, is independent of associations with other intraorganizational measures. A negative association, it signifies that greater Interorganizational Uncertainty is associated with lesser 
organizational emphasis on intraorganizational measures of success. This result is largely inconsistent with writings in the field of organizational analysis. Benson (1975), for example, posits that organizations in a system compete with one another for necessary resources. Under these circumstances one would anticipate greater emphasis on intraorganizational well-being as the interorganizational field becomes less predictable.

It is clear that some alternative explanation for this finding is necessary. First, it is appropriate to note again that the more explicit measures of intraorganizational well-being, Agency Enhancement and Autonomy, were not similarly related to Intraorganizational Uncertainty, although together they comprise a major component of Internal orientation. Three additional measures from Instrument 1 contribute to Internal orientation, addressing orientations to expand the range of agency services offered, the avoidance of activities not consistent with agency goals, and the furthering of the wishes of agency directors. From these, it would appear that the operational conservatism evident in this association may well be associated with organizational orientations toward alterations in domain as they might be expected to relate to interorganizational stability. To the extent that domain comprises an organizational characteristic of importance in associations with outside agencies as well as with other environmental components, the advent of interorganizational uncertainty might well be expected to generate an element of conservatism toward change of any type in domain. In short, reduced orientation toward Internal Orientation during times of heightened 
interorganizational uncertainty may well represent a compensatory behavior by organizations in the pursuit of a more stable interorganizational field.

\section{A Word About Community}

In no analyses was Community found to be an effective predictor of organizational emphasis on an intraorganizational decision making criterion.

These findings suggest that orientation to intraorganizational measures of success is derived from sources other than local environments. The fact that no meaningful intercommity differences were found directs attention to levels of social aggregation larger than the locale. While regional factors could produce such a pattern of results (all cities, it will be recalled, are situated in the American west), there exist a number of theoretical bases for ascribing these orientations to broader societal levels of national or larger scale. Microeconomic theory constitutes one basis for this expectation. The profit motivation as developed by Smith (1909) and Marshall (1948) is a common drive associated with all profit-oriented organizations. While no measures employed in these analyses directly reflect profit-indeed, very few organizations in the sample are profit-oriented--the parallels developed by subsequent authors would support the generalization of profit-related behavior to other classes of organizational goals. Organizational pursuits of growth (Niskanen, 1968; Galbraith, 1967), security (Schramm and Sherman, 1974), consistency (Monsen and Downs, 1965), managerial benefits (0. Williamson, 1964), and revenue maximization (Baumol, 1967) are all supported by reasoning which 
parallels those employed by earlier economists in support of profit maximization.

The literature on Community also provides general support for this pattern of results. The nesting of areal objects of identification suggested by MacIver (1970), Janowitz (1952), Hillery (1968), and others draws attention to the potential for influences born of higher levels of aggregation manifesting themselves throughout smaller aggregates. In this context, organizational motivations emanating from sources of national or higher scale could be expected to be reflected to greater or lesser degree among organizations throughout the nation. Warren (1963) and Coleman (1957) both suggest that the influence of local conditions is in large part predicated on the absence of competing extralocal influences on organizational behavior. In the case of the intraorganizational decision making criteria, it is apparent that extralocal value orientations predominate.

\section{Extraorganizational Criteria}

As was the case with the Intraorganizational Criteria discussed in the preceding pages, all measures of Extraorganizational Criteria were analyzed through three distinct analytical processes: analysis of variance with Community as independent variable, analysis of covariance employing each of the Organizational variables as covariates with Community as independent variable, and multiple regression analysis employing the organizational Variables as a set of independent variables and Community as the independent variable entered last into the analysis. 
It will be recalled that where the Intraorganizational Criteria were operationalized through three composite measures, the Extraorganizational Criteria were operationalized through five aggregate measures: three are factor-based and one is an overall aggregate. These measures share their derivations with those representing the intraorganizational measures. An additional index was developed from the items of Instrument 2 in order to assess a type of organizationalenvironmental interaction not evidenced through factor analysis.

\section{Analysis of Variance}

Table XXVII summarizes the analyses of variance relating Community to the extraorganizational variables. The results of these analyses are more fully presented in Appendix II.

It is apparent that Community does not reflect statistically significant associations with any of the five measures of extraorganizational decision making criteria. Only one association, that relating Community to Outside Input, registers a probability level of better than $\mathrm{p}<.10$.

Analysis of variance, then, does not in itself produce results which are supportive of the study's second hypothesis, relating different performance orientations to the different communities.

\section{Analysis of Covariance}

As with the analyses of intraorganizational criteria reported earlier, this stage of analysis assesses the degree to which community differences explain variance in the five measures of Extraorganizational Decision Making Criteria, while controlling individually for 
TABLE XXVII

ANALYSIS OF VARIANCE: GRAND MEAN AND COMMUNITY DEVIATIONS FROM GRAND MEAN BY EXTRAORGANIZATIONAL DEPENDENT VARIABLE

\begin{tabular}{|c|c|c|c|c|c|}
\hline & $\begin{array}{l}\text { Instrumental } \\
\text { Coordination }\end{array}$ & $\begin{array}{l}\text { Expressive } \\
\text { Coordination }\end{array}$ & $\begin{array}{l}\text { Outside } \\
\text { Input }\end{array}$ & Exclusion & $\begin{array}{c}\text { External } \\
\text { Orientation }\end{array}$ \\
\hline Grand Mean & 6.87 & 6.66 & 3.24 & 7.51 & 21.04 \\
\hline San Bernardino & .36 & .42 & .38 & .31 & 1.09 \\
\hline Tacoma & .16 & .06 & .01 & -.74 & -.52 \\
\hline Las Vegas & 1.08 & .68 & .23 & -.11 & 1.65 \\
\hline Tucson & -.52 & .30 & .15 & -.18 & -.40 \\
\hline Boulder & -.54 & -.94 & -.67 & .85 & -.63 \\
\hline Salt Lake City & -.58 & -.61 & -.20 & .03 & -1.17 \\
\hline $\mathrm{p}<$ & .159 & .160 & .096 & .345 & .353 \\
\hline
\end{tabular}


each of the six organizational variables. In all, 30 separate analyses of covariance were implemented. The full results of these analyses are reflected in Appendix II, and are summarized in Tables XXVIII - XXXIII.

In general, it can be said the community is a more effective predictor of extraorganizational criteria than of intraorganizational criteria. Where Community did not reflect an association with an intraorganizational criterion sufficiently strong to generate an alpha of less than .10, in 11 cases among the extraorganizational criteria associations reflect this probability level and in three cases statistical significance exceeds $p<.05$.

Expressive Coordination constitutes the criterion where the association appears to be strongest, for Community registers two statistically significant associations with this measures (with Organizational Goal, $F=2.618, \mathrm{~d} f=5,139, \mathrm{p}<.027$; and with Interorganizational Uncertainty, $F=2.716, d f=5,124, p<.024)$.

The third significant association is evidenced between Community and Outside Input, with Organizational Goal as the covariate $(F=2.41$, $\mathrm{df}=5,139, \mathrm{p}<.039)$. In addition, three non-significant associations are indicated between Community and Outside Input (with Organizational Resources, $F=1.970, d f=5,133, p<.087$; with State and Federal Uncertainty, $F=1.987, d f=5,124, p<.085$; and with Interorganizational Uncertainty, $F=2.085, d f=5,124, p<.078)$.

Two additional extraorganizational criterion measures are linked to Community through associations reflecting alpha levels between .05 and .10 . 
TABLE XXVIII

ANALYSIS OF COVARIANCE: COVARIATE CONTRIBUTIONS TO EXTRAORGANIZATIONAL DECISION MAKING CRITERIA, p<. 10

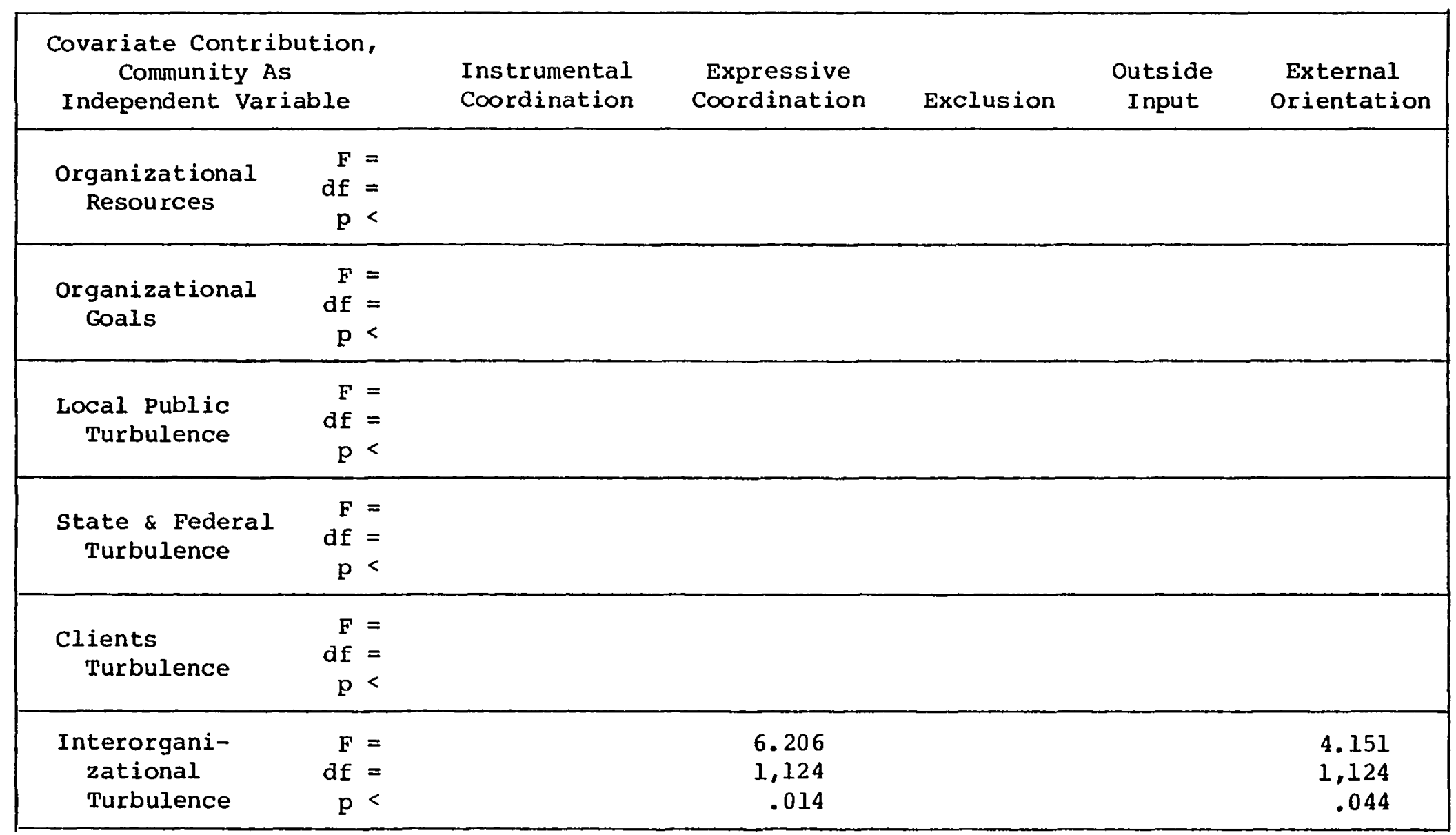


TABLE XXIX

INSTRUMENTAL COORDINATION: GRAND MEAN AND COMMUNITY DEVIATION BY COVARIATE

\begin{tabular}{|c|c|c|c|c|c|c|c|}
\hline & $\begin{array}{c}\text { With } \\
\text { No } \\
\text { Covariates }\end{array}$ & $\begin{array}{c}\text { With } \\
\text { Organiza- } \\
\text { tional } \\
\text { Resources }\end{array}$ & $\begin{array}{c}\text { With } \\
\text { Organiza- } \\
\text { tional } \\
\text { Goal } \\
\end{array}$ & $\begin{array}{l}\text { With } \\
\text { Local } \\
\text { Public } \\
\text { Uncer- } \\
\text { tainty } \\
\end{array}$ & $\begin{array}{l}\text { With } \\
\text { State \& } \\
\text { Federal } \\
\text { Uncer- } \\
\text { tainty } \\
\end{array}$ & $\begin{array}{l}\text { With } \\
\text { Client } \\
\text { Uncer- } \\
\text { tainty }\end{array}$ & $\begin{array}{c}\text { With } \\
\text { Interorgani- } \\
\text { zational } \\
\text { Uncer- } \\
\text { tainty } \\
\end{array}$ \\
\hline GRAND MEAN & 6.87 & 6.93 & 6.93 & 6.88 & 7.01 & 6.87 & 6.98 \\
\hline \multicolumn{8}{|l|}{$\begin{array}{l}\text { DEVIATIONS FROM } \\
\text { GRAND MEAN }\end{array}$} \\
\hline San Bernardino & .36 & .30 & .30 & .38 & .30 & .46 & .33 \\
\hline Tacoma & .16 & .31 & .11 & .37 & .18 & .09 & .10 \\
\hline Las Vegas & 1.08 & 1.17 & 1.29 & .91 & 1.09 & 1.08 & 1.16 \\
\hline Tucson & -.52 & -.58 & -.58 & -.73 & -.54 & -.52 & -.43 \\
\hline Boulder & -.54 & -.60 & -.60 & -.43 & -.34 & -.54 & -.75 \\
\hline Salt Lake City & -.58 & -.58 & -.64 & -.68 & -.83 & -.58 & -.78 \\
\hline$p<$ & .159 & .087 & .075 & .229 & .190 & .157 & .116 \\
\hline $\mathrm{F}=$ & 1.620 & 1.973 & 2.053 & 1.400 & 1.515 & 1.627 & 1.811 \\
\hline$d f=$ & 5,139 & 5,133 & 5,139 & 5,119 & 5,124 & 5,134 & 5,124 \\
\hline
\end{tabular}




\section{TABLE XXX}

EXPRESSIVE COORDINATION: GRAND MEAN AND COMMUNITY DEVIATION BY COVARIATE

\begin{tabular}{|c|c|c|c|c|c|c|c|}
\hline & $\begin{array}{c}\text { With } \\
\text { No } \\
\text { Covarlates } \\
\end{array}$ & $\begin{array}{l}\text { With } \\
\text { Organiza- } \\
\text { tional } \\
\text { Resources } \\
\end{array}$ & $\begin{array}{l}\text { With } \\
\text { Organiza- } \\
\text { tional } \\
\text { Goal } \\
\end{array}$ & $\begin{array}{l}\text { With } \\
\text { Local } \\
\text { Public } \\
\text { Uncer- } \\
\text { tainty }\end{array}$ & $\begin{array}{l}\text { With } \\
\text { State \& } \\
\text { Federal } \\
\text { Uncer- } \\
\text { tainty }\end{array}$ & $\begin{array}{l}\text { With } \\
\text { Client } \\
\text { Uncer- } \\
\text { tainty }\end{array}$ & $\begin{array}{c}\text { With } \\
\text { Interorgani- } \\
\text { zational } \\
\text { Uncer- } \\
\text { tainty } \\
\end{array}$ \\
\hline GRAND MEAN & 6.66 & 6.66 & 6.79 & 6.73 & 6.69 & 6.61 & 6.83 \\
\hline \multicolumn{8}{|l|}{$\begin{array}{l}\text { DEVIATIONS FROM } \\
\text { GRAND MEAN }\end{array}$} \\
\hline San Bernardino & .42 & .41 & .28 & .47 & .28 & .51 & .28 \\
\hline Tacoma & .06 & .10 & -.07 & .23 & -.07 & -.15 & -.43 \\
\hline Las Vegas & .68 & .74 & 1.34 & .43 & .81 & .72 & 1.35 \\
\hline Tucson & .30 & .29 & .17 & .02 & .27 & .35 & .32 \\
\hline Boulder & -.94 & -.95 & -1.07 & -.73 & -.82 & -.90 & -.89 \\
\hline Salt Lake city & -.61 & -.66 & -.75 & -.63 & -.69 & -.57 & -.88 \\
\hline$p<$ & .147 & .160 & .027 & .424 & .218 & .124 & .023 \\
\hline$F=$ & 1.664 & 1.618 & 2.618 & .995 & 1.430 & 1.768 & 2.716 \\
\hline$d f=$ & 5,139 & 5,133 & 5,139 & 5,119 & 5,124 & 5,134 & 5,124 \\
\hline
\end{tabular}


TABLE XXXI

EXCLUSION: GRAND MEAN AND COMMUNITY

DEVIATION BY COVARIATE

\begin{tabular}{|c|c|c|c|c|c|c|c|}
\hline & $\begin{array}{c}\text { With } \\
\text { No } \\
\text { Covariates } \\
\end{array}$ & $\begin{array}{l}\text { With } \\
\text { Organiza- } \\
\text { tional } \\
\text { Resources }\end{array}$ & $\begin{array}{l}\text { With } \\
\text { Organiza- } \\
\text { tional } \\
\text { Goal } \\
\end{array}$ & $\begin{array}{l}\text { With } \\
\text { Local } \\
\text { Public } \\
\text { Uncer- } \\
\text { tainty }\end{array}$ & $\begin{array}{l}\text { With } \\
\text { State \& } \\
\text { Federal } \\
\text { Uncer- } \\
\text { tainty } \\
\end{array}$ & $\begin{array}{l}\text { With } \\
\text { Client } \\
\text { Uncer- } \\
\text { tainty }\end{array}$ & $\begin{array}{c}\text { With } \\
\text { Interorgani- } \\
\text { zational } \\
\text { Uncer- } \\
\text { tainty }\end{array}$ \\
\hline GRAND MEAN & 7.51 & 7.51 & 7.60 & 7.51 & 7.57 & 7.49 & 7.68 \\
\hline \multicolumn{8}{|l|}{$\begin{array}{l}\text { DEVIATIONS FROM } \\
\text { GRAND MEAN }\end{array}$} \\
\hline San Bernardino & .31 & .31 & .22 & .29 & .28 & .35 & .02 \\
\hline Tacoma & -.74 & -.81 & -.83 & -.46 & -.55 & -.89 & -.66 \\
\hline Las Vegas & -.11 & -.18 & .38 & -.17 & -.15 & -.09 & .25 \\
\hline Tucson & -.18 & -.18 & -.27 & -.13 & -.11 & -.16 & .10 \\
\hline Boulder & .85 & .85 & .76 & .49 & .90 & .87 & .67 \\
\hline Salt Lake City & .03 & .06 & -.06 & .04 & -.07 & .05 & -.13 \\
\hline $\mathrm{p}<$ & .345 & .340 & .360 & .759 & .581 & .207 & .607 \\
\hline$F=$ & 1.134 & 1.144 & 1.106 & .523 & .760 & 1.462 & .723 \\
\hline$d f=$ & 5,139 & 5,133 & 5,139 & 5,119 & 5,124 & 5,134 & 5,124 \\
\hline
\end{tabular}


TABLE XXXII

OUTSIDE INPUT: GRAND MEAN AND COMMUNITY DEVIATION BY COVARIATE

\begin{tabular}{|c|c|c|c|c|c|c|c|}
\hline & $\begin{array}{c}\text { With } \\
\text { No } \\
\text { Covariates } \\
\end{array}$ & $\begin{array}{l}\text { With } \\
\text { Organiza- } \\
\text { tional } \\
\text { Resources } \\
\end{array}$ & $\begin{array}{l}\text { With } \\
\text { Organiza- } \\
\text { tional } \\
\text { Goal } \\
\end{array}$ & $\begin{array}{l}\text { With } \\
\text { Local } \\
\text { Public } \\
\text { Uncer- } \\
\text { tainty }\end{array}$ & $\begin{array}{l}\text { With } \\
\text { State \& } \\
\text { Federal } \\
\text { Uncer- } \\
\text { tainty } \\
\end{array}$ & $\begin{array}{l}\text { With } \\
\text { Client } \\
\text { Uncer- } \\
\text { tainty }\end{array}$ & $\begin{array}{c}\text { With } \\
\text { Interorgani- } \\
\text { zational } \\
\text { Uncer- } \\
\text { tainty } \\
\end{array}$ \\
\hline GRAND MEAN & 3.24 & 3.28 & 3.30 & 3.27 & 3.30 & 3.25 & 3.36 \\
\hline \multicolumn{8}{|l|}{$\begin{array}{l}\text { DEVIATIONS FROM } \\
\text { GRAND MEAN }\end{array}$} \\
\hline San Bernardino & .38 & .34 & .33 & .39 & .38 & .38 & .32 \\
\hline Tacoma & .01 & .08 & -.05 & .10 & -.03 & .06 & -.08 \\
\hline Las Vegas & .23 & .27 & .49 & .20 & .25 & .22 & .46 \\
\hline Tucson & .15 & .11 & .10 & .13 & .22 & .14 & .19 \\
\hline Boulder & -.67 & -.71 & -.72 & -.61 & -.70 & -.68 & -.66 \\
\hline Salt Lake city & -.20 & -.20 & -.25 & -.37 & -.39 & -.21 & -.46 \\
\hline $\mathrm{p}<$ & .096 & .087 & .039 & .160 & .085 & .105 & .072 \\
\hline$F=$ & 1.912 & 1.970 & 2.411 & 1.621 & 1.987 & 1.861 & 2.085 \\
\hline $\mathrm{df}=$ & 5,139 & 5,133 & 5,139 & 5,119 & 5,124 & 5,134 & 5,124 \\
\hline
\end{tabular}


TABLE XXXIII

EXTERNAL ORIENTATION: GRAND MEAN AND COMMUNITY DEVIATION BY COVARIATE

\begin{tabular}{|c|c|c|c|c|c|c|c|}
\hline & $\begin{array}{c}\text { With } \\
\text { No } \\
\text { Covariates } \\
\end{array}$ & $\begin{array}{l}\text { With } \\
\text { Organiza- } \\
\text { tional } \\
\text { Resources } \\
\end{array}$ & $\begin{array}{l}\text { with } \\
\text { Organiza- } \\
\text { tional } \\
\text { Goal } \\
\end{array}$ & $\begin{array}{l}\text { With } \\
\text { Local } \\
\text { Public } \\
\text { Uncer- } \\
\text { tainty }\end{array}$ & $\begin{array}{l}\text { With } \\
\text { State \& } \\
\text { Federal } \\
\text { Uncer- } \\
\text { tainty }\end{array}$ & $\begin{array}{l}\text { With } \\
\text { client } \\
\text { Uncer- } \\
\text { tainty }\end{array}$ & $\begin{array}{c}\text { With } \\
\text { Interorgani- } \\
\text { zational } \\
\text { Uncer- } \\
\text { tainty }\end{array}$ \\
\hline GRAND MEAN & 21.04 & 21.32 & 21.04 & 21.12 & 21.27 & 20.97 & 21.50 \\
\hline \multicolumn{8}{|l|}{$\begin{array}{l}\text { DEVIATIONS FROM } \\
\text { GRAND MEAN }\end{array}$} \\
\hline San Bernardino & 1.09 & 1.02 & .81 & 1.14 & .86 & 1.32 & .63 \\
\hline Tacoma & -.52 & -.40 & .80 & .14 & -.44 & -.95 & -1.00 \\
\hline Las Vegas & 1.65 & 1.72 & 3.01 & 1.17 & 1.76 & 1.72 & 2.75 \\
\hline Tucson & -.40 & -.47 & -.68 & -.84 & -.38 & -.33 & -.02 \\
\hline Boulder & -.63 & -.69 & -.91 & -.67 & -.27 & -.56 & -.97 \\
\hline salt Lake City & -1.17 & -1.19 & -1.44 & -1.27 & -1.59 & -1.10 & -1.80 \\
\hline $\mathrm{p}<$ & .353 & .341 & .072 & .431 & .351 & .253 & .078 \\
\hline$F=$ & 1.119 & 1.142 & 2.080 & .983 & 1.124 & 1.337 & 2.036 \\
\hline $\mathrm{df}=$ & 5,139 & 5,133 & 5,139 & 5,119 & 5,124 & 5,134 & 5,124 \\
\hline
\end{tabular}


Instrumental Coordination is linked to Community through associations involving two covariates (with organizational Resources, $F=1.973, d f=5,133, p<.087$; and with Organizational Goal, $F=2.053$, $d f=5,139, p<.075)$.

External orientation is similarly linked to Community through associations involving two covariates (with Organizational Goal, $F=2.080, d f=5,139, p<.072$; and with Interorganizational Uncertainty, $F=2.036, d f=5,124, p<.078)$.

Overall, two observations are pertinent with respect to these findings. First, Community evidences a pattern of associations with various of the extraorganizational criteria which support the study's second hypothesis, calling for intercommunity differences with respect to these measures. Second, the study's third hypothesis, calling for greater intercommunity distinctions among the extraorganizational criteria than among the intraorganizational measures, would appear supported through the analyses presented to now.

The covariates themselves present a different pattern. Where, in the analyses with the intraorganizational criteria as dependent variables, the organizational variables were involved in seven reportable associations, they reflect only two such associations with the extraorganizational measures.

Both associations involve Interorganizational Uncertainty, first with Expressive Coordination $(F=6.206, d f=1,124, p<.014)$ and second with External Orientation ( $F=4.151, d f=1,124, p<.044)$. It would appear from these analyses that the organizational variables, unlike Community, are much more effective in predicting 
variation among the Intraorganizational Criteria than among the Extraorganizational measures.

\section{Multiple Regression Analysis}

In accordance with the procedures followed in the analyses of the Intraorganizational Criteria, the final analytical step in the examination of the Extraorganizational Criteria involves multiple regression analysis. As before, all organizational variables were applied to the analysis prior to the addition of the focal variable, Community, through stepwise techniques (Nie et al., 1975). Results of these analyses are fully reported in Appendix II.

The operationalization and treatment of all variables and of the analyses themselves are identical to the practices described earlier for the intraorganizational measures.

1. Instrumental Coordination. Tables XXXIV and XXXV summarize the multiple regression analysis of expressive coordination.

It is apparent that none of the organizational variables entered into the equation evidence statistically significant associations with Instrumental Coordination. Indeed, only two produced statistical significance measures more favorable than $p<.20$, as is reflected in Table LV, Appendix II.

Community also reflects a non-significant association (p<.127). The $F$ test for this association is stronger than any yet encountered in the multiple regression analyses.

As noted above, none of the organizational variables evidence an association with Instrumental Coordination, indicating that 
TABLE XXXIV

SUMMARY OF MULTIPLE REGRESSION ANALYSIS, INSTRUMENTAL COORDINATION AS DEPENDENT VARIABIE 27

\begin{tabular}{|c|c|c|c|}
\hline Covariates & $\begin{array}{l}\text { Step } \\
\text { Entered }\end{array}$ & $\begin{array}{l}\text { Last Step } \\
\quad \text { Beta }\end{array}$ & $\mathrm{P}$ \\
\hline \multicolumn{4}{|l|}{$\begin{array}{l}\text { Organizational } \\
\text { Resources }\end{array}$} \\
\hline Organizational _Broker & & & \\
\hline $\begin{array}{r}\text { Goal } \\
\text { Service }\end{array}$ & & & \\
\hline \multicolumn{4}{|l|}{$\begin{array}{l}\text { Local Public } \\
\text { Uncertainty }\end{array}$} \\
\hline \multicolumn{4}{|l|}{$\begin{array}{l}\text { State \& Federal } \\
\text { Uncertainty }\end{array}$} \\
\hline \multicolumn{4}{|l|}{$\begin{array}{l}\text { Client } \\
\text { Uncertainty }\end{array}$} \\
\hline \multicolumn{4}{|l|}{$\begin{array}{l}\text { Interorgani- } \\
\text { zational } \\
\text { Uncertainty }\end{array}$} \\
\hline 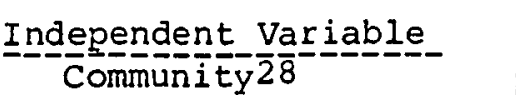 & 6 & -- & .127 \\
\hline
\end{tabular}

${ }^{27}$ only Community and independent variables with last step $p<.10$ are included.

${ }^{28}$ Community was programmed to be the last variable entered into the analysis. 
TABLE XXXV

\section{MULTIPLE REGRESSION ANALYSIS, BETA VALUES RELATING COMMUNITIES TO SAN BERINARDINO29 \\ INSTRUMENTAL COORDINATION}

\begin{tabular}{|cc|}
\hline Community & Beta \\
\hline Tacoma & -.02 \\
Las Vegas & .17 \\
Tucson & -.10 \\
Boulder \\
Salt Lake City \\
$p<.127$ \\
$F=1.761$ \\
df $=10,104$
\end{tabular}

29 Through dummy techniques, betas for each community signify its deviation from associations identified in San Bernardino. 
organizations of all types represented in the organizational variables share common orientations toward this decision making criterion. This universality of orientation toward the substantive coordination of organizational endeavors stands in contrast to differences evidenced in earlier analyses between organizations with different goals and between organizations in different states of environmental turbulence. This absence of differences is noteworthy, for it suggests that at least with respect to this criterion coordinated agencies share their orientations with coordinating organizations. This commonality would bode well for such organizations as Area Agencies on Aging which are charged with systematizing the operations and service offerings of direct service agencies. First, it allows for the early establishment of common orientations with agencies potentially to be included in a service network. It has been noted that this is one means of generating coordination in a service provision network (O'Brien and Wetle, 1978). Second, it promotes the potential inclusion of additional agencies to existing networks through the demonstrability of the network's contribution to operational coordination.

It is additionally noteworthy that no class of environmental turbulence was found to reflect an association with Instrumental Coordination. Where one type of environmental uncertainty was found to share associations with each measure of intraorganizational criteria, no such association is evident in this analysis. As such, organizational orientation to Instrumental Coordination is demonstrated to be largely unassociated with the turbulence measures employed in this dissertation, within the ranges encountered in this data. 
Organizational orientation to Instrumental Coordination, then, is unresponsive to variations in the organizational characteristics and environmental uncertainties addressed in this study.

There is a reasonably good indication, however, that Community affects this class of organizational orientation. Community surfaces as the strongest predictor of organizational emphasis on Instrumental Coordination, though the association is significant at a level of but $p<.127$. There is considerable theoretical support for this type of association. That communities can be differentiated on the basis of identifying characteristics has been posited by a number of authors (Logan, 1976; MacIver, 1970; J. Bernard, 1962), as cited in the dissertation's third chapter. That these distinctions may be expected to reflect in organizational operations within locales has been suggested as well (Dewey, 1954; Coleman, 1957; Warren, 1963). In all, it would appear that organizational orientation to Instrumental Coordination reflects very little variation born of organizational characteristics, nor or uncertainty among local input and output components, the interorganizational field, or state and federal agencies. More important in explaining these differences is the locale within which organizations are located.

2. Expressive Coordination. The multiple regression analysis of Expressive Coordination is summarized in Tables XXXVI and XXXVII. As with Instrumental Coordination, the organizational variables as a group are not good predictors of organizational orientation toward Expressive Coordination. While one measure does evidence a statistically significant association, the remaining six variables 
TABLE XXXVI

SUMMARY OF MULTIPLE REGRESSION ANALYSIS, EXPRESSIVE COORDINATION AS DEPENDENT VARIABLE 30

\begin{tabular}{|c|c|c|c|}
\hline Covariates & $\begin{array}{l}\text { Step } \\
\text { Entered }\end{array}$ & $\begin{array}{l}\text { Last Step } \\
\text { Beta }\end{array}$ & P \\
\hline \multicolumn{4}{|l|}{$\begin{array}{l}\text { Organizational } \\
\text { Resources }\end{array}$} \\
\hline Organizational & & & \\
\hline $\begin{array}{cr}\text { Goals } & \begin{array}{r}\text { Direct } \\
\text { Service }\end{array} \\
\end{array}$ & & & \\
\hline \multicolumn{4}{|l|}{$\begin{array}{l}\text { Local Public } \\
\text { Uncertainty }\end{array}$} \\
\hline \multicolumn{4}{|l|}{$\begin{array}{c}\text { State \& Federal } \\
\text { Uncertainty }\end{array}$} \\
\hline \multicolumn{4}{|l|}{$\begin{array}{l}\text { Client } \\
\text { Uncertainty }\end{array}$} \\
\hline $\begin{array}{l}\text { Interorgani- } \\
\text { zational } \\
\text { Uncertainty }\end{array}$ & 1 & -.244 & .010 \\
\hline Independent Variable & 7 & -- & .081 \\
\hline
\end{tabular}

${ }^{30}$ Only Community and independent variables with last step $\mathrm{p}<.10$ included.

${ }^{31}$ Community was programmed to be the last variable entered into the analysis. 
TABLE XXXVII

MULTIPLE REGRESSION ANALYSIS, BETA VALUES RELATING

COMMUNITIES TO SAN BERNARDINO 32

EXPRESSIVE COORDINATION

\begin{tabular}{|cc|}
\hline Community & Beta \\
\hline Tacoma & -.07 \\
Las Vegas & .17 \\
Tucson & .00 \\
Boulder \\
Salt Lake City \\
p $<.081$ \\
$F=2.023$ \\
df $=11,103$ \\
\hline
\end{tabular}

32 Through dummy techniques, betas for each community signify its deviation from associations identified in San Bernardino. 
fail to surpass probability levels of $p<.20$.

The one variable which is demonstrated to be associated with Expressive Coordination is Interorganizational Uncertainty $(p<.01)$. A negative association is indicated between this independent variable and Expressive Coordination, indicating that lower levels of local turbulence among members of the service industry are normally accompanied by increased organizational orientations toward the strengthening of interorganizational linkages.

Community proves to be more strongly associated with Expressive Coordination than has been found to be the case with any previously discussed dependent variable $(p<.081)$.

Expressive Coordination, like Instrumental Coordination, reflects a relatively high degree of association with Community. Unlike Instrumental Coordination, however, Expressive Coordination is found to be additionally associated with one measure of environmental turbulence, Interorganizational Uncertainty.

This latter result reflects the high degree to which the horizontal integration of service agencies is founded on symbolic foundations. As was noted earlier, much of the effort surrounding the development of these networks involves the aggregation of previously existing organizations into new interorganizational systems which themselves are oriented to a given target population. Participating agencies continue to perform their original function; through their participation in the network, however, they orient to new clients and communicate with other agencies in terms of new issues. In this context, symbolic support of and by other agencies is likely to be of 
considerable importance in terms of client referrals and, perhaps more importantly, in terms of legitimization. This type of support is expressive, and is frequently cited by practitioners in the field. That expressive support declines in periods of high interorganizational uncertainty seems a realistic result in this context.

This result is also consistent with those elements of the organizational literature which suggest inverse relationships between uncertainty in the organizational network and organizational interaction with other agencies. Frequently based on Exchange Theory, these authors (Benson, 1975; Mindlin and Aldrich, 1975) note that as interorganizational turbulence increases, organizational attention increasingly turns inward, implying heightened emphasis on the security of the organization itself in a competitive environment. This phase of the literature, however, is primarily oriented to that class of organizational criteria which are treated in this dissertation through the intraorganizational decision making criteria. In this respect, only one measure of the Intraorganizational Criteria, Internal Orientation, was found to display such a relationship. Among the Extraorganizational Criteria, the measure reflecting the greatest "action orientation" to interorganizational coordinative endeavors, Instrumental Coordination, was found largely unassociated with Interorganizational Uncertainty. This finding would suggest that functional emphasis on coordinative endeavors by affected organizations exists relatively independently of turbulence within the organizational network; what are associated are the expressive, more symbolic aspects of support for coordinative endeavor. Together, these results would 
seem to suggest that--at least within the ranges represented in this data--organizational reactions to interorganizational turbulence may well be more narrowly defined than is often posited. Orientations to such criteria as are reflected in Agency Enhancement and Autonomy are largely unrelated, though other internal issues, possibly domain, are accorded more attention. Interorganizational endeavors as actually manifested in organizational emphasis on coordinative action are similarly unaffected, although the degree to which such endeavors are symbolically supported diminishes.

As was the case with Instrumental Coordination, Expressive Coordination reflects a degree of association with Community. Again, the existence of this association is consistent with the contributions of many authors in that field. Coleman (1957), for example, has noted that not only will issues generating conflict vary between locales, but so will the means by which conflict is resolved. Further, once successful conflict resolution is achieved, the means employed in the first, precedent-setting case will tend to be employed in later instances. Particularly to the extent that coordination entails conflict (O'Brien and Wetle, 1975), much of Coleman's analysis can be applied directly to the arena of human service provision. As noted elsewhere, the work of Dewey (1954), MacIver (1970), and J. Bernard (1962) are generally supportive of this result as well.

3. Exclusion. Sumarized in Tables XXXVIII and XXXIX, the patterns evidenced in the analysis of Exclusion are at odds with those encountered in the analyses of extraorganizational criteria reported to now. The most apparent difference lies in the fact that the 
TABLE XXXVIII

SUMMARY OF MULTIPLE REGRESSION ANALYSIS, EXCLUSION AS DEPENDENT VARIABLE 33

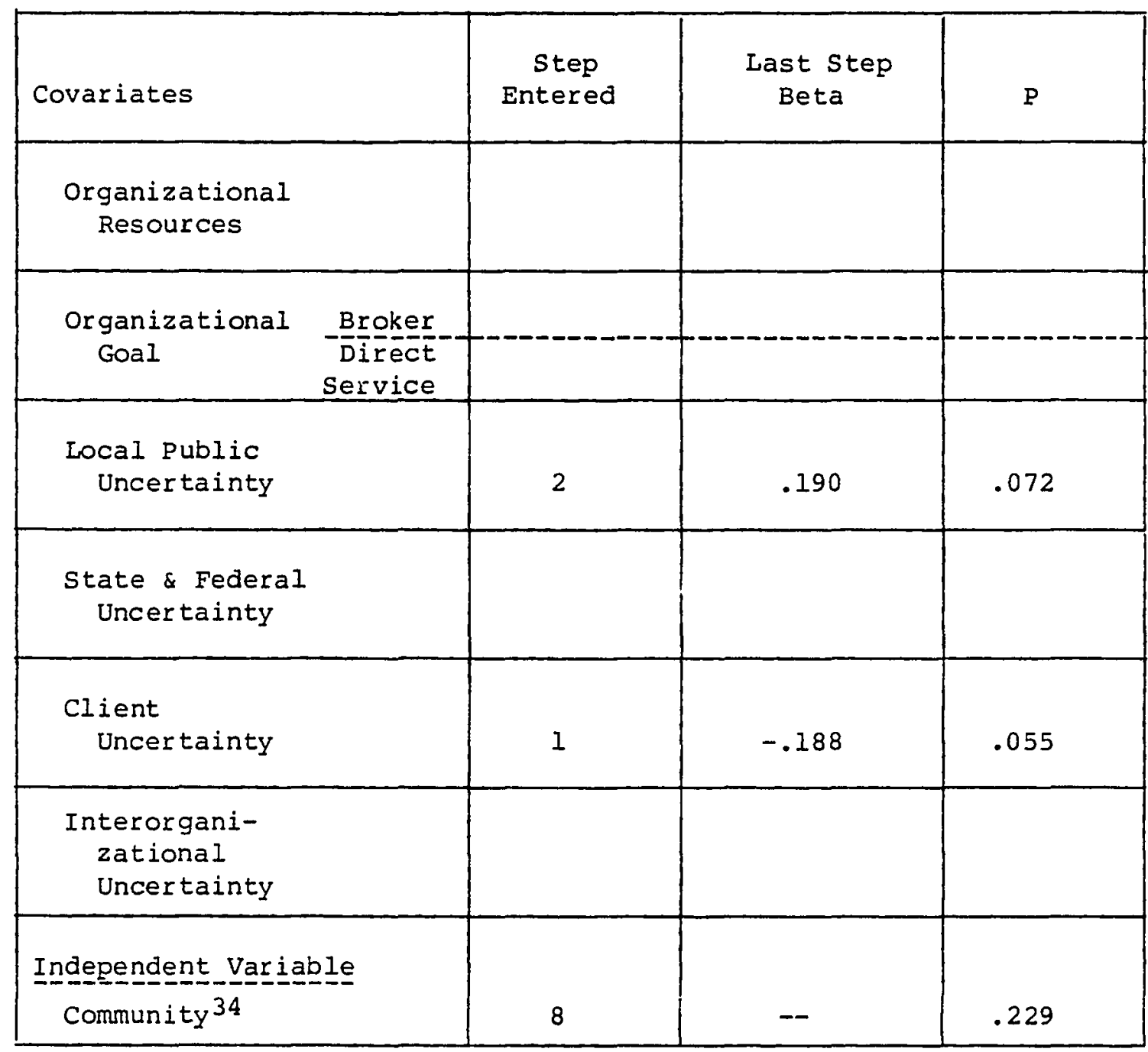

${ }^{33}$ Only Community and independent variables with last step $p<.10$ are included.

${ }^{34}$ Community was programmed to be the last variable entered into the analysis. 
TABLE XXXIX
MULTIPLE REGRESSION ANALYSIS,BETA VALUES RELATING COMMUNITIES TO SAN BERNARDINO 35
EXCLUSION

\begin{tabular}{|cc|}
\hline Community & Beta \\
\hline Tacoma & -.19 \\
Las Vegas & .05 \\
Tucson & -.10 \\
Boulder & .09 \\
Salt Lake City & -.04 \\
p $<.229$ & \\
F $=1.403$ & \\
df $=12,102$ & \\
\hline
\end{tabular}

${ }^{35}$ Through dummy techniques, betas for each community signify its deviation from associations identified in San Bernardino. 
organizational variables evidence themselves to a greater extent in this analysis than in the preceding two. Additionally, Community plays a more limited role with respect to this dependent variable. The organizational variables evidencing reportable associations with Exclusion are Local Public Uncertainty and Client Uncertainty. While neither relation is statistically significant $(p<.072$ and .055 , respectively), their presence in the formulation leads to an interesting picture of the local service industry. The association between Local Public Uncertainty and Exclusion is direct, indicting that heightened tendencies toward exclusionary strategies accompany increased community turbulence. Just the opposite relation is evidenced with respect to client uncertainty, where increased turbulence is inversely associated with exclusionary policies.

Community-related distinctions would appear to play a lesser role with respect to Exclusion than is encountered with respect to the other Extraorganizational Criteria (p<.229).

Perhaps the most interesting of the analyses conducted among the Extraorganizational Criteria is that involving Exclusion. Two organizational variables were found to be associated with Exclusion: Client Uncertainty was found to be inversely associated, while Local Public Uncertainty was found to be directly related.

These associations are consistent with Waldman's (1972) dichotomy of environments according to elements' relations to the flow of support to and from organizations. In the context of the local environment, Local Public Uncertainty is clearly descriptive of instability among agencies' input components; conversely, Clients Uncertainty is 
associated with the output component. That the two reflect opposite associations with organizations' use of exclusionary tactics with other agencies is supportive of Waldman's notation of their more generally opposite relationships with service agencies.

The direct association between Exclusion and Local Public Uncertainty is generally reflective of exchange theorists' suggestions that organizations make use of selected environmental support in their dealings with other agencies (Benson, 1975; Mindlin and Aldrich, 1975). By mobilizing support outside the system, the agency's potential for generating influence within the system is enhanced. The nature of the support generated outside the service industry, however, is important. Benson posits that the effectiveness of such support varies with its scale and with the status of its members. In very general terms, this description portrays the general characteristics associated with the input component, as reflected in Local Public Uncertainty.

That Exclusion is negatively associated with Client Uncertainty suggests that agencies tend on the whole to support one another in the face of uncertainty in the output components. The exact implications of this result are not identifiable in this data set. It is possible, for example, that agencies join together in order to provide system-wide responses of a conciliatory nature; if so, AAA's job would be easier in times of client unrest. Alternatively, agencies may join to present a united front against the "foe," with quite different implications. What is sure from this analysis, however, is the fact that responses to changing client demands is demonstrably different from those precipitated by demands from the non-client 
population.

4. Outside Input. As reflected in Table XL, no organizational variable is associated with Outside Input to a sufficient degree to generate a probability level better than $p<.10$.

Community, as shown in Table XLI, accounts for insufficient variance to achieve statistical significance measures of $p<.10$. Outside Input, a measure of the extent to which agencies emphasize inputs from community entities outside the service market, evidences no associations with any of the organizational variables. As was the case with Instrumental Coordination, this absence of associations generally suggests that to the extent that determinants of this openness exist, they are not associated with commonly recognized characteristics of organizations.

of particular interest is the fact that no measures of organizational-environmental association were found to evidence associations with Outside Input. Benson (1975) suggests that various components of the environment may well be recruitable by organizations for mobilization against other organizations during episodes of interorganizational conflict. Because certain environmental elements are capable of greater influence than others, most notably input components over output components (as noted above). Benson suggests that agencies may court members of the former for support in difficult times. Since one means of recruitment available to agencies in this industry is through the advisory function, it could be suggested that outside Input and Local Public Uncertainty, if no other source of environmental uncertainty, might be associated. This association is simply 
TABLE XI SUMMARY OF MULTIPLE REGRESSION ANALYSIS,
OUTSIDE INPUT AS DEPENDENT VARIABLE 36

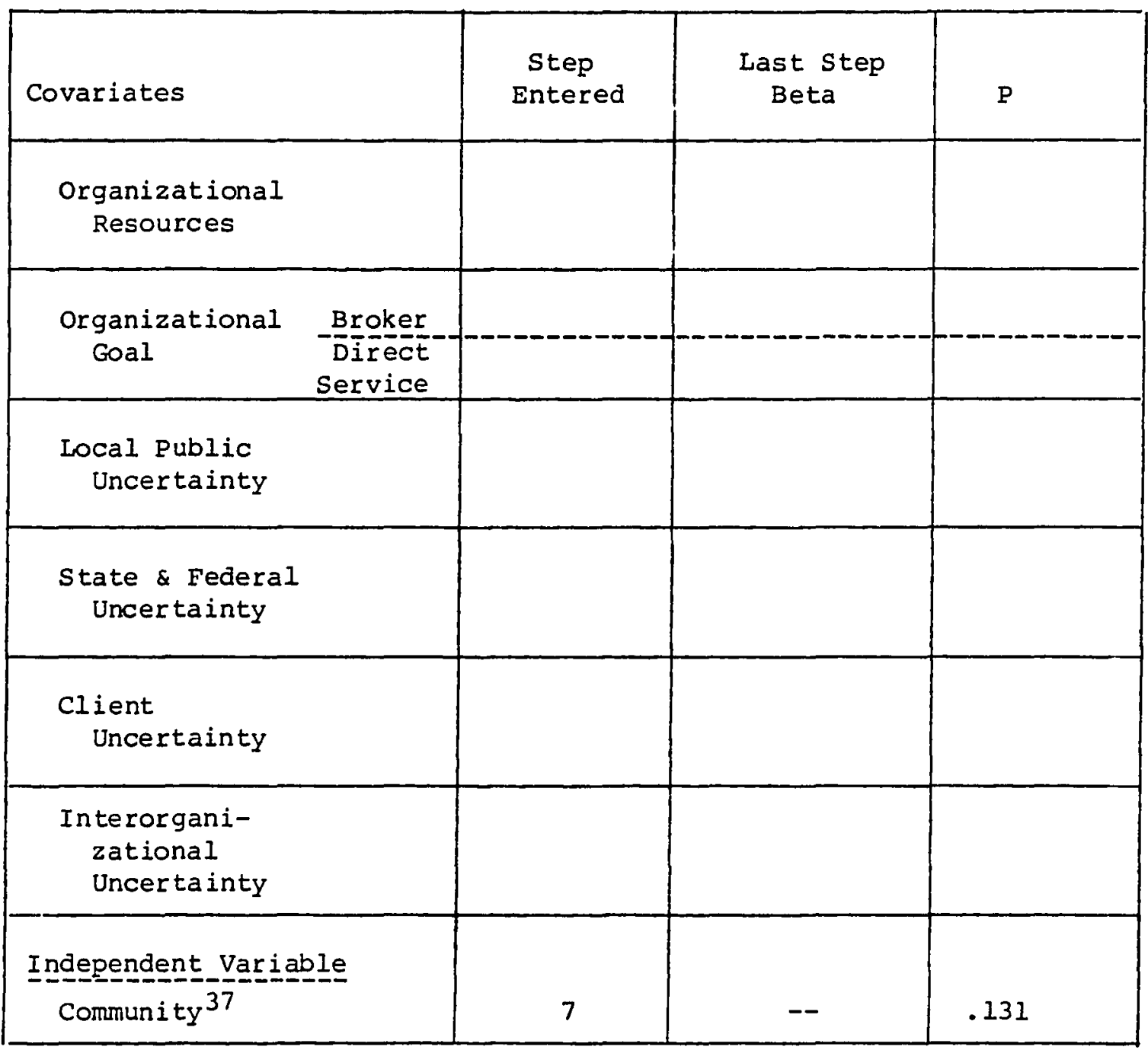

${ }^{36}$ only Community and independent variables with last step $\mathrm{p}<.10$ are included.

${ }^{37}$ Community was programmed to be the last variable entered into the analysis. 
TABLE XLI

MULTIPLE REGRESSION ANALYSIS, BETA VALUES RELATING COMMUNITIES TO SAN BERNARDINO38

OUTSIDE INPUT

\begin{tabular}{|cc|}
\hline Community & Beta \\
\hline Tacoma & -.12 \\
Las Vegas & .02 \\
Tucson & -.08 \\
Boulder & -.28 \\
Salt Lake City & -.17 \\
p $<131$ & \\
$F=1.746$ & \\
df $=10,104$ & \\
\hline
\end{tabular}

38 Through dummy techniques, betas for each community signify its deviation from associations identified in San Bernardino. 
not evident in this data, nor are others relating to funding sources, clients, or other agencies.

Community is shown to be a non-significant predictor of outside Input, evidencing an association with a significant level of p<.13l. This association is of insufficient strength to provide explicit support for expectations of intercity differences in organizational openness to extraindustry direction.

5. External Orientation. Again as indicated in Table XII, External orientation is indicated through the analysis to be relatively independent of the organizational variables. The one exception to the more general case is Interorganizational Uncertainty, where the association is indicated to be inverse; less interorganizational turmoil is associated with greater external orientation. This finding is consistent with discussions advanced earlier with respect to Expressive Coordination.

Community evidences a non-significant association with External Orientation $(p<.076)$, indicating that different locales are oriented in varying degrees to this criterion. This pattern is reflected in Table XIIII.

External Orientation evidences an association with only one organizational variable; a negative relation with Interorganizational Uncertainty.

In the same way that Internal Orientation, the overall aggregative measure of orientation to intraorganizational well-being, shares associations found to exist with various of its component measures, this overall measure of extraorganizational emphasis can be 
TABLE XLII

SUMMARY OF MULTIPLE REGRESSION ANALYSIS, EXTERNAL ORIENTATION AS DEPENDENT VARIABLE 39

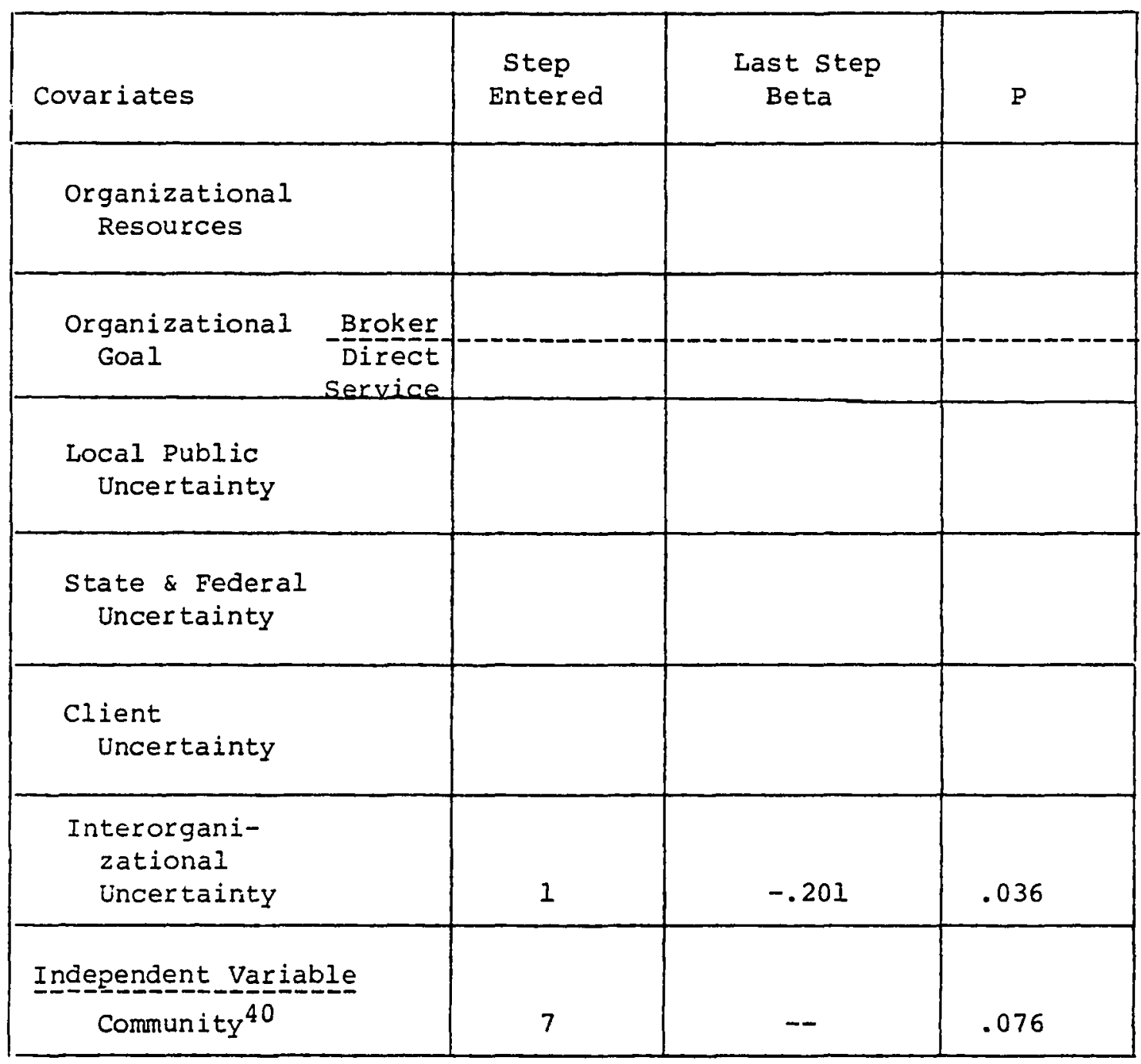

${ }^{39}$ only Community and independent variables with last step $p<.10$ are included.

${ }^{40}$ Community was programmed to be the last variable entered into the analysis. 
TABLE XLIII

MULTIPLE REGRESSION ANALYSIS, BETA VALUES RELATING

COMMUNITIES TO SAN BERNARDINO 41

EXTERNAL ORIENTATION

\begin{tabular}{|cc|}
\hline Community & Beta \\
\hline Tacoma & -.13 \\
Las Vegas & .18 \\
Tucson & -.09 \\
Boulder & -.09 \\
Salt Lake City & -.15 \\
p $<.076$ & \\
$F=2.057$ & \\
df $=11,103$ & \\
\hline
\end{tabular}

41 Through dummy techniques, betas for each community signify its deviation from associations identified in San Bernardino. 
expected to reflect the associations of narrower measures subsumed within. To a large extent this is likely the case here, reflecting the association found to relate Interorganizational Uncertainty with Expressive Coordination.

There is reason, however, to suspect that a more substantial significance is involved. Analys is involving the aggregate measure of emphasis on intraorganizational goals, Internal orientation, found that this focus of interest was inversely associated with Interorganizational Uncertainty. This result was ascribed in earlier discussion to domain-related issues which reflect one aspect of organizations' functional associations with other organizations. Missing, however, was any complementary increase in emphasis on such intraorganizational performance measures as are represented by Agency Enhancement or Autonomy. In this result, inversely linking Internal Orientation with Interorganizational Uncertainty, is evident a similar orientation favoring conservatism in interorganizational endeavors in the context of greater $r i s k$ in the organizational field. Emerging from these results is a suggestion that interorganizational contacts involve a more complex mix of motivations than is widely recognized in the organizational literature. Rather than serving only the long-run well-being of the organization through direct or indirect impacts on the flow of requisite resources, it would appear that interorganizational interaction may well be pursued for purposes entirely independent of individual organizations' perceptions of what might be good for them alone. This is an interesting possibility, and merits further investigation. 


\section{A Word About Community}

Community is associated with the extraorganizational decision making criteria to a greater and more consistent extent than was found to be the case through the intraorganizational analyses. While no extraorganizational association was found to be statistically significant as such, four of the five associations evidenced less than $a$ one in seven probability of being attributable to chance. These generally supportive probability levels, and the fact that four of the five associations establish a pattern of association with Community, lend indirect support to the notion of inter-community differences. While these significance levels fall short of conventional tests of significance, the patterns apparent in the findings suggest that forces other than mere chance are at work in the analyses and that judgment as to the veracity of findings should be suspended for the moment. This point will be further discussed in the following chapter.

Intraorganizational and Extraorganizational Decision Making Criteria: Summary

This section is designed to synopsize the findings of 64 separate analyses (intraorganizational and extraorganizational) undertaken during the first phase of the study. Where the previous pages of this chapter are oriented to brief discussions of the separate analyses, the pages to follow will be oriented to broader discussions of the patterns evidenced throughout the analyses. These will be analyzed with respect to conclusions and policy implications in the next chapter. 
It will be recalled that the analyses undertaken in this dissertation were oriented to the pursuit of a single research question: "Do the criteria by which organizations assess the benefits of entering into interagency agreements vary by city?" The research question was addressed through three hypotheses, as follow.

It is hypothesized that differences exist between cities in the intraorganizational criteria by which human service organizations assess the benefits of entering into interagency agreements.

It is hypothesized that differences exist between cities in the extraorganizational criteria by which human service organizations assess the benefits of entering into interagency agreements.

It is hypothesized that the inter-community differences found to exist for extraorganizational criteria will exceed those found to exist for intraorganizational criteria.

\section{Intraorganizational Criteria: Hypothesis I}

The first hypothesis was tested through the analyses implemented using intraorganizational criteria measures as dependent variables.

In general, Community is not a strong predictor of organizational orientation to the intraorganizational criteria.

The analyses of variance with Community as the independent variable and the intraorganizational criterion measures as the dependent variables failed to reflect any associations remotely approaching statistical significance. This is not supportive of the first hypothesis.

Analyses of covariance produced similar results, as reflected in 
Appendix II. In no case did the probability levels reflecting the associations between community and the three measures of intraorganizational decision making criteria better $p<.10$. Apparent in the tables, however, is a pattern of differentials between the associations linking Community with the various intraorganizational measures which are employed as covariates. Those probability levels associated with Agency Enhancement are consistently smaller than those involving Autonomy and Internal orientation. While this may be of interest to later investigations, it does not alter the basic fact that the results of the covariance analyses do not lend support to the study's initial hypothesis.

The multiple regression analyses allowed the effects of community to be measured after parceling out the variance of all selected organizational variables. The results of these anlyses are consistent with those of the analyses of variance and covariance: they do not reflect intercommunity variation in organizational orientations to the intraorganizational criteria.

Overall, the results of the analyses point to the inescapable conclusion that the first hypothesis of the study is not supported throughout the data; organizational assessments of the intraorganizational benefits attached to entering into interagency agreements do not vary by city.

\section{Extraorganizational Criteria: Hypothesis 2}

In a manner similar to that described above, the second hypothesis was tested through analyses employing extraorganizational 
criterion measures as dependent variables.

The results of the analyses of variance show community to be a more adequate predictor of extraorganizational orientations than was found to be the case with the intraorganizational criteria, although no analysis produced results consistent with commonly accepted measures of statistical significance. These results are reported in Appendix II.

Better than similar figures obtained through the analysis of the intraorganizational criteria, these analyses lend marginal support to the study's second hypothesis.

The analyses of covariance assessed the associations relating the extraorganizational decision making criteria to Community, while controlling for the organizational variables. These analyses are reported in Appendix II.

Overall, the findings are inconclusive. Three associations were found to be statistically significant, while seven more reflected probability levels between .05 and .10 . While not overwhelmingly supportive of the study's second hypothesis, these figures do surpass the results of the intraorganizational analyses.

As with the intraorganizational criteria, a separate step-wise multiple regression analysis was implemented for each measure of extraorganizational orientation, as reported in Appendix II.

The results of the multiple regression analyses are the most supportive of the dissertation's second hypothesis, although none of these analyses evidenced a statistically significant association between Community and the Extraorganizational Criteria (with 
Instrumental Coordination, $\mathrm{p}<.127$; with Expressive Coordination, p<.081; with Exclusion, p<.229; with Outside Input, $p<.131$; with External Orientation, $\mathrm{p}^{<.076)}$. Having noted the non-significance of these associations, it is appropriate to also note that in light of the fact that these results are not entirely negative. This dissertation constitutes the first attempt at operationalizing the Extraorganizational Criteria and at their analysis, and it is reasonable to expect that improvements could be realized in both activities. In this light, the fact that general support was realized in the associations between Community and four of the five Extraorganizational Criterion measures would seem to call for further work in the concepts entailed in this study, a point which will be discussed further in the following chapter.

Intraorganizational and Extraorganizational Criteria: Hypothesis 3

The third hypothesis, predicting greater intercommunity differences among the extraorganizational criteria than among the intraorganizational criteria is supported.

Three general approaches are employed to demonstrate the differences in the magnitude of Community contributions to variance for each of the eight dependent variables. First, the plotting of beta values for each of the towns with respect to each of the variables gives a visual indication of differences in intercommunity 
orientations to each dependent measure. ${ }^{42}$ second, differences in the community contribution to each dependent measure may be alternatively stated in terms of the variance associated with beta values, as derived from organizational responses in each city and calculated through the eight regression analyses. Finally, differences in the community contributions may be assessed in terms of the probability levels associated with the community contribution to each analysis. Figure 4 provides a graphic trace of each city's beta value, reflecting how agencies in each city differ from those of San Bernardino in their orientation to each dependent measure. In general, the greater the difference between the highest and lowest cities' values, and the greater the dispersion between values, the greater will be the contribution of the Community variable to the explanation of variance in the dependent variable. It can be seen in Figure 4 that by both indexes--spread between polar values and dispersion between values--differences between cities with respect to each extraorganizational dependent variable are greater than differences reflected among the intraorganizational criteria. This is supportive of the dissertation's third hypothesis.

A more precise means of assessing the inter-city differences addressed above lies in comparing the standard deviations associated

42 It will be recalled that for the purposes of multiple regression analysis, the community variable was dummied. As a result, beta values associated with each of the five cities named measures that city's deviation from San Bernardino's measure with respect to each dependent variable. Were San Bernardino to be plotted in Figure 4, its plots would lie on each of the eight zero points. 


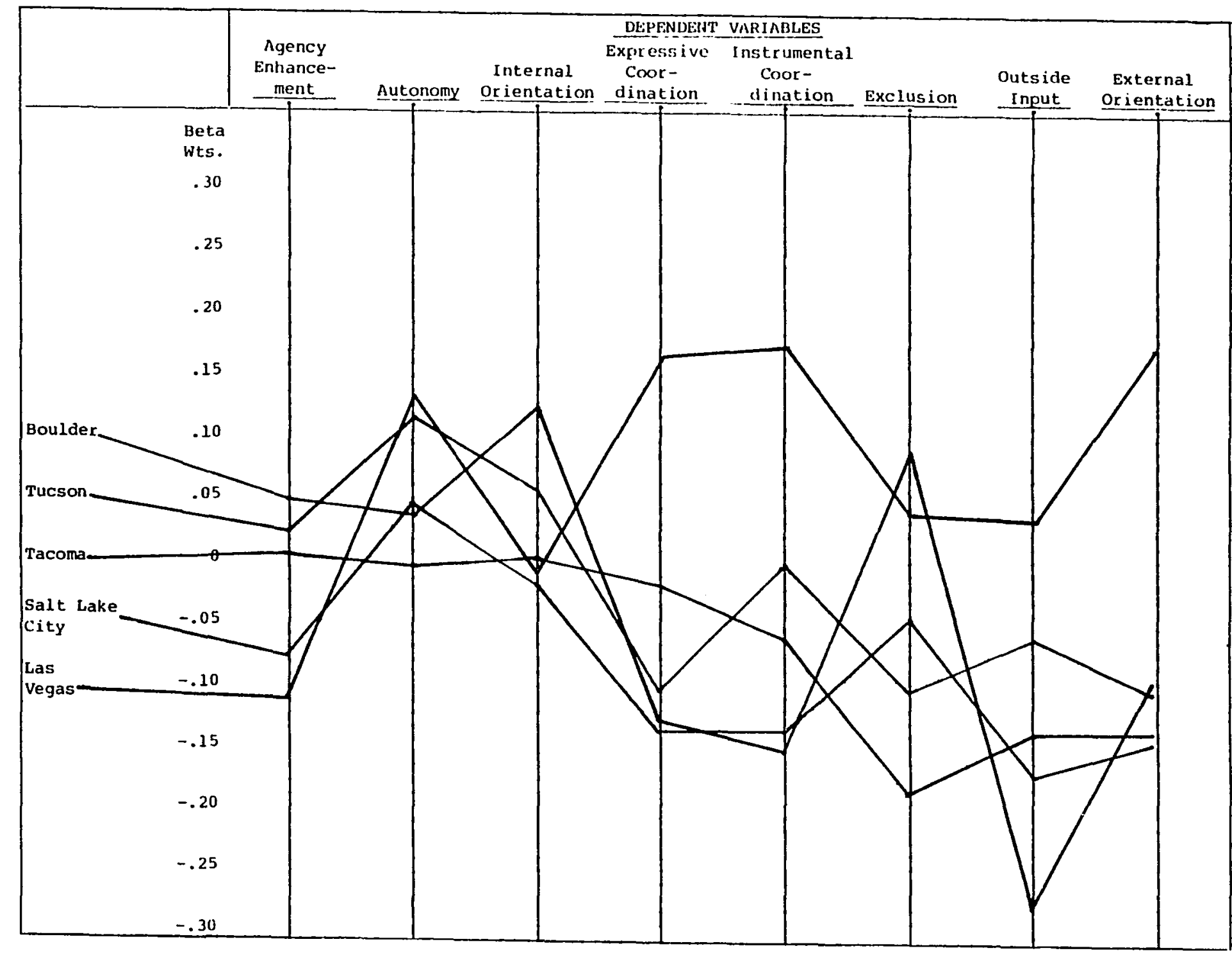


with the five cities' beta values for each dependent variable. Each figure reflects overall inter-city differences as they relate to each of the eight dependent variables. Figure 5 provides a graphic comparison of these standard deviations. As noted above, the standard deviation of beta weights associated with each of the extraorganizational criterion measures is greater than those associated with each of the intraorganizational criteria, a finding supportive of the dissertation's third hypothesis. A third method of comparing Community contributions to the various decision making criteria lies in comparing the statistical significance of the Community contribution to each.

Figure 6 provides a graphic comparison of these measures. Here, the statistical significance associated with each of the relationships between Community and the decision making criteria are plotted: the smaller the numerical value of the significance level, and the shorter the bar in Figure 6, the stronger the association. The three measures of Intraorganizational Criteria are positioned to the left of the figure, while the five Extraorganizational Criteria are to the right. The differences are dramatic.

As reflected in the multiple regression analyses, Comunity shares no association with the Intraorganizational Criterion Measure which is statistically significant beyond $p<.10$.

Among the Extraorganizational Criterion Measures, however, no association with Community is less statistically significant than $p<.230$, and two associations exceed measures of $p<.10$.

As is dramatized by the distinct differences between the lengths of each set of bars in the figure, Community shows much stronger 


\begin{tabular}{|c|c|c|c|c|c|c|c|c|}
\hline $\begin{array}{l}\text { Standard } \\
\text { Deviations }\end{array}$ & $\begin{array}{c}\text { Agency } \\
\text { Enhance } \\
\text { ment }\end{array}$ & Automony & $\begin{array}{c}\text { Internal } \\
\text { Onientation }\end{array}$ & $\begin{array}{l}\text { DEPENDEN7 } \\
\text { Express ive } \\
\text { Coor- } \\
\text { dination } \\
\end{array}$ & $\begin{array}{l}\text { VARIABLES } \\
\text { Instrumental } \\
\text { coor- } \\
\text { dination } \\
\end{array}$ & Exclusion & $\begin{array}{l}\text { Outside } \\
\text { Input } \\
\end{array}$ & $\begin{array}{c}\text { External } \\
\text { Orientation }\end{array}$ \\
\hline $\begin{array}{l}.12 \\
.11 \\
.10 \\
.09 \\
.08 \\
.07 \\
.06 \\
.05\end{array}$ & 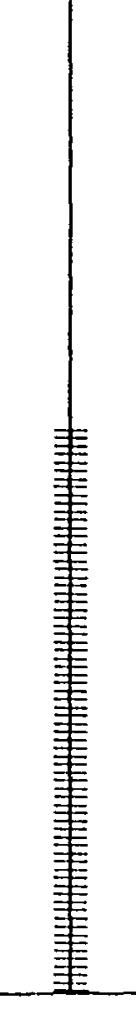 & 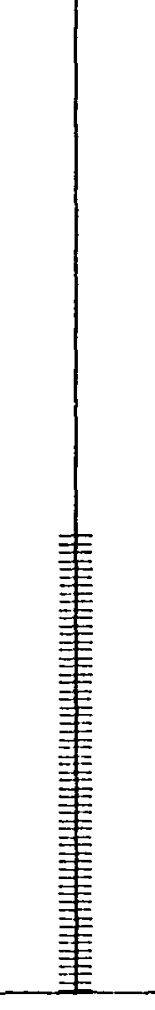 & 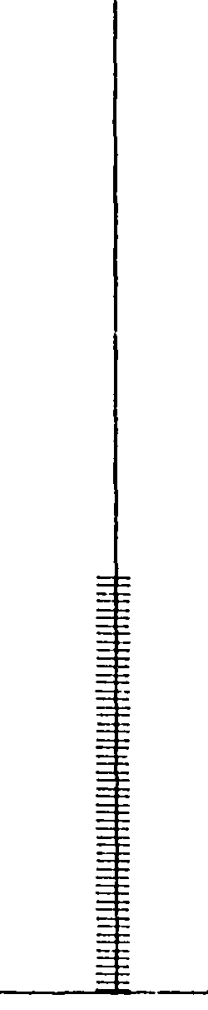 & 夆革 & 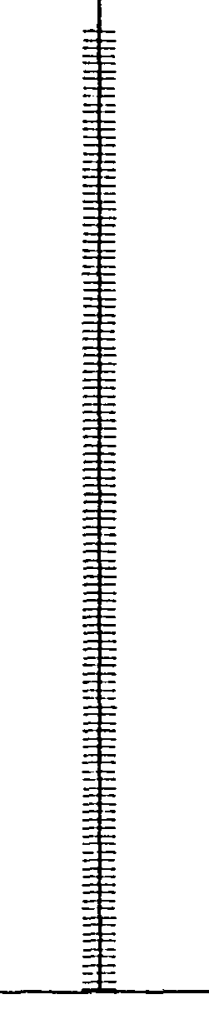 & 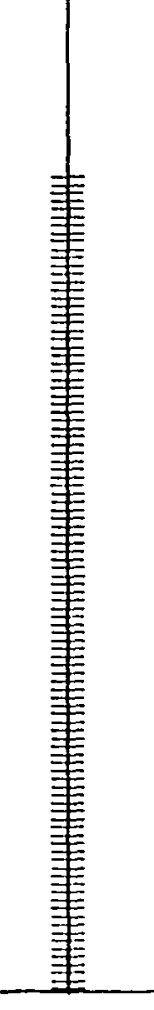 & 䡤 & 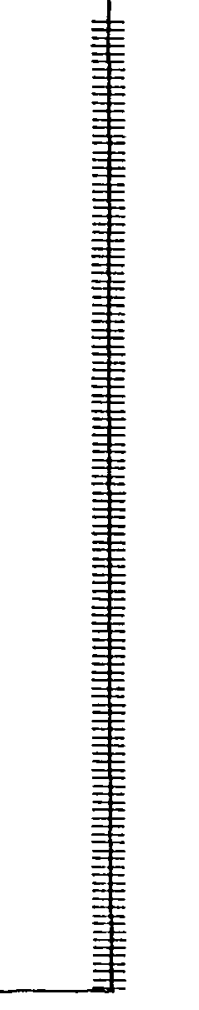 \\
\hline $\mathrm{s}$ & .065 & .052 & .050 & .113 & .117 & .098 & .100 & .118 \\
\hline
\end{tabular}

Figure 5. Multiple Regression Analyses: Standard Deviation of Cities' Beta Weights By Dependent Variable 


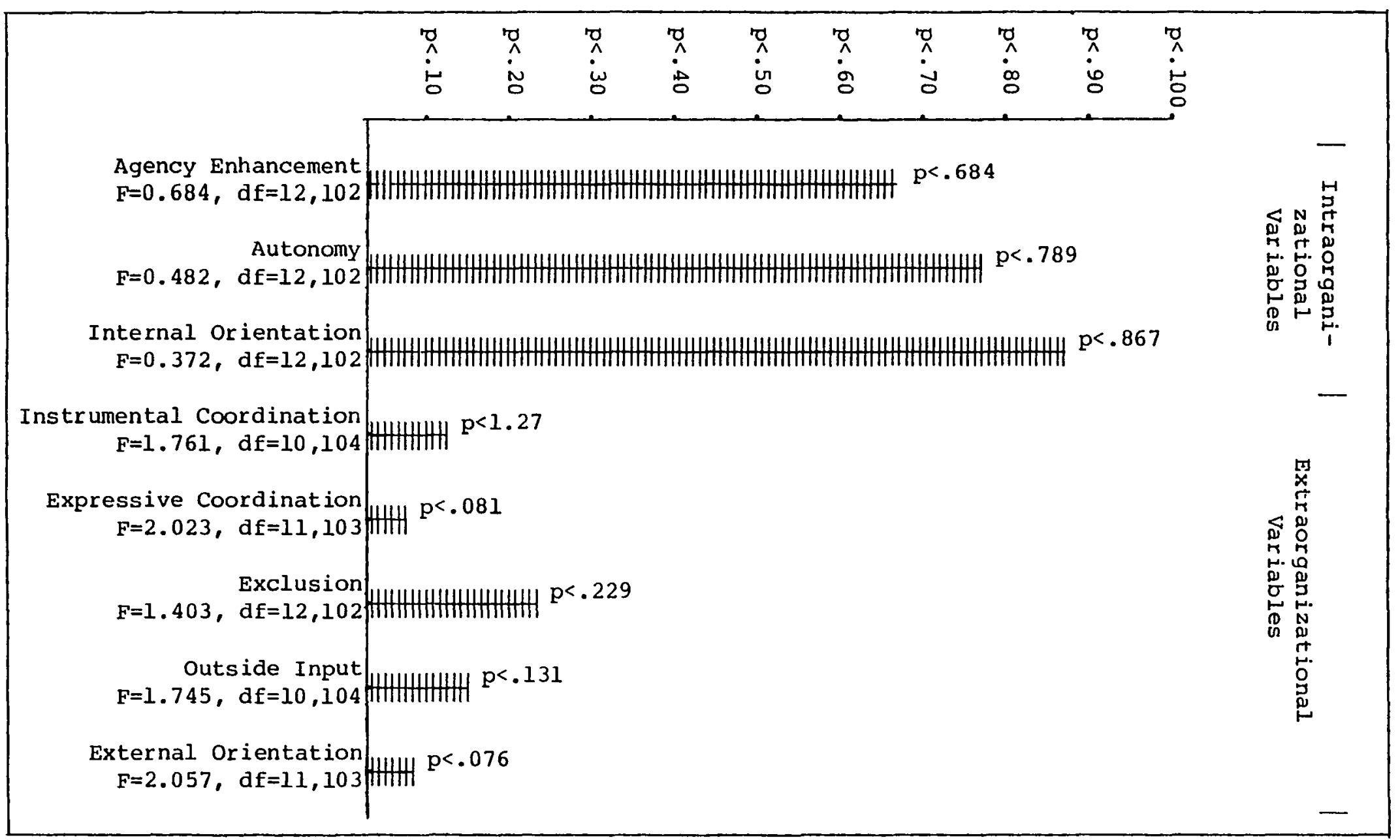

Figure 6. Comparison of Associations, Community With Decision Making Criteria 
interrelations with the extraorganizational criteria than with the intraorganizational criteria. The differences are clear not only with respect to paired comparisons of individual measures, but also with rexpect to the overall comparison. This is clearly supportive of the third hypothesis of Phase 1: Community Variation.

In sum, the analyses conducted in Part 1: Community Variation provide the following support for the phase's three hypotheses.

1. No support is provided for the first hypothesis. In no case does Community account for sufficient variance to general statistical significance.

2. Greater support is provided for the second hypothesis. Two of the five associations between Community and the extraorganizational criteria are statistically significant at levels between $p<.05$ and p<.10, while the three remaining associations generate alpha levels above .10 . While not meeting commonly accepted probability levels $(p<.05)$, the pattern established by these measures is generally consistent with the parameters of acceptability discussed by Hays (1973), and certainly support further investigation of the topic. 3. Full support is provided for the third hypothesis. The associations between Community and all extraorganizational measures are considerably stronger than between Community and all the intraorganizational measures. 
CHAPTER VI

CONCLUSIONS AND RELEVANCE

INTRODUCTION

The primary significance of this concluding chapter is the exploration of the dissertation's analytical results for more general findings, and their application to actual or potential situations which might be identified both in theory and in the "real world." This broad goal will be addressed in four sections. The first will briefly review the work which was reported in the dissertation's first five chapters. The second section will discuss the analytical findings reported in Chapter V: first, with respect to issues pertaining to organizational theory and operation and, second, with respect to issues which might be expected to impact on the analytical findings for reasons other than those which might derive from theoretical sources. The third section will draw this chapter's discussion into a concise statement of the dissertation's conclusions. Finally, the fourth section will address implications of the dissertation's findings: first, with respect to the theoretical issues which prompted the development of the research question and, second, with respect to the policies and practices employed in the delivery of human services to clients. 
REVIEW

As was noted in the fourth chapter, the dissertation research reported in this document was designed to address the following research question: Do the criteria by which organizations assess the benefits of entering into interagency agreements vary by city?

The pursuit of this research question demanded first, that a model of organizational decision making behavior which incorporates extraorganizatonal criteria be identified and, second, that the model be tested through empirical analysis.

The dissertation's first two chapters were devoted to developing a model for use in this research application. It will be recalled that the first chapter was devoted to the explication of four general theoretical bases developed for use in organizational analysis. Employing the microeconomic model (also termed the "Classical Theory of the Firm") as a basis, other models were described in terms of their further contributions to the understanding of organizational behavior. Economic contributions were described largely in terms of their emphasis on "utility-maximizing behavior," and for their generalizations of the concept of organizational goal to include those of parties other than owners. That body of organizational theory arising out of the other social sciences was described in terms of its implications for organizational goals. To the profit posited by economists was added the goal-related concepts of power, autonomy, integration, domain, status, and ideology. As a framework for examining the interactions arising out of these orientations, the 
Organizational Interaction Model (Wetle, 1976) was advanced as a concise explication of a more diverse literature on exchange. Finally, the Primitive Economy Model (O'Brien, 1976a, 1976b) was introduced as a natural extension of the preceding models, capable of incorporating extraorganizational goals into an organizational decision making model.

The Primitive Economy Model was formulated in terms of a general organizational utility function, as were those contributions previously discussed, in order to provide a general statement of the model's components and in order to stress the similarities and differences which relate it to other approaches to organizational analysis. This utility function, (14), constitutes a very general statement which in its current state offers a conceptual basis for use in testing the Primitive Economy Model through the Model's principal corollary, the Differential Mix Hypothesis. Simply stated, the Differential Mix hypothesis states that similar organizations pursue similar combinations of goals, and so will tend to behave similarly. In the context of interindustrial comparisons, for example, the Differential Mix Hypothesis would lead to expectations of different goal mixes between groups of organizations identified by their industrial context. In terms of this dissertation, where organizations within an industry-the human service industry--are identified in terms of locale, the Differential Mix Hypothesis suggests differences born of locale. In terms of formula (14), which constitutes a formulation of the PEM as noted above, the Differential Mix Hypothesis suggests that firms of a given type, however defined, will tend on the whole to reflect similar 
patterns of valuation (as represented by the $V_{I i}$ and $V_{E j}$ terms) among the various goals available for organizational pursuit. To the extent that this position is found to be valid, it constitutes a means of verifying systems of organizational classification.

As noted above, organizations in this dissertation were classified according to locale. Because organizations--particularly organizations of the type encountered in the human service industry-receive much of their operational direction from their environments, and because operational environments in the human services industry are largely local in scope and therefore subject to local differentiation, it was hypothesized that organizations operating in different locales would reflect different operational orientations or goals. Three hypotheses were employed in the testing of the research question.

The first posited different organizational orientations toward intraorganizational goals in different cities. (Intraorganizational goals are those by which organizations assess success in terms of conditions associated directly with the organization itself.) Analytical results yielded no support for the first hypothesis, reflecting rather that locale is not a pertinent factor in the emphasis lent by organizations to intraorganizational classes of goals.

The second hypothesis suggested that organizational emphases on extraorganizational goals vàry by city, extraorganizational goals being those by which success is identified with respect to entities outside the organization. Results indicated that locale is much more influential in accounting for variance among the extraorganizational 
criteria than among intraorganizational measures. While no analytical results produced probability levels exceeding $p<.05$, four of the five analytical results are generally consistent with other standards as they relate to exploratory research (Hays, 1973).

The third hypothesis, calling for greater inter-city differences among the extraorganizational criteria than among the intraorganizational was deemed fully supported by the analyses. All measures of intercity differences among the extraorganizational criteria were found to exceed all intercity difference measures among the intraorganizational criteria.

\section{DISCUSSION}

To this point, discussion has been limited to one of the two classes of organizational decision making criteria. While useful, the original goal of the dissertation was to additionally develop a model within which both classes of criteria could be incorporated, a goal necessitating a general discussion of the findings employing both series of analyses. Accordingly, the pages which follow will address simultaneously the intraorganizational as well as the extraorganizational decision making criteria in order to assess the worth of the two when considered together.

At the most fundamental level, the dissertation employed the Primitive Economy Model as a general statement of how an organizational entity might address two distinct classes of goals. Limitation of the model to two classes of goals, as opposed to three or more, was a decision made in order to simplify the initial analysis of 
extraorganizational goals as a newly recognized class of influences. While simplifying the analytical process, this approach left unaddressed many of the criteria addressed in the initial chapter including such motivators as managerial goals, and a number of the organizational goals. The exclusion of these measures from the analyses undertaken in this research undoubtedly affected the findings of the research, but allowed the assessment of two broad classes of goals with a relatively efficient interviewing instrument. Subject to the limitations born of this necessary decision, the analyses presented in the preceding pages allowed for a relatively crude initial application of the Primitive Economy Model employing goals which roughly represent internal motivations as perceived by non-profit organizations, as well as those more directly identified as extraorganizational.

Interesting is the fact that the two classes of goals were shown to be responsive to different classes of influence. This is probably the most important finding of the study. Where intraorganizational criteria were found to be responsive primarily to organizational characteristics and not at all to community influences, the extraorganizational criteria were found to be less subject to influence by organizational variables and considerably more responsive to contextual influences identified as being associated with the organizations' community contexts. This set of findings suggests a number of ideas concerning organizational behavior as it is encountered in the human services industry.

First and foremost, it appears from the findings that 
organizational decision making is more complex than is generally acknowledged. Not only were two independent general types of criteria found to be employed in the assessment of benefits associated with organizational decision making, but each was found to respond to different classes of influence.

on the one hand lie the intraorganizational criteria. These include the general notion of profit (broadened to include beneficial trades of commodities other than money), growth, staff welfare, autonomy, and time preference as applied to returns on investment. These criteria were found to be resistant to local variations in their valuation, but were found to cuvary with such organizational variables as organizational goal (function, and position in network), and environmental uncertainty as identified in the local public, at the state and federal levels, and within the interorganizational network.

On the other hand are the extraorganizational criteria. Existing independently of the intraorganizational measures addressed above, these measures of success were found to vary considerably by locale, and to additionally reflect influence born of organizational characteristics.

The simultaneous existence of the two classes of goals and the two classes of influence suggests that the simultaneous acknowledgement, if not the actual treatment, of both classes of phenomena involves a sophisticated and complex decision making process and a discerning eye for influences.

This general pattern of findings would tend to lend support to the Primitive Economy Model, at least to the extent that the limited 
application of the model in this dissertation would allow. It will be recalled that the PEM suggests that organizations respond simultaneously to goals which are unique to the organizations themselves, and to goals which are associated most directly with entities outside the organization. Moreover, the model suggests that the two classes of goals are independent of one another. Both general stipulations were vindicated in this application. First, it was found that organizational identification of valuation patterns pertaining to intraorganizational goals was not linearly associated with their treatment of extraorganizational goals, as is explained in Appendix I. This lack of association was additionally supported through the distinctions which separate the influences impacting upon each class of goal, as identified in Chapter IV and above. Finally, it was found that the actual locus of influence impacting upon each type of goal is different: intraorganizational goals tend on the whole to be affected by forces outside the locale, while extraorganizational orientations tend to be associated with local influences.

The Differential Mix Hypothesis, a derivative of the Primitive Economy Model suggesting that organizations may be typed according to their mixes of goals, also gained support in this dissertation. Typing organizations by locale, it was found that organizational orientations toward extraorganizational measures of success do indeed reflect differences by city: in this respect, organizations may be typed by location. With respect to intraorganizational criteria, however, location does not constitute an effective means of classifying organizations. This conclusion is derived from the fact that Community 
shares little variance with these measures of organizational success.

Over and above the discussion of the implications of the dissertation's findings, it is appropriate to address the findings themselves. By and large, the analytical results of this study are clouded by significance levels which fall short in varying degree of commonly accepted parameters. While due note has been made in the textual discussions of the analytical results, it is appropriate to discuss possible reasons why the associations did not meet these criteria. A clear explanation centers on the null hypothesis: it is entirely possible that the analyses do not meet commonly accepted parameters of statistical significance simply because the theoretical development of the dissertation's hypotheses is faulty, and because the Primitive Economy Model itself is an ineffective model of organizational behavior.

Unfortunately, the findings themselves do not offer sufficient grounds to fully refute the null hypothesis in the traditional way; measures of statistical significance do not permit it. There are a number of reasons, however, to question whether the dissertation's premises should be dismissed, and these will be discussed in the pages to follow. They include observations relating to sampling, to the application of the model, and to the methodological approaches employed in analysis.

1. Exploratory Nature of the Dissertation. Perhaps the greatest single impediment to this study is the fact that this constitutes the first empirical application of the Primitive Economy Model and of the 
Differential Mix Hypothesis.

This in itself constitutes a potential weakness in the anlytical work simply because it connotes no prior work in those areas where the model offers novel insights; no author has previously addressed extraorganizational decision making criteria in this type of an empirical application. Because this is the model's first application it is reasonable to assume that mistakes may well have been made or, in the absence of mistakes, that various steps in the execution of the research design may have been less effective than could have been the case. At least two steps in the conduct of the research could well have suffered as a result.

Instmument development. The dependent variables for the dissertation, it will be recalled, were developed from two instruments designed explicitly to yield measures of intra- and extraorganizational goals. These were not haphazardly developed. In each case, items were developed in order to plumb a range of carefully selected types of goals which would reflect not only organizational orientations, but also those of the market in which they operate and those of other entities with whom service agencies transact business as identified in prior work (O'Brien and Wetle, 1978). These efforts notwithstanding, the fact that many of the issues addressed through the instruments-particularly those relating to the extraorganizational criteria--had not been addressed in earlier empirical work undoubtedly affected the veracity of the measures actually employed in the instruments, and this condition would ultimately reflect in the analyses employing these measures as dependent variables. 
Dependent variable development. The potential for weakness in the various individual measures were critical in the decision to employ composite measures as dependent variables. It is widely recognized that factor analysis allows the development of indexes which represent variables only indirectly reflected in data through measures explicitly included in data gathering instruments. Through the selective inclusion of these explicit measures into a composite representation of the indirectly represented variable, it is possible to operationalize that concept. There are several benefits associated with this approach to variable development, including the recognition of variables potentially more fundamental to a researchable issue than was initially thought to be the case, and the ability to gain more widely-based measures of a concept than would be possible through single measures. Unfortunately, there are also potential costs in precision which accompany the development of factor-based composite measures. The first point of potential loss involves the selection of variables for inclusion in a composite index; some arbitrary decision is ultimately necessary. While a number of approaches have been documented in the literature, one which is widely employed and which was used in this application involves the selection of measures with factor loadings exceeding . 30 ; often accompanying this approach is a parallel decision to assign measures with loadings over . 30 on two or more factors to that factor upon which it loads most highly. While this approach serves the ends of parsimony and univocity, it does not necessarily maximize precision in the operationalization of the 
factor-derived variable. Three potential limitations bear upon this problem. First, the contributions of measures with loadings under .30 are lost. While the contributions of these measures would likely be small, they nonetheless represent contributions and in their absence they detract from the composite variable's precision. Second, variables loading more highly than .30 on two factors are lost to the factor upon which the lesser loading occurred. This problem in assignment occurred in the operationalization of Expressive Coordination, doubtless with costs for that measure's precision.

The third point of potential loss in precision involves the manner in which the variance of these measures included in a factor are treated in the process of aggregation. As noted in Chapter III, a number of approaches exist for addressing this treatment, each offering relative advantages and disadvantages. The approach employed in this dissertation was found to offer mid-range performance with respect to four standards of performance (univocity, validity, reliability, correlatedness), while others offered more advantageous performance among certain standards of performance at the expense of others. Having acknowledged these issues, it is appropriate to note that the method selected--the simple summing of all measures-overstates the contribution of each individual measure to total variance and therefore introduces error variance which will adversely impact the precision with which the composite measure is operationalized. As with the other polnts mentioned above, analytical precision must ultimately reflect this condition. Each of these three points represents a calculated risk. While 
each frequently accompanies the analytical application of early models, they nonetheless are likely reflected in tests of statistical significance.

2. Model Operationalization. The Primitive Economy Model, which forms the conceptual basis for this dissertation's development and execution, was developed in the first and second chapters as a utility function. As such, it was presented essentially as a statement of organizational goal $\mathrm{mix}$ and, through the valuation terms, as a goal hierarchy. In this form, problems associated with the comparable operationalization of largely incomparable goals were minimized, and the concept of cost was designed out of the problem. These were necessary precautions taken to avoid problems which have defied adequate solution in a wide range of applications (for example, see Clawson and knetsch, 1966). In spite of this necessity, however, this skeletal treatment of the Primitive Economy Model almost certainly diminishes the degree to which differences in goal orientation can be assessed.

3. Methodological Issues. While the discussion presented above bears a number of methodological implications, a number of other forces more closely associated with design-related issues also warrant discussion.

Selection of cities. As noted in Chapter III, the selection of cities was governed by a number of parameters designed to enhance certain types of variance and to diminish others. The use of six cities and those cities' specific selection were in part determined through budgetary constraints. While the ability to employ comparable 
data gathered virtually simultaneously in six cities constitutes an opportunity of the highest order--particularly for the manner of research employed in this dissertation--it is still appropriate to note that six is not a large number and that the hypotheses advanced in this study could possibly have been better assessed through the employment of a greater number of cities, or through greater geographic dispersion among the six, with particular emphasis on the latter. As noted earlier, communities tend to exist in open systems of social units extending in steadily increasing scales to the national and world levels. The fact that all cities selected for this study are located in the western third of the nation, in this context, undoubtedly diminishes the differences apparent between locaies by effectively reducing the differences arising out of regional differences. On the one hand, this regional concentration lends greater weight to those differences identified as being associated with intercity distinctions and therefore largely local in scale. On the other hand, national policy connotes implementation in locales within all regions of the country, and so differences manifested at the local level from regional influences are appropriate matters of study. They would also likely enhance the degree of interlocal difference identified in a study such as this.

Contextual analysis. Contextual analysis, as described earlier, comprises an analytical approach which allows the researcher to assess influences born of environmental sources affecting focal units of analysis. While its use in prior studies (Wright, 1977; Meyer, 1970; Farkas, 1974; Heyck and Klecka, 1973) is well reported, a 
consistent characteristic of these studies involves general weakness of findings as evidenced in relatively low measures of statistical signisignificance. In large measure, it is reasonable to suggest that contextual influences, such as those identified in education (Meyer, 1970), constitute subtle forces which are difficult to define and measure. This assessment would seem to be appropriate to the research reported in this document, where community-related influences generated associations among the extraorganizational decision making criteria which, in terms of probability levels, are relatively weak. The preceding discussion is oriented to a brief explication of the findings of the research reported in this dissertation, and to the provision of possible explanations for relatively weak results which could compete with the null hypothesis. The most powerful argument in this respect, however, lies in patterns reflected in the findings themselves. While this issue was largely addressed in preceding discussion, it bears brief reconsideration here as well. Two classes of findings are appropriate to note.

First, the findings of the dissertation as they relate to relevant literatures are consistent with expectations advanced in those literatures; this class of associations lend a measure of indirect external validation to this work. Particularly relevant in this respect are a number of points relating to the organizational exchange literature. Waldman's (1972) input and output components are frequently apparent in the results of these analyses, and associations between organizations and relevant environmental entities tend on the whole to mirror expectations born of that literature. 
Second, patterns apparent in the findings themselves tend to reinforce inclinations away from the null hypothesis. Particularly apparent in this regard is the difference in strengths of associations linking community with the intraorganizational criteria and with the extraorganizational criteria. Were these associations strictly spurious in nature, it is doubtful that degrees of strength between Community and the two classes of criteria would have differed so markedly. It will be recalled that associations between community and the intraorganizational criteria were found to reflect probability levels ranging from $p<.684$ to $p<.867$, while those reflecting extraorganizational criteria varied from $p<.076$ to $p<.229$, with three reflecting $p<.100$. While none of the individual significance measures meet normal criteria, the patterns in which the findings are encountered makes difficult the wholesale rejection of the dissertation's findings. In his discussion of significance levels, William L. Hays (1973) warns that the unquestioning application of tests of statistical significance can lead to the dismissal of valuable findings. In so doing, he notes the following.

Stripped of the language of decision theory and of concern with personal probabilities, all that a significant result implies is that one has observed something relatively unlikely given the hypothetical situation, but relatively more likely given some alternative situation. Everything else is a matter of what one does with this information. Statistical significance is a statement about the likelihood of the observed result, nothing else. It does not guarantee that something important, or even meaningful, has been found (p. 384).

He goes on to point out that investigators should be aware that meaningful findings can easily be dismissed through their failures to meet conventional measures of statistical significance. He says that, 
conventions about significant results should not be turned into canons of good scientific practice. Even more emphatically, a convention must not be made a superstition. It is interesting to speculate how many of the early discoveries in physical science would have been statistically significant in the experiments where they were first observed. Even in the crude and poorly controlled experiment, some departures from expestation stand out simply because they are interesting and suggest things to us that we might not be able to explain. These are matters that warrant looking into further regardless of what the conventional rule says to decide. Statistics cannot do the scientist's basic job-looking and wondering and looking again (p. 385).

It is suggested that the findings and conclusions of this dissertation are consistent with these caveats. Alone, conventional measures of statistical significance preclude the acknowlegement of community differences in the orientations of agencies to the interests of the communities in which they operate. The patterns evident in the data, however, suggest that these differences are differentially active among the two classes of organizational goals studies. These consistent differences, combined with supportive expectations derived from the literature, suggest that there may indeed be substantive associations in the data which, for a number of reasons, fail to meet conventional measures of statistical significance. Mindful of these issues, the most general finding of the dissertation may be advanced as follows: general support has been found for the notion that organizations do orient to extraorganizational as well as intraorganizational issues in the conduct of their affairs. Moreover, the patterns evident in the goals identified as more important than others to organizations were found to differentially vary between cities. While no variation was discerned between locales with respect to intraorganizational decision making criteria, 
considerable variation was identified among the extraorganizational decision making criteria. This pattern of results suggests the rejection of the study's first hypothesis--that inter-local differences would be found in organizations' orientations to intraorganizational goals. Results further suggest that the dissertation's second and third hypotheses--that interlocal differences would be identified among the extraorganizational criteria, and that these differences would exceed those found among the intraorganizational criteria--not be rejected.

\section{CONCLUSIONS}

The preceding pages in this chapter are generally oriented to a brief recounting of the theoretical development of the Primitive Economy Model, and to a general discussion of analytical findings. The section immediately preceding discussed various strengths and weaknesses in the initial application of the Primitive Economy Model as undertaken in this research endeavor. This section will attempt in the broadest possible terms to summarize the conclusions of the research reported in this dissertation. Discussion will be limited to broad conclusions as distilled from the analyses reported earlier, and will be followed by a discussion of theoretical and policy implications which might be derived from the conclusions presented here.

As noted earlier, one of the most important conclusions to emanate from this dissertation relates to organizational decision making, which is indicated here to be a more complex process than is widely acknowledged to be the case. The literature reviewed in the 
early phases of the dissertation was designed to trace the development of current organizational theory, which in large measure constitutes a treatment of organizational goals. Two issues were apparent throughout that discussion. First, the degree of specificity required in a model of organizational decision making is largely a product of the planned uses of the model. Until relatively recently, the microeconomic model of the firm, the simplest model discussed, was more than sufficient to meet the demands placed upon it, and there continue to exist a range of uses for which it is admirably suited. Nonetheless, there also exist a range of uses for which its simplicity ill suits it for use. It is for these uses that the various models discussed later, including the Primitive Economy Model, are potentially better equipped. This point leads to a second observation: organizational decision making is oriented to a range of goals and, when examined closely, demands a complex model. Employing only those models discussed in the first chapter, it is reasonable to posit an organizational utility function embracing a dozen or more goals, most of which are not consistent with one another. This observation alone suggests a managerial capacity for decision making which is very highly developed, even in models embracing only intraorganizational goals. The addition of goals which are best associated with extraorganizational parties and conditions lends even greater complexity to the model, and suggests the existence of a valuational mechanism for relating goals of considerable dissimilarity.

Just as important is the fact that stimulants of organizational activity appear to be multi-faceted and, on the whole, relatively 
limited in the type of response they generate. Indeed, in terms of the policy implications to be discussed shortly, this may be the most important finding to emanage from the study. In this regard, a certain class of variables tends to covary with organizational orientations toward various measures of their own welfare. The function of the organization, for example, is clearly associated with its orientation toward funding and other, similar issues, such as instability among extralocal governmental bodies. Similarly, instability among the local population as a whole tends to heighten organizational orientations toward autonomy. While instability among local agencies diminishes organizational orientations toward its own welfare, interlocal distinctions do not impact upon these orientations. However, phenomena active at the local level, such as local public and interorganizational turbulence, do. Orientations toward expressive indications of interorganizational support are inversely associated with turbulence in that arena. Finally, interlocal distinctions appear to be important in orientations to the extraorganizational benefits arising out of concerted organizational activity. In general, the impacts of those influences identified as impacting upon organizational goals appear to be quite specific.

Finally, within the context identified by the previous discussion, it appears that organizations in different communities do in fact differ in their orientations to certain classes of goals, and so very likely differ in their behaviors. This issue, addressed explicitly in the study's research question, constitutes the analytical focus of the dissertation and, more generally, bears important implications for the 
administration and delivery of human services.

\section{IMPLICATIONS}

\section{Theoretical Implications}

As was noted earlier, the findings of the dissertation bear directly on two relevant literature: community theory and organizational theory.

While not accorded a prominent role in the theoretical development of this dissertation's analytical approach, an important element of the project's design involved expectations of orientational differences between organizations in different cities. That these differences were identified only among one of two classes of organizational goals is noteworthy and generally consistent with expectations born of this literature. The identification of such differences among extraorganizational goals connotes differences in the goals and values of organizations' environments as identified by location. This finding implies the existence of social cohesion and of uniqueness within communities, both of which are characteristics of communities identified in the literature. In this sense, the findings of this study provide a new source of empirical verification for those theoretical explications. That community was not identified as a determinant of intraorganizational orientations is probably not so much a denial of communityrelated influences as it is an indication of how far community-related influences can be expected to extend. Stated alternatively, this pattern of findings would lend credence to a general tendency among organizations to engage in endeavors which at least up to a point serve 
their own interests.

Closely related to these points is the role of environments as determinants of organizational behavior. Five environmental components were addressed in the analyses reported earlier, including four measures of turbulence, and Community. That each was found to exhibit unique patterns of association with various organizational orientations is supportive both of contentions that environments share operative associations with organizations, and that environments may best be conceptualized not as integral, but rather as collections of heterogeneous sub-components. Again, this finding is consistent with the literature.

This dissertation employed as its integrating model a relatively recent contribution to organizational theory, the Primitive Economy Model (O'Brien, 1976b), and its corollary, the Differential Mix Hypothesis. Each warrants discussion.

The Primitive Economy Model in itself constitutes a theoretical development of considerable magnitude in that it provides a basis for incorporating the two classes of goal into a common statement. As such, it suggests new approaches to the concepts of exchange and reciprocity which have not gained common favor among those who analyze organizations. These fundamental considerations aside, however, the Primitive Economy Model is a logical extension of the work advanced by others and described in the first chapter. First, it incorporates the work of economists and others who suggest a range of goals relating to the economic well-being of the organization and of parties associated with the organization. Second, the Primitive Economy Model 
incorporates into the context established by economists the work of organizational theorists addressing environmental issues. Together, these characteristics of the model promise the analysis of organizational issues at a level of considerably greater specificity and precision than would otherwise be possible. Above all, the model is adaptable to a wide range of research contexts. While those environmental components of greatest interest in this particular application of the Primitive Economy Model were local in nature, a myriad of others are amenable to the model as well: environments could be identified in terms of funding sources, markets, regulatory bodies, industries, regional locations, and a host of others as dictated by the nature of potential research. Similarly, the nature of extraorganizational benefits and beneficiaries can be adapted to suit the needs of the researcher. While acknowledging that the Primitive Economy Model could only be applied in partial form in this dissertation, it is nonetheless appropriate to claim support for the model within those limitations.

The Differential Mix Hypothesis constitutes the means by which the Primitive Economy Model was adapted to this research application. Like the model from which it was developed, this analytical tool is amenable to a broad range of uses and research settings. Moreover, the model is consistent with existing approaches to organizational analysis. Probably the most readily identifiable value of the Differential Mix Hypothesis lies in its potential for verifying taxonomies developed from theoretical grounds. To the extent that classificatory schemes are posited to reflect potential differences in behavior or goal, this 
tool provides a device by which such differences may be specified and tested.

\section{Policy Implications}

It will be recalled that the research undertaken in this dissertation is based on a rather specific class of organizations and, further, that the cities within which sampling occurred exhibit a restricted range of populations. Because these findings of necessity reflect decisions made in the sampling process, it is necessary to explicitly limit the implications drawn from the research to the population of organizations from which the sample was derived. Two such restrictions apply.

1. Organizations. The organizational sample upon which analyses are based and findings derived is almost solely comprised of human service agencies. While these agencies display a broad range of characteristics pertaining to function, location, relation to federal funding sources, and others, they nonetheless are distinguishable from most other organizational types through the relatively complete separation of their input components from those benefitting from their operation. Where commercial firms typically derive their income from precisely those parties--their customers--employing their products, service agencies generally orient to transfer programs whereby resources from one element of a constituency are passed to members of another constituent population. This is an important distinction.

2. Cities. It will be recalled from Chapter IV that for a number of reasons the sites addressed in this survey were limited to 
mid-sized cities. Smaller cities were deleted in order to avoid simplicity in interorganizational networks, while larger cities were avoided in order to obviate unwanted complexity in organizations' operational environments. Implicit in this sampling stipulation is an awareness that realities in both operational settings--large and small cities--likely differ from those of mid-sized locales, and these differences necessarily limit the direct application of the dissertation's findings.

Within these parameters, the dissertation's findings suggest three policy implications of merit.

First and foremost, the tendency for local organizations to orient to different extraorganizational goals in different locales suggests that coordinating programs designed to be implemented throughout states, regions, and the nation must embrace a degree of flexibility in order to "fit" with operational realities in various locales. Accordingly, goals identified by extralocal entities undertaking such strategies should be kept general, allowing for a range of diversity in the development of specific implementation strategies at the local level. In a real sense, this point is largely a vindication of the approach employed by the Administration on Aging in its organization of aging services networks in locales around the country. By mandating a general condition--the creation of agency networks so as to provide a range of services to elderly clients--the AOA left room for the local tailoring of programs as demanded by local conditions and needs. second, it appears from this dissertation's findings that extralocal funding is not a major factor in the orientation of firms 
toward their communities. Virtually all firms contacted in the survey were dependent in same measure upon federal or state sources for their funding, yet the findings suggest differences in extraorganizational goal hierarchies between locales. This finding is substantiated in the lack of associations evidenced between agencies' reliance on federal funding and their orientations toward the eight decision making criteria. In short, federal monies do not appear to be influential in establishing the nature of organizational-environmental linkages at the local level; rather, it would appear that organizations do in fact develop in response to local conditions and that external support follows as agencies mature, as their early funding sources are lost, or as support is sought for new, locally-initiated organizations. This observation is not intended to suggest that federal funding is not instrumental in developing new services for clients. It was not unusual during interviews with agency directors, for example, to encounter agencies which would extend their services to new classes of clients were resources available. In these cases, funding availability would benefit new classes of clients with services which would be new to them. In virtually all cases, however, the services themselves and the motivation for their initial introduction were locally derived. Indeed, the identity of target populations was found to vary considerably from locale to locale. In sum, the role of locale in the development of human services is both important and pervasive. Third, to the extent that monetary and other classes of intraorganizational inducements are effective in promoting desired ends among service agencies, this effectiveness is likely to be universally 
realized in spite of intercity differences. Agencies in all cities studied were equally attuned to intraorganizational measures of success. This is not an inconsequential finding, for a great deal of policy can be implemented within the parameters of locally-defined organizational responsibilities and goals. Agencies, for example, can provide needed, existing services to new classes of clients, and interorganizational systems can be established or combined for a broad range of ends. In each case and in many others, a clearly defined desired end and requisite resources can lead to very clear and desired responses at the local level.

In the final analysis, the findings of this dissertation research suggest that local service provision is best seen as a cooperative endeavor undertaken by local and extralocal organizations acting in concert, each providing a set of mutually compatible resources in responding to a problem. Local entities can identify problems, act appropriately, and provide staffing and direction. Extralocal agencies-the federal government, the United Jewish Appeal, the Salvation Army, the Red Cross, and countless others--provide funds and, perhaps, technologies and operational procedures. In large measure, each is reliant upon the other, and each is a determinant of the other's ability and success.

In the final analysis, the research presented in this document offers support to the theoretical foundations upon which it is based. Findings suggest that economic considerations tend to be universal among agencies, as is posited in the economic literature. Other findings suggest, however, that organizations respond to influences 
other than the purely intraorganizational, and that in so doing they address issues relating to their operational environments. In many cases, characteristics of environmental influence were found to yield relatively constant reactions regardless of community setting, though it was also shown that the simple fact of geographic location also influences certain aspects of organizational operation. In all, this research suggests that the operational reality of human services organizations is a complex of goals, environmental forces, and linkages which, if fully understood, would allow considerable finetuning of existing and potential service networks. It is hoped that the dissertation, in exploring this array of forces, added a degree of insight to that end.

In all, the research reported in this document shares with most other investigations the disquieting quality of producing more questions than it answered. This ubiquitous quality would seem to suggest that perhaps the real value of academic inquiry lies not in providing answers to questions, but rather in compounding our perceived ignorance by adding to the scales against which it is measured. 
SELECTED BIBLIOGRAPHY

Aiken, Michael and Paul E. Mott (Eds.). The structure of community power. New York: Random House, 1970.

Alwin, Duane $F$. The use of factor analysis in the construction of linear composites in social research. Sociological Methods and Research, $\underline{2}$ (2), November 1973.

Angell, Robert Cooley. The moral integration of american cities. American Journal of Sociology, 80 (3), November 1974.

Azariadis, C., K.J. Cohen, and A. Porcare. A partial utility approach to the theory of the firm. Southern Economic Journal, April 1972.

Baumol, William J. Business behavior, value and growth (Rev. ed.). New York: Harcourt, Brace and World, 1967.

Bell, Bill D. Disaster impact and response: Overcoming the thousand natural shocks. The Gerontologist, 18 (6), December 1978.

Bell, Daniel. The coming of post-industrial society: A venture in social forecasting. New York: Basic Books, 1973.

Benson, J. Kenneth. The interorganizational network as a political economy. American Sociological Quarterly, 20, June 1975.

Bernard, Chester. The functions of the executive. Cambridge, Mass.: Harvard University Press, 1950.

Bernard, Jessie. American community behavior. New York: Holt, Rinehart, and winston, 1952 .

Bernard, Jessie. Community तisorganization. In n. L. Sills (Ed.), International encycloperia of social sciences. New York: Mac Millan Free Press, 1968.

Bish, Robert L. and Vincent Ostram. Understanding urban government: Metropolitan reform reconsidered. Washington: American Enterprise Institute for Public Policy Research, 1973.

Blalock, Hubert M., Jr. Social statistics. New York: McGraw-Hill Book Co., 1972.

Blau, Peter M. Presidential address: Parameters of social structure. American Sociological Review, 39 (1), October 1974. 
Blau, Peter M. Organizations. In David L. Sills (Ed.), International encyclopedia of the social sciences. New York: MacMillan Co. and Free Press, 1968.

Bourne, Barry S. Private development of the central city (Research paper No. 112). Chicago: Department of Geography, University of Chicago, 1967.

Burki, Mary. Typologies of organizations. In John E. O'Brien and Terrie Wetle (Eds.), Testing a community intervention model. Portland: Institute on Aging, Portland State University, 1978.

Catrice-Lorey, Antoinette. Social security and its relations with its beneficiaries: The problem of bureaucracy in social administration. In Daniel Katz and Dana Katz (Eds.), Bureaucracy and the public. New York: Basic Books, 1973.

Child, John. Organizational structure, environment, and performance. Sociology, 6 (1), January 1972.

Clawson, Marion and Jack L. Knetsch. Economics of outdoor recreation. Baltimore: Johns Hopkins Press (for Resources for the Future), 1966.

Cohen, Kalman J. and Richard M. Cyert. Theory of the firm: Resource allocation in a market economy. Englewood Cliffs, N.J.: Prentice-Hall, 1965.

Coleman, James S. Community conflict. Glencoe, Ill.: The Free Press, 1957.

Coleman, James S. Relational analysis: The study of social organizations with survey methods. In Merlin B. Brinkerhoff and Philip R. Kunz (Eds.), Complex organizations and their environments. Dubuque, Iowa: William C. Brown Co., 1972.

Craven, Paul and Barry Wellman. The network city. Sociological Inquiry, $42(3-4), 1972-1973$.

Crew, M.A., M.W. Jones-Lee, and C.K. Rowley. X-theory versus management discretion theory. Southern Economic Journal, XXXVIII (2), October 1971.

Cyert, R.M. and J.G. March. Organizational structure and pricing behavior in an oligopolistic market. American Economic Review, XLV (1), March 1955.

Cyert, R.M. and J.G. March. Organizational factors in the theory of oligopoly. Quarterly Journal of Economics, LXX (1), February 1956. 
Cyert, Richard Michael and James G. March. A behavioral theory of the firm. Englewood Cliffs, N.J.: Prentice-Hall, 1963.

Dahl, Robert A. Who governs? Democracy and power in an American city. New Haven: Yale University Press, 1961.

Dalton, George. Primitive, archaic and modern economics: Essays of Karl Polanyi. Boston: Beacon Press, 1968.

Dewey, John. The public and its problems. Chicago: The Swallow Press, 1954.

Dill, William R. The impact of environment on organization development. In Sidney Mailick and Edward H. Van Ness (Eds.), Concepts and issues in administrative behavior. Englewood Cliffs, N.J.: Prentice-Hall, 1962 .

Drabek, James E. and Judity B. Chapman. On assessing organizational priorities: Concept and method. Sociological Quarterly, 14 (3), Summer 1973.

Emerson, Richard M. Power-dependence relations. American Sociological Review, 27 (1), February 1962.

Estes, Carroll L. The aging enterprise. San Francisco: Josey Bass, 1979.

Etzioni, Amitai. A comparative analysis of complex organizations: On power, involvement, and their correlates. New York: Free Press, 1975.

Farkas, George. Specification, residuals and contextual effects. Sociological Methods and Research, 2 (3), February 1974.

Farley, Reynolds. Suburban persistance. American Sociological Review, 29 (I), February 1964 .

Fischer, Claude S. Toward a subcultural theory of urbanism. American Journal of Sociology, 80 (6), May 1975.

Flinn, William L. Influence of community values on innovativeness. American Journal of Sociology, 75 (6), May 1970.

Galbraith, J.K. The new industrial state. Boston: Houghton Mifflin, 1967.

Gans, Herbert J. The Levittowners. New York: Vintage Press, 1967.

Gawthrop, Iouis C. Organizational change: A conceptual model. Bureaucratic behavior in the executive branch: An analysis of organizational change. New York: Free Press, 1969. 
George, Victor and Paul wilding. Social values, social class and social policy. Social and Economic Administration, 6 (3), September 1972.

Gordon, M.J. The investment, financing, and valuation of the corporation. Homewood, Ill.: Richard D. Irwin, Inc., 1962.

Griffith, James, Lewis N. Gray, and Bruce Mayhew, Jr. Formal structures and communication: An examination of two models. Sociological Methods and Research, 2 (1), May 1973.

Grimes, Michael D., Charles M. Bonjean, J. Larry Lyon, and Robert I. Iineberry. Community structure and leadership arrangements: A multidimensional analysis. American Sociological Review, 41 (4), August 1976.

Gross, Edward. The definition of organizational goals. British Journal of Sociology, XX (3), September 1969.

Hannan, Michael T. and John Freeman. The population ecology of organizations. American Journal of Sociology, 82 (5), March 1977.

Hawley, Amos. Ecology. In David L. Sills (Ed.), International encyclopedia of the social sciences. New York: MacMillan Co. and the Free Press, 1968.

Hays, William L. Statistics for the social sciences (2nd ed.). New York: Holt, Rinehart and Winston, 1973.

Herendeen, James B. Alternative models of the corporate enterprise: Growth maximization and value maximization. quarterly Review of Economics and Business, 14 (4), winter 1974.

Heyck, T.W. and William Klecka. British radical M.P.s, 1874-1895: New evidence from discriminant analysis. Journal of InterDisciplinary History, IV (2), Autum $1 \overline{973 .}$

Hillery, George A., Jr. Conmunal organizations: A study of local societies. Chicago: The University of Chicago Press, 1968.

Hunter, Albert. The loss of community : An empirical test through replication. American Sociological Review, 40 (5), October 1975.

Janowitz, Morris. The community press in an urban setting. Glencoe, III.: The Free Press, 1952.

Kania, John J. and John R. McKean. Decision-making in the extensive firm. Nebraska Journal of Economics and Business, 18 (1), Winter 1979. 
Kaplan, Abraham. On the strategy of social planning. Policy Sciences, 4 (1), March 1973.

Katz, Daniel and Robert L. Kahn. Organizations and the system concept. In Merlin B. Brinkerhoff and Phillip R. Kunz (Eds.), Complex organizations and their environments. Dubuque, Iowa: William C. Brown Co., 1972 .

Kerlinger, Fred N. Foundations of behavioral research. New York: Holt, Rinehart and Winston, 1973.

Khandwalla, Pradip N. Environment and its impact on the organization. International Studies of Management and Organizations, 12 (3), Fall 1972 .

Kilijanek, Thomas S. and Thomas E. Drabek. Assessing the long-term impacts of a natural disaster: A focus on the elderly. The Gerontologist, 19 (6), December 1979.

Koplin, H.T. The profit maximization assumption. Oxford Economic Papers, I5 (2), July 1963.

Koplin, H.T. Microeconomic analysis: Welfare and efficiency in private and public sectors. New York: Harper and Row, 1971.

Kroll, Martin. Hypotheses and designs for the study of public policies in the United States. Midwest Journal of Political Science, VI (4), November 1962 .

Laumann, Edward O., Peter V. Marsden, Joseph Galaskiewicz. Communityelite influence structures: Extension of a network approach. American Journal of Sociology, 83 (3), November 1977.

Ieibenstein, H. Economic theory and organizational analysis. New York: Harper and Row, 1960.

Leibenstein, H. Allocative efficiency versus 'x-efficiency'. American Economic Review, LVI (3), June 1966.

Levine, Sol and Paul E. White. Exchange as a conceptual framework for the study of interorganizational relationships. In Merlin B. Brinkerhoff and Phillip R. Kunz (Eds.), Complex organizations and their environments. Dubuque, Iowa: William C. Brown Co., 1972.

Iogan, John R. Industrialization and the stratification of cities in suburban areas. American Journal of Sociology, 82 (2), September 1976.

Lowry, Ritchie P. Who's running this town? Community leadership and social change. New York: Harper and Row, 1968. 
Iyden, Fremont James. Using Parson's functional analysis in the study of public organizations. Administrative Science Quarterly, 20 20 (1), March 1975.

MacIver, Robert M. In Leon Bramson (Ed.), Robert MacIver on community, society, and power. Chicago: University of Chicago Press, 1970.

Magid, Alvin. Organizational character versus citizen involvement: The New York school decentralization controversy. The Urban and Social Change Review, 3 (1), Fall 1969.

Maniha, John and Charles Perrow. The reluctant organization and the aggressive environment. American Sociological Quarterly, 10 (2), September 1965.

Marris, R. The economic theory of managerial capitalism. London: MacMilian and Co., Ltd., 1964.

Marsh, C. Paul and A. Lee Coleman. The relation of neighborhood of residence to adoption of recommended farm practices. Rural Sociology, 19 (4), December 1954.

Marshall, Alfred. Principles of economics. New York: MacMillan Co., 1948.

McClelland, Donald A. and William H. Form. Economic dominants and community power: A comparative analysis. American Journal of Sociology, IXIX (5), March 1964.

Mercer, B.E. American community. New York: Random House, 1956.

Meyer, John M. High school effects on college intentions. American Journal of Sociology, 76 (1), July 1970.

Middleton, Russell. Regional differences in prejudice. American Sociological Review, 41 (1), February 1976.

Miernyk, william H. The elements of input-output analysis. New York: Random House, 1965.

Miller, Jerry L. and Maynard L. Erickson. On dummy variable regression analysis: A description and illustration of the method. Sociological Methods and Research, 2 (4), May 1974.

Mindlin, Sergio E. and Howard Aldrich. Interorganizational dependence: A review of the concept and a reexamination of the findings of the Aston group. Administrative Science guarterly, 20 (2). September 1975. 
Monsen, R. Joseph, Jr. and Anthony Downs. A theory of large managerial firms. The Journal of Political Economy, LXXIII (3), June 1965.

Nie, Norman H., C. Hadlai Hull, Jean G. Jenkins, Karin Steinbrenner, and Dale H. Bent. Statistical package for the social sciences

(2nd ed.). New York: McGraw-Hill, 1975.

Niskanen, William A. Nonmarket decision making: The peculiar economics of bureaucracy. American Economic Review, LVIII (2), May 1968.

Nunnally, Jum C. Psychometric theory. New York: McGraw-Hill Co., 1967.

O'Brien, John E. The problem of exchange theory for interorganizational analysis: A critical review. Paper presented at the annual meeting of the American Sociological Association, New York, 1976a.

O'Brien, John E. Toward a reconceptualization of exchange theory for interorganizational analysis. Unpublished paper, Institute on Aging, Portland State University, Portland, Oregon, 1976b.

O'Brien, John E. and Terrie Wetle. Analysis of conflict in coordination of aging services. Portland, Oregon: Institute on Aging, Portland State University, 1975.

O'Brien, John E. and Terrie Wetle. Testing a community intervention model. Portland, Oregon: Institute on Aging, Portland State University, 1978.

Ostram, Vincent, Charles M. Tiebout and Robert Warren. The organization of government in metropolitan areas. American Political Science Review, 55, December 1961.

Parsons, Talcott. Suggestions for a sociological approach to the theory of organizations (Part I). American Sociological guarterly, I (1), June 1956.

Parsons, Talcott. Suggestions for a sociological approach to the theory of organizations (Part II). American Sociological guarterly, 1 (2), September 1956.

Penrose, E.T. The theory of growth of the firm. Oxford: Basil Blackwood and Mott, Ltd., 1959.

Perrow, Charles. The analysis of goals in complex organizations. American Sociological Review, 26 (6), December 1961.

Polanyi, Karl. The great transformation. New York: Rinehart, 1944.

Polsby, Nelson $w$. The study of community power. In David L. Sills (Ed.), International encyclopedia of the social sciences. New York: MacMillan Co. and the Free Press, 1968. 
Rees, Phillip H. Factorial ecology: An extended definition, survey and critique of the field. Economic Geography, 47 (2), June 1971.

Rickson, Roy E. and Charles E. Simpkins. Industrial organizations and the ecological process: The case of water pollution. In Merlin B. Brinkerhoff and Phillip R. Kunz (Eds.), Complex organizations and their environments. Dubuque, Iowa: William C. Brown Co., 1972.

Rogers, Everett M. and Rabel J. Burdge. Community norms, opinion leadership and innovativeness among truck growers (Research Bulletin No. 912). Wooster, Ohio: Agricultural Experiment Station. (Cited in William I. Flinn, Influence of community values on innovativeness, American Journal of Sociology, 75 (6), May 1970).

Roistacher, Richard C. A review of mathematical methods in sociometry. Sociological Methods and Research, $\underline{3}$ (2), December 1974.

Saltzstein, Alan L. Federal categorical aid to cities: Who needs it vs. who gets it. Western Political Science Quarterly, XXX (3), September 1977.

Samuelson, Paul A. Economics. New York: McGraw-Hill, 1964.

Samuelson, Paul A. Foundations of economic analysis. New York: Atheneum, 1976 .

Schein, Edgar H. The organization as a complex system. In Organizational psychology (2nd ed.). Englewood cliffs, N.J.: PrenticeHall, 1970.

Schjmpeire, Charles G. and William L. Greco. Systems evaluation: An approach based on community structure and value. In Ida $M$. Robinson (Ed.), Decision-making in urban planning. Beverly Hills; Sage Publications, 1972 .

Schnore, Leo F. and Robert R. Alford. Forms of government and socioeconomic characteristics of suburbs. Administrative Science Quarterly, \& (1), June 1963.

Schramm, Richard and Roger Sherman. Profit, risk management, and the theory of the firm. Southern Economic Journal, 40 (3), January 1974 .

Simon, Herbert A. Theories of decision-making in economics and behavioral science. American Economic Review, XIIX (3), June 1959).

Simon, Herbert A. New developments in the theory of the firm. American Economic Review, III (2), May 1962.

Smith, Adam. Wealth of nations. New York: P.F. Collier and Son Co., 1909. 
Srole, Leo. Urbanization and mental health: Some reformulations. American Scientist, 60 (5), September-October 1972.

Stacey, Margaret. The myth of conmunity studies. British Journal of Sociology, XX (2), June 1969

Stinchcombe, Arthur I. Social structure and organizations. In Merlin B. Brinkerhoff and Phillip R. Kunz (Eds.), Complex organizations and their environments. Dubuque, Iowa: William C. Brown Co., 1972 .

Susmilch, Charles E. and Weldon T. Johnson. Factor scores for constructing linear composites: Do different techniques make a difference? Sociological Methods and Research, $\underline{4}$ (2), November 2975.

Suttles, Gerald D. The social construction of communities. Chicago: University of Chicago Press, 1972.

Terreberry, Shirley. The evolution of organizational environments. American Sociological Quarterly, 12, March 1968.

Thernstrom, Stephan. 'Yankee City' revisited: The perils of historic naivete. In Michael Aiken and Paul E. Mott (Eds.), The structure of community power. New York: Random House, 1970.

Thompson, James D. and William J. McEwen. Organizational goals and environment: Goal setting as an interaction process. In Merlin B. Brinkerhoff adn Phillip R. Kunz (Eds.), Complex organizations and their environments. Dubuque, Iowa: William $C$. Brown Co., 1972 .

Timms, D.W.G. The urban mosaic: Towards a theory of residential differentiation. Cambridge: Cambridge University Press, 1971.

Waldman, Sidney R. Exchange theory and political analysis. Sociological Inquiry, $42(3-4), 1972$.

Warren, Roland I. The comnunity in America. Chicago: Rand McNally, 1963.

Warren, Roland $\mathrm{L}$. The interaction of community decision organizations: Basic concepts and needed research. Social Service Review, 41 41 (3), September 1967.

Weber, Max. The theory of social and economic organization. New York: Free Press, 1947.

Wetle, Terrie Todd. Coordination in social service systems: The area agency on aging as a case study. Unpublished doctoral dissertation, Portland State University, Portland, Oregon, 1976. 
Williams, Robin M., Jr. Individual and group values. Annals (Vol. 371), May 1967.

Williamson, J. Profit, growth, and sales maximization. Economica, XXXIII (129), February 1966.

Williamson, Oliver E. The economics of discretionary behavior: Managerial objectives in a theory of the firm. Englewood Cliffs, N.J.; Prentice-Hall, 1964.

Wilson, James Q. and Edward C. Banfield. City politics. Cambridge: Harvard University Press, 1963.

Winsborough, Hal N. City growth and city structure. Journal of Regional Science, $\underline{4}$ (2), Winter 1962.

Wright, Gerald C., Jr. Contextual models of electoral behavior: The southern Wallace vote. American Political Science Review, IXXI (2), June 1977.

Young, James N. and A. Lee Coleman. Neighborhood norms and the adoption of farm practices. Rural Sociology, 24, December 1962. 


\section{APPENDIX I}

TESTS OF MUTUAL INDEPENDENCE OF INSTRUMENTS I AND 2 
A critical assumption in this application of the Primitive Economy Model lies in the independence of intraorganizational decision criteria from the extraorganizational decision criteria.

As represented in formula (14), the two are envisioned as separate considerations in the decision making process, independent of one another except through their functional relations to the decision making process and outcome. They are derived from different sources, and compel organizations to assess their operational options both with respect to the direct net rewards accruing to the organization itself and to entities outside the organization. Accordingly, the independence of the two types of criteria constitute a cornerstone of the Primitive Economy Model.

A quite different conceptualization, not supportive of the Primitive Economy Model, could also be intuitively derived. Here, extraorganizational considerations are important only to the extent that they enhance the likelihood of attaining intraorganizational goals. An example could be cited in the sponsorship for public relations purposes of public broadcasting programming by numerous firms.

The instruments and variables developed both in the original study and in this dissertation were developed to assess the former model, implicitly citing the mutual independence of the two sets of criteria. It is, therefore, appropriate to test the various operationalizations of the two sets of criteria in order to assess their demonstrated independence.

Two such tests were undertaken. The first compares 
intercorrelations between the 24 items comprising Instruments 1 and 2 (see Chapter IV), the second involves the factor analysis of all 24 items, and the third assesses intercorrelations between the eight composite variables employed in the dissertation's analyses as operationalizations of the two types of criteria.

The results of these tests are reported below.

1. Correlational Analysis. The first analytical test of the two instruments' mutual independence involved the inspection of the correlation matrix relating the 24 items from both instruments. Three sets of comparisons were performed. First, the number of correlations exceeding an absolute value of .30 were counted; if the two instruments are in fact unrelated, there should be a higher incidence of correlations greater than .30 between paired items from the same instruments than between pairs representing both. Second, the median correlation was determined for pairs within each of the instruments, and for pairs representing both; here the median values representing pairs within instruments should exceed that found for pairs between the two. Finally, the highest correlations for pairs within and between instruments were determined; again, this value should be higher for pairs derived from the same instrument than for pairs derived from both. Table XLIV summarizes these comparisons.

of the 144 pairs of items representing both instruments, none reflected a correlation equalling or exceeding .30. This compares with 10 of 66 pairs from Instrument 1, and with 14 of 66 pairs from Instrument 2 which exceed .30 . This comparison is interpreted as supportive of the two instruments' independence. 
Median correlation values support the same interpretation. Correlations relating items within Instrument 1 reflect a median of .16968, while those reflecting pairs derived from Instrument 2 present a median of .16683. Paired items from both instruments, however, have a median value of .07749 .

TABLE XLIV

SELECTED DESCRIPTORS OF CORRELATIONS BETWEEN PAIRED ITEMS FROM INSTRUMENTS 1 AND 2

\begin{tabular}{|c|c|c|}
\hline & $\begin{array}{c}\begin{array}{c}\text { Number of } \\
\text { Correlations } \\
<.30\end{array} \\
\end{array}$ & $\begin{array}{c}\text { Median } \\
\text { Correlation }\end{array}$ \\
\hline $\begin{array}{l}\text { Pairs of Items } \\
\text { From } \\
\text { Instrument } 1\end{array}$ & 10 of 66 & .16968 \\
\hline $\begin{array}{l}\text { Pairs of Items } \\
\text { From Both } \\
\text { Instruments }\end{array}$ & 0 of 144 & .07749 \\
\hline $\begin{array}{l}\text { Pairs of Items } \\
\text { From } \\
\text { Instrument } 2\end{array}$ & 14 of 66 & .16683 \\
\hline
\end{tabular}

Overall, however, these analyses do lend credence to the assumption being tested. Both of the comparisons, involving the number of correlations exceeding . 30 and median correlations, provide clear support for the assumption.

2. Factor Analysis. As a different test of independence between the two instruments, a factor analysis was undertaken employing all 24 items from the two instruments. In this analysis, it was hypothesized that factors developed would all fall within one of the two checklists. 
To the extent that no factor was comprised of items from both instruments, their mutual independence would be supported.

Table XLV presents the results of the analysis. Eight factors were generated before the program's default option terminated the analysis. As can be seen in the table, only on the eighth factor did items from both instruments load above .30 load on the same factor. In each of the first seven factors, all items loading higher than .30 on a factor represent the same instrument.

Like that of the correlation analysis, this result is deemed supportive of the mutual independence of the two instruments.

3. Correlational Analys is of Composite Variables. While the two analyses described above are deemed supportive of the assumption in question, it was deemed wise to assess the degree to which the composite variables derived from the items which display mutual freedom of variance.

Accordingly, Pearson's Product-Moment Correlations measuring the strength of relation between paired variables representing Intraorganizational and Extraorganizational criteria were developed. These correlations are reported in Table XLVI. As can be seen, the highest correlation relating External Orientation to Autonomy is .263 . The median correlation is .137. As with the others, this analysis was deemed supportive of the mutual independence of the two instruments.

In sum, the three results described above were all deemed supportive of the mutual independence of the Intraorganizational and Extraorganizational Decision Making criteria. Accordingly, the analyses comprising the testing of the dissertation's thesis, and the 
TABLE XLV

FACTOR ANALYSIS OF INSTRUMENTS 1 AND 2

\begin{tabular}{|c|c|c|c|c|c|c|c|c|}
\hline$\frac{\text { Instrument }}{\text { Item }}$ & $\begin{array}{c}\text { Factor } \\
1 \\
\end{array}$ & $\begin{array}{c}\text { Factor } \\
2 \\
\end{array}$ & $\begin{array}{c}\text { Factor } \\
3 \\
\end{array}$ & $\begin{array}{c}\text { Factor } \\
4 \\
\end{array}$ & $\begin{array}{c}\text { Factor } \\
5\end{array}$ & $\begin{array}{c}\text { Factor } \\
6 \\
\end{array}$ & $\begin{array}{c}\text { Factor } \\
7 \\
\end{array}$ & $\begin{array}{c}\text { Factor } \\
8 \\
\end{array}$ \\
\hline \multicolumn{9}{|l|}{ Instrument 1 , Interagency Agreements } \\
\hline $\begin{array}{l}\text { 1. (Increase Services) } \\
\text { 2. (Avoid Entanglements) } \\
\text { 3. (Here and Now Basis) } \\
\text { 4. (Avoid Publicity) } \\
\text { 5. (Staff Interests) } \\
\text { 6. (Maintain Goals) } \\
\text { 7. (Bread and Butter) } \\
\text { 8. (Increase Departments) } \\
\text { 9. (Stress Clear Agreements) } \\
\text { 10. (Hard Bargain) } \\
\text { 11. (Wishes of Board) } \\
\text { 12. (Maximize Return) }\end{array}$ & $\begin{array}{r}.252 \\
.075 \\
.230 \\
.039 \\
-.014 \\
.063 \\
.053 \\
-.273 \\
.161 \\
-.069 \\
.014 \\
.068\end{array}$ & $\begin{array}{l}.181 \\
.056 \\
.251 \\
.157 \\
.178 \\
-.044 \\
.181 \\
.221 \\
.348^{\star} \\
.569^{\star} \\
.497^{\star} \\
.675^{\star}\end{array}$ & $\begin{array}{r}.169 \\
.030 \\
.126 \\
.183 \\
-.019 \\
.089 \\
-.021 \\
.116 \\
.070 \\
.021 \\
.037 \\
-.046\end{array}$ & $\begin{array}{l}-.143 \\
.630^{\star} \\
.361^{\star} \\
.029 \\
.163 \\
.443^{\star} \\
.109 \\
-.088 \\
.442^{\star} \\
.161 \\
.040 \\
-.010\end{array}$ & $\begin{array}{l}.132 \\
-.016 \\
.170 \\
.449 \star \\
.440^{\star} \\
.048 \\
.701^{\star} \\
.405^{\star} \\
.134 \\
.267 \\
.035 \\
.238\end{array}$ & $\begin{array}{r}-.017 \\
.007 \\
.067 \\
.005 \\
.026 \\
.011 \\
-.154 \\
.149 \\
.072 \\
-.071 \\
.123 \\
-.069\end{array}$ & $\begin{array}{r}-.187 \\
.043 \\
-.033 \\
.026 \\
.233 \\
-.089 \\
-.136 \\
.065 \\
.159 \\
.131 \\
.072 \\
-.125\end{array}$ & $\begin{array}{r}.395^{\star} \\
-.070 \\
.007 \\
-.021 \\
.417 \star \\
.128 \\
-.059 \\
.101 \\
-.298 \\
.105 \\
.112 \\
-.025\end{array}$ \\
\hline \multicolumn{9}{|c|}{ Instrument 2 , Interagency Agreements and the Community } \\
\hline $\begin{array}{cl}\text { 1. } & \text { (Link Agencies) } \\
\text { 2. (Avoid Struggle) } \\
\text { 3. (Exclude Uncooperative) } \\
\text { 4. (Promote Cooperation) } \\
\text { 5. (Avoid Agency Building) } \\
\text { 6. (Avoid Self-Serving Orgs) } \\
\text { 7. (Example of Fair Play) } \\
\text { 8. (Community Leaders) } \\
\text { 9. (Increase Regard) } \\
\text { 10. (Avoid Undependable Orgs) } \\
\text { 11. (Strengthen Capacity) } \\
\text { 12. (Client Input) }\end{array}$ & $\begin{array}{l}.259 \\
.162 \\
-.039 \\
.597^{\star} \\
.193 \\
.130 \\
.651^{\star} \\
.193 \\
.571^{\star} \\
.157 \\
.524^{\star} \\
.546^{\star}\end{array}$ & $\begin{array}{r}.030 \\
.160 \\
-.089 \\
-.006 \\
.0116 \\
.054 \\
.102 \\
.056 \\
-.072 \\
.054 \\
.160 \\
-.124\end{array}$ & $\begin{array}{l}-.079 \\
.225 \\
.645^{\star} \\
.014 \\
.209 \\
.470^{\star} \\
.159 \\
.057 \\
.106 \\
.560^{\star} \\
.046 \\
.038\end{array}$ & $\begin{array}{r}.027 \\
.298 \\
.001 \\
.129 \\
.083 \\
.119 \\
.081 \\
-.055 \\
.016 \\
.134 \\
-.016 \\
.062\end{array}$ & $\begin{array}{r}-.047 \\
-.167 \\
.220 \\
.013 \\
-.236 \\
.048 \\
-.205 \\
-.003 \\
.083 \\
-.034 \\
.001 \\
.055\end{array}$ & $\begin{array}{l}.729 \star \\
.293 \\
.120 \\
.470^{\star} \\
.145 \\
-.039 \\
.135 \\
.083 \\
.209 \\
-.125 \\
-.029 \\
.086\end{array}$ & $\begin{array}{l}.053 \\
.259 \\
-.128 \\
.185 \\
.128 \\
.157 \\
.046 \\
.699 \\
.303 \\
.048 \\
.020 \\
.031\end{array}$ & $\begin{array}{l}.030 \\
.036 \\
-.099 \\
.043 \\
.401 \star \\
.078 \\
.071 \\
.006 \\
.137 \\
.206 \\
-.034 \\
.076\end{array}$ \\
\hline
\end{tabular}


TABLE XLVI

INTERCORRELATIONS BETWEEN DEPENDENT VARIABLES

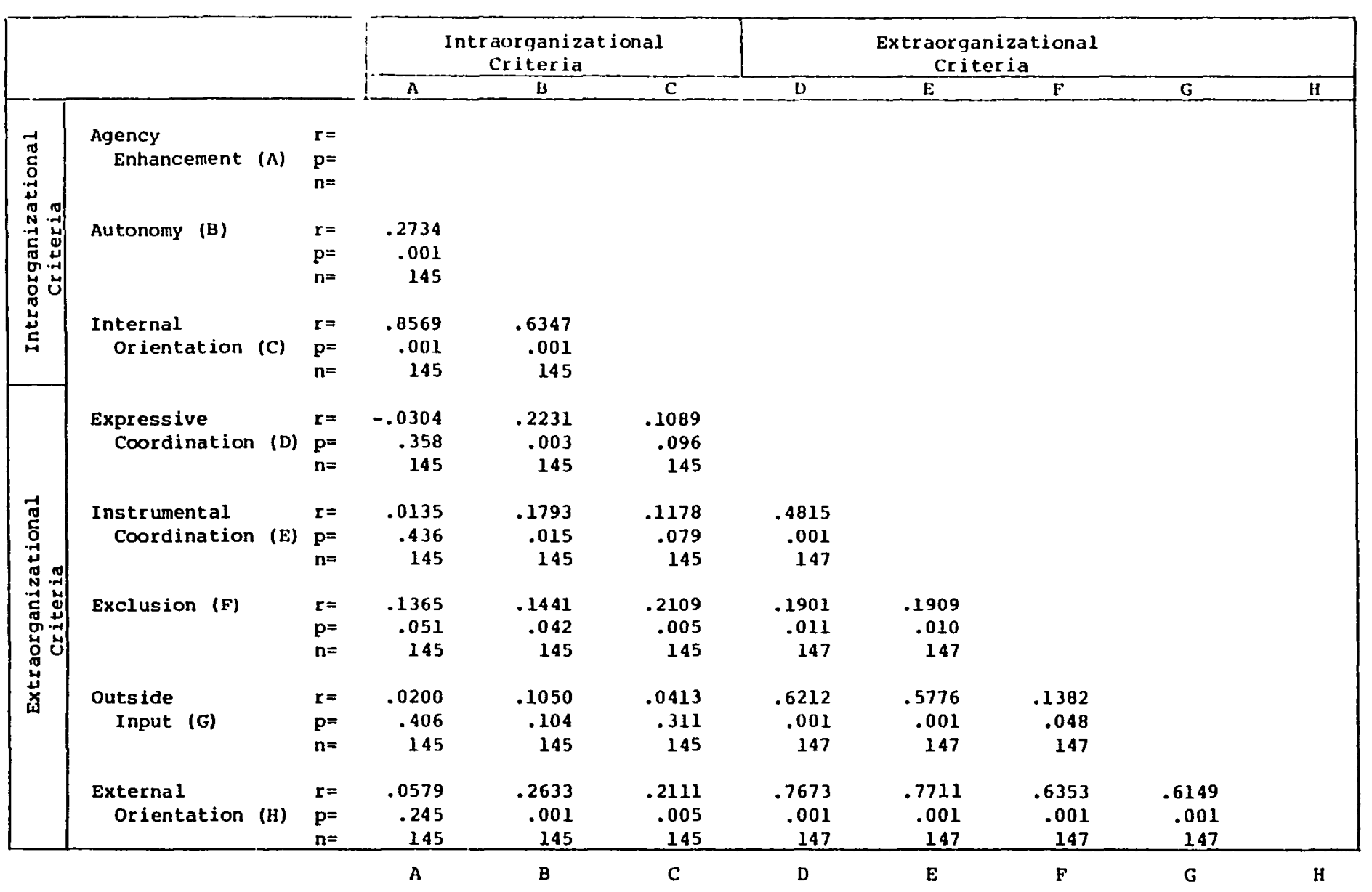


interpretations of the analyses' results, will reflect the tested assumption of this independence. 
APPENDIX II

ANALYSES 
TABLE OF CONTENTS

Page

I. Intraorganizational Decision Making Criteria

A. Analyses of Variance (TABLE XLVII). . . . . . . . 244

B. Analyses of Covariance. . . . . . . . . . . 245

1. Agency Enhancement as Dependent Variable (TABLE

(TABLE XIVIII).................. 245

2. Autonomy as Dependent Variable (TABLE XLIX) . . . 246

3. Internal orientation as Dependent Variable

(TABLE L) . . . . . . . . . . . . . . 247

C. Multiple Regression Analysis. . . . . . . . . . 248

1. Agency Enhancement as Dependent Variable

(TABLE II). . . . . . . . . . . . . . 248

2. Autonomy as Dependent Variable (TABLE LII). . . . . 249

3. Internal Orientation as Dependent Variable

(TABLE LIII). . . . . . . . . . . . . 250

II. Extraorganizational Decision Making Criteria

A. Analyses of Variance (TABLE LIV). . . . . . . . 251

B. Analyses of Covariance. . . . . . . . . . . . 252

1. Instrumental Coordination as Dependent Variable

(TABLE LV). . . . . . . . . . . . . 252

2. Expressive Coordination as Dependent Variable (TABLE LVI) . . . . . . . . . . . . . . . 253

3. Exclusion as Dependent Variable (TABLE LVII). . . . 254

4. Outside Input as Dependent Variable

(TABLE LVIII) . . . . . . . . . . . . . 255

5. External Orientation as Dependent Variable

(TABLE LIX) . . . . . . . . . . . . . 256 
c. Multiple Regression Analysis. . . . . . . . . 257

1. Instrumental Coordination as Dependent Variable

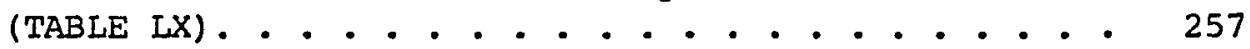

2. Expressive Coordination as Dependent Variable (TABLE LXI) . . . . . . . . . . . 258

3. Exclusion as Dependent Variable (TABLE LXII). . . 259

4. Outside Input as Dependent Variable (TABLE LXIII) . . . . . . . . . . . 260

5. External Orientation as Dependent Variable (TABLE LXIV).................. . 261 
TABLE XLVII

ANALYSES OF VARIANCE, INTRAORGANIZATIONAL CRITERIA BY COMMUNITY

\begin{tabular}{|c|c|c|c|c|c|}
\hline $\begin{array}{l}\text { INTRAORGANI ZATIONAL } \\
\text { CRITERIA } \\
\end{array}$ & & & & & \\
\hline Source of Variance & sS & $d f$ & MS & $F$ & $\mathrm{p}$ \\
\hline \multicolumn{6}{|l|}{ Agency Enhancement } \\
\hline Between Communities & 98.678 & 5 & 19.736 & 1.096 & .365 \\
\hline Within Communities & 2502.542 & 139 & 18.004 & & \\
\hline \multicolumn{6}{|l|}{ Time Preference } \\
\hline Between Communities & 22.160 & 5 & 4.432 & .666 & .650 \\
\hline Within Communities & 924.756 & 139 & 6.653 & & \\
\hline \multicolumn{6}{|l|}{ Internal orientation } \\
\hline Between Communities & 107.639 & 5 & 21.528 & .485 & .787 \\
\hline Within Communities & 6169.565 & 139 & 44.365 & & \\
\hline
\end{tabular}


TABLE XLVIII

ANALYSES OF COVARIANCE, AGENCY ENHANCEMENT

AS DEPENDENT VARIABLE

\begin{tabular}{|c|c|c|c|c|c|}
\hline $\begin{array}{l}\text { Covariate } \\
\text { Source of Variance } \\
\end{array}$ & ss & de & MS & $\mathbf{E}$ & 2 \\
\hline \multicolumn{6}{|l|}{ ․ Organizational Resources } \\
\hline Organizational Resources & 9.635 & 1 & 9.635 & .523 & .471 \\
\hline Community & 102.341 & 5 & 20.468 & 1.111 & .358 \\
\hline Residual & 2450.442 & 133 & 18.424 & & \\
\hline \multicolumn{6}{|l|}{ 2. Organizational Goal } \\
\hline Organizational coal & 187.413 & 2 & 93.707 & 5.645 & .004 \\
\hline Broker Agencies & 139.886 & 1 & 139.886 & 8.426 & .004 \\
\hline Direct Service Agencies & 5.526 & 1 & 5.526 & .333 & .565 \\
\hline Community & 139.500 & 5 & 27.900 & 1.681 & .143 \\
\hline Residual & 2274.307 & 137 & 16.601 & & \\
\hline \multicolumn{6}{|l|}{ 3. Local Public Uncertainty } \\
\hline Local Public Uncertainty & 34.958 & 1 & 34.958 & 2.016 & .158 \\
\hline Community & 70.618 & 5 & 14.124 & .814 & .542 \\
\hline Residual & 2063.966 & 119 & 17.344 & & \\
\hline \multicolumn{6}{|l|}{ 4. State and Federal Uncertainty } \\
\hline State and Federal Uncertainty & 107.892 & 1 & 107.892 & 7.081 & .009 \\
\hline Community & 85.760 & 5 & 17.152 & 1.126 & .350 \\
\hline Residual & 1889.441 & 124 & 15.238 & & \\
\hline \multicolumn{6}{|l|}{ 5. Client Uncertainty } \\
\hline Client Uncertainty & 1.931 & 1 & 1.931 & .106 & .745 \\
\hline Community & 97.416 & 5 & 19.483 & 1.069 & .381 \\
\hline Residual & 2443.365 & 134 & 18.234 & & \\
\hline \multicolumn{6}{|l|}{ 6. Interorganizational Uncertainty } \\
\hline Interorganizational Uncertainty & 56.597 & 1 & 56.597 & 3.391 & .068 \\
\hline Community & 82.333 & 5 & 16.467 & .987 & .429 \\
\hline Residual & 2036.012 & 122 & 16.689 & & \\
\hline
\end{tabular}


TABLE XLIX

ANALYSES OF COVARIANCE, AUTONOMY AS DEPENDENT VARIABLE

\begin{tabular}{|c|c|c|c|c|c|}
\hline $\begin{array}{l}\text { Covariate } \\
\text { Source of Variance }\end{array}$ & ss & $d f$ & MS & $\boldsymbol{F}$ & $p$ \\
\hline \multicolumn{6}{|l|}{ 1. Organizational Resources } \\
\hline Organizational Resources & 13.939 & 1 & 13.939 & 2.136 & .146 \\
\hline Community & 17.749 & 5 & 3.550 & .544 & .743 \\
\hline Residual & 867.954 & 133 & 6.526 & & \\
\hline \multicolumn{6}{|l|}{ 2. Organizational Goal } \\
\hline Organizational Goal & 55.046 & 2 & 27.523 & 4.322 & .015 \\
\hline Broker Agencies & 24.381 & 1 & 24.381 & 3.829 & .052 \\
\hline Direct Service Agencies & 1.107 & 1 & 1.107 & .174 & .677 \\
\hline Community & 19.503 & 5 & 3.901 & .613 & .690 \\
\hline Residual & 872.367 & 137 & 10.650 & & \\
\hline \multicolumn{6}{|l|}{ 3. Local Public Uncertainty } \\
\hline Local Public Uncertainty & 14.315 & 1 & 14.315 & 2.096 & .150 \\
\hline Community & 21.876 & 5 & 4.375 & .641 & .669 \\
\hline Residual & 812.669 & 119 & 6.032 & & \\
\hline \multicolumn{6}{|l|}{ 4. State and Federal Uncertainty } \\
\hline State and Federal Uncertainty & 8.255 & 1 & 8.255 & 1.287 & .259 \\
\hline Comunity & 14.379 & 5 & 2.876 & .448 & .814 \\
\hline Resioual & 795.442 & 124 & 6.415 & & \\
\hline \multicolumn{6}{|l|}{ 5. Client Uncertainty } \\
\hline Client Uncertainty & 8.832 & 1 & 8.832 & 1.318 & .253 \\
\hline Community & 15.912 & 5 & 3.182 & .475 & .795 \\
\hline Residual & 898.142 & 134 & 6.703 & & \\
\hline \multicolumn{6}{|l|}{ 6. Interorganizational Uncertainty } \\
\hline Interorganizational Uncertainty & 10.005 & 1 & 10.005 & 1.551 & .215 \\
\hline Community & 19.514 & 5 & 3.903 & .605 & .696 \\
\hline Residual & 787.114 & 122 & 6.452 & & \\
\hline
\end{tabular}


TABLE L

ANALYSES OF COVARIANCE, INTERNAL ORIENTATION

AS DEPENDENT VARIABLE

\begin{tabular}{|c|c|c|c|c|c|}
\hline$\frac{\text { Covariate }}{\text { Source of Variance }}$ & ss & $d f$ & MS & F & p \\
\hline \multicolumn{6}{|l|}{ 1. Orgnizational Resources } \\
\hline Organizational Resources & 54.661 & 1 & 54.661 & 1.228 & .270 \\
\hline Community & 126.075 & 5 & 25.215 & .566 & .726 \\
\hline Residual & 5920.308 & 133 & 44.514 & & \\
\hline \multicolumn{6}{|l|}{ 2. Organizational Goal } \\
\hline Organizational Goal & 357.686 & 2 & 178.843 & 4.273 & .016 \\
\hline Broker Agencies & 219.205 & 1 & 219.205 & 5.237 & .024 \\
\hline Direct Service Agencies & .295 & 1 & .295 & .007 & .933 \\
\hline Community & 185.393 & 5 & 37.079 & .886 & .492 \\
\hline Residual & 5734.124 & 137 & 41.855 & & \\
\hline \multicolumn{6}{|l|}{ 3. Local Public Uncertainty } \\
\hline Local Public Uncertainty & 157.521 & 1 & 157.521 & 3.626 & .059 \\
\hline Community & 75.353 & 5 & 15.071 & .347 & .883 \\
\hline Residual & 3087.662 & 119 & 25.947 & & \\
\hline \multicolumn{6}{|l|}{ 4. State and Federal Uncertainty } \\
\hline State and Federal Uncertainty & 149.404 & 1 & 149.404 & 3.606 & .060 \\
\hline Community & 56.001 & 5 & 11.200 & .270 & .929 \\
\hline Residual & 5137.590 & 124 & 41.432 & & \\
\hline \multicolumn{6}{|l|}{ 5. Client Uncertainty } \\
\hline Client Uncertainty & 24.799 & 1 & 24.799 & .554 & .458 \\
\hline Community & 91.931 & 5 & 18.386 & .411 & .840 \\
\hline Residual & 5993.828 & 134 & 44.730 & & \\
\hline \multicolumn{6}{|l|}{ 6. Interorganizational Uncertainty } \\
\hline Interorganizational Uncertaint & 191.317 & 1 & 191.317 & 4.848 & .030 \\
\hline Community & 102.486 & 5 & 20.497 & .519 & .761 \\
\hline Residual & 4814.202 & 122 & 39.461 & & \\
\hline
\end{tabular}


TABLE LI

MULTIPLE RE'GRESSION ANALYSIS: AGENCY ENHANCEMENT AS DEPENDENT VARIABLE

\begin{tabular}{|c|c|c|c|c|c|c|c|}
\hline Step & Variable & $\begin{array}{l}\text { Beta At } \\
\text { Last Step }\end{array}$ & $\begin{array}{c}\text { F At } \\
\text { Last Step }\end{array}$ & $\begin{array}{c}\text { Signifi- } \\
\text { cance } \\
\text { Of } \mathrm{F} \\
\end{array}$ & $\begin{array}{c}\text { Overall } \\
\text { F At } \\
\text { Each Step }\end{array}$ & $\mathrm{df}$ & $\begin{array}{l}\text { Signifi- } \\
\text { cance of } \\
\text { stepwise } \\
\text { E }\end{array}$ \\
\hline 1 & Broker Agencies & .312 & 6.527 & .012 & 8.495 & 1,113 & .004 \\
\hline 2 & $\begin{array}{l}\text { State and Federal } \\
\text { Uncer tainty }\end{array}$ & -.278 & 7.349 & .008 & 9.309 & 2,112 & .000 \\
\hline 3 & $\begin{array}{l}\text { Interorganizational } \\
\text { Uncertainty }\end{array}$ & .127 & 1.927 & .168 & 7.067 & 3,111 & .000 \\
\hline 4 & $\begin{array}{l}\text { Organizational } \\
\text { Resources }\end{array}$ & .104 & 1.078 & .302 & 5.592 & 4,110 & .000 \\
\hline 5 & $\begin{array}{l}\text { Direct Service } \\
\text { Agencies }\end{array}$ & .083 & .451 & .503 & 4.537 & 5,109 & .001 \\
\hline 6 & $\begin{array}{l}\text { Clients } \\
\text { Uncertainty }\end{array}$ & .021 & .051 & .822 & 3.768 & 6,108 & .002 \\
\hline 7 & $\begin{array}{l}\text { Local Public } \\
\text { Uncertainty }\end{array}$ & .032 & .089 & .766 & 3.207 & 7,107 & .004 \\
\hline 8 & Community & -- & .621 & .684 & 2.097 & 12,102 & .023 \\
\hline
\end{tabular}


TABLE LII

MULTIPLE REGRESSION ANALYSIS: AUTONOMY AS DEPENDENT VARIABLE

\begin{tabular}{|c|c|c|c|c|c|c|c|}
\hline Step & Variable & $\begin{array}{l}\text { Beta At } \\
\text { Last Step }\end{array}$ & $\begin{array}{c}\text { F At } \\
\text { Last step }\end{array}$ & $\begin{array}{c}\text { Signifi- } \\
\text { cance } \\
\text { of } \mathrm{E} \\
\end{array}$ & $\begin{array}{c}\text { Overall } \\
\text { F At } \\
\text { Each Step }\end{array}$ & $\mathrm{df}$ & $\begin{array}{c}\text { Signifi- } \\
\text { cance of } \\
\text { stepwise } \\
F\end{array}$ \\
\hline 1 & Broker Agencies & .168 & 1.615 & .207 & 6.826 & 1,113 & .010 \\
\hline 2 & $\begin{array}{l}\text { Local Public } \\
\text { Uncertainty }\end{array}$ & -.179 & 2.924 & .090 & 4.327 & 2,112 & .015 \\
\hline 3 & $\begin{array}{l}\text { State and Federal } \\
\text { Uncertainty }\end{array}$ & .111 & 1.079 & .301 & 3.398 & 3,111 & .020 \\
\hline 4 & $\begin{array}{l}\text { Clients } \\
\text { Uncertainty }\end{array}$ & .079 & .658 & .419 & 2.843 & 4,110 & .028 \\
\hline 5 & $\begin{array}{l}\text { Interorganizational } \\
\text { Uncertainty }\end{array}$ & .094 & .970 & .327 & 2.400 & 5,109 & .042 \\
\hline 6 & $\begin{array}{l}\text { Direct Service } \\
\text { Agencies }\end{array}$ & -.043 & .107 & .744 & 2.000 & 6,108 & .072 \\
\hline 7 & $\begin{array}{l}\text { Organizational } \\
\text { Resources }\end{array}$ & -.005 & .002 & .961 & 1.708 & 7,107 & .115 \\
\hline 8 & Community & -- & .482 & .789 & 1.173 & 2,112 & .312 \\
\hline
\end{tabular}


TABLE LIII

MULTIPLE REGRESSION ANALYSIS: INTERNAL ORIENTATION AS DEPENDENT VARIABLE

\begin{tabular}{|c|c|c|c|c|c|c|c|}
\hline Step & Variable & $\begin{array}{l}\text { Beta At } \\
\text { Last Step }\end{array}$ & $\begin{array}{c}\text { F At } \\
\text { Last Step }\end{array}$ & $\begin{array}{c}\text { Signifi- } \\
\text { cance } \\
\text { Of F } \\
\end{array}$ & $\begin{array}{c}\text { Overall } \\
\text { F At } \\
\text { Each Step } \\
\end{array}$ & $\mathrm{df}$ & $\begin{array}{c}\text { Signifi- } \\
\text { Cance of } \\
\text { stepwise } \\
\text { F } \\
\end{array}$ \\
\hline 1 & Broker Agencies & .227 & 3.117 & .080 & 6.822 & 1,113 & .010 \\
\hline 2 & $\begin{array}{l}\text { State and Federal } \\
\text { Uncertainty }\end{array}$ & -.195 & 3.498 & .064 & 6.139 & 2,112 & .003 \\
\hline 3 & $\begin{array}{l}\text { Interorganizational } \\
\text { Uncertainty }\end{array}$ & .174 & 3.504 & .064 & 5.375 & 3,111 & .002 \\
\hline 4 & $\begin{array}{l}\text { Organizational } \\
\text { Uncertainty }\end{array}$ & .099 & .941 & .334 & 4.467 & 4,110 & .002 \\
\hline 5 & $\begin{array}{l}\text { Local Public } \\
\text { Uncertainty }\end{array}$ & -.127 & 1.552 & .216 & 3.779 & 5,109 & .003 \\
\hline 6 & $\begin{array}{l}\text { Clients } \\
\text { Uncertainty }\end{array}$ & .059 & .385 & .537 & 3.220 & 6,108 & .006 \\
\hline 7 & $\begin{array}{l}\text { Direct Service } \\
\text { Agencies }\end{array}$ & .015 & .014 & .978 & 2.737 & 7,107 & .012 \\
\hline 8 & Community & -- & .372 & .867 & 1.704 & 2,112 & .076 \\
\hline
\end{tabular}


TABLE LIV

ANALYSES OF VARIANCE, EXTRAORGANIZATIONAL CRITERIA BY COMMUNITY

\begin{tabular}{|c|c|c|c|c|c|}
\hline \multicolumn{6}{|l|}{$\begin{array}{c}\text { INTRAORGANIZATIONAL } \\
\text { CRITERIA } \\
\end{array}$} \\
\hline Source of Variance & SS & df & MS & $\mathrm{F}$ & $\underline{p}$ \\
\hline \multicolumn{6}{|c|}{ Instrumental Coordination } \\
\hline Between Communities & 49.403 & 5 & 9.881 & 1.620 & .159 \\
\hline Within Communities & 847.663 & 139 & 6.098 & & \\
\hline \multicolumn{6}{|l|}{ Expressive Coordination } \\
\hline Between Communities & 44.320 & 5 & 8.864 & 1.664 & .147 \\
\hline Within Communities & 740.439 & 139 & 5.327 & & \\
\hline \multicolumn{6}{|l|}{ Exclusion } \\
\hline Between Communities & 34.391 & 5 & 6.878 & 1.134 & .345 \\
\hline Within Communities & 843.181 & 139 & 6.066 & & \\
\hline \multicolumn{6}{|l|}{ Outside Input } \\
\hline Between Communities & 16.193 & 5 & 3.239 & 1.912 & .096 \\
\hline Within Communities & 235.414 & 139 & 1.694 & & \\
\hline \multicolumn{6}{|l|}{ External Orientation } \\
\hline Between Communities & 142.409 & 5 & 28.482 & 1.119 & .353 \\
\hline Within Communities & 3539.289 & 139 & 25.463 & & \\
\hline
\end{tabular}


TABLE LV

ANALYSES OF COVARIANCE, INSTRUMENTAL COORDINATION AS DEPENDENT VARIABLE

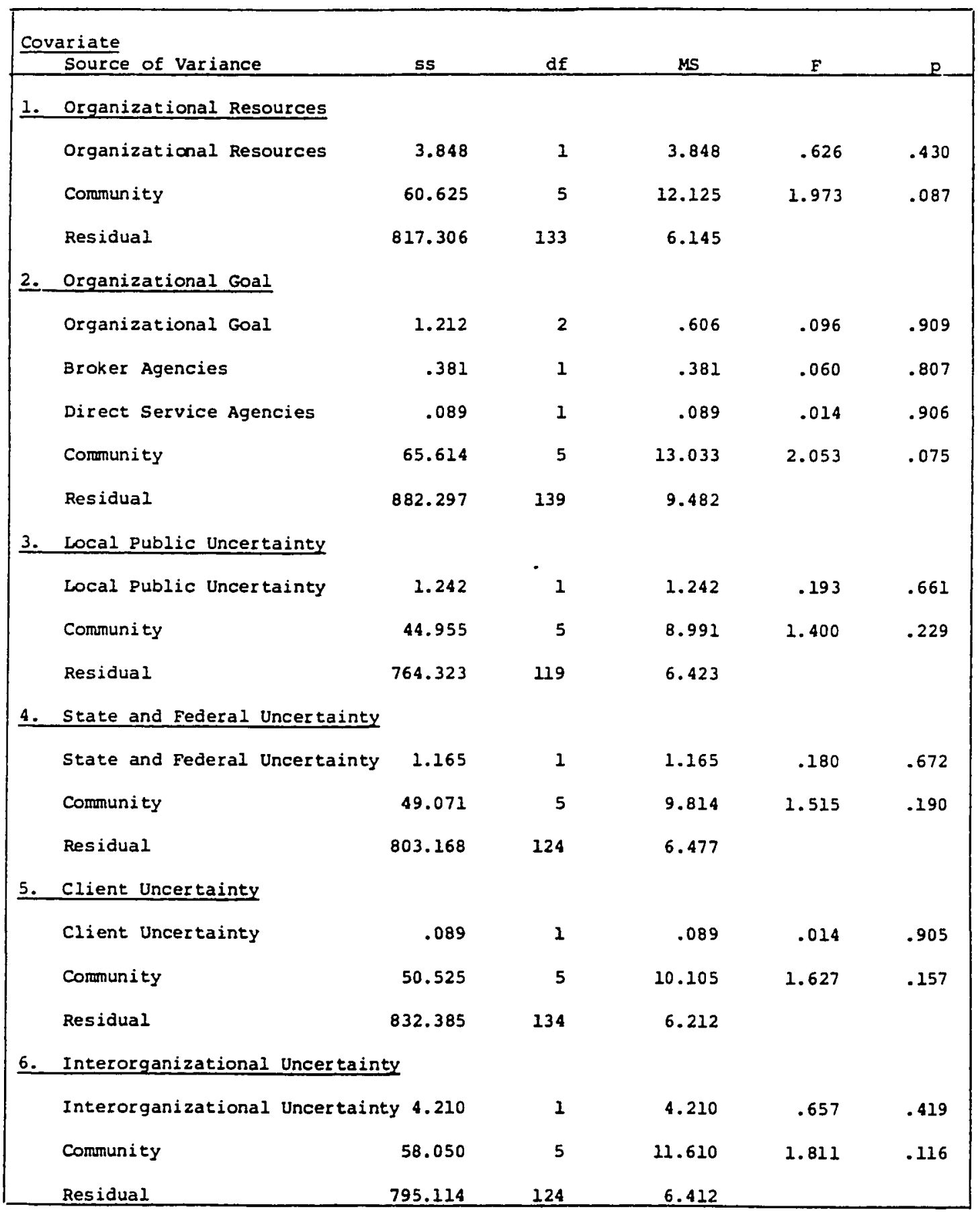


TABLE LVI

ANALYSES OF COVARIANCE, EXPRESSIVE COORDINATION

AS DEPENDENT VARIABLE

\begin{tabular}{|c|c|c|c|c|c|}
\hline$\frac{\text { Covariate }}{\text { Source of variance }}$ & ss & $d f$ & MS & $\mathbf{F}$ & p \\
\hline 1. Organizational Resources & & & & & \\
\hline Organizational Resources & 2.778 & 1 & 2.778 & .510 & .476 \\
\hline Commun ity & 44.060 & 5 & 8.812 & 1.618 & .160 \\
\hline Residual & 724.383 & 133 & 5.446 & & \\
\hline 2. Organizational Goal & & & & & \\
\hline Organizational Goal & 6.882 & 2 & 3.441 & .540 & .584 \\
\hline Broker Agencies & 6.095 & 1 & 6.095 & .956 & .330 \\
\hline Direct Service Agencies & 5.157 & 1 & 5.157 & .809 & .370 \\
\hline Community & 83.447 & 5 & 16.689 & 2.618 & .027 \\
\hline Residual & 886.134 & 139 & 6.375 & & \\
\hline 3. Local Public Uncertainty & & & & & \\
\hline Local Public Uncertainty & 10.661 & 1 & 10.661 & 1.906 & .170 \\
\hline Community & 27.696 & 5 & 5.539 & .995 & .424 \\
\hline Residual & 662.519 & 119 & 5.567 & & \\
\hline 4. State and Federal Uncertainty & & & & & \\
\hline State and Federal Uncertainty & .712 & 1 & .712 & .133 & .716 \\
\hline Community & 38.248 & 5 & 7.650 & 1.430 & .218 \\
\hline Residual & 663.208 & 124 & 5.348 & & \\
\hline 5. Client Uncertainty & & & & & \\
\hline Client Uncer tainty & 3.805 & 1 & 3.805 & .721 & .397 \\
\hline Community & 46.644 & 5 & 9.329 & 1.768 & .124 \\
\hline Residual & 707.097 & 134 & 5.277 & & \\
\hline 6. Interorganizational Uncertainty & & & & & \\
\hline Interorganizational Uncertainty & 38.116 & 1 & 38.116 & 6.206 & .014 \\
\hline Community & 83.521 & 5 & 16.704 & 2.716 & .023 \\
\hline Residual & 762.618 & 124 & 6.510 & & \\
\hline
\end{tabular}


TABLE LVII

ANALYSES OF COVARIANCE, EXCLUSION AS DEPENDENT VARIABLE

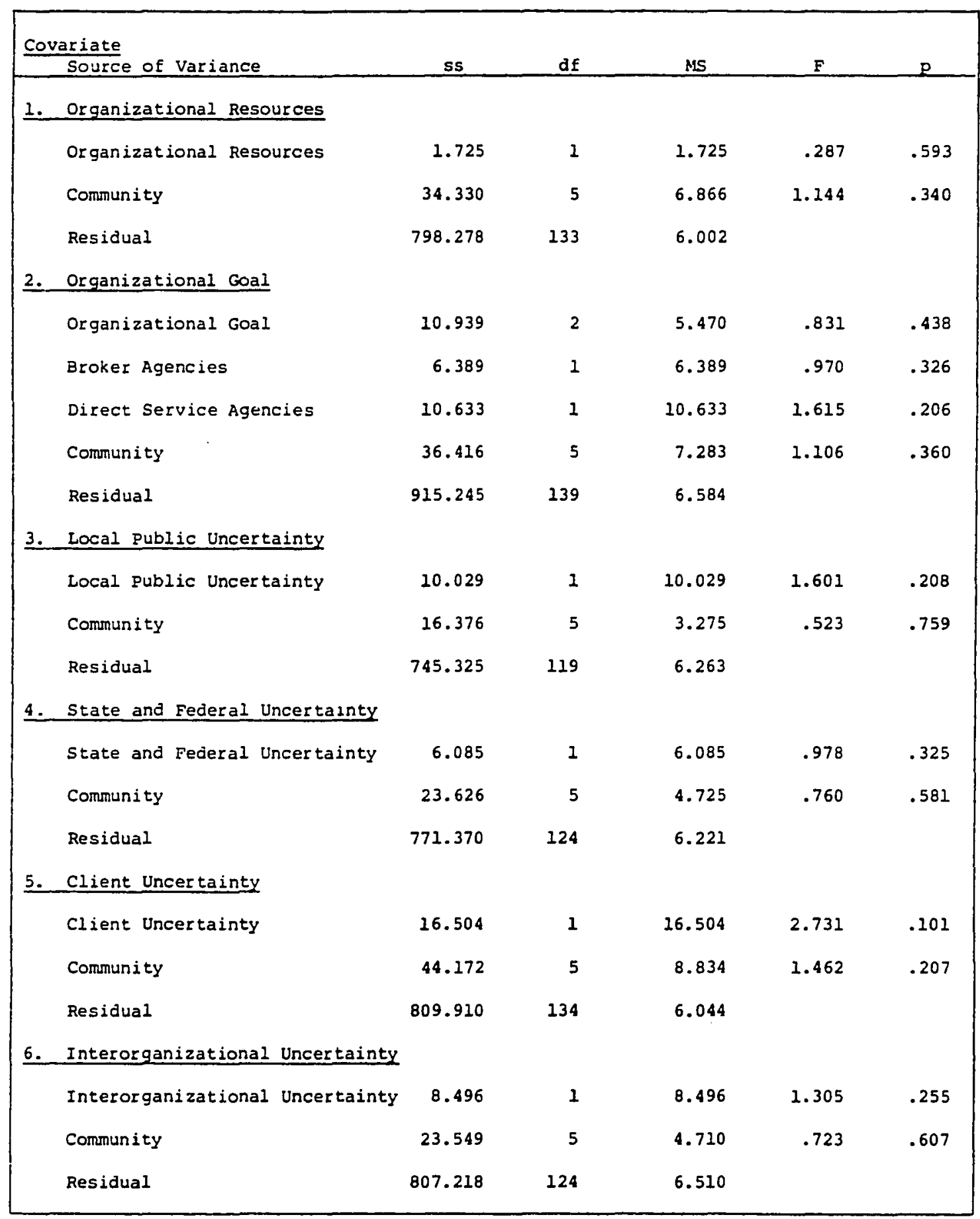


TABLE LVIII

ANALYSES OF COVARIANCE, OUTSIDE INPUT AS DEPENDENT VARIABLE

\begin{tabular}{|c|c|c|c|c|c|}
\hline $\begin{array}{l}\text { Covariate } \\
\text { Solirce of variance }\end{array}$ & ss & $d f$ & MS & E & p \\
\hline \multicolumn{6}{|l|}{ 1. Organizational Resources } \\
\hline Organizational Resources & .056 & 1 & .056 & .033 & .857 \\
\hline Community & 16.899 & 5 & 3.380 & 1.970 & .087 \\
\hline Residual & 228.197 & 133 & 1.716 & & \\
\hline \multicolumn{6}{|l|}{ 2. Organizational Goal } \\
\hline Organizational Goal & .655 & 2 & .328 & $.17 E$ & .839 \\
\hline Broker Agencies & .000 & 1 & .000 & .000 & .999 \\
\hline Direct Service Agencies & .382 & 1 & .382 & .206 & .651 \\
\hline Community & 22.407 & 5 & 4.481 & 2.411 & .039 \\
\hline Residual & 258.361 & 139 & 1.895 & & \\
\hline \multicolumn{6}{|l|}{ 3. Local Public Uncertainty } \\
\hline Local Public Uncertainty & .109 & 1 & .109 & .062 & .804 \\
\hline Community & 14.397 & 5 & 2.879 & 1.621 & .160 \\
\hline Residual & 211.344 & 119 & 1.776 & & \\
\hline \multicolumn{6}{|l|}{ 4. State and Federal Uncertainty } \\
\hline State and Federal Uncertainty & .153 & 1 & .153 & .090 & .765 \\
\hline Community & 16.930 & 5 & 3.386 & 1.987 & .085 \\
\hline Residual & 211.302 & 124 & 1.704 & & \\
\hline \multicolumn{6}{|l|}{ 5. Client Uncertainty } \\
\hline Client Uncertainty & .058 & 1 & .058 & .033 & .855 \\
\hline Community & 44.172 & 5 & 8.834 & 1.462 & .205 \\
\hline Residual & 809.910 & 134 & 6.044 & & \\
\hline \multicolumn{6}{|l|}{ 6. Incerorganizational Uncertainty } \\
\hline Interorganizational Uncertainty & .780 & 1 & .780 & .409 & .524 \\
\hline Community & 19.872 & 5 & 3.974 & 2.085 & .072 \\
\hline Residual & 236.418 & 124 & 1.907 & & \\
\hline
\end{tabular}


TABLE LIX

ANALYSES OF COVARIANCE, EXTERNAL ORIENTATION

AS DEPENDENT VARIABLE

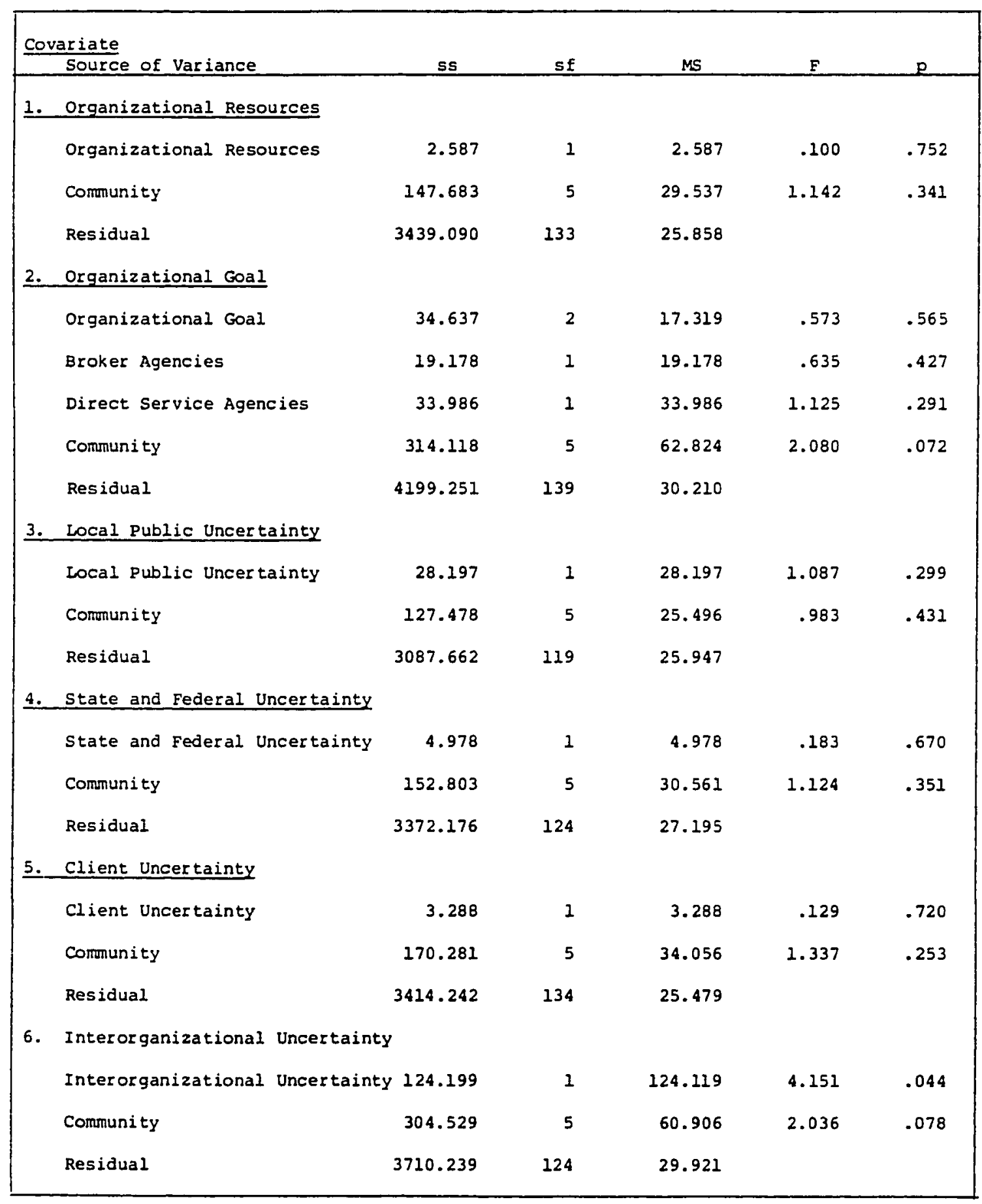


TABLE LX

MULTIPLE REGRESSION ANALYSIS: INSTRUMENTAL COORDINATION AS DEPENDENT VARIABLE

\begin{tabular}{|c|c|c|c|c|c|c|c|}
\hline Step & Variable & $\begin{array}{l}\text { Beta At } \\
\text { Last Step }\end{array}$ & $\begin{array}{c}\text { F At } \\
\text { Last Step }\end{array}$ & $\begin{array}{l}\text { Signifi- } \\
\text { cance } \\
\text { of } \mathrm{F} \\
\end{array}$ & $\begin{array}{c}\text { Overall } \\
F \text { At } \\
\text { Each Step } \\
\end{array}$ & $\mathrm{df}$ & $\begin{array}{c}\text { Signifi- } \\
\text { cance of } \\
\text { stepwise } \\
\text { F } \\
\end{array}$ \\
\hline 1 & $\begin{array}{l}\text { Organizational } \\
\text { Resources }\end{array}$ & .143 & 1.814 & .181 & .681 & 1,113 & .411 \\
\hline 2 & $\begin{array}{l}\text { Interorganizational } \\
\text { Uncertainty }\end{array}$ & -.075 & .594 & .443 & .650 & 2,112 & .524 \\
\hline 3 & $\begin{array}{l}\text { State and Federal } \\
\text { Uncertainty }\end{array}$ & -.036 & .111 & .740 & .519 & 3,111 & .670 \\
\hline 4 & Broker Agencies & -.063 & .220 & .640 & .419 & 4,110 & .795 \\
\hline 5 & $\begin{array}{l}\text { Local Public } \\
\text { Uncertainty }\end{array}$ & -.004 & .001 & .972 & .340 & 5,109 & .888 \\
\hline 6 & Community & & 1.761 & .127 & 1.056 & 10,104 & .403 \\
\hline 7 & $\begin{array}{l}\text { Clients } \\
\text { Uncertainty }\end{array}$ & -.016 & .025 & .876 & .953 & 11,103 & .493 \\
\hline 8 & $\begin{array}{l}\text { Direct Service } \\
\text { Agencies }\end{array}$ & -.018 & .018 & .893 & .867 & 12,102 & .582 \\
\hline
\end{tabular}


TABLE LXI

MULTIPLE REGRESSION ANALYSIS: EXPRESSIVE COORDINATION AS DEPENDENT VARIABLE

\begin{tabular}{|c|c|c|c|c|c|c|c|}
\hline Step & Variable & $\begin{array}{l}\text { Beta At } \\
\text { Last Step }\end{array}$ & $\begin{array}{c}\text { F AT } \\
\text { Last Step }\end{array}$ & $\begin{array}{c}\text { Signifi- } \\
\text { cance } \\
\text { Of } F \\
\end{array}$ & $\begin{array}{c}\text { Overall } \\
\text { F At } \\
\text { Each Step }\end{array}$ & $\mathrm{df}$ & $\begin{array}{c}\text { Signifi- } \\
\text { cance of } \\
\text { stepwise } \\
\text { F }\end{array}$ \\
\hline 1 & $\begin{array}{l}\text { Interorganizational } \\
\text { Uncertainty }\end{array}$ & -.244 & 6.920 & .010 & 5.097 & 1,113 & .026 \\
\hline 2 & $\begin{array}{l}\text { Local Public } \\
\text { Uncertainty }\end{array}$ & .132 & 1.932 & .168 & 3.465 & 2,112 & .035 \\
\hline 3 & Broker Agencies & .160 & 1.572 & .213 & 2.559 & 3,111 & .059 \\
\hline 4 & $\begin{array}{l}\text { Direct Service } \\
\text { Agencies }\end{array}$ & .116 & .836 & .363 & 2.146 & 4,110 & .080 \\
\hline 5 & $\begin{array}{l}\text { Organizational } \\
\text { Resources }\end{array}$ & .014 & .021 & .884 & 1.810 & 5,109 & .117 \\
\hline 6 & $\begin{array}{l}\text { Clients } \\
\text { Uncertainty }\end{array}$ & .047 & .245 & .622 & 1.554 & 6,108 & .168 \\
\hline 7 & Community & -- & 2.023 & .081 & 1.807 & 11,103 & .062 \\
\hline
\end{tabular}


TABLE LXII

MULTIPLE REGRESSION ANALYSIS: EXCLUSION AS DEPENDENT VARIABLE

\begin{tabular}{|c|c|c|c|c|c|c|c|}
\hline Step & Variable & $\begin{array}{l}\text { Beta At } \\
\text { Last Step }\end{array}$ & $\begin{array}{c}\text { F At } \\
\text { Last Step }\end{array}$ & $\begin{array}{l}\text { Signifi- } \\
\text { cance } \\
\text { Of F } \\
\end{array}$ & $\begin{array}{c}\text { Overall } \\
\text { F At } \\
\text { Each Step }\end{array}$ & $\mathrm{df}$ & $\begin{array}{c}\text { Signifi- } \\
\text { cance of } \\
\text { Stepwise } \\
\text { F } \\
\end{array}$ \\
\hline 1 & $\begin{array}{l}\text { Clients } \\
\text { Uncertainty }\end{array}$ & -.188 & 3.753 & .055 & 2.478 & 1,113 & .118 \\
\hline 2 & $\begin{array}{l}\text { Local Public } \\
\text { Uncertainty }\end{array}$ & .190 & 3.317 & .072 & 2.283 & 2,112 & .107 \\
\hline 3 & $\begin{array}{l}\text { Interorganizational } \\
\text { Uncertainty }\end{array}$ & -.120 & 1.580 & .212 & 1.856 & 3,111 & .141 \\
\hline 4 & $\begin{array}{l}\text { Organizational } \\
\text { Resources }\end{array}$ & .051 & .242 & .624 & 1.577 & 4,110 & .185 \\
\hline 5 & $\begin{array}{l}\text { Direct Service } \\
\text { Agencies }\end{array}$ & .154 & 1.419 & .236 & 1.328 & 5,109 & .258 \\
\hline 6 & Broker Agencies & .139 & 1.127 & .291 & 1.303 & 6,108 & .262 \\
\hline 7 & $\begin{array}{l}\text { State and Federal } \\
\text { Uncertainty }\end{array}$ & .061 & .327 & .569 & 1.135 & 7,106 & .347 \\
\hline 8 & Community & & 1.403 & .229 & 1.259 & 12,102 & .255 \\
\hline
\end{tabular}


TABLE LXIII

MULTIPLE REGRESSION ANALYSIS: OUTSIDE INPUT AS DEPENDENT VARIABLE

\begin{tabular}{|c|c|c|c|c|c|c|c|}
\hline Step & Variable & $\begin{array}{l}\text { Beta At } \\
\text { Last step }\end{array}$ & $\begin{array}{l}\text { F At } \\
\text { Last Step }\end{array}$ & $\begin{array}{c}\text { Signifi- } \\
\text { cance } \\
\text { of } \mathbf{F}\end{array}$ & $\begin{array}{c}\text { Overall } \\
\text { F At } \\
\text { Each Step }\end{array}$ & $\mathrm{df}$ & $\begin{array}{c}\text { Signifi- } \\
\text { cance of } \\
\text { Stepwise } \\
\text { F }\end{array}$ \\
\hline 1 & $\begin{array}{l}\text { Interorganizational } \\
\text { Uncertainty }\end{array}$ & -.064 & .446 & .506 & .344 & 1,113 & .559 \\
\hline 2 & $\begin{array}{l}\text { Direct Service } \\
\text { Agencies }\end{array}$ & -.063 & .424 & .516 & .348 & 2,112 & .707 \\
\hline 3 & $\begin{array}{l}\text { Clients } \\
\text { Uncertainty }\end{array}$ & -.043 & .189 & .665 & .264 & 3,111 & .851 \\
\hline 4 & $\begin{array}{l}\text { Local Public } \\
\text { Uncertainty }\end{array}$ & .019 & .031 & .861 & .211 & 4,110 & .932 \\
\hline 5 & $\begin{array}{l}\text { State and Federal } \\
\text { Uncertainty }\end{array}$ & -.018 & .028 & .867 & .185 & 5,109 & .968 \\
\hline 6 & Community & & 1.746 & .131 & .969 & 10,104 & .475 \\
\hline 7 & $\begin{array}{l}\text { Organizational } \\
\text { Resources }\end{array}$ & .047 & .199 & .656 & .892 & 11,103 & .551 \\
\hline
\end{tabular}


TABLE LXIV

MULTIPLE REGRESSION ANALYSIS: EXTERNAL ORIENTATION AS DEPENDENT VARIABLE

\begin{tabular}{|c|c|c|c|c|c|c|c|}
\hline Step & Variable & $\begin{array}{l}\text { Beta At } \\
\text { Last Step }\end{array}$ & $\begin{array}{l}\text { F At } \\
\text { Last Step }\end{array}$ & $\begin{array}{l}\text { Signifi- } \\
\text { cance } \\
\text { of } F \\
\end{array}$ & $\begin{array}{c}\text { Overall } \\
\text { F At } \\
\text { Each Step }\end{array}$ & $d f$ & $\begin{array}{c}\text { Signifi- } \\
\text { cance of } \\
\text { Stepwise } \\
\text { F } \\
\end{array}$ \\
\hline$\perp$ & $\begin{array}{l}\text { Interorganizational } \\
\text { Uncertainty }\end{array}$ & -.201 & 4.511 & .036 & 3.496 & 1,113 & .064 \\
\hline 2 & $\begin{array}{l}\text { Local Public } \\
\text { Uncertainty }\end{array}$ & .147 & 1.998 & .161 & 2.222 & 2,112 & .113 \\
\hline 3 & $\begin{array}{l}\text { Clients } \\
\text { Uncertainty }\end{array}$ & -.072 & .564 & .454 & 1.558 & 3,111 & .204 \\
\hline 4 & $\begin{array}{l}\text { Organizational } \\
\text { Resources }\end{array}$ & .082 & .627 & .430 & 1.220 & 4,110 & .306 \\
\hline 5 & $\begin{array}{l}\text { Direct Service } \\
\text { Agencies }\end{array}$ & .116 & .817 & .368 & 1.008 & 5,109 & .417 \\
\hline 6 & Broker Agencies & .109 & .703 & .404 & .999 & 6,108 & .430 \\
\hline 7 & Community & & 2.057 & .076 & 1.507 & 11,103 & .140 \\
\hline 8 & $\begin{array}{l}\text { State and Federal } \\
\text { Uncer tainty }\end{array}$ & .012 & .013 & .911 & 1.369 & 12,102 & .193 \\
\hline
\end{tabular}


APPENDIX III

INSTRUMENTS 
For purposes of the next series of questions, we would like to give you a hypothetical problem to consider.

Assume that legislation is passed enacting Human Services Revenue Sharing. The program will be implemented by the designation of a local government agency to broker and monitor the pass through and use of the services funds. The actual service monies will be awarded through contracts with various local service agencies such as the one you work for.

Assume that your agency is approached to participate in the program. To do so will result in certain modifications in your program and in your funding picture. In order to participate, your agency must negotiate a contract setting down the terms of this interagency agreement.

We are specifically interested in what factors you would consider in attempting both to decide whether or not to seek to participate in the program and, later, assuming you were interested, in how you would set your priorities relative to the specifics involved in the contract. 


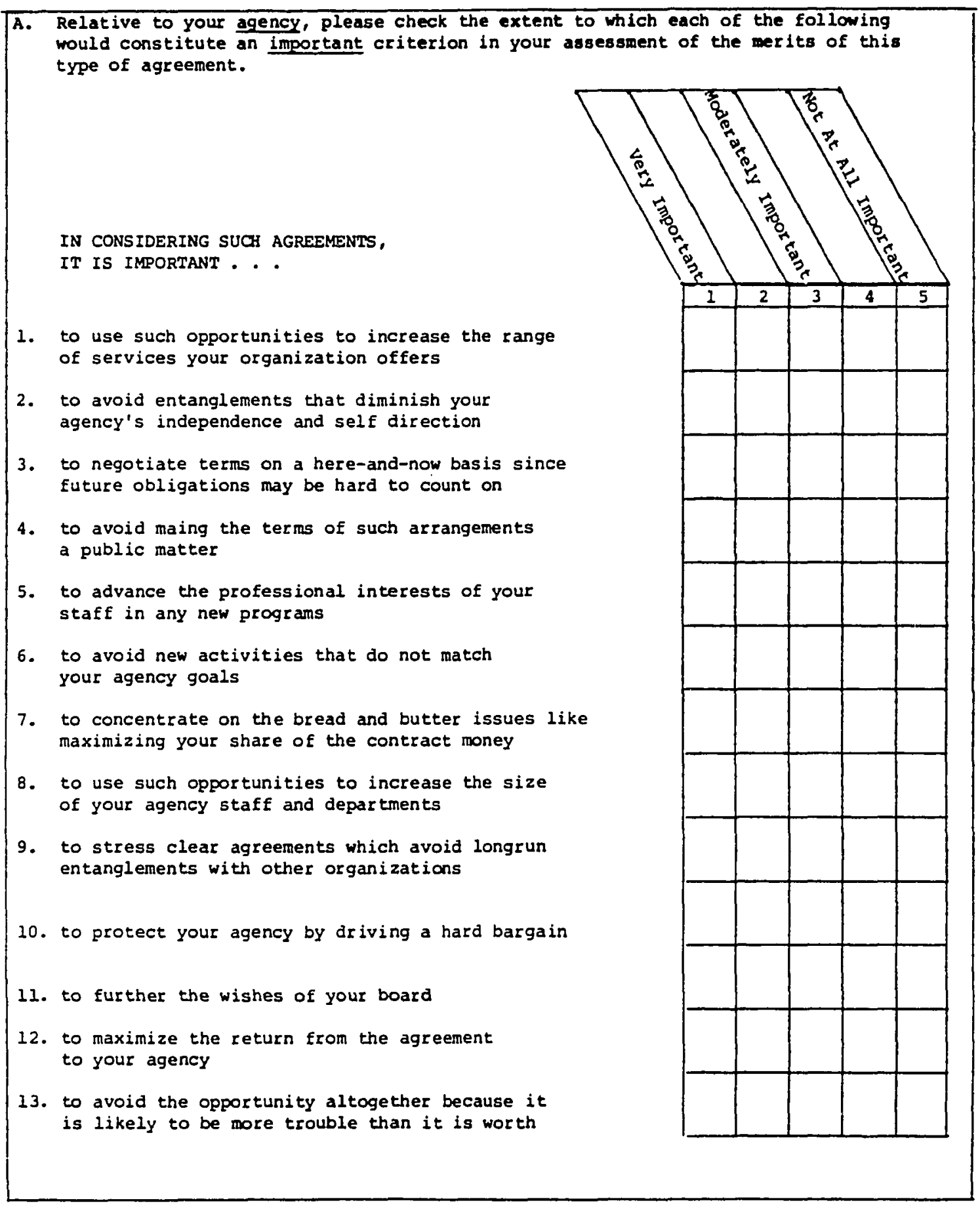


STILL KEEPING IN MIND THE HYPOTHETICAL SITUATION ON THE PREVIOUS RAGE...

B. Relative to the community, please check the extent to which each of the following would constitute an important criterion in your assessment of the merits of this type of agreement.

IN CONSIDERING SUCA AGREEMENTS, IT IS IMPORTANT . .

1. to use the opportunity to link many comunity agencies for close coordination

2. to avoid allowing the program to become a competitive struggle among many organizations

3. to exclude agencies which have been uncooperative with past comunity efforts

4. to promote a sense of cooperation among agencies in the comunity

5. to minimize the share of the resources which go for agency building and administration

6. to avoid participation if the distribution process is likely to be dominated by a few self serving agencies

7. to set an example of fair play in conducting the negotiations

8. to stimulate competition among agencies for better distribution of funds

9. to seek consultation with community leaders before settling on specific terms

10. to increase the positive regard of agencies for one another

11. to discourage the award of funds to agencies with a reputation of not following through with their agreements

12. to use the funds for strengthening the capacity for human services delivery in the comulunity

13. to assure open input from client representatives

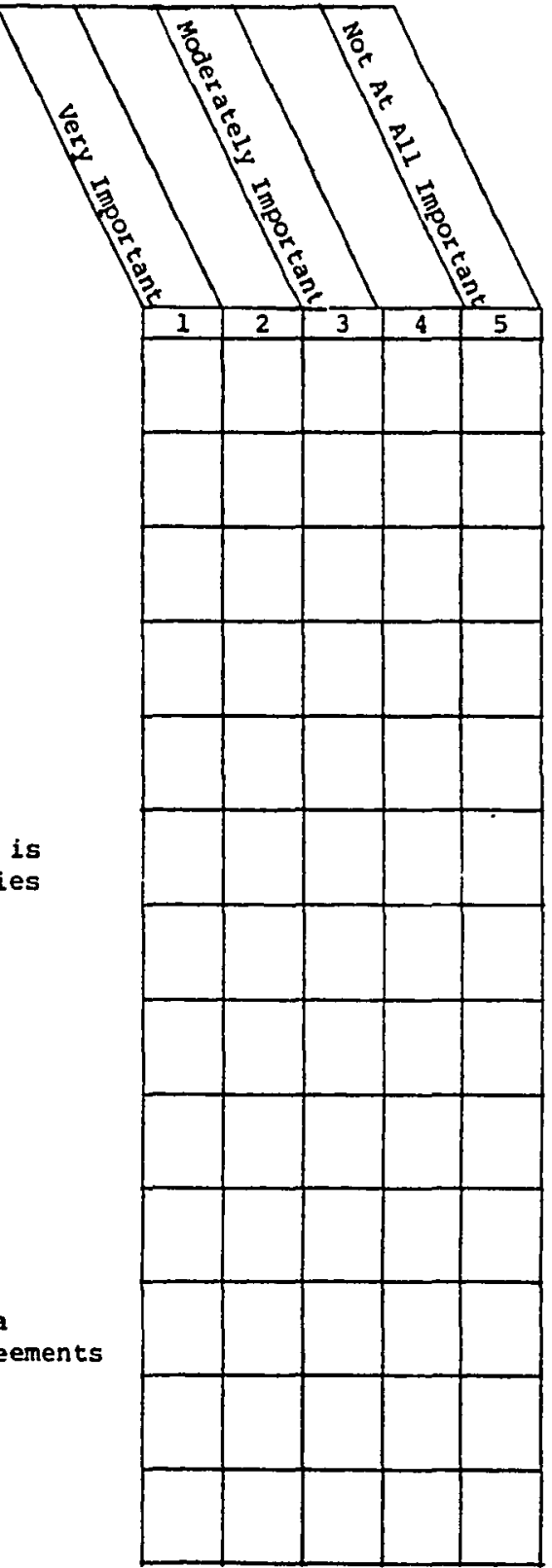

